\title{
CONTRIBUCIÓN AL ESTUDIO DE SELECCIÓN DE PARÁMETROS PARA IDENTIFICACIÓN DE ESTRÉS EN LA $\mathrm{VOZ}$
}

PRESENTADA EN LA

ESCUELA TÉCNICA SUPERIOR DE INGENIEROS INFORMÁTICOS

DE LA

UNIVERSIDAD POLITÉCNICA DE MADRID

PARA LA OBTENCIÓN DEL

GRADO DE DOCTOR EN COMPUTACIÓN AVANZADA PARA CIENCIAS E INGENIERÍAS

AUTOR: DANIEL PALACIOS ALONSO

DIRECTORA: Mª VICTORIA RODELLAR BIARGE

MADRID, JULIO 2017 

Dedicado a todos aquellos que han hecho posible este trabajo 



\section{Agradecimientos}

Una vez más, me vuelvo a enfrentar a estas líneas, pero esta vez para mi tesis doctoral.

Me gustaría dar las gracias a $\mathrm{M}^{\mathrm{a}}$ Victoria Rodellar Biarge, mi directora, que me ha enseñado a razonar y cuestionar todo lo relativo al mundo de la investigación. Descubrir y disfrutar de tardes llenas de ideas, locuras y entusiasmo. A enseñar y dirigir a otras personas, porque me ha hecho crecer en lo personal y en lo profesional. Pero sobre todo, me gustaría agradecer todo el apoyo y cariño que me ha ofrecido todos estos años, haciéndome partícipe en mil y una "batallas" y siempre con una sonrisa y palabras amables.

Gracias a Pedro Gómez Vilda, que me ha aportado tanto y sin pedir nada a cambio. Siempre ha valorado y tenido en cuenta mis ideas y opiniones. Me ha integrado en el equipo y me ha dado la oportunidad de viajar, publicar y asistir a congresos. Me ha presentado a mucha gente interesante con la que poder colaborar y siempre ha estado presente para cada nueva idea que ha surgido.

Gracias al equipo IWINAC, José Manuel Ferrández Vicente, Félix de la Paz López, José Ramón Álvarez Sánchez y Fco. Javier Toledo Moreo por ofrecerme la oportunidad de participar en varias escuelas de verano como ponente e invitarme a grabar un programa sobre ciencia en la radio.

Me gustaría agradecer especialmente a la Asociación Española de Inteligencia Artificial (AEPIA) por el premio otorgado y la oportunidad de poder hacer una estancia en la Universidad de Granada. Gracias también al equipo que me acogió en Granada, Carlos G. Puntonet, Javier Ramírez, Pablo Padilla y Juan Manuel Górriz. Sin ellos, esto tampoco habría sido posible.

Gracias a todos mis amigos, por acompañarme a lo largo de estos años y siempre con palabras de ánimo y aliento, pero muy especialmente a Román Barredo y Ana Barderas. A Román porque siempre me ha apoyado en todo momento, y a Ana por ayudarme en la captación de muestras de voz y la valoración de publicaciones.

Y por supuesto, gracias a mi familia, pero especialmente a mi madre. Si no fuera por ella, seguramente jamás habría podido haber llegado hasta aquí. Y por último y fundamental, gracias a Esther, porque ella ha sido el motor de esta aventura desde el primer momento. 


\section{Resumen}

En este trabajo se presenta un estudio de la caracterización de emociones y más concretamente del estrés a través de la voz, haciendo hincapié en la obtención de muestras de calidad espontáneas, en el conjunto de parámetros que mejor determinen la presencia de estrés y en aquellos algoritmos matemáticos que por un lado mejor validen unos conjuntos de datos, y por otro lado, aquellos que ofrezcan unas tasas de reconocimiento más elevadas con niveles de cómputo asequibles y extrapolables para su posible implementación en interfaces hombre-máquina.

En el primer capítulo se ofrece una introducción al estudio de las emociones realizando una retrospectiva sobre el tema y ofreciendo los avances paulatinos a lo largo de la historia, empezando por los antiguos filósofos griegos, pasando por los racionalistas y llegando hasta los mayores exponentes en nuestros días. Por otro lado, se muestra el concepto de estrés, sus posibles estados, qué estímulos lo provocan, etc. Además, se explica de manera somera la producción de la voz, qué órganos participan y las funciones que realiza cada uno de ellos. Finalmente, se ofrece una serie de potenciales aplicaciones que derivarían como consecuencia de este trabajo.

En el siguiente capítulo se presentan los datos de voz que expresan emociones. Primeramente, se menciona la disponibilidad actual de las diferentes bases de datos emocionales o de estrés que maneja la comunidad científica. A continuación, se formaliza la estructura propuesta en este trabajo con la presentación de las principales características recogidas en nuestra base de datos y se presenta la metodología utilizada para la obtención de datos espontáneos. Finalmente, se introduce una aplicación web diseñada e implementada para obtener y validar muestras de voz espontáneas y los diversos conjuntos de datos o corpora utilizados a lo largo de este estudio.

En el capítulo 3, se comentan los parámetros más comunes para la detección de emociones a través de la voz y además los utilizados para la detección de estrés. Estos parámetros, que podrían denominarse "clásicos", son comentados y definidos de forma sucinta. Se presenta la herramienta utilizada para la extracción de los parámetros en este trabajo y la definición de los mismos de forma detallada, dando especial relevancia a aquellos que tienen un significado biométrico.

A continuación, el capítulo 4 introduce los métodos de clasificación más comunes en la literatura. Seguidamente, se presentan los métodos utilizados a lo largo de este trabajo, organizados como métodos paramétricos y no paramétricos. Además, se presentan las técnicas utilizadas para la separación de fuentes y reducción de 
parámetros o dimensionalidad del problema y finalmente se muestran los métodos de clasificación y validación usados.

Algunas de las principales aportaciones de este estudio se ofrecen en el capítulo 5, Resultados, donde se discute la relevancia de unos parámetros frente a otros, las tasas de clasificación de estrés a partir de diferentes técnicas, algunas individuales y otras con proceso de concatenación de varias técnicas de forma iterativa y un método para validar nuestro conjunto de datos inicial eliminando posibles datos anómalos.

En el último capítulo, se resaltan las principales conclusiones a las que se ha llegado a partir de los objetivos planteados y los resultados obtenidos y también las líneas futuras de investigación que se pueden derivar de este trabajo.

Palabras Clave: Emociones en la voz, Estrés en la voz, Extracción de Parámetros, Selección de Parámetros, Clasificación, Temblor, Parámetros Biomecánicos, Detección. 


\section{Abstract}

In this work, the characterization of emotions and more precisely, stress in speech is addressed, taking into account the significance of emotional sample gathering, the most relevant features to detect stress and mathematical algorithms is explored, which had attained the best performance and the highest accuracy rates, to develop human-computer interfaces.

In the first chapter, an introduction about emotions where the state of the art in the advancement of this topic is presented, beginning with the Greeks to reach the highest exponents till nowadays. On the other hand, regarding the definition of stress, different states and stimuli are explained. For such, the structures involved in speech production are briefly explained. Finally, some potential applications which have arisen from this work are summarized.

In the next chapter, the way in which speech expresses emotions is introduced. Firstly, the availability of different emotional or stress databases is addressed. The structure of the present proposal with the presentation of principal characteristics of the database, corpora and methodologies in this work is formalised. Finally, the design and implementation of a web application to capture and validate spontaneous speech samples are shown.

In chapter three, common features to detect emotions and stress in voice are discussed. These features, which can be considered classic, are defined succinctly. Besides, the extraction tool and their parameters are formalised, but with special detail in the biomechanical parameters.

Chapter four is divided into three parts. In the first one, frequent classification methods in the literature are explained. In the second part separation and reduction techniques are examined. Finally, classification and validation algorithms are proposed.

Some of the principal contributions attributed to this work are presented in chapter five(Results), where feature relevance, achieved accuracy rates from the different techniques proposed, single and hybrid systems and validation algorithms to eliminate anomalous data are highlighted.

In the last chapter, the key conclusions derived from the objectives, and future research lines are explained. 
Keywords: Speech Emotions, Speech Stress, Feature Extraction, Feature Selection, Classification, Tremor, Biomechanical Parameters, Detection. 


\section{Objetivos}

La detección de emociones a través de la voz es una tarea ardua y compleja. Dicho estudio requiere de un enfoque multidisciplinar, donde muchos aspectos distintos están relacionados, tales como los biométricos, neurológicos, psicológicos, sociológicos y culturales. Hoy en día, el alto número de aplicaciones informáticas que intentan dotar de inteligencia emocional a sus programas afronta un desafío que se verá resuelto en un futuro próximo.

El estrés, no es considerado una emoción per se, pero sí un desencadenante de emociones. En la actualidad el estrés es uno de los grandes problemas en nuestra sociedad. Largos periodos de tiempo bajo niveles altos de estrés pueden acabar degenerando en enfermedades cardiovasculares y neurológicas de gravedad, entre otras. Por otro lado, las enfermedades neurodegenerativas generan altas dosis de frustación y estrés en los individuos que las padecen. El estudio del estrés posee un alto interés en el mundo científico y en múltiples áreas de trabajo, no solo en el enfoque biosanitario, sino también en otros ámbitos como por ejemplo marketing (neuromarketing), forense (fuerzas y cuerpos de seguridad del estado, bancos y ámbito forense), el mundo empresarial (compañías aseguradoras) y robótica (interfaces hombre-máquina).

Una de las mayores dificultades a las que se enfrenta la comunidad científica al abordar este problema es la falta de referentes o estándares que permitan contrastar de forma objetiva el progreso del estado del arte, empezando por los datos utilizados, los cuales son obtenidos de maneras diversas. La mayoría de las bases de datos en la literatura se han elaborado a partir de emociones impostadas por actores, no suelen ser de dominio público y no existe un consenso sobre los parámetros más característicos o de mayor relevancia que identifiquen de forma precisa el estrés, al igual que los métodos de clasificación más idóneos.

Dadas todas estas premisas este trabajo se plantea los siguientes objetivos:

1. Creación de un conjunto de datos fiable y espontáneo basado en una metodología de captura de emociones evocadas. Para ello se definirá una metodología de captura y validación de las muestras de forma subjetiva. Además, se elaborará una plataforma web con el fin de realizar las dos anteriores acciones (capturar y validar), abierta a la comunidad científica. De esta forma este trabajo promueve la idea de establecer una comunidad que coopere en la colección y análisis de datos de habla emocional y defina un corpus estándar en diferentes lenguas, acentos y orígenes. 
2. Extracción y selección de rasgos característicos. Dado un conjunto de datos espontáneos, extraer rasgos de índole clásico y otros que abran nuevos horizontes, tales como los basados en la biomecánica de la producción de voz y estudiar el comportamiento de estos parámetros en función del género.

3. Clasificación del estrés a partir de diversas técnicas. El objetivo final de este trabajo es comprobar si los parámetros obtenidos en el proceso de extracción son suficientes para alcanzar tasas de clasificación competitivas respecto a los presentados en el estado del arte. Por tanto, se utilizarán diversas técnicas individuales y concatenadas para obtener la mejor tasa de clasificación de estrés posible. 


\section{Objectives}

Emotional speech detection is an arduous and complex task. This work requires a multidisciplinary approach, where several aspects such as biometrical, neurological, psychological, sociological and cultural are involved. Nowadays, a large number of apps is facing this great challenge, that is to endow their programs with artificial intelligence. It is expected that this challenge will be solved in the near future.

The stress is not considered an emotion "per se", but the research community defines it like an emotional trigger. In our society, the stress is one of the most important issues. People under long periods of stress could suffer serious cardiovascular and neurologic problems, among others. On the other hand, neurodegenerative diseases produce high doses of frustration and stress in individuals who suffer them. The study of stress has raised a keen interest in the research community and other areas, not just under a clinical approach, but also for instance in marketing (neuromarketing), forensics (banks, trials, police department), business (assurance companies) and robotics (human-computer interfaces).

One of the many difficulties is the lack of standards which provide a benchmark to the objective progress of the state of art. An example is the creation of corpora. Most of the databases in the literature have elaborated their corpora from actors. Besides, these databases are not available for the community, are not free of charge and there are not consensus about the relevant parameters and classification methods which characterise the stress in a precisely way.

Under these circumstances and conditions, the following objectives are proposed:

1. Creation of reliable and spontaneous dataset based on a capture methodology of evoked emotions. For this task, a capture and validation subjective methodology is defined. Moreover, an open web application is developed in order to carry out the last two actions (capture and validate) for the research community. This initiative promotes the creation of a community that cooperates in the gathering and analysis of emotional data and defines a standard corpus in different languages, accents and origins.

2. Extraction and selection of relevant features. Given a spontaneous dataset, classic and novel features are extracted. The last ones are based on the biomechanics of speech production. 
3. Use of diverse techniques to classify stress. The final target of this study is to check if the relevant features obtained in the extraction process are robust enough to achieve competitive accuracy rates with regard to the state of art. Therefore, different single and hybrid techniques to attain the best accuracy rate of stress will be implemented and tested. 


\section{Índice general}

$\begin{array}{ll}\text { Agradecimientos } & \text { III }\end{array}$

Resumen $\quad$ V

$\begin{array}{lll}\text { Abstract } & \text { VII }\end{array}$

$\begin{array}{lll}\text { Objetivos IX } & \text { IX }\end{array}$

$\begin{array}{ll}\text { Objectives } & \text { XI }\end{array}$

$\begin{array}{ll}\text { Lista de figuras } & \text { XVII }\end{array}$

$\begin{array}{ll}\text { Lista de tablas } & \text { XXI }\end{array}$

1. INTRODUCCIÓN 1

1.1. Emociones .......................... 2

1.2. Estrés . . . . . . . . . . . . . . . . . 8

1.3. Producción de la Voz . . . . . . . . . . . . . . . . . . . . 9 9

1.4. Aplicaciones . . . . . . . . . . . . . . . . . 16

2. DATOS DE VOZ QUE EXPRESAN EMOCIONES 19

2.1. Disponibilidad de datos . . . . . . . . . . . . . . . . . . . 20

2.2. Propuesta: Plataforma Emotions Portal . . . . . . . . . . . . . . . 26

2.2.1. Estructura de la base de datos . . . . . . . . . . . . . . . 27

2.2.2. Donación de la voz . . . . . . . . . . . . . . . . . 29

2.2.3. Validación de Emociones . . . . . . . . . . . . . . . . 37

2.2.4. Implementación . . . . . . . . . . . . . . . . . . . . 41

2.3. Adquisición de la colección de datos . . . . . . . . . . . . . . . . . 43

2.3.1. Cuestionario para evocar estrés . . . . . . . . . . . . . . . 43

2.3.2. Datos por género y tipo de grabación . . . . . . . . . . . . 44

2.3.3. Conjunto de datos por caso práctico . . . . . . . . . . . . 50

3. EXTRACCIÓN DE CARACTERÍSTICAS 53

3.1. Aspectos generales . . . . . . . . . . . . . . . . 54

3.2. Rasgos clásicos más usados . . . . . . . . . . . . . . . . . . 55

3.2.1. Frecuencia . . . . . . . . . . . . . . . 55

3.2.2. Tiempo . . . . . . . . . . . . . . . . 59

3.2.3. Rasgos de perturbación . . . . . . . . . . . . . . . 61 
3.3. Rasgos propuestos . . . . . . . . . . . . . . . . 62

3.3.1. La fuente glótica . . . . . . . . . . . . . . . . . 62

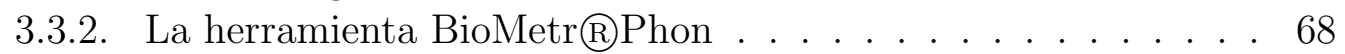

3.3.3. Hipótesis inicial . . . . . . . . . . . . . . . . . . . 73

3.3.4. Visión específica . . . . . . . . . . . . . . . . . . . . 74

3.3.4.1. Rasgos Biomecánicos . . . . . . . . . . . . . . 74

3.3.4.2. Coeficientes Cíclicos . . . . . . . . . . . . 78

3.3.4.3. Parámetros de temblor . . . . . . . . . . . . . 79

4. CLASIFICACIÓN 85

4.1. Algoritmos más usados . . . . . . . . . . . . . . . . . 86

4.2. Algunos recursos paramétricos . . . . . . . . . . . . . . 87

4.3. Estadística No Paramétrica _. . . . . . . . . . . . . . . 90

4.3.1. Prueba de Kolmogorov-Smirnov . . . . . . . . . . . . . . 90

4.3.2. Prueba de Mann-Whitney-Wilcoxon . . . . . . . . . . . . . . 91

4.3.3. Distancia de Kullback-Leibler . . . . . . . . . . . . . . . . 92

4.4. Reducción de Parámetros . . . . . . . . . . . . . . . . . . . 93

4.4.1. Principal component analysis (PCA) . . . . . . . . . 93

4.4.2. Independent component analysis (ICA) . . . . . . . . . 95

4.4.3. Partial Least Squares (PLS) _ . . . . . . . . . . . . . 96

4.5. Algoritmos de Clasificación . . . . . . . . . . . . . . . . 97

4.5.1. Support Vector Machine (SVM) _ . . . . . . . . . . . 98

4.5.2. Log-likelihood Ratio . . . . . . . . . . . . . . . . . 100

5. RESULTADOS 103

5.1. Conjunto de Datos . . . . . . . . . . . . . . . . . . 104

5.2. Rasgos biométricos: indicadores del estado emocional . . . . . . 106

5.2.1. Estimación de la Rigidez de las Cuerdas Vocales . . . . . . . 106

5.2.1.1. Hipótesis Inicial . . . . . . . . . . . . . . . . 106

5.2.1.2. Casos de Estudio . . . . . . . . . . . . . . . 108

5.2.2. Comportamiento de los parámetros biométricos frente al género113

5.2.3. Metodología para Monitorizar Estrés Emocional . . . . . . . . 115

5.3. Validación de la coherencia de datos . . . . . . . . . . . . . . . . 119

5.4. Prospectiva inicial para la selección de rasgos característicos . . . . 126

5.5. Modelos Paramétricos . . . . . . . . . . . . . . . . . . 130

5.5.1. Metodología . . . . . . . . . . . . . . . . . . . . 131

5.5.2. Resultados . . . . . . . . . . . . . . . . . . . 133

5.5.3. Comparando algoritmos de clasificación . . . . . . . . . . 141

5.5.3.1. Rank Features y PLS . . . . . . . . . . . . . . 141

5.5.3.2. Independent Component Analysis - ICA . . . . . . 145

5.6. Modelos no paramétricos . . . . . . . . . . . . . . . . . . . 147

5.6.1. Validación de rasgos . . . . . . . . . . . . . . . . . 148

5.6.1.1. Prueba de Kolmogorov-Smirnov . . . . . . . . . . 150

5.6.1.2. Prueba de U-Mann-Whitney . . . . . . . . . . . . 157 
7. APORTACIONES

8. LÍNEAS FUTURAS

$\begin{array}{ll}\text { Bibliografía } & 177\end{array}$

$\begin{array}{ll}\text { Apéndices } & 195\end{array}$

A. ÍNDICE DE SÍMBOLOS

B. TABLAS ESTADÍSTICA NO PARÁMETRICA 199

B.1. Kolmogorov-Smirnov . . . . . . . . . . . . . . . . . . . . . 199

B.1.1. Primera Parte: Todos vs Todos . . . . . . . . . . . . . . . 199

B.1.2. Segunda Parte: Pair-Wise . . . . . . . . . . . . . . . . 208

B.2. Mann-Whitney . . . . . . . . . . . . . . . . . . . . 213

B.2.1. Primera Parte: Todos vs Todos . . . . . . . . . . . . . 213

B.2.2. Segunda Parte: Pair-Wise . . . . . . . . . . . . . . . . 222

C. TABLA DE RELACIÓN DE PARÁMETROS 227

D. CONSENTIMIENTO INFORMADO PARA DONANTES DE SU $\mathrm{VOZ}$ 



\section{Índice de figuras}

1.1. Rueda de emociones de Plutchik. (Imagen de Dominio Público - Licencia CC0 1.0). . . . . . . . . . . . . . . . . . 5

1.2. Las seis emociones definidas en el trabajo de Ekman y Friesen sobre el test de afecto facial. De arriba a abajo y de izquierda a derecha. Temeroso, enfadado, triste, feliz, asqueado y sorprendido. [47] . . . . 6

1.3. Sistema respiratorio. (Imagen de Dominio Público - Licencia CC0 1.0). 10

1.4. Laringe externa. (Imagen realizada por Olek Remesz y traducida al castellano por Alejandro Navarro López - Licencia CC 2.5) . . . . . . . 11

1.5. Estructura de las pliegues vocales obtenida del libro Gray's Anatomy. (Imagen de Dominio Público - Licencia CC0 1.0) . . . . . . . . . . . . 12

1.6. Mecanismo de producción del ciclo vocal. (Imágenes de Dominio Público - Licencia CC0 1.0). . . . . . . . . . . . . . . . . . 13

1.7. Imagen de la sección sagital de la cavidad supraglotal (partes para la articulación): 1. Exo-labial, 2. Endo-labial, 3. Dental, 4. Alveolar, 5. Post-alveolar, 6. Pre-palatal, 7. Palatal, 8. Velar, 9. Uvular, 10. Faríngea, 11. Glotal, 12. Epiglotal, 13. Radical, 14. Postero-dorsal, 15. Antero-dorsal, 16. Laminar, 17. Apical, 18. Sub-apical. (Imagen basada en los trabajos [27] y [123] y elaborada por Rohieb bajo Licencia CC BY-SA 3.0) . . . . . . . . . . . . . . . . . . 14

1.8. Vista simplificada de los principales caminos involucrados en la producción de la fonación. . . . . . . . . . . . . . . . . . . . 15

1.9. Transiciones para la producción de voz. . . . . . . . . . . . . . . 16

2.1. Imagen de Lena Söderberg. "Playmate del mes". Revista Playboy. Noviembre 1972, fotografía de Dwight Hooker. Alexander Sawchuk escaneó la imagen y la recortó específicamente para el uso de investigación en compresión de imagen y no tiene ningún derecho de autor sobre ella. Licencia de uso justo o fair use. . . . . . . . . . . . . . . 21

2.2. Estructura de la Plataforma para toma de datos online. . . . . . . . . 27

2.3. Diagrama de Entidad Relación de la base de datos construida. . . . . 29

2.4. Relación entre las bases de datos y los módulos de evocación de muestras. . . . . . . . . . . . . . . . 31

2.5. Encuesta online para identificar respuestas con total acuerdo o desacuerdo y grado de convencimiento muy alto. . . . . . . . . . . . . . 32

2.6. Pantalla de grabación. . . . . . . . . . . . . . . . . . . 33

2.7. Proceso de descarga y subida de muestras al servidor. . . . . . . . . . . 34

2.8. Nueva versión del proceso de grabación. . . . . . . . . . . . . . . 35 
2.9. Bloqueo de pantalla mientras un usuario está realizando una grabación. 36

2.10. Imagen informando al usuario que ya ha realizado el caso de la encuesta online. . . . . . . . . . . . . . . . . 36

2.11. Pantalla de validación de emociones. . . . . . . . . . . . . . . . 39

2.12. Nueva pantalla de validación de muestras. . . . . . . . . . . . . . . . 40

2.13. Proceso de validación con información adicional sobre la respuesta del informante. . . . . . . . . . . . . . . . . . 4 40

2.14. Validación de si el usuario ha realizado o no la encuesta. . . . . . . . 41

2.15. Secciones principales de la plataforma implementada. . . . . . . . . . 42

2.16. Panel principal con las diferentes estadísticas presentadas al usuario. . 43

2.17. Comparativa entre la duración de las grabaciones para el conjunto femenino. .................... 46

2.18. Comparativa del número de fillers obtenidos entre ambas grabaciones para el conjunto femenino. . . . . . . . . . . . . . 47

2.19. Comparativa entre la duración de las grabaciones para el conjunto masculino. . . . . . . . . . . . . . . . . . . 49

2.20. Comparativa del número de fillers obtenidos entre ambas grabaciones para el conjunto masculino. . . . . . . . . . . . . . . . . . 49

3.1. Triángulo vocálico según el Alfabeto Fonético Internacional (IPA). Obtenida de ${ }^{\circledR}$ IPA 2015. . . . . . . . . . . . . . . . . . . . 57

3.2. Espéctograma representando los diferentes formantes. . . . . . . . . . 57

3.3. Vocales en Español (parte superior), primer y segundo formante (parte intermedia) y triángulo vocálico (parte inferior) de una voz masculina. 58

3.4. Vocales en Español (parte superior), primer y segundo formante (parte intermedia) y triángulo vocálico (parte inferior) de una voz femenina. 58

3.5. Modelo de Fuente-Filtro de Gunnar Fant. . . . . . . . . . . . . . . . . 63

3.6. Proceso de inversión iterativo basado en filtros inversos y sus filtros espejo, implementados en la aplicación BioMet $\AA$ Phon. . . . . . . . . 65

3.7. Reconstrucción de la Fuente Glótica (c) y el Flujo Glótico (d) a partir de la voz (a). . . . . . . . . . . . . . . . 66 66

3.8. Fuente Glótica típica. Parte superior: Reproducción de un ciclo glótico entre dos puntos MFDR (mínimos de presión). Parte inferior: tren de pulsos glóticos consecutivos, uno de los cuales (el central) se presenta en detalle en la parte superior. . . . . . . . . . . . . . . . . . 67

3.9. Interfaz de usuario de BioMetr $囚$ Phon. . . . . . . . . . . . . . . 68

3.10. Representación de la hipótesis inicial llevada a cabo en este trabajo. 74

3.11. Estructura de los pliegues vocales y su equivalente mecánico. . . . . . 75

3.12. Circuito equivalente electromecánico de dos masas. . . . . . . . . . . 76

3.13. Adaptación de la densidad espectral de potencia de la fuente glótica (línea azul fina) ajustada por la densidad espectral de la onda acústica promedio (triángulos verdes) y la función de aproximación (círculos

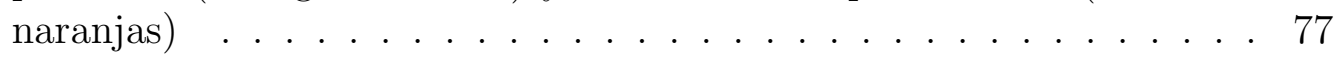

3.14. Rigidez de cuerpo (body) a la izquierda y de cubierta (cover) a la derecha para hombres y mujeres. . . . . . . . . . . . 78

3.15. Rangos para los parámetros $C_{1}$ y $C_{2}$ para hombres y mujeres. . . . . 79 
3.16. Resumen del proceso de estimación del temblor. Las bandas de frecuencia del temblor $f_{p m}, f_{n m}, f_{f m}$ y amplitudes $\xi_{p m}, \xi_{n m}, \xi_{f m}$ son los factores más relevantes . . . . . . . . . . . . . . . . .

5.1. Distribución de los tres primeros parámetros cíclicos para conjunto masculino. . . . . . . . . . . . . . . . 107

5.2. Distribución de los tres primeros parámetros cíclicos para conjunto femenino. . . . . . . . . . . . . . . . . . . 108

5.3. Análisis del filler /eh/ para los locutores masculinos expresando su opinión congruente o espontánea. . . . . . . . . . . . . . . . . . . 109

5.4. Análisis del filler /eh/ para los locutores masculinos expresando su opinión opuesta. . . . . . . . . . . . . . . . . . . . 110

5.5. Análisis del filler /eh/ para los locutores femeninos expresando su opinión congruente o espontánea. . . . . . . . . . . . . . . . . . 110

5.6. Análisis del filler /eh/ para los locutores femeninos expresando su opinión opuesta. . . . . . . . . . . . . . . . . . . 111

5.7. Comparación de la rigidez del cuerpo de las cuerdas vocales entre las muestras con versus pro para el conjunto de muestras masculinas. La expresión de la regresión lineal se muestra con una línea negra sólida. 118

5.8. Comparación de la rigidez del cuerpo de las cuerdas vocales entre las muestras con versus pro para el conjunto de muestras femeninas. La expresión de la regresión lineal se muestra con una línea negra sólida. 119

5.9. Distribuciones del parámetro 66 (frecuencia del temblor fisiológico) relativo a la distribución neutra o congruente (azul - diamante) y la distribución de estrés o engaño (rojo - cuadrados). El eje de abscisas representa los Hercios de la frecuencia y el eje de ordenadas están los recuentos normalizados. Ambas distribuciones se pueden representar como distribuciones cuasi-Gaussianas. . . . . . . . . . . . . . . . . . 120

5.10. Locutores masculinos representados en dos áreas: confiable - diamantes y no-confiable - cuadrados. . . . . . . . . . . . . . . . . . . 122

5.11. Locutoras femeninas representadas en dos áreas: confiable - diamantes y no-confiable - cuadrados. . . . . . . . . . . . . . . . . . . 124

5.12. Áreas específicas para la detección de la coherencia de los datos. . . . 125

5.13. Interpretación geométrica del máximo y mínimo coeficiente de correlación de Pearson. . . . . . . . . . . . . . . . . . . . . . . . . 127

5.14. Clasificación utilizando los parámetros Body Mass y Body Stiffness. . 129

5.15. Clasificación utilizando los parámetros Frecuencia Fundamental y Body Stiffness. . . . . . . . . . . . . . . . . . . . . . . 129

5.16. Etapas básicas para la selección de características utilizando PCA y SVM. . . . . . . . . . . . . . . . . . . 131

5.17. Ejemplo de (leave-one-out) para $\mathrm{N}=4$. . . . . . . . . . . . . 132

5.18. Resumen de las ejecuciones realizadas para jerarquizar los parámetros más relevantes para el conjunto de datos femenino. . . . . . . . . . 137

5.19. Resumen de las ejecuciones realizadas para jerarquizar los parámetros más relevantes para el conjunto de datos masculino. . . . . . . . . . 138 
5.20. Resumen de las ejecuciones realizadas para jerarquizar los componentes independientes más relevantes en el caso del conjunto (a) masculino. (b) - femenino. . . . . . . . . . . . . . . . . . . 147

5.21. Prueba sobre la colección completa de datos según cada parámetro. 149

5.22. Prueba pair-wise sobre la colección completa de datos según cada individuo. . . . . . . . . . . . . . . . . . . . . . . . . 149

5.23. Resumen del número de veces en que es rechazada la hipótesis nula por individuo para el conjunto de datos masculino según la prueba $K S(5 \%)$ y $K S(10 \%) . \ldots \ldots \ldots \ldots \ldots \ldots$

5.24. Resumen del número de veces en que es rechazada la hipótesis nula por individuo para el conjunto de datos femenino según la prueba $K S(5 \%)$ y $K S(10 \%)$. . . . . . . . . . . . . . . . 157

5.25. Resumen del número de veces en que es rechazada la hipótesis nula por individuo para el conjunto de datos masculino según la prueba $M W(5 \%)$ y $M W(10 \%) \ldots \ldots \ldots \ldots . \ldots \ldots$

5.26. Resumen del número de veces en que es rechazada la hipótesis nula por individuo para el conjunto de datos femenino según la prueba $M W(5 \%)$ y $M W(10 \%) \ldots \ldots \ldots \ldots \ldots$

5.27. Resumen del número de veces en que es rechazada la hipótesis nula por individuo para el conjunto de datos masculino según las pruebas $K S(5 \%), K S(10 \%), M W(5 \%)$ y $M W(10 \%) \ldots \ldots \ldots \ldots$

5.28. Resumen del número de veces en que es rechazada la hipótesis nula por individuo para el conjunto de datos femenino según las pruebas $K S(5 \%), K S(10 \%), M W(5 \%)$ y $M W(10 \%) \ldots \ldots \ldots$

6.1. Rasgos más relevantes respecto al conjunto masculino. El grado de relevancia viene dado por su posición central y por el tamaño del rotulado. . . . . . . . . . . . . . . . . . . . . . 170

6.2. Rasgos más relevantes respecto al conjunto femenino. El grado de relevancia viene dado por su posición central y por el tamaño del rotulado. . . . . . . . . . . . . . . . . . . . . . . 170

C.1. Representación del número de veces que cada parámetro ha sido seleccionado como relevante para el conjunto de todos los casos de estudio y para ambos géneros. . . . . . . . . . . . . . . . . . 232 


\section{Índice de Tablas}

1.1. Distintas propuestas de modelos de emociones. . . . . . . . . . . . 6

2.1. Lista de preguntas para las encuestas. . . . . . . . . . . . . . . . . . . 44

2.2. Discurso incongruente para el conjunto femenino. . . . . . . . . . . . 45

2.3. Discurso congruente para el conjunto femenino. . . . . . . . . . . . 45

2.4. Discurso incongruente para el conjunto de los hombres. . . . . . . . . 47

2.5. Discurso congruente para el conjunto de los hombres. . . . . . . . . . 48

2.6. Relación de respuestas según género. . . . . . . . . . . . . . . 50

3.1. Características usadas en el reconocimiento de emociones en el habla [73]. . . . . . . . . . . . . . . . . . . . 5 55

5.1. Rigidez de las cuerdas vocales y coeficientes cíclicos. De izquierda a derecha: Inicio y fin de los fillers, medias del cuerpo y la cubierta, desviaciones típicas del cuerpo y la cubierta y los tres parámetros de ciclicidad. . . . . . . . . . . . . . . . . . . . . . 112

5.2. Variaciones de los parámetros para mujeres. . . . . . . . . . . . . . 114

5.3. Variaciones de los parámetros para hombres. . . . . . . . . . . . . 115

5.4. Valores medios obtenidos para la rigidez del cuerpo body stiffness para las situaciones de congruencia ( $p r o=a$ favor) e incongruencia (con=en contra) para el conjunto de los hombres. . . . . . . . . . 116

5.5. Valores medios obtenidos para la rigidez del cuerpo body stiffness para las situaciones de congruencia ( $p r o=$ a favor) e incongruencia (con=en contra) para el conjunto de las mujeres. . . . . . . . . . . 116

5.6. Diferentes estadísticos para los tests de la t-Student . . . . . . . . . . 117

5.7. Resultados de la probabilidad logarítmica para los hombres. . . . . . 121

5.8. Resultados de la probabilidad logarítmica para las mujeres. . . . . . . 123

5.9. Rasgos relevantes en orden descendente. . . . . . . . . . . . . . . 128

5.10. Características para los resultados con mejor precisión. . . . . . . . . 134

5.11. Resultados de clasificación para las mujeres. . . . . . . . . . . . . 135

5.12. Resultados de clasificación para los hombres. . . . . . . . . . . . . . 135

5.13. Resultados de clasificación para las mujeres incluyendo PCA. . . . . . 139

5.14. Resultados de clasificación para los hombres incluyendo PCA. . . . . 140

5.15. Características para los resultados con mejor precisión incluyendo PCA.140

5.16. Resultados de clasificación utilizando Rank Features y Partial Least Squares para el conjunto de datos masculino. . . . . . . . . . . . . . 141 
5.17. Resultados de clasificación utilizando Rank Features y Partial Least Squares para el conjunto de datos femenino. . . . . . . . . . . . . 142

5.18. Características para los resultados con mayor tasa de clasificación incluyendo PLS. . . . . . . . . . . . . . . . . . . . . . . 142

5.19. Relación media de tasas de clasificación para el conjunto de datos masculino para los dos casos con Rank Feautres según los criterios utilizados. . . . . . . . . . . . . . . . . . . . . . 143

5.20. Relación media de tasas de clasificación para el conjunto de datos masculino para los dos casos con Rank Feautres según los kernels utilizados. . . . . . . . . . . . . . . . . . . . . . . . . 144

5.21. Relación media de tasas de clasificación para el conjunto de datos femenino para los dos casos con Rank Features según los criterios utilizados. . . . . . . . . . . . . . . . . . . .

5.22. Relación media de tasas de clasificación para el conjunto de datos femenino para los dos casos con Rank Features según los kernels utilizados. . . . . . . . . . . . . . . . . . . . . . . . . . . . . 144

5.23. Resultados de clasificación utilizando $I C A$ para el conjunto de datos masculino. . . . . . . . . . . . . . . . . . . 145

5.24. Resultados de clasificación utilizando ICA para el conjunto de datos femenino.

5.25. Rasgos que rechazan la hipótesis nula para la prueba de contraste de Kolmogorov-Smirnov en el conjunto masculino cuando enfrentamos todas las muestras neutras frente a las muestras de estrés, teniendo en cuenta un $\alpha=0,05 \ldots \ldots \ldots$. . . . . . . . . . . . 151

5.26. Rasgos que rechazan la hipótesis nula para la prueba de contraste de Kolmogorov-Smirnov en el conjunto masculino cuando enfrentamos todas las muestras neutras frente a las muestras de estrés, teniendo en cuenta un $\alpha=0,1 \ldots \ldots \ldots \ldots$. . . . . . . . . . . . 151

5.27. Rasgos que rechazan la hipótesis nula para la prueba de contraste de Kolmogorov-Smirnov en el conjunto femenino cuando enfrentamos todas las muestras neutras frente a las muestras de estrés, teniendo

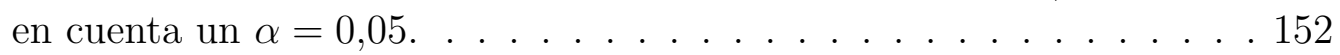

5.28. Rasgos que rechazan la hipótesis nula para la prueba de contraste de Kolmogorov-Smirnov en el conjunto femenino cuando enfrentamos todas las muestras neutras frente a las muestras de estrés, teniendo

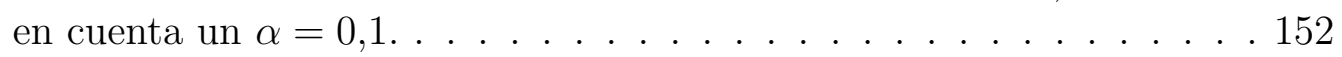

5.29. Número de individuos para el conjunto de datos masculino y femenino para el estudio del segundo caso, pair-wise. . . . . . . . . . . . . 153

5.30. Resultados para el conjunto masculino, cuando realizamos un estudio de tipo pair-wise para la prueba KS con un $\alpha=0,05 \ldots \ldots \ldots . . .154$

5.31. Resultados para el conjunto masculino, cuando realizamos un estudio de tipo pair-wise para la prueba KS con un $\alpha=0,1 \ldots \ldots$. . . . 154

5.32. Resultados para el conjunto femenino, cuando realizamos un estudio de tipo pair-wise para la prueba KS con un $\alpha=0,05 \ldots \ldots$. . . . 155

5.33. Resultados para el conjunto femenino, cuando realizamos un estudio de tipo pair-wise para la prueba KS con un $\alpha=0,1 \ldots \ldots \ldots \ldots$ 
5.34. Rasgos que rechazan la hipótesis nula para la prueba de contraste de Mann-Whitney en el conjunto masculino cuando enfrentamos todas las muestras neutras frente a las muestras de estrés, teniendo en

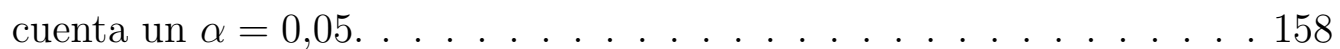

5.35. Rasgos que rechazan la hipótesis nula para la prueba de contraste de Mann-Whitney en el conjunto masculino cuando enfrentamos todas las muestras neutras frente a las muestras de estrés, teniendo en cuenta un $\alpha=0,1$. . . . . . . . . . . . . . . . . . . . 159

5.36. Rasgos que rechazan la hipótesis nula para la prueba de contraste de Mann-Whitney en el conjunto femenino cuando enfrentamos todas las muestras neutras frente a las muestras de estrés, teniendo en cuenta

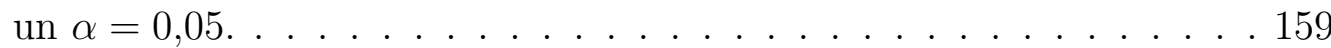

5.37. Rasgos que rechazan la hipótesis nula para la prueba de contraste de Mann-Whitney en el conjunto femenino cuando enfrentamos todas las muestras neutras frente a las muestras de estrés, teniendo en cuenta

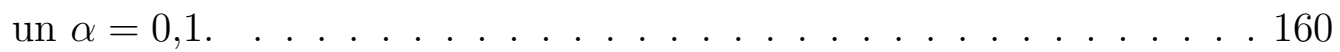

5.38. Resultados para el conjunto masculino, cuando realizamos un estudio de tipo pair-wise para la función de contraste de Mann-Whitney para

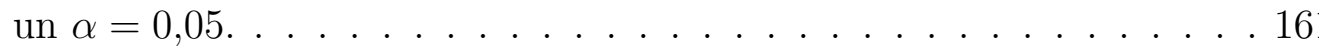

5.39. Resultados para el conjunto masculino, cuando realizamos un estudio de tipo pair-wise para la función de contraste de Mann-Whitney para un $\alpha=0,1$.

5.40. Resultados para el conjunto femenino, cuando realizamos un estudio de tipo pair-wise para la función de contraste de Mann-Whitney para un $\alpha=0,05 \ldots \ldots$. . . . . . . . . . . . . . . . . 162

5.41. Resultados para el conjunto femenino, cuando realizamos un estudio de tipo pair-wise para la función de contraste de Mann-Whitney para un $\alpha=0,1$.

B.1. Resultados para la prueba de contraste de Kolmogorov-Smirnov el conjunto masculino cuando enfrentamos todas las muestras neutras frente a las muestras de estrés, teniendo en cuenta un $\alpha=0,05$.

B.2. Resultados para la prueba de contraste de Kolmogorov-Smirnov el conjunto masculino cuando enfrentamos todas las muestras neutras frente a las muestras de estrés, teniendo en cuenta un $\alpha=0,1$. . . . 203

B.3. Resultados para la prueba de contraste de Kolmogorov-Smirnov el conjunto femenino cuando enfrentamos todas las muestras neutras frente a las muestras de estrés, teniendo en cuenta un $\alpha=0,05$. . . 205

B.4. Resultados para la prueba de contraste de Kolmogorov-Smirnov para el conjunto femenino cuando enfrentamos todas las muestras neutras frente a las muestras de estrés, teniendo en cuenta un $\alpha=0,1$. . . . 207

B.5. Resultados para la prueba de contraste de Kolmogorov-Smirnov para el conjunto masculino cuando realizamos un estudio de tipo pair-wise, teniendo en cuenta un $\alpha=0,05 \ldots$. . . . . . . . . . . . . 209 
B.6. Resultados para la prueba de contraste de Kolmogorov-Smirnov para el conjunto masculino cuando realizamos un estudio de tipo pair-wise, teniendo en cuenta un $\alpha=0,1$. . . . . . . . . . . . . . . . . . 210

B.7. Resultados para la prueba de contraste de Kolmogorov-Smirnov para el conjunto femenino cuando realizamos un estudio de tipo pair-wise, teniendo en cuenta un $\alpha=0,05 \ldots$. . . . . . . . . . . . . . 211

B.8. Resultados para la prueba de contraste de Kolmogorov-Smirnov para el conjunto femenino cuando realizamos un estudio de tipo pair-wise, teniendo en cuenta un $\alpha=0,1 . \ldots 213$

B.9. Resultados para la prueba de contraste de Mann-Whitney para el conjunto masculino cuando enfrentamos todas las muestras neutras frente a las muestras de estrés, teniendo en cuenta un $\alpha=0,05$. . . 215

B.10.Resultados para la prueba de contraste de Mann-Whitney para el conjunto masculino cuando enfrentamos todas las muestras neutras frente a las muestras de estrés, teniendo en cuenta un $\alpha=0,1$. . . . 217

B.11.Resultados para la prueba de contraste de Mann-Whitney para el conjunto femenino cuando enfrentamos todas las muestras neutras frente a las muestras de estrés, teniendo en cuenta un $\alpha=0,05$. . . 219

B.12.Resultados para la prueba de contraste de Mann-Whitney para el conjunto femenino cuando enfrentamos todas las muestras neutras frente a las muestras de estrés, teniendo en cuenta un $\alpha=0,1$. . . . 221

B.13. Resultados para la prueba de contraste de Mann-Whitney para el conjunto masculino cuando realizamos un estudio de tipo pair-wise, teniendo en cuenta un $\alpha=0,05 \ldots$. . . . . . . . . . . . . . . 222

B.14.Resultados para la prueba de contraste de Mann-Whitney para el conjunto masculino cuando realizamos un estudio de tipo pair-wise, teniendo en cuenta un $\alpha=0,1$. . . . . . . . . . . . . . . 223

B.15.Resultados para la prueba de contraste de Mann-Whitney para el conjunto femenino cuando realizamos un estudio de tipo pair-wise, teniendo en cuenta un $\alpha=0,05$. . . . . . . . . . . . . . . . . . 224

B.16.Resultados para la prueba de contraste de Mann-Whitney para el conjunto femenino cuando realizamos un estudio de tipo pair-wise, teniendo en cuenta un $\alpha=0,1$. . . . . . . . . . . . . . . . 226

C.1. Parámetros relevantes respecto de los casos de estudio llevados a cabo para el conjunto de datos femenino. RF1 = t-test, $\mathrm{RF} 2=$ entropía, $\mathrm{RF} 3=\mathrm{ROC}, \mathrm{RF} 4=$ Wilcoxon, $\mathrm{KS}=$ Kolmogorov-Smirnov, $\mathrm{MW}=$ U-Mann-Whitney y $\mathrm{P}=$ Pearson. . . . . . . . . . . . . . . 229

C.2. Parámetros relevantes respecto de los casos de estudio llevados a cabo para el conjunto de datos masculino. $\mathrm{RF} 1=t$-test, $\mathrm{RF} 2=$ entropía, $\mathrm{RF} 3=\mathrm{ROC}, \mathrm{RF} 4=$ Wilcoxon, $\mathrm{KS}=$ Kolmogorov-Smirnov y $\mathrm{MW}=$ U-Mann-Whitney. . . . . . . . . . . . . . . . . . . . 231 


\section{Capítulo 1}

\section{INTRODUCCIÓN}

Alegría, tristeza, enfado, desagrado, ... Son solo algunas de las emociones que podemos sentir a lo largo de un día normal en nuestras vidas, incluso en unos pocos segundos, podemos transitar entre varias de ellas de forma fugaz e imperceptible para nosotros mismos. Desde filósofos griegos, como Platón o Aristóteles, pasando por Descartes o Darwin, hasta nuestros días; las emociones han sido un tema de debate y de confrontación.

El estudio de las emociones es una ardua tarea donde muchos factores están involucrados, tales como los fisiológicos, sociales y neurológicos, entre otros. Un ejemplo para desarrollar esta idea, no exento de polémica, es la poligamia o infidelidad. Algunos la consideran necesaria para la perpetuación de la especie y para otros suscita traición y uno de los mayores pecados capitales. Todo depende desde el punto de vista que se tome. Por ejemplo, tribus esquimales realizan intercambios de esposas entre diferentes miembros; una vez que el chaman o angekok ha dado su visto bueno, favoreciendo el beneplácito de sus dioses. La religión islámica también defiende la poligamia entre una de sus creencias. Mientras que la religión judeocristiana considera un pecado capital este acto. Se puede concluir con los ejemplos mencionados que las emociones suscitadas ante un mismo hecho es un tema particular de cada individuo y caracterizado o afectado por muchas variables o factores.

Fruto de nuestras emociones se pueden generar efectos o estados favorables o adversos. Un efecto o estado positivo puede ser la plenitud. Esta se puede definir como un estado donde la persona se siente satisfecha consigo misma, completa y equilibrada emocionalmente hablando, o dicho de otra forma su homeostasis es perfecta. Según la definición de la Real Academia de la Lengua Española (RAE), la homeostasis puede ser definida como "Autorregulación de la constancia de las propiedades de un sistema influido por agentes exteriores". Por otro lado, un estado negativo y bastante conocido en nuestra sociedad actual es el estrés. Nuevamente, la RAE describe este concepto como "Tensión provocada por situaciones agobiantes que originan reacciones psicosomáticas o trastornos psicológicos a veces graves".

Las emociones se expresan a través de gestos, posturas, habla y voz. Este trabajo se centra única y exclusivamente en la detección de emociones a través de la voz y 
específicamente en la detección de estrés.

En las últimas tres décadas se ha realizado una intensa investigación en los temas de reconocimiento automático del habla y del hablante. Sin embargo en estos últimos años ha suscitado especial interés la identificación y clasificación de estados emocionales en el habla. La identificación de emociones en el habla puede proporcionar interfaces hombre-máquina más naturales, complejas y efectivas que las que existen en la actualidad. Este campo tiene muchas aplicaciones potenciales, como se podrá ver en secciones posteriores.

El objetivo de este capítulo es enmarcar el problema, de esta forma, se podrá entender mejor la metodología llevada a cabo en este trabajo. A continuación se presentan las distintas secciones en las que está dividido este capítulo. La primera sección explicará el estudio de las emociones a lo largo de la historia. En la siguiente sección se presentará el estrés como fenómeno a tener en cuenta. A continuación se examinará la producción de voz desde varios puntos de vista. Finalmente, se describirán las posibles aplicaciones reales que tiene la detección de emociones con la voz y en especial la detección de estrés.

\subsection{Emociones}

Según Casado y Colomo [26] el conocimiento y exploración de las emociones son piezas fundamentales en la comprensión y explicación de la conducta del hombre. A continuación se realizará un breve viaje a través de la historia de las emociones, comenzando por los clásicos y concluyendo en un futuro no tan lejano teniendo como su máximo exponente al celuloide o también conocido como Séptimo Arte.

El primer trabajo sobre emociones del que se tiene noticia fue llevado a cabo por Platón en su obra Filebo [142]; enfrentando a Socrates y Protarco: el dolor y el placer. Platón describe tres características, la razón, el apetito y el espíritu. Actualmente, la Psicología ha adoptado estos términos y los ha adaptado a cognición, motivación y emoción.

Pero es en la Retórica de Aristóteles donde se realiza un desarrollo más exhaustivo sobre las emociones. De acuerdo con el Estagirita, una emoción es la reacción inmediata del ser vivo a una situación que le es favorable o desfavorable [7]. Además, unifica las dos dimensiones del alma, la racional y la irracional, siendo precursor de lo que hoy se conoce como teorías cognitivas de la emoción [8].

Dando un salto temporal bastante amplio y dejando por el camino a los estóicos y a San Agustín, entre otros, avanzamos hasta Descartes, el cual ofrece una visión dualista -alma y cuerpo-, en su obra Las pasiones del alma [42], donde se definen seis emociones básicas, simples o primitivas. Éstas son: asombro, amor, odio, deseo, alegría y tristeza siendo todas las demás derivadas o compuestas de estas seis.

Olvidando por el camino a muchos filósofos importantes, tales como, Kant, Hegel 
o Schopenhauer, haremos una parada, si bien esta vez el personaje en cuestión no fue filosofo o psicólogo "per se"; en realidad fue un naturalista inglés que revolucionó el mundo tal y como hoy se conoce. Charles Robert Darwin se hizo universalmente conocido por su obra fundamental, El origen de las especies por medio de la selección natural, o la preservación de las razas preferidas en la lucha por la vida [36], publicada en 1859. Pero además de esta magnífica obra, escribió otra titulada, $L a$ expresión de las emociones en los animales y en el hombre [37] que enmarca de forma idónea este trabajo.

Esta obra permaneció olvidada durante décadas casi hasta mitad del siglo XX, en que fue recuperada de manera sucinta por Chóliz [31], convirtiéndose en un referente en la psicología de la emoción.

Existen tres principios fundamentales en las emociones, según las teorías de Darwin, que se resumen a continuación:

- Hábitos útiles asociados. Una emoción provoca una serie de gestos y movimientos, que tal vez sean o no de utilidad, pero que en ocasiones anteriores han surgido el efecto deseado y por tanto se repiten de manera involuntaria.

- Antítesis. Dado un hábito consolidado, se realiza una acción divergente si se genera un estado de ánimo contrario al que produce semejante patrón conductual. Este concepto lo define Fernández como asociación por contraste [54].

- Acción directa del sistema nervioso. En palabras de Darwin, "la energía fluye con la independencia del hábito, pero las acciones expresivas dependen de éste". Es por ello que, un impulso nervioso en situaciones de estrés o de gran excitación puedan provocar movimientos expresivos. Por tanto, el impulso neurológico puede afectar de manera directa a la musculatura expresiva asociada con una emoción determinada. Izard [87] y Tomkins [181] defienden la existencia de programas subcorticales innatos para la expresión de cada una de las emociones básicas o primitivas.

Además, Darwin define tres acciones fundamentales que son reflejos, hábitos e instintos. Desde su punto de vista, las acciones innatas, como reflejos e instintos son las acciones más importantes. Estas acciones se han heredado de sus progenitores y estos a su vez de los suyos, por tanto esta teoría pone de manifiesto la teoría de la filogenética y la evolución biológica. Por otro lado, los hábitos quedan en un segundo plano, siendo estos el resultado de la asociación de los reflejos, pudiendo modificarse o incluso desaparecer en algunos casos.

Darwin intentó demostrar de forma pragmática las anteriores aseveraciones realizando estudios sobre personas invidentes, pueblos étnicos diferentes, niños de temprana edad y animales. De estos estudios surgieron varias cuestiones como por ejemplo:

- ¿Pueden los invidentes responder de forma similar a ciertos estímulos? 
- ¿Pueden animales biológicamente cercanos presentar emociones análogas al ser humano?

- ¿Culturas diferentes expresan emociones faciales similares?

- ¿Pueden los niños pequeños presentar respuestas emocionales similares a sus progenitores desde una edad muy temprana?

La respuesta a todas estas preguntas se pueden resumir con un $\mathbf{S i}$, es decir, los invidentes ofrecen respuestas similares a personas sin dicha minusvalía. Pueblos en Nueva Guinea expresan felicidad, sorpresa y enfado de formas similares a hombres y mujeres europeos. Los bebes presentan respuestas emocionales similares a sus progenitores. Finalmente, los chimpancés y otros simios utilizan gestos y posturas similares a las humanas.

Seguidamente se va a presentar a dos de los nombres más representativos en el campo de la expresión de las emociones en la actualidad. Ambos describieron diferentes modelos emocionales a lo largo del siglo XX. Dichos modelos poseen grandes similitudes con algunas de las afirmaciones que Darwin enunció, pero también ofrecen grandes analogías con los conceptos primigenios de Descartes. Estos modelos son considerados por algunos como universalistas por su grado de aceptación en el mundo científico. Los referidos autores son:

- Robert Plutchik. Este psicólogo postuló que existen 8 emociones básicas las cuales se han desarrollado o evolucionado para aumentar la aptitud reproductiva del animal [145]. Además, a partir de estas emociones primitivas y a través de ciertos desencadenantes se producen o elaboran el resto de las emociones conocidas. Un ejemplo de lo anterior podría ser la necesidad de salir huyendo de un individuo si el miedo evoluciona o transita al pánico. Plutchik explicó estás 8 emociones como primitivas y antagónicas 2 a 2 , por ejemplo: alegría/tristeza, enfado/miedo, confianza/disgusto y sorpresa/anticipación, tal y como se representa en la Figura 1.1. En 1962 presentó un modelo cónico en tres dimensiones y en una versión posterior en 1980 representó su modelo en forma de flor y explicó en detalle la relación de las emociones primitivas para generar emociones derivadas o compuestas [144]. Toda emoción posee tres características diferentes para definir un estado emocional, excitación o arousal (término anglosajón ampliamente utilizado en el campo), valencia y potencia o intensidad, los cuales son los detonantes en la transición entre los diferentes estados emocionales. La excitación representa un grado de actividad o pasividad respecto del estado emocional. La valencia representa si la emoción es positiva o negativa y finalmente la intensidad proporciona la información sobre la "energía" de dicho estado. Por poner un ejemplo, una persona puede estar sentada en medio de un bosque serenamente contemplando el paisaje de alrededor, por lo tanto se podría suponer el siguiente caso: esta persona está en un estado de calma (sereno), por consiguiente su nivel de excitación sería pasivo, la valencia positiva y con una intensidad leve. Otro supuesto podría ser un estudiante al que acaban de dar la última nota para terminar su carrera. Entonces, esta persona puede estar jubilosa (saltos de alegría), en otras palabras, 
su nivel de excitación sería activo, la valencia positiva y su intensidad sería elevada o de euforia/éxtasis. Esta transición entre posibles emociones queda reflejada en la Figura 1.1, donde estas pueden generarse a partir de las tres variables anteriores y transitar de un estado positivo, pasivo y de intensidad moderada a un estado positivo, activo pero con una potencia muy elevada. De esta forma todo estado emocional queda adecuadamente definido.

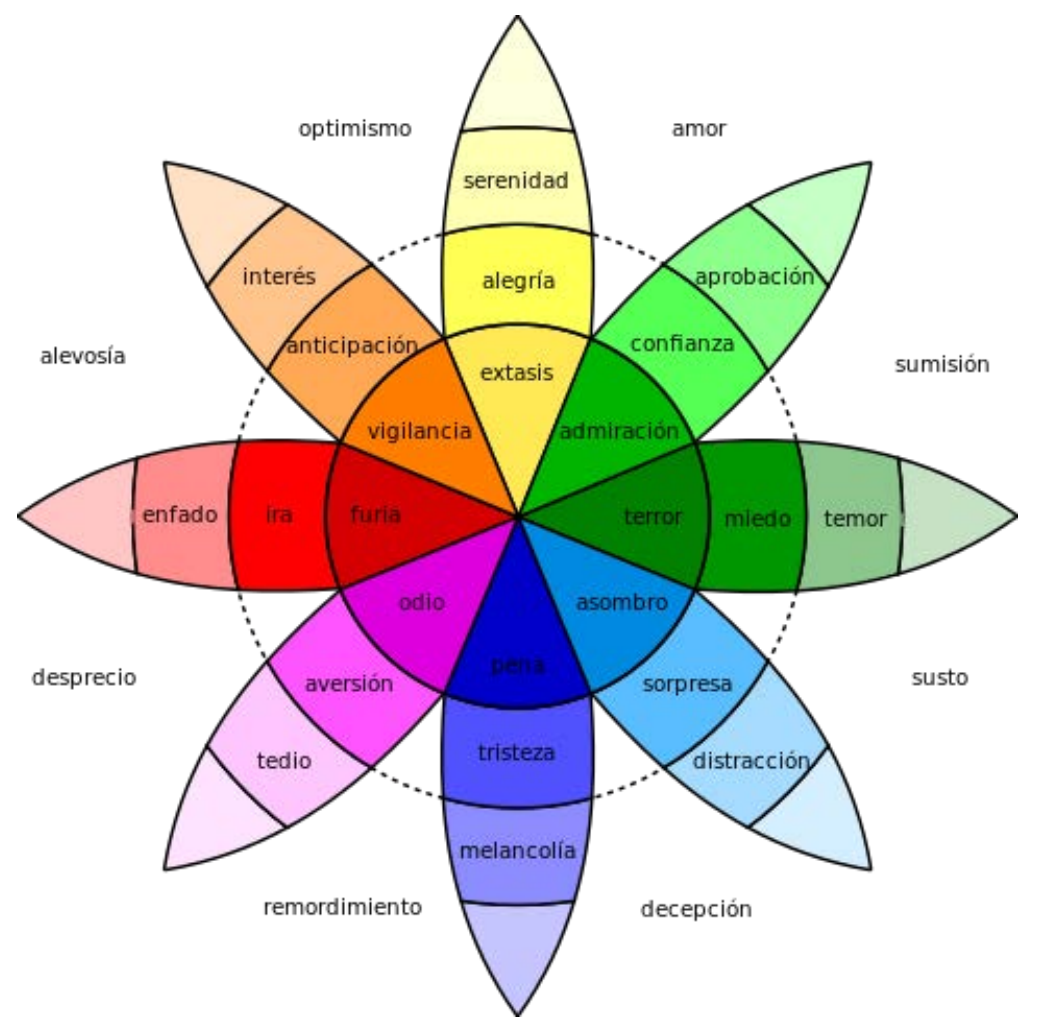

Figura 1.1: Rueda de emociones de Plutchik. (Imagen de Dominio Público - Licencia CC0 1.0).

- Paul Ekman. Psicólogo y precursor del estudio de las emociones faciales y gestuales, enfocó su estudio en gran medida a la detección de la mentira a través de estos "canales". Se puede decir que acuñó el término "microexpresiones", las cuales delatan a los sujetos y expresan sus emociones de manera completamente involuntaria. Ekman asegura que las expresiones faciales son universales y por consiguiente su origen es de tipo fisiológico, este pensamiento o planteamiento es análogo al que postuló Darwin en su hipótesis. En uno de sus primeros trabajos [46], Ekman definió 6 emociones universales. Estas emociones eran la ira, el asco, el miedo, la alegría, la tristeza, la sorpresa y el desprecio o desdén como se pueden ver en la figura 1.2.

Tal ha sido la aceptación del trabajo de este psicólogo que la industria cinematográfica ha producido una serie de televisión, Lie to me basada en la obra de Paul Ekman. Se trata de un equipo de investigación que trabaja con el FBI y la policía para resolver casos policiales de toda índole. Algunos de los protagonistas utilizan sus habilidades de deducción en el campo de la expresión 
de las emociones para saber si los criminales estaban diciendo o no la verdad.
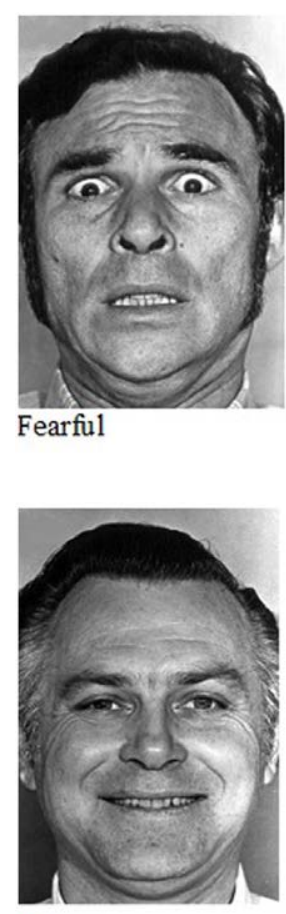

Happy

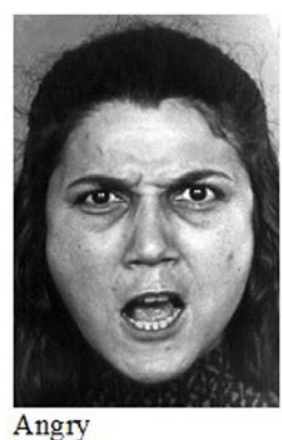

Angry

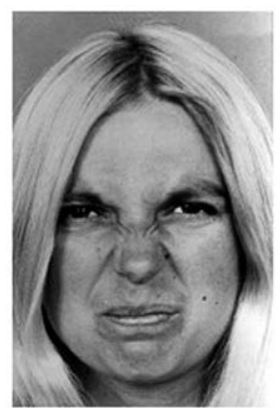

Disgusted
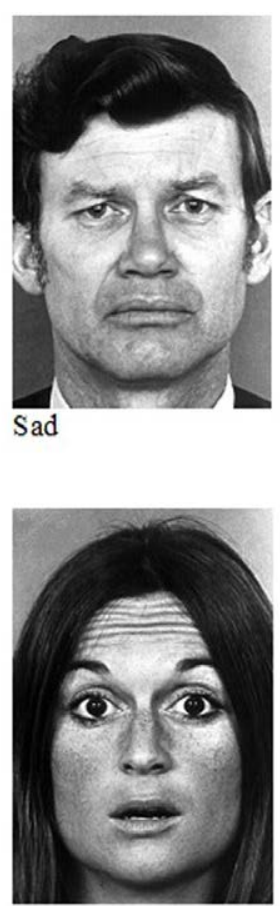

Surprised

Figura 1.2: Las seis emociones definidas en el trabajo de Ekman y Friesen sobre el test de afecto facial. De arriba a abajo y de izquierda a derecha. Temeroso, enfadado, triste, feliz, asqueado y sorprendido. [47]

Queda patente que ambos investigadores aportan ideas innovadoras en el campo de la expresión de las emociones, pero sin olvidar que sus modelos o teorías se cimientan en ideas aportadas con anterioridad por Descartes y Darwin. Tal y como presenta la Tabla 1.1, existen varias emociones en ambos modelos que coinciden con el modelo postulado por Descartes. Estas emociones son alegría, tristeza y sorpresa. Huelga decir que se está haciendo una analogía entre el asombro y la sorpresa, considerando ambas emociones idénticas.

\begin{tabular}{cc}
\hline Autor & Emociones \\
\hline \hline Descartes & $\begin{array}{r}\text { asombro/sorpresa, amor, odio, } \\
\text { deseo, alegría y tristeza }\end{array}$ \\
\hline Plutchik & $\begin{array}{c}\text { alegría/tristeza, confianza/disgusto, } \\
\text { enfado/miedo, sorpresa/anticipación }\end{array}$ \\
\hline Ekman & $\begin{array}{c}\text { tristeza, miedo, sorpresa, disgusto, } \\
\text { enfado, asco, alegría }\end{array}$ \\
\hline
\end{tabular}

Tabla 1.1: Distintas propuestas de modelos de emociones.

Para finalizar este apartado, se quiere destacar un pequeño apunte a colación de lo que se expone en posteriores secciones, más concretamente en la sección 2.1 del 
presente capítulo, Datos. Otros autores como Ortony y Turner que afirman que no existen tales emociones básicas o primitivas, puesto que, de existir, todos los investigadores deberían de ser capaces de establecer de forma "sencilla" o "consensuada" un estándar o patrón de reconocimiento [134]. Esta idea es interesante y extrapolable al caso de los datos que se utilizan para realizar investigación en el campo de las emociones.

En algunas ocasiones se dice que la realidad supera a la ficción, pero por ahora es la ficción la que ofrece un futuro emocional mucho más rico que el presente. En las últimas décadas el celuloide ha fantaseado con futuros plausibles en la creación de interfaces "hombre-máquina" casi-humanas y con altos niveles de inteligencia emocional. Algunos títulos que ilustran estas ideas pueden ser:

- Her. El protagonista (Joaquin Phoenix) es un hombre complejo y deprimido por su reciente separación matrimonial. Un día decide comprar un novedoso sistema operativo que promete ser único para cada comprador. La interpretación del sistema operativo, Samantha, fue llevada a cabo por Scarlett Johansson. La película presenta la evolución emocional de Samantha con el protagonista. Como si de un niño pequeño se tratara, el sistema operativo se cuestiona todo lo que lo que le sucede alrededor y con el transcurso de los minutos, el sistema operativo va madurando y crea sentimientos profundos tales como amor, comprensión, felicidad, tristeza e incluso celos. Como se puede observar, la cinta expone un interfaz con altas capacidades emocionales que incluso llega a rivalizar con la del propio ser humano [89].

- El hombre bicentenario. Andrew, Robin Williams, es un robot de hogar con una anomalía en su programación. Esta anomalía le proporciona un nivel de inteligencia emocional fuera de lo común para un androide. Al principio tiene que aprender a corregir los modismos del lenguaje y habituarse a los dobles sentidos de los seres humanos. Poco a poco va adquiriendo creatividad y sentido del humor, comprendiendo en algunas ocasiones mejor a los humanos que ellos mismos [35].

- Frank \& Robot. Frank, Frank Langella, es un hombre de avanzada edad con principio de enfermedad neurogenerativa; más concretamente, Alzheimer [162]. Sus hijos deciden comprar un robot de última generación capaz de proporcionar a Frank una rutina diaria, una dieta equilibrada y actividades al aire libre para procurarle los mejores cuidados. A lo largo de la película, el robot va aprendiendo del humano y muestra una maduración en su nivel emocional.

De forma natural, a partir de lo expuesto en esta sección; surgen dos preguntas a estos puntos.

- ¿Podrá un sistema operativo amar en el futuro?

- ¿Las interfaces hombre-máquina (IHM) podrán interactuar de manera similar a los seres humanos? 


\subsection{Estrés}

Mientras que el estudio de las emociones se ha llevado a cabo de forma intensiva a lo largo de los siglos, la detección del estrés ha recibido un menor foco de atención hasta el momento. Existen muchas y diversas definiciones del estrés, la inicial fue postulada por Hans Selye en 1936, pero tal vez la más completa es la ofrecida por Vigas en 1984, "Se entiende por estrés la situación creada en el organismo por la exposición a agentes (estímulos estresantes) que pueden alterar, real o simbólicamente, la integridad del organismo. Esta respuesta tiene como objetivo mantener el equilibrio homeostático frente a una perturbación real o frente al riesgo potencial de que dicha perturbación acabe poniendo en peligro la integridad del organismo y que no puede afrontarse con los mecanismos homeostáticos normales".

Tal y como presentan Armario y Nadal [129], el estrés engloba una serie de cambios fisiológicos y conductuales que permiten enfrentarse a situaciones peligrosas y por lo tanto se puede considerar un proceso adaptativo del individuo y su supervivencia. El estrés es un estado de presión o tensión mental o emocional que resulta adverso en determinadas circunstancias. No recibe la consideración de una emoción primaria, pero es un estado que puede activar algunas de las emociones primarias o la combinación de las mismas.

El estrés se genera a partir de unos estímulos, los cuales se definen de las siguientes características: tipo o naturaleza, intensidad y duración. Además, el estrés depende de dos factores muy destacados en la respuesta a los estímulos estresantes: la imprevisibilidad en su aparición y el grado de control que se puede ejercer para modificar su impacto. Estos dos factores son vitales a la hora de estimar estrés en los distintos individuos. Por consiguiente, la elaboración de una metodología genérica y de amplio espectro es fundamental si se quiere conseguir reproducir los resultados deseados en la evocación de estrés.

Según [32] existen tres estados dependiendo de la interacción homeoestática, los estresores y las respuestas adaptativas de los estresores activados. Se define estresor, como el factor o desencadenante que provoca alcanzar un estado de estrés.

- Eustasis. Es considerado la homeostasis basal, es decir, dados unos estresores el individuo es capaz de volver a un estado de no estrés.

- Allostasis (Cacostasis). La respuesta adaptativa puede ser inapropiada debido a estresores inadecuados o prolongados en el tiempo.

- Hiperstasis. Este es una conexión perfecta, donde el individuo gana experiencia y nuevas habilidades y se alcanza nuevamente la capacidad homeostática.

Estos estímulos o estresores en dosis adecuadas pueden considerarse beneficiosos si el tiempo sometido al los mismos es corto. Esto es así, porque el individuo es capaz de asimilar o asumir un mayor grado de responsabilidad. Al estrés positivo se le conoce como eustrés. Mientras que si el periodo de tiempo sometido a estrés es largo o prolongado, el sujeto puede sufrir nervios, angustia, frustración, enfado, etcétera. 
Distrés es el término que se utiliza para definir el estrés negativo. Algunas de las posibles consecuencias de un estrés negativo, pueden desembocar en enfermedades relacionadas con el sistema fonador (disfonía espasmódica), el sistema nervioso o incluso sistema circulatorio (hipertensión).

Respecto a la disfonía espasmódica cabe decir que se trata de una enfermedad rara ya que dentro de una población de 100.000 individuos, esta enfermedad la padece 1 de cada 4 sujetos estudiados. Los síntomas se empiezan a producir en el rango de edad comprendido entre los 30-50 años y es más frecuente en las mujeres. Existen 3 tipos de disfonía: de abducción o apertura de las cuerdas vocales, adducción u oclusión de las cuerdas vocales y la mixta. Para detectar dicha enfermedad es necesario realizar una nasofaringolaringoscopía, la cual se realiza por medio de una fibra óptica flexible. Este método es invasivo y molesto, pero necesario hasta el día de hoy para poder detectar un diagnóstico de esta enfermedad.

Tal y como explican en el trabajo anteriormente citado, Armario y Nadal [129], los estímulos sistémicos activan áreas muy específicas del Sistema Nervioso Central (SNC) en el tallo encefálico y áreas circunventriculares. Desde estas ubicaciones se envían señales al núcleo paraventricular del hipotálamo (PVN), que es clave en la respuesta fisiológica del estrés. Sin embargo, los estímulos emocionales inducen la activación de un gran número de ubicaciones del SNC, tales como corteza prefrontal y núcleos límbicos (estriado ventral, septum y amígdala).

La detección automática del estrés tiene un ámbito de aplicación importante en la vida moderna. Sin embargo, la recopilación de datos, la extracción de características, algoritmos de clasificación y los resultados están demasiado dispersos y es muy difícil hacer comparaciones entre ellos para comprobar el progreso del estado del arte a día de hoy.

\subsection{Producción de la Voz}

En palabras del Profesor Antonio Quilis, "El habla es la realización concreta de la lengua en un momento y en un lugar determinados, por cada uno de los miembros de esa comunidad lingüistica" [146]. El habla es la forma natural de comunicación entre los seres humanos. Además de la información lingüística, el habla ofrece la identidad, y refleja el estado de salud y emocional del hablante, a través de la voz.

El sistema fonador o el sistema de producción del sonido articulado puede dividirse en tres grupos, el sistema respiratorio, el sistema fonatorio y el sistema resonatorio, que se describirán brevemente a continuación.

- Sistema respiratorio o cavidades infraglóticas. El sistema respiratorio se compone de diafragma, pulmones, bronquios y tráquea. Este tiene dos únicos movimientos, inspiración y espiración; es con este último movimiento con el que se consigue la producción de sonido articulado. El funcionamiento consiste 
primeramente en la introducción de aire en los pulmones, el cual llega hasta los bronquios, a continuación el diafragma ejerce presión sobre los pulmones y éstos expulsan el aire hacia la tráquea, órgano constituido por anillos cartilaginosos, hasta llegar a la laringe. Este proceso se puede ver con más detalle en la figura 1.3. Este torrente de aire se va a denominar flujo glotal.

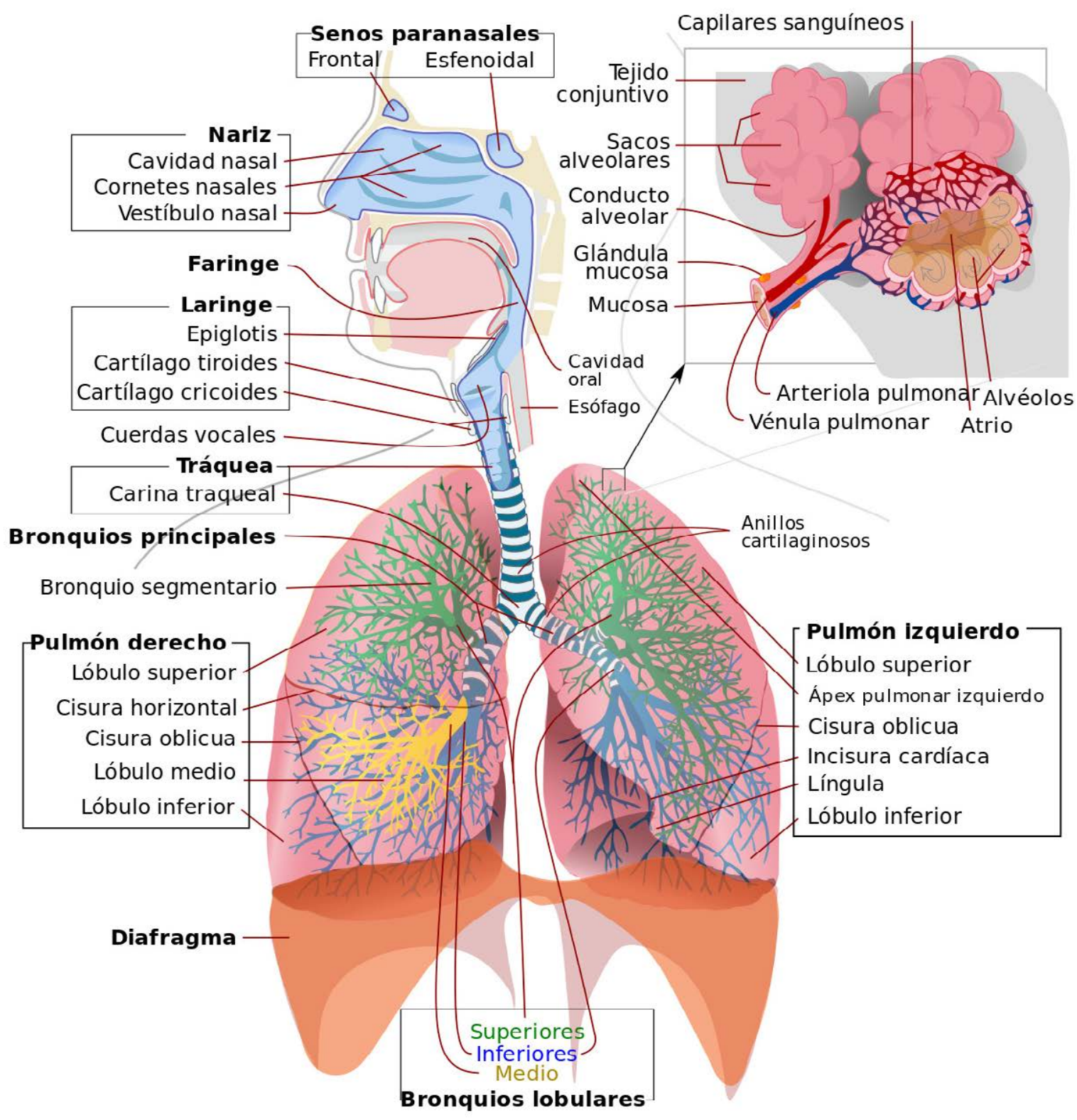

Figura 1.3: Sistema respiratorio. (Imagen de Dominio Público - Licencia CC0 1.0).

- Laringe u órgano fonador. Tal y como se ha descrito en el punto anterior, la laringe está en continuación ascendente de la tráquea. Está formada por cuatro cartílagos: el cricoides con forma de anillo y se encuentra en la base de la laringe que está unida a la tráquea. El tiroides, se encuentra articulado con el cricoides; posee forma de envoltura o escudo y su diseño anguloso hace que se le 
denomine "nuez o bocado de Adán". Finalmente, dos aritenoides, con forma de pirámide y ubicados en el engarce del cricoides; se mueven gracias a un sistema de músculos (interaritenoideo, tiroaritenoideo, aritenoideo transversal, oblicuo y cricoaritenoideos). En la figura 1.4 se puede ver la parte externa de la laringe.

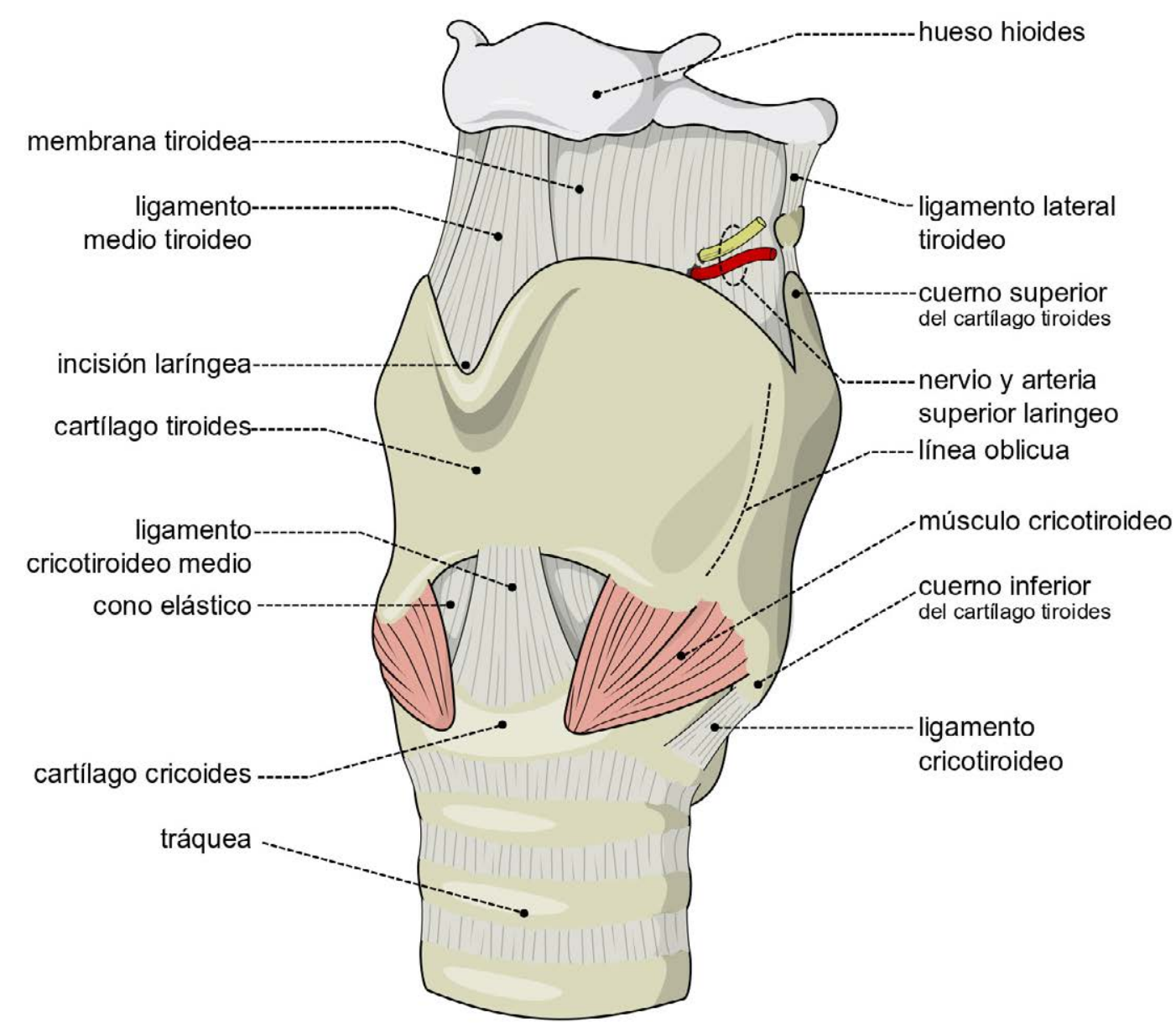

Figura 1.4: Laringe externa. (Imagen realizada por Olek Remesz y traducida al castellano por Alejandro Navarro López - Licencia CC 2.5).

En la parte interna de la laringe se encuentran las cuerdas o pliegues vocales, estas están conectadas con el tiroides en su parte anterior y por la parte posterior con los aritenoides. El espacio libre entre las cuerdas vocales se llama glotis. Es importante destacar que el movimiento de los músculos interaritenoideos y cricoaritenoideos provocan que los cartílagos aritenoideos cierren y abran las cuerdas vocales. En la Figura 1.5 se puede ver la estructura de los pliegues vocales.

En las últimas décadas se han expuesto diferentes teorías y modelos para la vibración glotal, tal y como se presenta en el trabajo de la Doctora Isabel Vilaseca [66]. Los autores, en su mayoría, postulan que las cuerdas vocales poseen una estratificación anatómica en capas, la cual es denominada como 


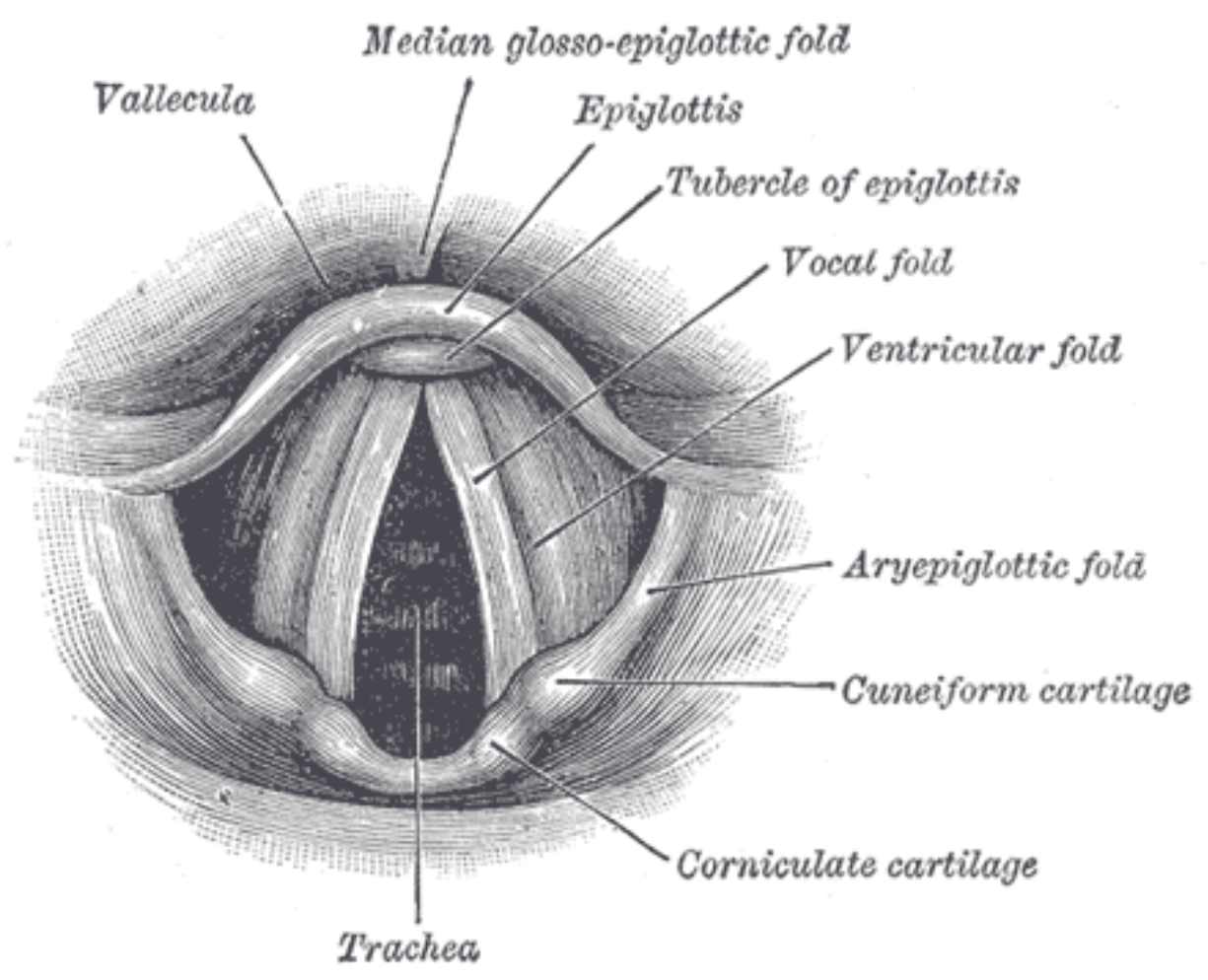

Figura 1.5: Estructura de las pliegues vocales obtenida del libro Gray's Anatomy. (Imagen de Dominio Público - Licencia CC0 1.0).

"body-cover complex" [76]. Esta estructura en capas con distintas propiedades biomecánicas permitirá el desplazamiento de la mucosa y submucosa de la cuerda vocal (cover) sobre un cuerpo muscular más rígido (body) formado por el ligamento y músculo vocal.

La cuerda vocal está constituida por una capa superficial de epitelio respiratorio (epitelio escamoso estratificado). En la parte inferior de ésta se hallaría la llamada lamina propria. Esta lámina está compuesta por fibras de colágeno, fibras elásticas y sustancia fundamental (también conocida como "quintaesencia”) [28]. Ésta última es una sustancia traslúcida e incolora de composición gelatinosa y es la máxima responsable de la viscoelasticidad y filtrado del tejido conectivo. El ligamento vocal está compuesto por el conjunto de dos capas, una más fina y otra más densa y robusta. Por tanto, el epitelio respiratorio junto a la lamina propria superficial constituirían la cubierta, la cual posee movimiento, y el cuerpo rígido (body) de la cuerda vocal.

En la Figura 1.6 se representa la producción del ciclo vocal en diferentes fases o momentos. Así desde el punto de vista funcional, una vez que el torrente de aire llega a la cavidad laríngea genera un incremento de la presión infraglótica y pequeños escapes de aire entre los pliegues vocales. Dicha presión produce un movimiento ondulatorio vertical de abajo a arriba, permitiendo que las cuerdas vocales se separen y se junten; gracias a las contracciones musculares que ejercen movimiento sobre los aritenoides y por el efecto Bernoulli de succión (véase la figura 1.6). La fase inicial o cero es aquella en que ambos pliegues 
se encuentran en fase de apertura, la fase uno representa la aproximación de ambas cuerdas vocales por el movimiento ondulatorio (aducción), a continuación la fase dos representa el momento en que ambas cuerdas vocales se tocan (contacto), comenzando por el borde subglótico y seguidamente las fases 3,4 y 5 representan los diferentes pasos de mayor contacto hasta la oclusión casi completa de los pliegues vocales. Las fases 6 y 7 representan la fase de abducción (separación de los pliegues). Una vez que se produce nuevamente la apertura glótica se concluye lo que se conoce como ciclo glótico completo. El aire que pasa a través de la glotis y las cuerdas vocales se va a denominar flujo glotal.
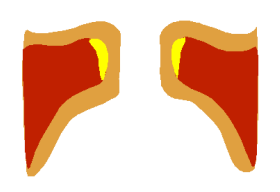

(a) Fase 0 .

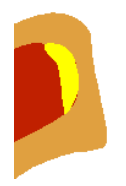

(b) Fase 1.

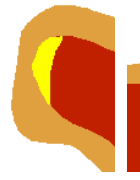

(c) Fase 2 .

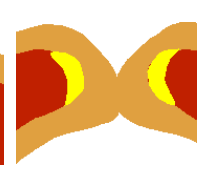

(d) Fase 3 .

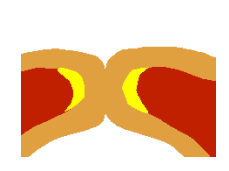

(e) Fase 4 .

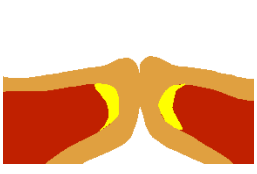

(f) Fase 5 .

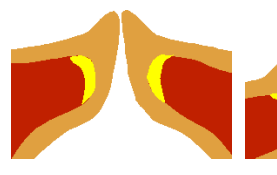

(g) Fase 6.

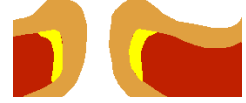

(h) Fase 7 .

Figura 1.6: Mecanismo de producción del ciclo vocal. (Imágenes de Dominio Público - Licencia CC0 1.0).

Además el movimiento o vibración de las cuerdas vocales define si los sonidos articulados son o no sonoros [146]

- Algunas consonantes como [b, d, g, m, n, l, r,...] y las vocales son producidos por la vibración en las cuerdas vocales, por tanto son sonidos fonados.

- Otras consonantes como [s, f, x, $\theta$ ] no producen vibración en las cuerdas vocales, por tanto son sonidos no fonados, o sin voz.

Al igual que otros músculos en el organismo, las cuerdas vocales pueden modificar tu tamaño y tensión. Es lógico pensar que unas cuerdas vocales gruesas desembocarán en una $F_{0}$ baja, mientras que unas delgadas provocarán el efecto contrario [179].

La edad y el género son elementos fisiológicos importantes en la producción de la voz. Es por ello que los niños, al tener cuerdas vocales más cortas y delgadas producen unas frecuencias más altas, que con el paso de la pubertad se ven disminuidas por el engrosamiento de aquellas.

- Cavidades supraglóticas. Tras el paso por la cavidad laríngea, el flujo de aire (fonado o turbulento) llega a la zona laringofaríngea para desembocar finalmente en las cavidades faríngea, oral y nasal. Como se puede observar en la Figura 1.7 las cavidades oral y nasal se definen como el espacio libre para 
el paso del aire delimitado por los órganos articulatorios, tales como lengua, labios, dientes, alvéolo, úvula o campanilla y fosas nasales. El espacio libre que el conjunto de órganos dejan se le denomina tracto vocal. La cavidad supraglótica se encarga de articular diferentes sonidos dependiendo de la posición de todos sus órganos. Dicho espacio genera resonancias que modifican la forma y crean diferentes filtros acústicos, los cuales imprimen distintas características sobre la onda glotal y crean diversos sonidos. Por consiguiente, el habla es el resultado de la emisión sonora de un lenguaje articulado sobre un juego determinado de símbolos, emitido desde el extremo de la cavidad oral (labios), que puede conllevar sonidos fonados o no, debidamente modificados por las cavidades oro-naso-faríngeas.

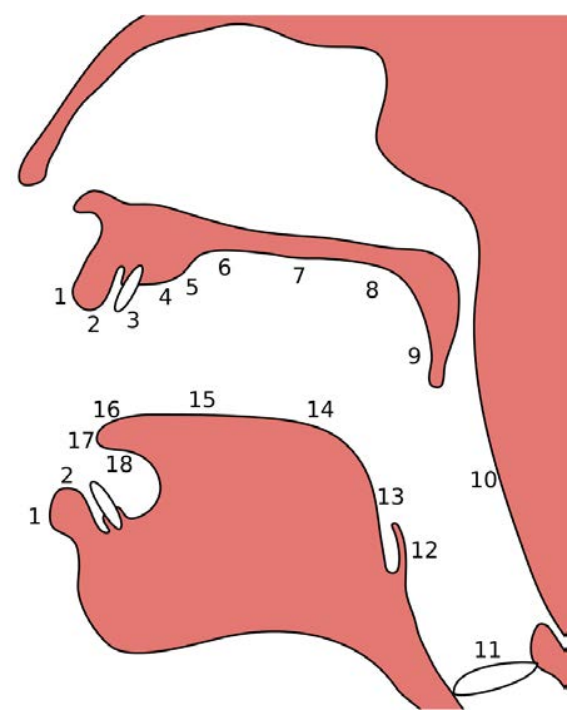

Figura 1.7: Imagen de la sección sagital de la cavidad supraglotal (partes para la articulación): 1. Exo-labial, 2. Endo-labial, 3. Dental, 4. Alveolar, 5. Post-alveolar, 6. Pre-palatal, 7. Palatal, 8. Velar, 9. Uvular, 10. Faríngea, 11. Glotal, 12. Epiglotal, 13. Radical, 14. Postero-dorsal, 15. Antero-dorsal, 16. Laminar, 17. Apical, 18. Subapical. (Imagen basada en los trabajos [27] y [123] y elaborada por Rohieb bajo Licencia CC BY-SA 3.0).

Realizando un resumen de todo lo anteriormente descrito, podríamos decir de forma esquemática que la producción de voz se debe a la vibración inducida por la presión transglotal. Las cuerdas vocales vibran por la acción coordinada de un sistema complejo de cartílagos, músculos y tejidos conectados. Este sistema se activa por la actividad neuromotora inducida desde las zonas pre-motoras y motoras del cortex, derivado por vías neuromotoras bulborraquídeas hacia los músculos gestores de los órganos articulatorios tal y como queda reflejado en la figura 1.8. Las etapas sucesivas que se numeran en la figura, se detallan a continuación.

1. Enlaces desde la corteza neuromotora lingüística hasta las capas de los ganglios basales.

2. Conjunto neuromotor que actúa sobre los músculos de la compuerta velofaríngea (elevador del velo del paladar, palatogloso y palato-faríngeo). 
3. De igual forma actuando sobre el interruptor retro-lingual conectado al interruptor epiglotal (constrictores faríngeos superiores, medios e inferiores y estilofaríngeo).

4. Conjunto de nervios laríngeos actuando sobre los músculos aritenoide transversal y oblicuo y el cricoaritenoide; este último responsable de la adducción y abducción de las cuerdas vocales.

5. Conjunto del nervio vago (frénico) actuando sobre los músculos diafragmáticos (diagragma crural).

6. Bucle de retroalimentación en los ganglios basales amortiguación del tono muscular.

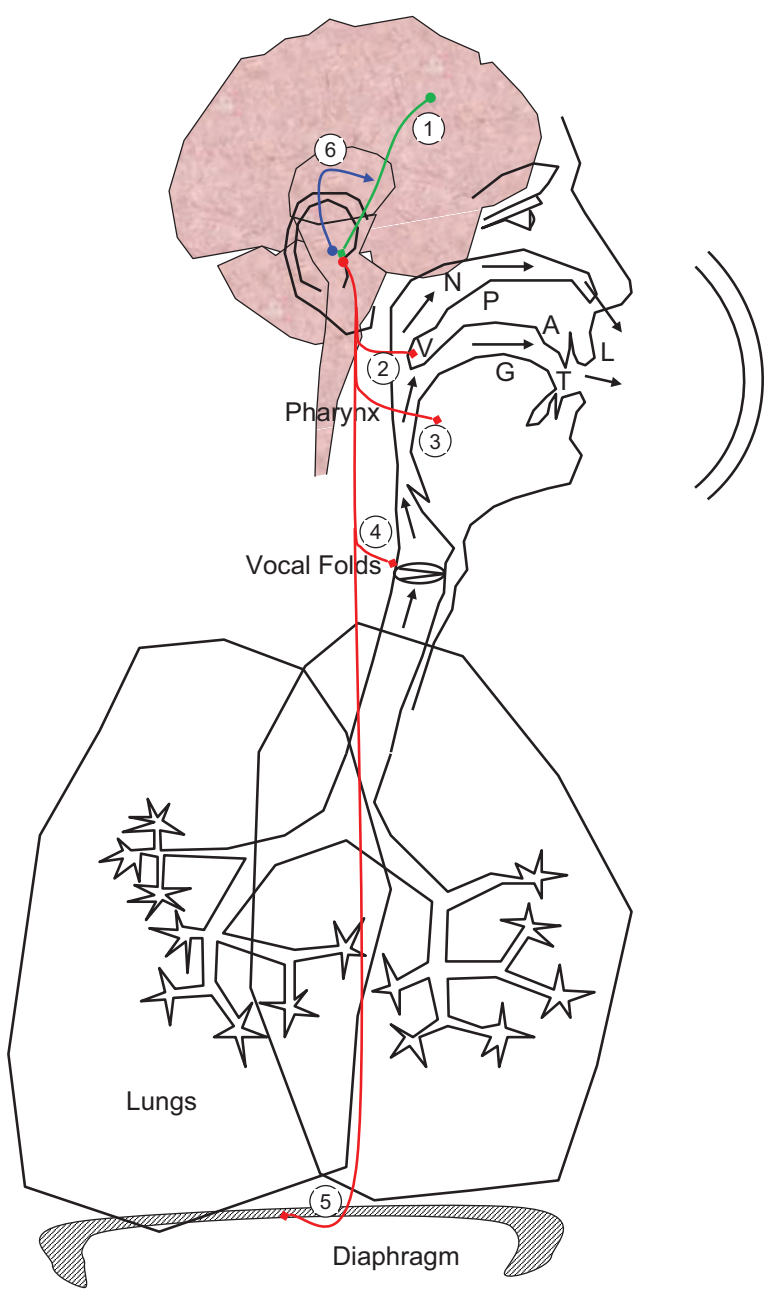

Figura 1.8: Vista simplificada de los principales caminos involucrados en la producción de la fonación.

En la figura 1.9 podemos observar el recorrido completo en el mecanismo de la producción de la voz. Se ha querido representar en forma de diagrama de transiciones para representar las entradas y salidas obtenidas en cada una de sus etapas. 


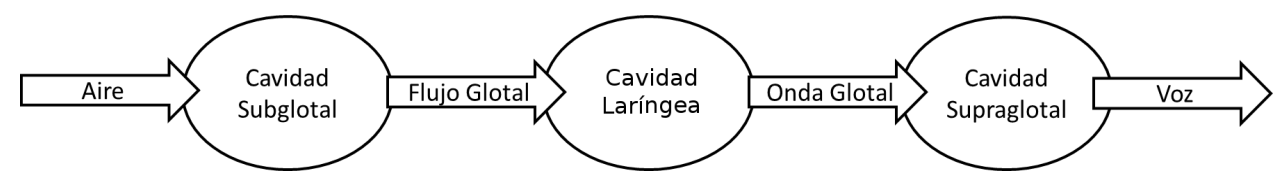

Figura 1.9: Transiciones para la producción de voz.

El sonido puede ser identificado por cuatro características fundamentales, tales como tono, intensidad, duración y timbre:

- Tono o pitch. El tono indica la frecuencia fundamental, representada normalmente como Fo. La frecuencia fundamental es la frecuencia más baja del espectro de frecuencias de una onda periódica. Todas las demás frecuencias se pueden representar como múltiplos de la frecuencia fundamental. El tono se mide en Hercios $(\mathrm{Hz})$.

- Intensidad de sonido. Es la potencia acústica transferida por una onda sonora por unidad de área normal a la dirección de propagación. La intensidad representa la amplitud de un sonido, es decir, como de fuerte o débil es la señal. Se mide en decibelios $(d B S P L)$, donde SPL son las siglas de nivel de presión estándar en inglés. Normalmente equivale a 20 micronewton por metro cuadrado, que se considera el umbral de percepción grosso modo.

- Duración. Esta característica mide cuán larga o corta es la señal a lo largo del tiempo. La duración de una señal acústica se mide normalmente en horas, minutos, segundos y milisegundos.

- Timbre. Esta cualidad es definida como la distribución de energía sobre los armónicos de la frecuencia fundamental (espectro), que se agrupan en picos de intensidad, llamados formantes, según una envolvente, dada por las resonancias del tracto oro-naso-faríngeo. El oído humano percibe los sonidos complejos como un todo, con una calidad que depende del número de contribuciones simultáneas, en frecuencias múltiplos de una dada (fundamental), escaladas según un patrón de energía (timbre). Por lo tanto, el timbre puede ser definido tanto en hercios $(H z)$, como en decibelios $(d B S P L)$.

\subsection{Aplicaciones}

La detección de emoción en la voz juega un papel importante en la interacción hombre-máquina (IHM). Además, tiene muchas aplicaciones potenciales, como el aprendizaje a distancia (e-learning), feedback de testeo y usabilidad, mejora en las ventas (neuromarketing), seguimiento de personas de la tercera edad, juguetes inteligentes, conversores de texto a voz, traductores de lenguaje, juegos, centros de servicio al consumidor, acústica forense, etc.

Un campo que hoy en día está en auge y que también se puede beneficiar de este tipo de investigación es el del mundo del videojuego. Cada día vemos que los videojuegos aumentan en calidad gráfica, estrategia, interacción con el jugador, etc. 
Sin embargo, existe todavía mucho camino por recorrer respecto de lo que se denomina inteligencia emocional artificial. Los personajes se pueden considerar actores estancos sujetos a un guión fijo. Hoy en día las empresas buscan dotar a sus personajes de una capa superior de interactuación entre el jugador y los protagonistas que aparecen en la historia. De esta forma, la experiencia de usuario sería única y se podría concluir que el videojuego sería un ente con vida propia.

La detección de estrés tiene interés para aplicaciones en muchos y diferentes sectores, tales como banca y seguros, servicios al consumidor, análisis de pruebas forenses, etc. Además los servicios de policía y bomberos, hospitales y otros de emergencias con Call Centers podrían beneficiarse de esta tecnología porque reciben una gran cantidad de llamadas telefónicas y deben de saber filtrar de manera eficaz y no aleatoria las mismas. Estas decisiones en la actualidad se realizan por el sentido común del teleoperador al cargo, mientras que utilizando una tecnología más apropiada las decisiones se tomarían de acuerdo a un grado de confianza y relevancia para priorizar y optimizar las actuaciones que hayan de llevarse a cabo.

La ludificación, palabra traducida del término anglosajón gamification [174], es un campo de investigación que trata de utilizar técnicas recreativas para mejorar y modificar ciertos aspectos del usuario. Por ejemplo, es muy común utilizar juegos para la realización de tareas repetitivas y dotar al usuario de ciertas recompensas condicionadas a modo de refuerzo positivo, tal y como presentó Pávlov en sus trabajos de reflejos condicionados [137]. Uniendo esta línea de investigación con la de los videojuegos, la detección de estrés en la voz podría utilizarse para graduar adaptativamente la dificultad del videojuego a partir de los comentarios del jugador durante una sesión. De esta forma se evitarían estados de frustación o abandono y se mejoraría el nivel de satisfacción final del jugador [157].

Otro campo en auge es el de la robótica. Japón, Francia, China, Estados Unidos, Inglaterra, Canada o Alemania son algunos de los países que han desarrollado algún tipo de humanoide. Sin embargo, los más famosos respecto por presentar pinceladas de inteligencia emocional son Aibo de la empresa Sony (descatalogado), NAO, Romeo y Pepper de la empresa Aldebaran Robotics, entre otros. Estos androides son capaces de interactuar con el usuario y realizar actividades cotidianas como informar de correos electrónicos, hacer fotos, etcétera, pero distan mucho de tener una respuesta emocional similar a la de los humanos. 



\section{Capítulo 2}

\section{DATOS DE VOZ QUE EXPRESAN EMOCIONES}

En toda obra, trabajo o plato gastronómico, los materiales o ingredientes con los que se construye o elabora son esenciales para que el resultado final sea de calidad, robusto y con fundamento. Un ejemplo que escenifica de manera sencilla e inteligible este concepto es la elaboración de un plato gastronómico, por ejemplo una paella, donde los ingredientes son muchos y variados, pero si dichos ingredientes no son de calidad, el plato no ofrecerá el sabor y la textura adecuados.

Gastronomía aparte, un proyecto de investigación requiere estas mismas pautas, es decir, la obtención de muestras de calidad es vital.

En la primera etapa de todo proceso, las condiciones a tener en cuenta deben de ser ideales; de esta forma se puede formular una hipótesis inicial de la que partir. Por este motivo, los datos capturados deben ser de alta calidad y en condiciones óptimas. Además, estas muestras deben de ser almacenadas de manera ordenada y con una semántica asociada que proporcione futuribles respuestas a las preguntas que vayan surgiendo a lo largo del estudio científico. Si realizamos una pequeña analogía al principio periodístico de las $\mathbf{5}$ Ws $+\mathbf{1}$ H - Why?, What?, When?, Where?, Who? and How?; una base de datos debe de tener como máxima ofrecer respuesta a todas estas incógnitas de igual manera que lo hace un artículo periodístico que se considere completo. Algunos ejemplos pueden ser los siguientes:

- ¿Cuántas mujeres entre 30 y 45 años son o han sido fumadoras?

- ¿Qué patología en la voz ha sufrido el sujeto ENV-1?

- ¿Dónde se ha realizado la grabación de los sujetos RBT-1, RGM-1?

- ¿En qué fecha o cuándo se ha realizado la sesión de grabación número 3 ?

- Etcétera...

Otro factor importante a tener en cuenta a la hora de tratar datos de calidad es la metodología llevada a cabo para recabar dicha información. Realizar un protocolo o esquema es esencial si se quiere obtener equidad y homogeneidad en las muestras, 
puesto que si no se sigue un riguroso planteamiento, los datos quedan expuestos y pueden ser evaluados como sesgados o subjetivos.

Este capítulo se va a dividir en las siguientes secciones. Primeramente, se ofrecerá el estado del arte sobre la situación actual que nos encontramos al comenzar a abordar este tema. Para ello, se comentarán las bases de datos más importantes en la literatura divididas en dos categorías, bases de datos de emociones y aquellas que están especializadas en estrés. Además, se reflexionará sobre cuáles son las características fundamentales a la hora de elaborar una base de datos emocional. A continuación, se detallará en profundidad nuestro corpus o conjunto de muestras, explicando en detalle su composición, elaboración de subconjuntos para diversos casos de estudio, etc. En el siguiente apartado se hablará sobre los métodos de obtención y validación de datos. Finalmente, se expondrá la metodología llevada a cabo para la captación de muestras con estrés utilizada en este trabajo y la aplicación informática elaborada para la captura y validación de los datos.

\subsection{Disponibilidad de datos}

A diferencia de otros campos de la investigación la detección de emociones en el habla no posee un conjunto de datos aceptados como estándar en el que todos los investigadores o la industria tengan un banco de pruebas donde poder comparar sus resultados. Un ejemplo de estándar podría ser el que se utiliza en el mundo del procesado de la imagen, donde encontramos el icono mítico de Lenna, Figura 2.1. Debido a sus mezclas, zonas planas y texturas esta imagen es idónea para trabajar con diferentes tipos de algoritmos de comprensión de imagen. Por consiguiente, esta imagen se ha convertido en un estándar científico e industrial. Otro ejemplo podría ser el Instituto Nacional de Estándares y Tecnología (NIST por sus siglas en inglés) de Estados Unidos. Fue fundado en 1901 y actualmente forma parte del Departamento de Comercio. El INET es uno de los laboratorios más antiguos y alberga algunas de las competiciones internacionales más prestigiosas, las cuales se utilizan para evaluar los mejores algoritmos en diferentes áreas, tales como rich transcription, reconocimiento del locutor, diarización de locutores o criptografía, entre otros.

Como se comentó con anterioridad, la expresión y percepción de las emociones son muy dependientes de aspectos culturales y sociológicos. Esta sección se va a dividir en dos apartados. En la primera se van a presentar bases de datos de emociones en su término más amplio (alegría, enfado, etc.) y por otro lado, en la siguiente se mostrarán bases de datos específicas de voz producidas bajo estrés.

Según presentan El Ayadi y Ververidis [10] y [187] en sus trabajos, existen múltiples bases de datos de emociones en diferentes idiomas. La mayoría de ellas contienen habla actuada, la cual no poseen ni naturalidad, ni espontaneidad. El habla espontánea es la forma en la que las personas expresan sus emociones de forma natural y sin presión, por consiguiente los locutores deberían de haber sido grabados sin que ellos lo hubieran sabido, o de otra forma, la espontaneidad y/o la naturalidad se pierden. 


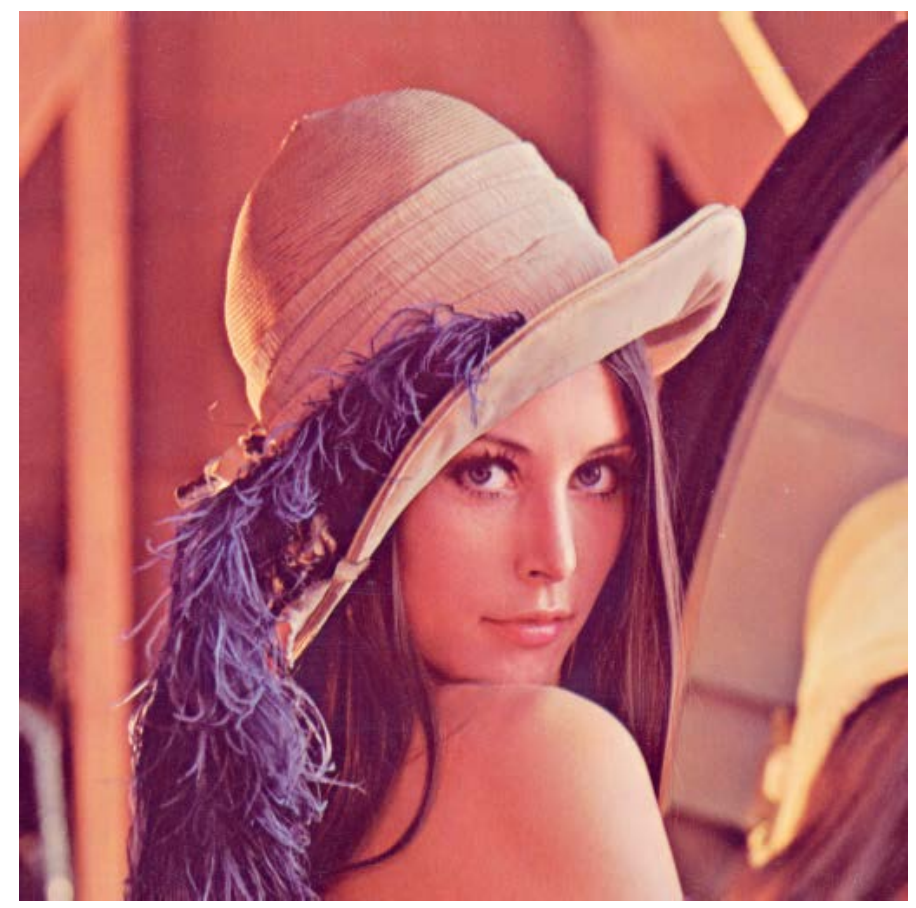

Figura 2.1: Imagen de Lena Söderberg. "Playmate del mes". Revista Playboy. Noviembre 1972, fotografía de Dwight Hooker. Alexander Sawchuk escaneó la imagen y la recortó específicamente para el uso de investigación en compresión de imagen y no tiene ningún derecho de autor sobre ella. Licencia de uso justo o fair use.

Por supuesto, lo anteriormente expuesto entra en conflicto directo con lo que es ético o no, puesto que la Ley de Protección de Datos se estaría vulnerando de forma tácita. Además, realizando este tipo de grabaciones la calidad del audio se vería comprometida en la mayoría de los casos y las grabaciones tendrían ruido o distorsiones varias. Tal vez, la utilización de grabaciones de radio o de televisión serían una buena fuente de espontaneidad y de naturalidad, pero volveríamos al problema inicial, el "copyright".

En otras ocasiones, las muestras han sido llevadas a cabo con la intención de evocar una emoción en los diferentes locutores. El problema de esta técnica es que la reacción de cada individuo puede ser diferente y el estimulo utilizado es controlado por los investigadores. Por consiguiente, encontrar un patrón o un estándar sería arduo y tal vez poco efectivo.

El progreso en el campo del reconocimiento de emociones depende directamente del desarrollo de bases de datos de calidad. La expresión y percepción de emociones están ligadas directamente con aspectos neurológicos, fisiológicos, culturales y sociológicos, entre otros, como ya se ha dicho con anterioridad. Algunos autores han realizado una revisión en detalle de las bases de datos más conocidas en la literatura [10], [187] y [148]. Sin embargo, la mayoría de estas bases de datos no son de libre acceso y la naturaleza de sus datos es demasiado heterogénea. 
Los tipos de colecciones de datos que encontramos en la literatura son los siguientes:

- Actuadas. El habla simulada o interpretada se obtiene por la actuación o interpretación de un actor simulando cierta emoción.

- Elicitadas. El habla elicitada o "no solicitada" se obtiene desde la provocación de emociones de manera artificial, es decir, la emoción se obtiene gracias a los estímulos a los que el usuario se ve sometido en diferentes escenarios [191].

- Naturales. El habla natural es aquella que se obtiene de manera espontánea, sin pretensión de elicitación o evocación alguna de emociones. Un ejemplo podrían ser las grabaciones realizadas en los "Call Centers", conversaciones de pilotos de aeronaves o grabaciones multimedia.

Las grabaciones de emociones genuinas traen consigo problemas éticos así como dificultades en el proceso de etiquetado. Estas grabaciones son difíciles de manejar debido al ruido de fondo, interferencias entre los locutores/hablantes, a las condiciones acústicas de las grabaciones y a la calidad del micrófono.

El número de sujetos en las colecciones de datos que se pueden encontrar en la literatura varía desde 4 hasta 250. Las poblaciones suelen estar desbalanceadas, muchos hombres y pocas mujeres o viceversa. Además, en la mayoría de los estudios, la edad de los sujetos no es tenida en cuenta y como se ha mencionado en el capítulo anterior, el aparato fonador se va modificando con el transcurso de los años, por lo tanto los valores de rasgos similares pueden tener semánticas/lecturas diferentes dependiendo de la edad del sujeto [128]. Por otro lado, existe una gran variedad, respecto a qué tipo de datos se graban, por ejemplo: vocales, palabras o frases completas. La duración también es objeto de estudio (minutos, segundos, etc.).

La mayoría de las bases de datos recogen de forma total o parcial las siguientes emociones: enfado, aburrimiento, disgusto, alegría, estado neutro, tristeza y sorpresa, sin embargo muy pocas incluyen estrés dentro de ellas. Tal y como se avanzó en la Sección 2.1, la falta de estandarización en la forma de adquisición de los datos y en los datos en sí, genera una dificultad añadida a la creación de escenarios de tipo benchmarking, donde se evalúa la calidad de las características y/o de los métodos utilizados en la clasificación [73]. Por consiguiente, para poder garantizar el progreso real en el campo de la detección de emociones debe de realizarse un arduo esfuerzo para la estandarización y disponibilidad de datos que puedan ser compartidos por los investigadores [18].

Sin embargo, el objetivo de este trabajo es estudiar las emociones y más concretamente el estrés que se encuentra oculto en la voz de locutores hablantes de español. Hasta el momento, no existen bases de datos de libre acceso o públicas que cubran el objetivo anteriormente planteado. Por consiguiente, la labor de crear, diseñar y 
poblar una base datos de locutores hablantes de español ha sido desarrollada a lo largo de este trabajo y se verá en profundidad en secciones posteriores.

A continuación se presentan algunas de las bases de datos de emociones que aparecen en la literatura, y son de libre disposición:

- A Database of German Emotional Speech (BES) [24]. Idioma: Alemán. Esta base de datos también es conocida como Emo-Database. Interpretada por 10 actores alemanes profesionales, 5 hombres y 5 mujeres. Las emociones que se han grabado son neutra, alegría, enfado, tristeza, miedo, disgusto y aburrimiento. Los registros que posee la base de datos son 800 frases aproximadamente. El resultado de este número de registros se obtiene de 10 actores por 7 emociones por 10 frases ( 5 largas y 5 cortas), las cuales pueden ser utilizadas en cualquier conversación del ámbito diario y son aplicables a todas las emociones; mas algunas dobles grabaciones que se han añadido para completar el corpus. Todas las emociones han sido evaluadas por 20-30 jueces. Las frases que han sido evaluadas y han obtenido como mínimo una tasa de acierto del $80 \%$, son utilizadas para análisis posteriores. La base de datos es pública y libre y pertenece al Instituto para el habla y la comunicación del Departamento de ciencias de la comunicación de la universidad Técnica de Alemania de Berlín.

- Danish Emotional Speech Database (DES) [48]. Idioma: Danés. Interpretada por 4 actores daneses profesionales, 2 hombres y 2 mujeres. Las emociones que se han grabado son neutra, sorpresa tristeza, alegría y enfado. Los registros se han dividido en 2 palabras, 9 frases y 2 fragmentos o pasajes de habla continua. La base de datos es pública y con licencia gratuita del departamento de Sistemas Electrónicos de la universidad de Aalborg, Dinamarca.

Seguidamente se presentan algunas de las bases de datos emocionales que no han tenido, hasta el momento, tanto impacto en la literatura:

- Ahumada III [149]. Idioma: Español. Base de datos con casos forenses reales que contiene 61 locutores masculinos como corpus. Estas muestras han sido grabadas y almacenadas en cintas magnéticas analógicas a partir de llamadas de tipo GSM. El lanzamiento o release de la base de datos se ha codificado como Ahumada III Release 1 (Ah3R1). La base de datos ha sido creada por el Departamento de Acústica y Procesamiento de Imagen de la Guardia Civil. Esta base de datos es pública y posee diferentes condiciones, tales como ruido de ambiente, estados emocionales, locutores de diferentes orígenes y acentos, etcétera.

- RekEmozio [110]. Idiomas: Español y Euskera. Según sus autores, RekEmozio, es una base de datos bilingüe y multimodal. El corpus está compuesto por 7 actores para el vascuence de los cuales 4 eran hombres y 3 mujeres. La edad media de los locutores era de 31.28 años. Por otro lado, el número de actores para las grabaciones en castellano fue de 10, 5 mujeres y 5 hombres. 
La edad media de los individuos era de 30.70 años. Las emociones grabadas fueron tristeza, miedo, alegría, enfado, sorpresa, asco y estado neutro. El método de obtención de muestras se llevó a cabo a través de voz e imágenes actuadas. La base de datos fue creada por el Laboratorio de Interacción Persona-Computador para Necesidades Especiales (LIPCNE) y el Grupo de Inteligencia Computacional de la Universidad del País Vasco.

- CEMO corpus [43]. Idioma: Francés. Esta base de datos está compuesta por las interacciones de las conversaciones telefónicas de individuos que llamaban a un call center de emergencias médicas. Debido a las características del call center, los pacientes o familiares o amigos de los pacientes expresaban emociones diversas, como por ejemplo, miedo, enfado, tristeza, dolor, estado positivo, sorpresa y estado neutro. El tamaño del corpus consta de 20 horas a partir de 874 locutores, de los cuales 7 eran agentes del call center ( 3 hombres y 4 mujeres) y 867 "pacientes o familiares" (303 hombres y 564 mujeres). Esta base de datos fue elaborada por el Departamento de Interacción Hombre-Máquina de LIMSI-CNRS y el Departamento de Ciencias de la Computación de la universidad de Orsay en Francia.

- EmoVox corpus [43] y [185]. Idioma: Francés. Los datos de este corpus fueron tomados a partir del call center de la empresa francesa de electricidad EDF. Está compuesto por 243 extractos a partir de 77 llamadas. Cada extracto representa la parte emocional de cada llamada. La duración del corpus es de 2 horas y 42 minutos de habla. Se utilizaron 20 tipos diferentes de etiquetas para catalogar los extractos, pero finalmente se agruparon en 5 macroemociones, miedo, tristeza, estado positivo, enfado y estado neutro. La base de datos fue creada por el Departamento de Interacción Hombre-Máquina de LIMSI-CNRS de la universidad de Orsay en Francia.

- FAU Aibo Emotion Corpus [171]. Idioma: Alemán. Este conjunto de datos se basa en la grabación de muestras espontáneas cuando un conjunto de niños utilizan un robot Aibo del fabricante Sony. La base de datos consta de 51 locutores, los cuales son todos niños (30 niñas y 21 niños) con un rango de edad entre los 10 y los 13 años. El tiempo de grabación es de casi 9 horas donde la mayoría de estas grabaciones son comandos cortos. Posee 48.401 palabras y 13.642 ficheros de audio. Está disponible para uso científico y no comercial.

Respecto a las bases de datos enfocadas al estrés existen muy pocos corpora. A continuación se muestran las más relevantes en la literatura.

- Speech Under Simulated and Actual Stress Database (SUSAS) [68] y [69]. Idioma: Inglés. La base de datos contiene muestras de 32 locutores, 19 hombres y 13 mujeres, con edades comprendidas entre los 22 a los 76 años. El número de muestras grabadas llega hasta las 16.000. Además se grabó a cuatro pilotos de helicóptero en vuelo. El vocabulario consta de 35 palabras espontáneas, obtenidas de estos pilotos. Se puede considerar el referente como base de datos de estrés. SUSAS posee 5 escenarios diferentes creados específicamente para simular estrés en la voz. El primero se refiere a Talking Styles, 
o estilos al hablar, los cuales son neutro, lento, rápido, suave, alto, claro, enfadado y pregunta. El siguiente escenario se basa en Single Tracking Task, o habla producida con ruido (efecto Lombard [103]). El ruido rosa se presentó binauralmente a un nivel global de $85 \mathrm{~dB}$ SPL. Al siguiente escenario se le denominó Dual Tracking Computer Response Task; el concepto de dual viene determinado porque la muestra se compensa y se adquiere al mismo tiempo. El cuarto escenario se basaba en cambios bruscos de altitud y dirección dentro de la cabina del piloto. Este caso provoca en el usuario ansiedad y miedo. Finalmente, el último escenario son muestras de pacientes bajo tratamiento psiquiátrico en un entorno doctor-paciente. Esta base de datos ha sido grabada por el Consorcio de Datos Lingüisticos de la Universidad de Pennsilvania, Estados Unidos.

- MIT Labs [53]. Idioma: Inglés. Fernández y Picard consiguen suscitar estrés realizando preguntas de aritmética entre dos números menores de 100 a cuatro personas mientras conducen un coche.

- Base de datos de la Universidad de Brno [166]. Idioma: Checo. Las grabaciones se realizaron a unos estudiantes de la Universidad de Brno durante su examen final oral. La base de datos contiene registros del habla y la tasa cardíaca de 34 estudiantes varones, la mayoría nativos checos.

- Base de datos multilingüe en Mandarín, Cantonés e Inglés [206]. Contiene las respuestas de los estudiantes universitarios durante su periodo de examenes. Todas las respuestas fueron anotadas por locutores nativos para cada base de datos dividida por género.

Tal y como ya se ha avanzado al comienzo de este capítulo existen muchos problemas cuando se trata de estandarizar el trabajo en el campo de detección de las emociones en la voz. A continuación, a modo de resumen, se presentan los problemas fundamentales que consideramos encuentran los investigadores en la utilización de datos:

1. Grabaciones actuadas no espontáneas.

2. Calidad de las grabaciones a veces demasiado pobre (la calidad).

3. Edad de los sujetos no etiquetada.

4. Género no etiquetado.

5. Emociones superpuestas.

6. Transcripciones de las grabaciones no siempre disponibles.

7. Validación de datos poco depurada en ocasiones.

8. Número escaso de sujetos de las bases de datos.

9. Falta de una metodología consensuada para realizar captura de datos.

10. La mayoría de las bases de datos no son públicas o de libre acceso. 


\subsection{Propuesta: Plataforma Emotions Portal}

A continuación vamos a mostrar la nueva metodología planteada en este trabajo para obtener muestras emocionales de voz espontáneas. Además, se presentará la aplicación que alberga el proceso de obtención y validación de las muestras recogidas.

Se propone una plataforma genérica para la captura y validación de habla emocional. El desarrollo de la plataforma es cooperativo y se puede usar para cualquier idioma. Como ejemplo se ha desarrollado un módulo para la elicitación de estrés en el habla gracias a un conjunto de entrevistas online y otros módulos para el etiquetado de las grabaciones realizadas en Español.

Una de las ideas que subyacen en la propuesta de este método es la de promover la formación de una comunidad que coopere en la colección y análisis de datos de habla emocional y defina un corpus estándar en diferentes lenguas, acentos y orígenes. Las muestras de voz son etiquetadas de forma objetiva haciendo uso de un método de votación simple, es decir, lo que diga la mayoría más uno. Estas muestras serán etiquetadas y clasificadas con la emoción que la mayoría seleccione.

La plataforma puede ser definida como cooperativa, escalable o modular y no subjetiva. De acuerdo a la Fig. 2.2, se ha divido la plataforma online en tres etapas diferentes: Identificación del Usuario, Donación de Voz y Validación de Emociones.

En la parte superior de la figura se representa un usuario utilizando dispositivos electrónicos, los cuales poseen conexión a Internet. El paso de Identificación de Usuario comienza una vez que el usuario está conectado a la plataforma, y consiste en un proceso como se realiza en la mayoría de las plataformas web actualmente. El formulario solicita al usuario datos personales tales como, nombre y apellidos, lengua materna, país de origen, si es hombre o mujer, la edad y un email de contacto por si está interesado en saber los progresos que se van publicando en la plataforma. Una vez autenticado en la plataforma, el usuario puede elegir entre dos posibles escenarios, donar su voz mediante las respuestas dadas a un conjunto de preguntas o validar emociones mediante un sistema de votación. 


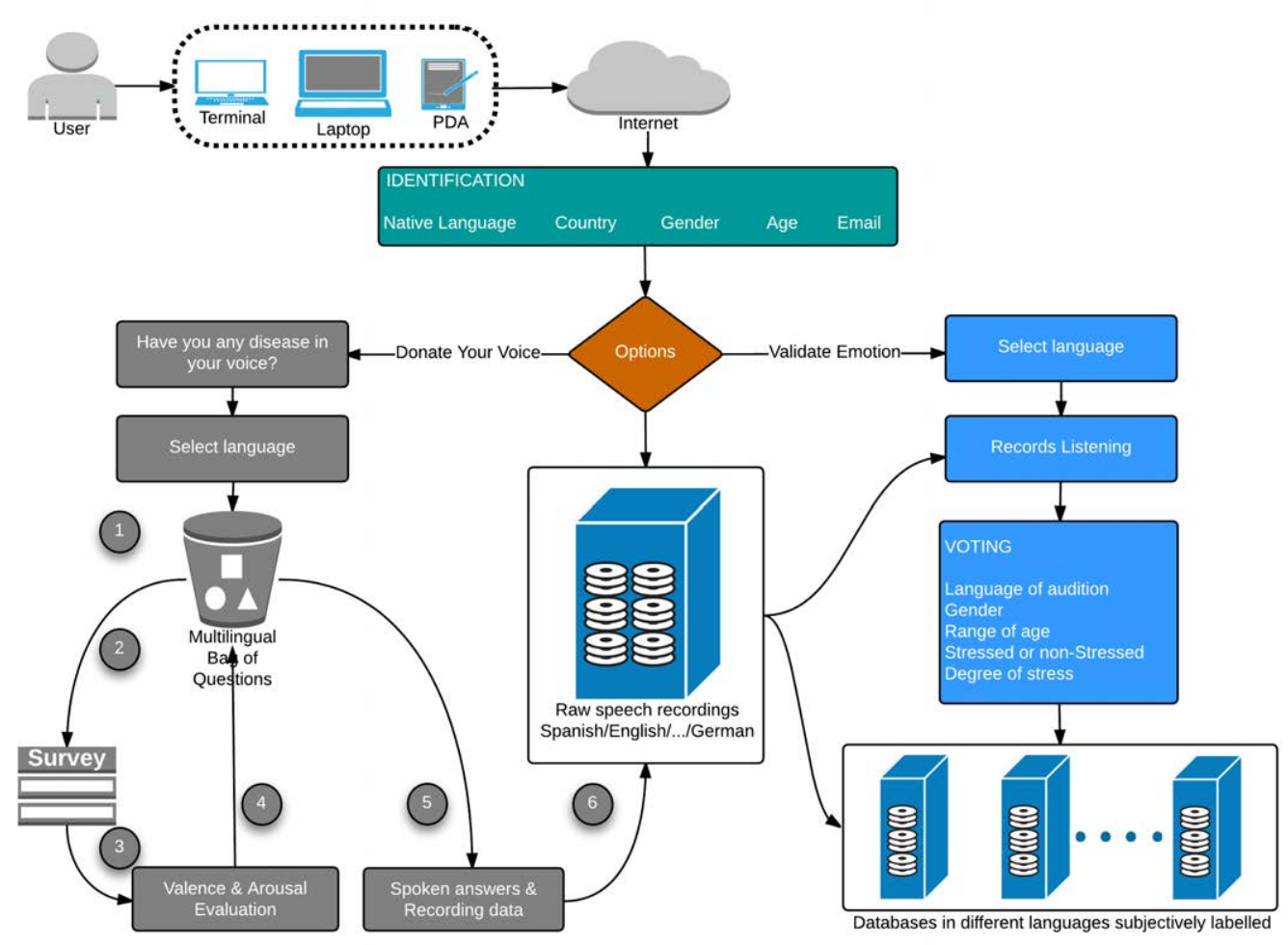

Figura 2.2: Estructura de la Plataforma para toma de datos online.

\subsubsection{Estructura de la base de datos}

Seguidamente se presentará una propuesta de diseño de base de datos, donde se mostrarán las características más relevantes que se han tenido en cuenta y que son diferenciales respecto de planteamientos anteriores, aparecidos en la literatura, en el estudio de la detección de emociones.

- Edad. Se utilizará para generar grupos histográficos por grupos de edad.

- Duración. Cantidad de milisegundos, segundos o minutos grabados.

- Tipo de muestra. Si la muestra obtenida es una vocal, una palabra, una frase o discurso completo.

- Género. Es vital saber el sexo del sujeto, ya que la morfología y fisiología es distinta y por tanto el tratamiento de los datos debe de ser sensible a este aspecto.

- Patologías en la voz. El sujeto puede padecer o haber padecido trastornos en la fonación o en la articulación.

- Aspectos circunstanciales. Hábitos (tabaco, alcohol, medicamentación, etc.), condiciones que puedan alterar circunstancialmente la fonación (embarazo, etc.), y otros afines. 
La captura física de los datos es importante pero el etiquetado de los mismos es vital si se quiere en un futuro poder realizar análisis prospectivos robustos.

Se han determinado las siguientes entidades y relaciones:

- Usuario: Esta entidad representa toda la información relacionada con el usuario, como por ejemplo, nombre completo, edad, género, si es o no fumador y los años relativos a dicha actividad o inactividad y correo electrónico. Este último atributo de la entidad es vital para poder contactar con el usuario en caso de necesidad futura. Además, esta entidad está íntimamente relacionada con tres de las cuatro restantes entidades. El usuario pertenece a un país de origen, por consiguiente su relación es de 1:1, es decir, un sujeto solo ha podido nacer en un único país. Un usuario dona dos respuestas. En secciones posteriores se explicará el motivo de por qué tan solo ofrece 2 respuestas y no más. La relación inversa es que una respuesta puede ser ofrecida por muchos usuarios. Finalmente, un sujeto puede padecer una, varias o ninguna enfermedad en la voz. Por ejemplo, el sujeto puede tener pólipos o disartria, aunque en la mayoría de los casos el sujeto no padecerá patología alguna.

- Enfermedad: La entidad Enfermedad recoge un catálogo de enfermedades o patologías en la voz, la base de datos recoge cuatro descripciones traducidas al inglés, francés y alemán, además por supuesto del español. Una enfermedad se relaciona de forma única con un usuario teniendo de relación one to many, o dicho de otra forma, un usuario puede padecer una sola enfermedad, mientras que esa enfermedad puede ser padecida por muchos usuarios. El lector puede pensar que es un error de diseño, pero en realidad lo que se ha planteado es obtener la enfermedad de carácter más grave padecida por el usuario hasta el momento.

- País: De forma análoga a la entidad anterior, país está definido por cuatro diferentes descripciones para la lista de todos los países definidos por la Agencia Europea de Estadística. Esta entidad está relacionada únicamente con la entidad usuario y su cardinalidad es de 1:n, es decir, un usuario solo ha podido nacer en un único territorio, pero en un territorio han podido nacer muchos usuarios.

- Pregunta: Esta entidad está formada por cinco atributos. El primero es el campo asunto, el cual se utiliza para resumir la pregunta en cuestión. Por consiguiente, se podría entender como una descripción corta. Los otros cuatro campos restantes son la misma pregunta traducida a los cuatro idiomas referidos con anterioridad, inglés, francés, alemán y español. La entidad pregunta se relaciona única y exclusivamente con respuestas y se entiende que una pregunta obtiene muchas respuestas o ninguna, si dicha pregunta jamás es seleccionada por ningún usuario.

- Respuesta: La entidad respuesta se puede entender como un "puente" entre la entidad pregunta y la entidad usuario. Por consiguiente, esta entidad posee atributos de relación o claves ajenas (foreign keys) en todas y cada una de las 
entidades involucradas. Por consiguiente, el diseño queda de la siguiente forma: un usuario puede validar muchas respuestas de otros usuarios, mientras que una respuesta es ofrecida a la misma pregunta por muchos usuarios. Por otro lado, una respuesta requiere una serie atributos adicionales a tener en cuenta y que se entenderá mejor más adelante, donde se explicará la metodología diseñada, implementada y llevada a cabo para obtener nuestras muestras. Por ejemplo, una respuesta llevará asociados unos valores numéricos que representarán el grado de excitación o arousal de la respuesta ofrecida y además el grado de convencimiento que el usuario tiene sobre el tema preguntado (potencia o intensidad). Desde el punto de vista de la validación una respuesta ofrecida por un usuario tendrá una serie de valores para poder clasificarla y evaluar dicha muestra, como por ejemplo la edad del locutor, el género y el nivel de estrés que posee el sujeto en el momento de contestar a la pregunta.

Aparte de lo anteriormente mencionado, cabe añadir que todas y cada una de las entidades con tipos de relación múltiples poseen claves ajenas y un campo de auditoria para registrar todos los cambios realizados en cada una de las tablas maestras. En la figura 2.3 se puede observar el diagrama de Entidad/Relación de la base de datos.

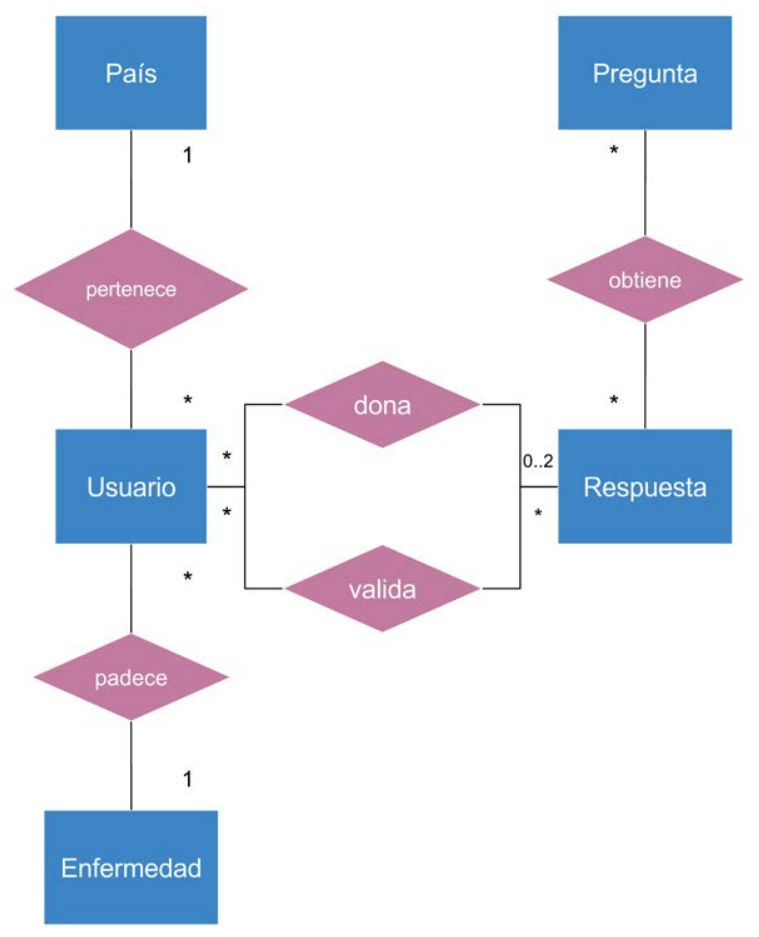

Figura 2.3: Diagrama de Entidad Relación de la base de datos construida.

\subsubsection{Donación de la voz}

Previamente los usuarios tienen que contestar si sufren o han sufrido algún trastorno en la voz. Es crucial saber, si el usuario sufre algún tipo de disfonía funcional u orgánica. Estas alteraciones pueden afectar a la voz y dificultar el uso de técnicas biométricas. Seguidamente, el locutor escoge el idioma en el que se va expresar. 
Evocar de forma natural alegría, disgusto o enfado no es tarea baladí y por tanto es preciso utilizar un proceso de preparación concienzudo y sistemático. Se han utilizado en la literatura para evocar emociones o estrés en el habla diferentes estrategias y escenarios. Algunos ejemplos presentados son grabaciones durante una entrevista de trabajo a diez mujeres y cuatro hombres [106]. Otro ejemplo consistiría en realizar registros durante un examen oral en frente de un jurado [70], el discurso es grabado junto a otras métricas tales como tasa cardíaca, presión sanguínea y tono de voz. Los sujetos participantes fueron seis soldados evaluados por un jurado militar, donde dichos jueces eran de mayor nivel jerárquico que los sujetos en estudio. Fernández y Pickard [53], elicitaron estrés en cuatro sujetos mientras estos utilizaban un simulador de conducción y realizaban operaciones matemáticas con dos números que no sumaban más de 100. En [161] quince sujetos tuvieron que contestar determinadas cuestiones mientras que utilizaban un simulador de vuelo cuya dificultad iba en aumento, provocando mayor cantidad de estrés en los usuarios.

Se quiere destacar que todos los ejemplos mencionados anteriormente, tienen como puntos en común que los datos utilizados de la investigación poseen un número muy limitado de muestras o locutores y los efectos buscados fueron evocados gracias a diferentes escenarios y protocolos. Como consecuencia de esta situación, los modelos desarrollados pueden producir resultados pobres o de baja calidad, debido a la falta de generalidad, y hay que destacar que es imposible contrastar dichos resultados con cualesquiera disponibles en la literatura.

En este punto, el principal problema es decidir cómo evocar una emoción, cómo se manifiesta esta emoción en la voz y finalmente cómo se registra la misma. Se ha desarrollado un módulo diferente para cada tipo de emoción. Esto es así, porque no es lo mismo evocar miedo que felicidad. Estos módulos están compuestos por una serie de imágenes y de sonidos que se presentan al usuario de manera inesperada. Una vez la emoción ha sido evocada en el usuario se comienza a grabar su reacción y se le formula la siguiente cuestión: ¿qué has sentido?

Cada emoción se almacena en una base de datos diferente. En la Figura 2.4 se puede observar un sencillo diagrama de relación entre las bases de datos y los módulos de evocación de muestras de voz. Tal como se avanzó párrafos anteriores se ha realizado un ejemplo con la evocación de estrés en el locutor y se puede observar dicho módulo en la figura 2.4.

El estrés se elicita o evoca de acuerdo con el método propuesto por Arciuli en [6], [5] y [192]. La idea principal de este trabajo se basa en preguntar al usuario sobre un tema que sea de actualidad y que pueda resultar incómodo por lo controvertido. A continuación solicitarle que exponga la opinión más sincera y congruente posible con su forma de pensar, y acto seguido solicitar que defienda la opinión opuesta, como si esta fuera realmente lo que él pensara. Un locutor muestra estrés en su habla de diferente forma cuando produce una aseveración que concuerda con su punto de vista real que en el caso de tener que elaborar un discurso ficticio para parecer creíble cuando expresa una opinión contraria a su punto de vista. Este estrés 

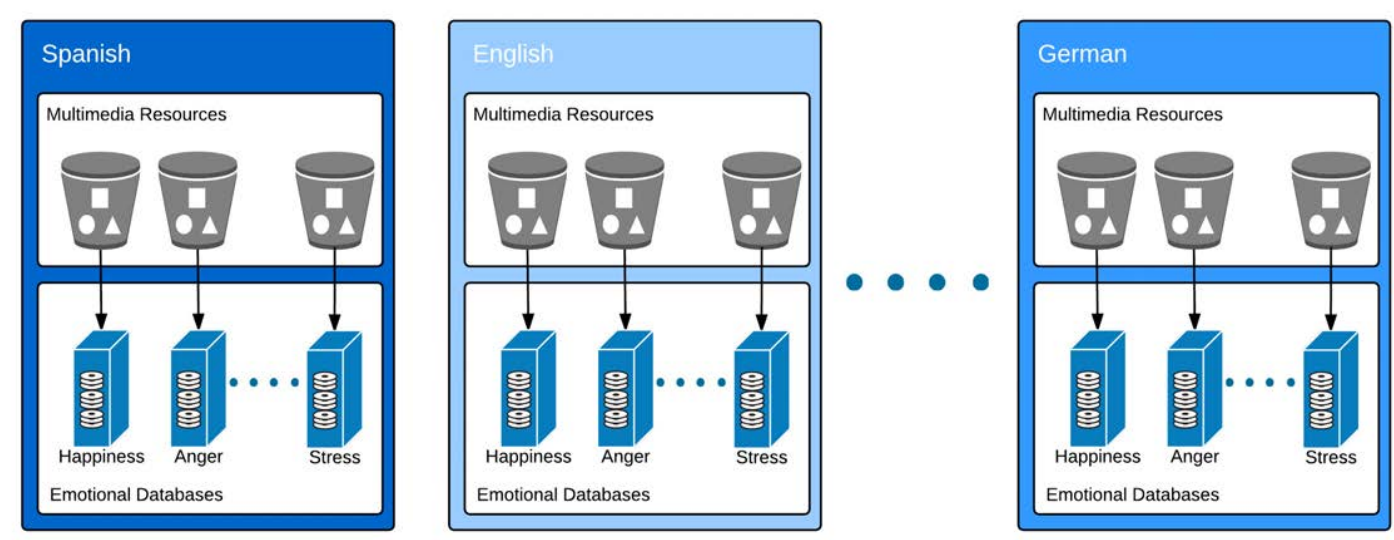

Figura 2.4: Relación entre las bases de datos y los módulos de evocación de muestras.

se manifiesta en su calidad de fonación [125].

El método se basa en una encuesta escrita, y dos preguntas que han de contestarse de forma hablada. La encuesta está compuesta por 10 preguntas, las cuales han sido extraídas de una bolsa de preguntas categorizada, tal y como se indica en la Figura 2.2. Las preguntas están directamente relacionadas con toda la información personal que el usuario aportó en el momento del registro. En otras palabras, la edad, el género, el país y la lengua materna son parámetros básicos para escoger las 10 preguntas aleatorias. Esto es debido a que tales cuestiones no influyen de la misma manera en diferentes poblaciones. A continuación, la encuesta evalúa el grado de convencimiento y el grado de acuerdo o desacuerdo sobre temas sociales controvertidos como se muestra en la Figura 2.5. Estos temas dependen de la cultura y del idioma y por supuesto están en constante cambio de acuerdo con el panorama actual para evocar fuertes sentimientos en la gente. En la Sección 2.3 se explicará con más detalle las preguntas utilizadas para la obtención de muestras. A modo de ejemplo, algunas cuestiones podrían ser:

- ¿Está usted de acuerdo con el Brexit?

- ¿Deberían de prohibirse los toros?

- ...

El usuario debe de contestar en cada pregunta el grado de acuerdo/desacuerdo entre los valores 1 y 7 , siendo 1 "Muy en Desacuerdo" y 7 "Muy de acuerdo"; de forma análoga el usuario debe de puntuar del 1 al 7 su grado de convencimiento sobre la respuesta que ha dado anteriormente, siendo 1 "Indiferencia" y 7 "Sentimientos muy fuertes" sobre el tema en cuestión. En la Figura 2.5 se puede ver un par de preguntas de un posible cuestionario contestado por un usuario.

Una vez que la encuesta ha sido completada en su totalidad, la aplicación identifica aquellos temas que han recibido una puntuación más extrema, en los que el 


\section{Encuesta}

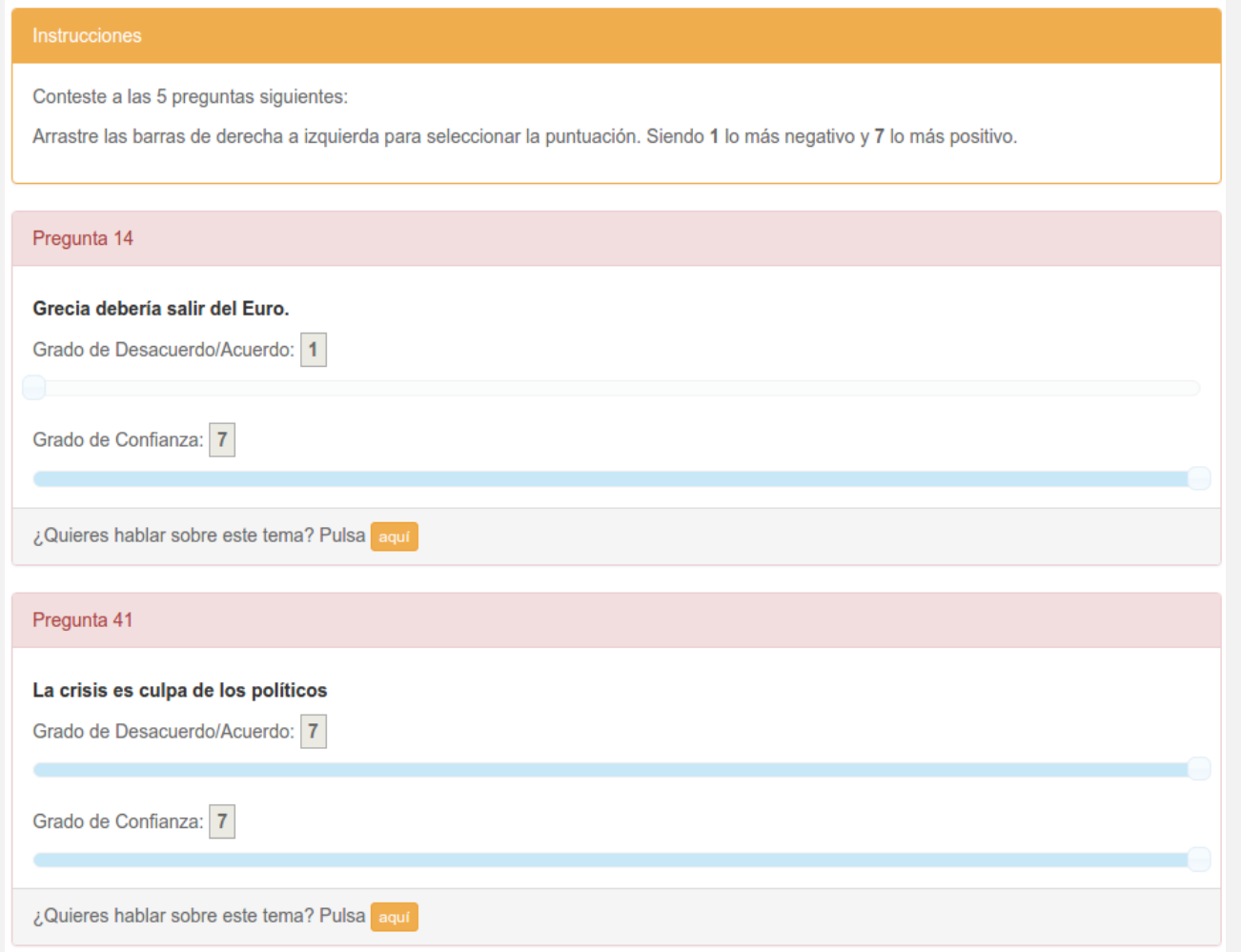

Figura 2.5: Encuesta online para identificar respuestas con total acuerdo o desacuerdo y grado de convencimiento muy alto.

usuario está muy en desacuerdo con un tema y tiene un fuerte convencimiento de su respuesta $1 / 7$, o bien estando también muy convencido de su respuesta, está totalmente de acuerdo con la idea que expresa la pregunta $7 / 7$.

A continuación el sistema realiza al usuario una pregunta de las que han obtenido un 1/7 ó $7 / 7$ y el usuario tiene que expresar de forma oral un punto de vista que este a favor de la pregunta y a continuación un punto de vista que sea el contrario. La dificultad para construir y expresar una opinión contradictoria en tan solo 20 segundos refleja un incremento en las pausas silenciosas, duración de las mismas y presencia de pausas fonadas "fillers", bien aisladas, bien ligadas a un final de palabra, etc., producidos de forma totalmente inconsciente y que se ven reflejados en el habla.

Si se observa la mecánica del caso, lo que se busca es inducir dificultad en la creación del discurso en el usuario. Cuando la opinión es sincera y congruente la persona no tiene la necesidad de construir un discurso alternativo y su discurso es fluido, mientras que cuando tiene que argumentar una idea que no es congruente con su opinión sincera, debe de hacer un esfuerzo adicional para construir dicho discurso. 
Una vez que la encuesta ha sido contestada, llega el momento de llevar a cabo las dos grabaciones consecutivas. Esta tarea tuvo diversas evoluciones en la plataforma hasta llegar a un punto de máximo automatismo y fiabilidad. En una primera implementación el usuario debía interactuar con la interfaz y presionar ciertos botones que realizaban llamadas a funciones tales como grabar, parar la grabación y descargar muestra, entre otras.

En la Figura 2.6 muestra el momento dónde el usuario va a comenzar su primera sesión de grabación en la plataforma online para la versión preliminar de la interfaz de usuario. El usuario tenía que presionar el botón de grabación (botón rojo con un micrófono en su interior) y comenzar a hablar. Una vez hubiera transcurrido el tiempo de grabación el usuario pulsaría el botón de parada (botón azul con un cuadrado en su interior). Este proceso se llevaba a cabo dos veces; la primera para responder al tema de forma congruente con su opinión personal y la segunda con la opuesta.

Después de realizar la grabación, el usuario debía descargar la muestra en una ruta local de su ordenador y a continuación enviar dicha muestra al servidor. Ambas acciones estaban aunadas en una misma página web para que la usabilidad de la página no se viera perjudicada y el usuario comprendiera fácilmente los pasos a seguir. En la Figura 2.7 se muestran ambas acciones.

Sin embargo este proceso no era óptimo para nuestro propósito final de obtener muestras espontáneas del usuario. Después de evaluar algunos casos realizados hasta el momento, tomamos nota de ciertos aspectos negativos como los que se detallan a continuación:

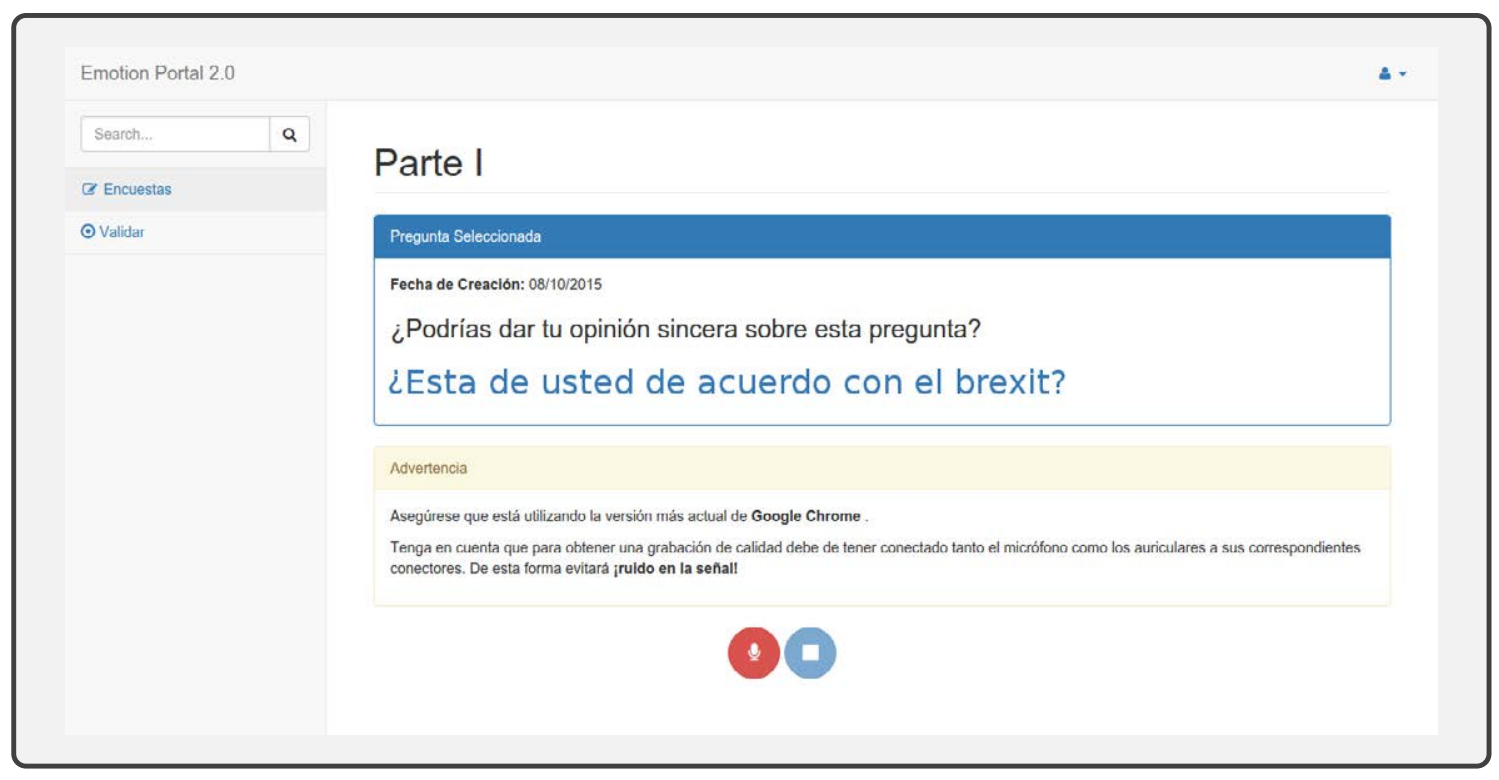

Figura 2.6: Pantalla de grabación. 


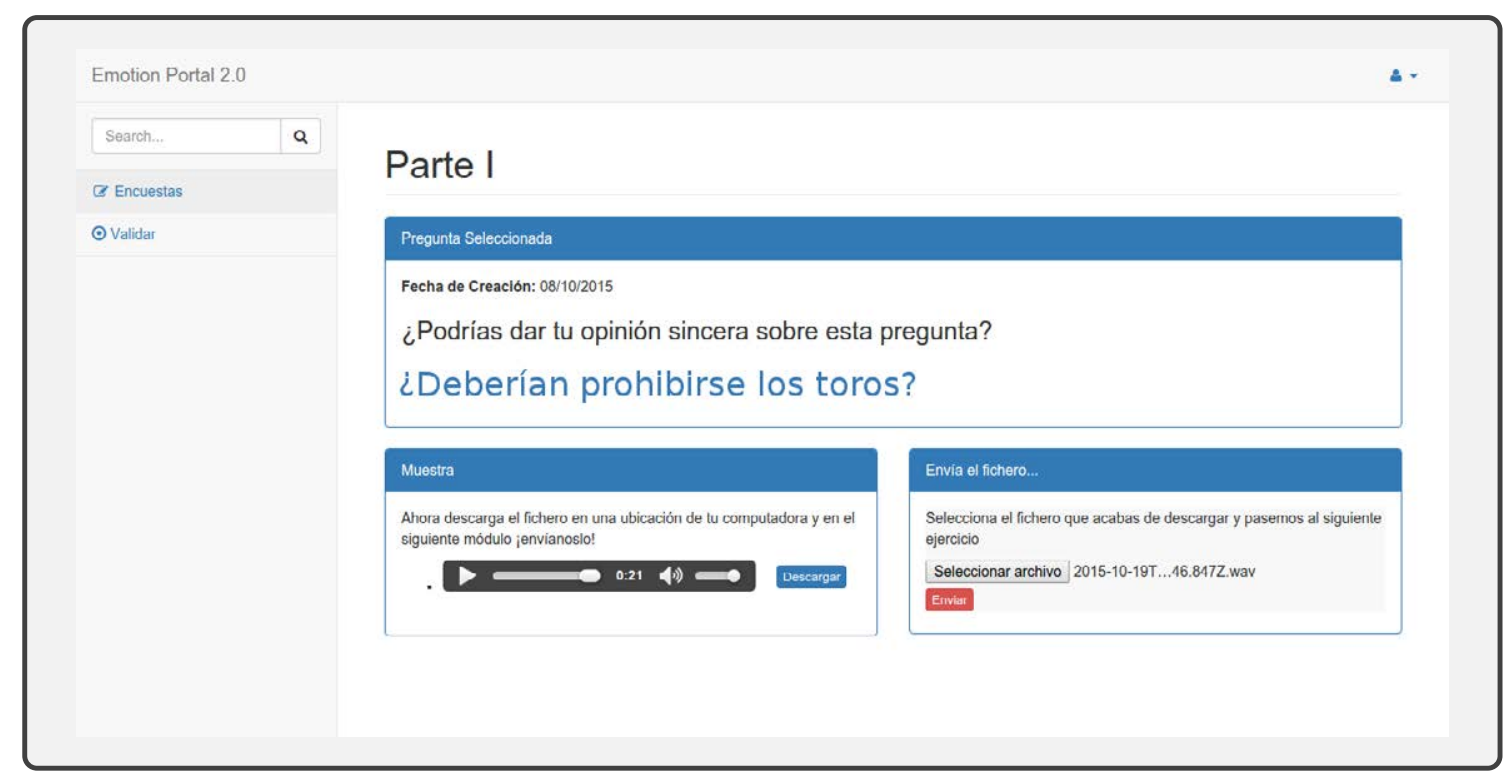

Figura 2.7: Proceso de descarga y subida de muestras al servidor.

- El usuario tenía control sobre el proceso de grabación de forma íntegra. Esto era muy negativo, puesto que el usuario tenía que pulsar el botón de comenzar grabación y después pulsar el botón de parada. Uno de los requisitos fundamentales de la metodología se basa en la franja para llevar a cabo la grabación, entre 20 segundos y un minuto, por lo que darle la libertad al usuario de "encender y apagar" el capturador de audio, no parecía lo más acertado.

- Tiempo entre preguntas no controlado. Además del punto anterior, otro aspecto importante es el poder realizar las dos grabaciones de forma continua y sin paradas. De este modo se consigue que el usuario no esté preparado o concienciado previamente en la siguiente tarea que vaya a llevar a cabo.

- Archivos de audio demasiado grandes. Las muestras se van a utilizar para explotarlas más adelante en la extracción y selección de parámetros característicos. La calidad de la grabación debe ser máxima y por tanto el tipo de fichero en el que se almacena el audio es de tipo $W A V$. Este tipo de archivos no están comprimidos y por consiguiente el tamaño del fichero resultante suele ser bastante grande. Un descuido por parte del usuario a la hora de parar la grabación podría provocar que el fichero a subir al servidor ocupase demasiado.

- Proceso de descarga y subida al servidor. Este proceso, además de tedioso, era peligroso y acarreaba un nivel de seguridad muy bajo para la plataforma, debido a que un usuario podía subir cualquier tipo de fichero al servidor.

Debido a los motivos aquí expuestos, se decidió rediseñar estas páginas de forma que el usuario tuviera que interactuar con la página lo mínimo posible, centrando el foco de atención en contestar a las preguntas que se presentaban por pantalla en cada caso. Para ello se implementaron las siguientes mejoras: Temporizador de cuenta atrás automático. Dada una constante de tiempo preconfigurada en la 
aplicación, la pregunta se muestra al usuario mientras que un reloj va descontando los segundos. En la Figura 2.8 se puede observar una captura cuando el sujeto está leyendo la tarea a realizar.

Pasados los segundos estimados se activa un bloqueo de pantalla, indicando al usuario que comience a responder a la pregunta seleccionada. Este bloqueo impide cualquier tipo de acción sobre la pantalla. Una vez que el reloj consume todo el tiempo restante, la grabación capturada por la aplicación es subida al servidor por un proceso automático en background y paralelo. Mientras que se lleva a cabo esta tarea se presenta al usuario la segunda pregunta sin dilación y con idéntica sistemática, es decir, un pequeño slot de tiempo para que el usuario lea la siguiente tarea a realizar, seguido de un bloqueo de pantalla, grabación de la segunda muestra y finalización del caso. En la Figura 2.9 se muestra la acción de bloqueo de pantalla.

Este proceso aun siendo más arduo en su implementación que el primero, presenta una serie de ventajas respecto al anterior, como por ejemplo:

- El usuario no posee en ningún momento la posibilidad de parar el caso, a menos claro está, que abandone la página de manera premeditada.

- El efecto psicológico del reloj descontando los segundos es una mejora sustancial en el proceso de evocación de estrés en el usuario.

- La nueva implementación ofrece una versión más depurada para dispositivos móviles, puesto que es adaptable a cualquier tipo de pantalla.

Parte I

Pregunta Seleccionada

Fecha de Creación: 24/11/2015

¿Podrías dar tu opinión sincera sobre este tema?

¿Le parece correcto que el Estado subvencione el fútbol?

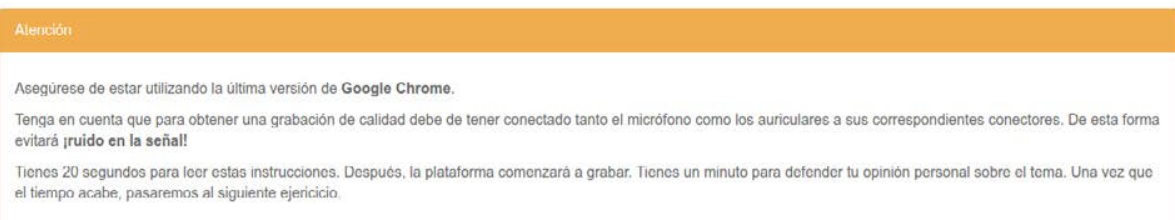

el tiempo acabe, pasaremos al siguiente ejericicio

45

Figura 2.8: Nueva versión del proceso de grabación. 


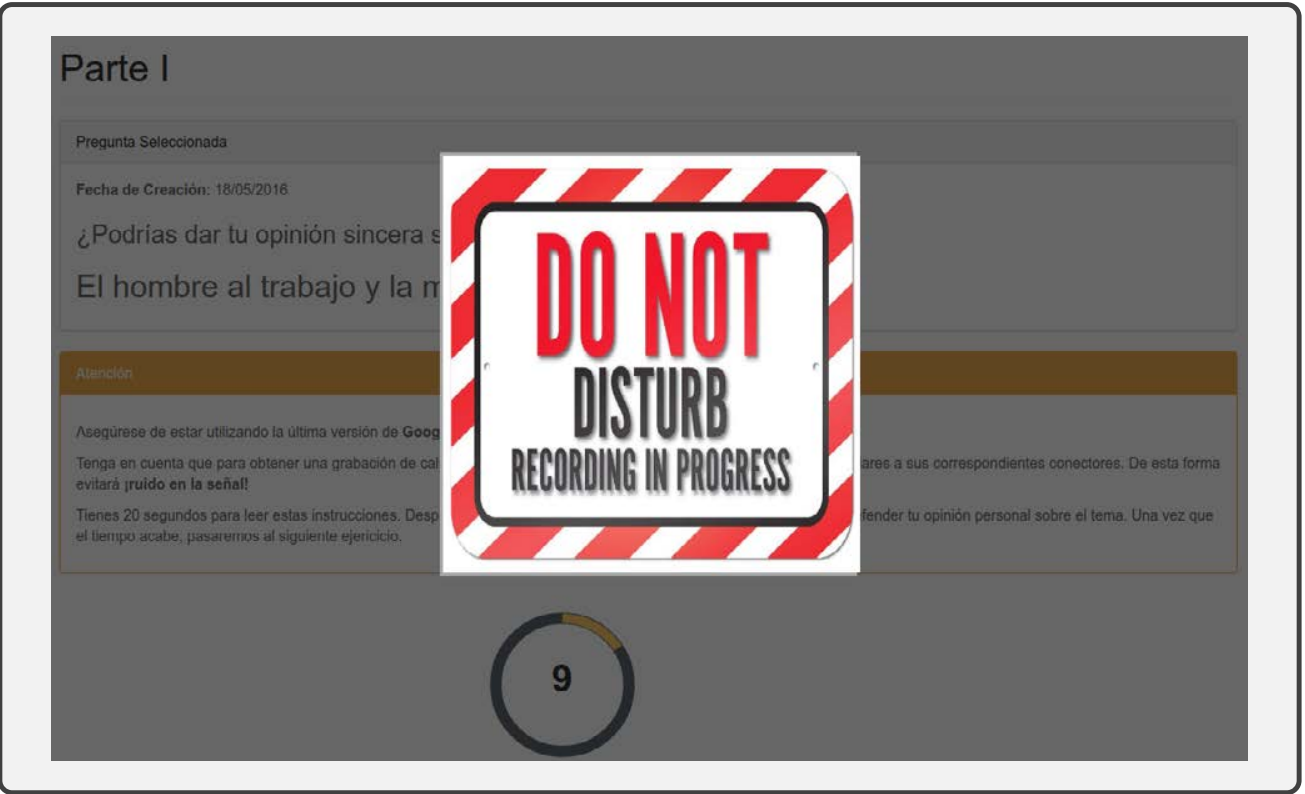

Figura 2.9: Bloqueo de pantalla mientras un usuario está realizando una grabación.

Un usuario puede grabar tan solo dos respuestas correspondientes a un caso de grabación respecto de la pregunta seleccionada en la encuesta. Es por ello que se han generado filtros específicos para impedir que un usuario realice las grabaciones más de una vez. Si por el motivo que fuera, el usuario interrumpió el caso práctico, tampoco se le permitirá lanzar nuevamente el proceso de grabación, evitando así la posibilidad de obtener muestras "contaminadas" y carentes de espontaneidad debido al conocimiento previo de la metodología llevada a cabo en alguno de sus puntos. En la Figura 2.10 se puede observar un mensaje informando al usuario que ya ha completado el ejercicio y que tan solo puede contribuir validando las muestras de otros usuarios.

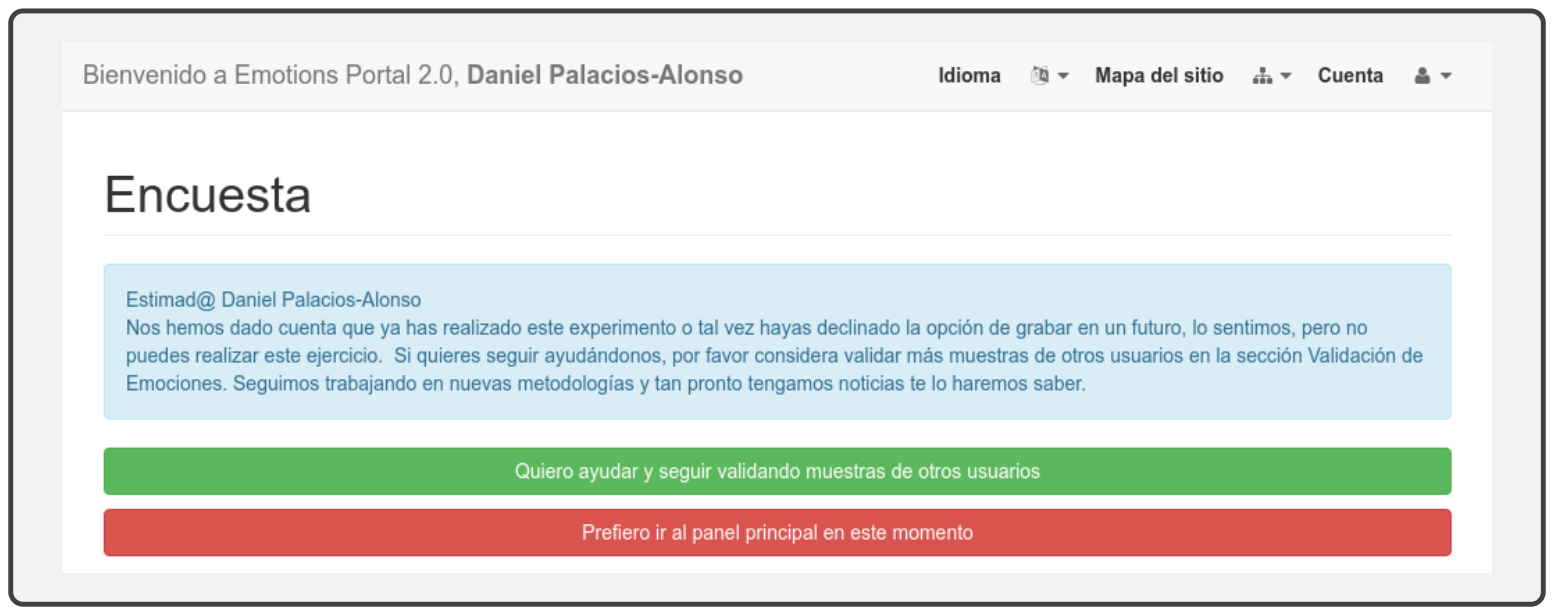

Figura 2.10: Imagen informando al usuario que ya ha realizado el caso de la encuesta online. 
Para completar el proceso de grabación, el usuario fonará de forma sostenida una vocal durante 5 segundos. Esta vocal depende del país y la lengua del usuario. Los fillers más comunes en los hispanohablantes son las palabras /de/ y / que/ y la vocal más utilizada la /e/; mientras que la /a/o / uh/ son más típicas en los angloparlantes.

Gracias a este caso se podrá obtener una cantidad importante de muestras de voz "crudas" en diferentes idiomas por locutores de distintas edades, género, acentos, etc. El proceso completo permitirá la población de bases de datos multilingües con muestras respuestas de habla normal y estresada de duración entre 20 segundos y un minuto y de las las vocales solicitadas a los usuarios.

\subsubsection{Validación de Emociones}

La última etapa a la hora de diseñar una base de datos emocional es la validación, sin la cual el trabajo anterior no puede concluirse y definirse como objetivo. Definimos tres tipos de validaciones para cualquier base de datos.

- Validación interna. Es aquella en la que se realiza el proceso de validación de forma parcial o total por el equipo de diseño, captura o etiquetado, sin que ningún juez externo intervenga en dicho proceso. En [117] encontramos un claro ejemplo donde los usuarios/locutores del experimento extraen sus propias conclusiones de las grabaciones e imágenes que han sido capturadas a partir de ellos mismos.

- Validación externa. Es aquella validación que no ha sido realizada por ningún miembro del equipo de diseño, captura o etiquetado. Un caso ya citado es la base de datos alemana (BES) [24].

- Validación híbrida. Proceso en el que se involucran varias etapas en el proceso de validación. La primera fase la realiza el equipo interviniente en cualquiera de las etapas para llevar a cabo un primer cribaje de las muestras y su correspondiente etiquetado muestral. En una segunda etapa esas muestras quedan expuestas a un grupo totalmente ajeno al proceso de diseño, captura o etiquetado y realizan su valoración de modo totalmente "ciego". Finalmente, se comparan ambos resultados y se observan las posibles desviaciones en el proceso de etiquetado por ambos equipos de validación.

Cada técnica posee ciertas ventajas y desventajas. En el caso del primer tipo de validación, el equipo involucrado conoce a los sujetos, tiene sus historiales o formularios de inscripción y sabe perfectamente las metodologías utilizadas para la captura de las muestras, por tanto realiza un juicio bajo un escenario conocido y muy detallado, lo cual puede resultar muy subjetivo. Por otro lado, el segundo tipo de validación utiliza un agente o evaluador externo. Si el equipo investigador desea encontrar algún tipo de pauta o proceso en la muestra utilizada, esta tarea será más compleja, puesto que dicho evaluador ajeno desconoce el proceso diseñado por el equipo investigador en su origen. Sin embargo, el proceso será más objetivo, pero en algunas ocasiones puede desvirtuar la metodología escogida, ya que la forma de 
entender o gestionar un caso es única para cada individuo y por tanto, todo caso es enfocado de manera diferente por cada evaluador que no ha estado en el proceso de diseño. Finalmente, el último tipo de validación funciona en modo de "pipeline" primero se completa una etapa y a continuación se pasa a la siguiente. Esto puede considerarse una gran desventaja si se tiene en cuenta el tiempo requerido por el proceso de validación, lo cual no siempre es una característica deseada. Algunas de las ventajas de este último método son la orientación de las muestras por el equipo de investigación y la clasificación por agentes externos. Sin embargo, se debe de tener en cuenta que la primera parte del proceso, donde el equipo investigador realiza el primer subproceso de criba, puede llevarse a cabo desde un prisma demasiado exigente y eliminar muestras que tal vez posean información oculta a simple vista. En conclusión, la obtención y validación de los datos es un proceso complejo y crítico de cara las etapas posteriores del proceso.

El procedimiento elaborado que a continuación se comenta busca mejorar el etiquetado y evaluación de las grabaciones de las respuestas orales presentes en la base de datos de la plataforma.

La actividad comienza con la selección del lenguaje de evaluación. Seguidamente, la aplicación presenta al usuario una muestra o grabación de forma completamente aleatoria, pero teniendo en cuenta que dicha grabación no debe haber sido realizada por él mismo. Por tanto, el origen de tales muestras es totalmente desconocido para el usuario.

Análogamente al proceso de captura de muestras de voz, el diseño para esta actividad fue mejorado en sucesivos procesos iterativos gracias a las pruebas con usuarios finales que realizaban labores de usabilidad de la aplicación. En la Figura 2.11 se puede observar el formulario web que el usuario tenía que contestar en una primera versión.

Esta versión era sencilla y directa. La página contenía la grabación y el usuario podía escucharla tantas veces como considerara oportuno. Una vez el usuario tuviera un juicio de valor sobre la muestra presentada, tan solo debía de contestar si la grabación expuesta era congruente, incongruente o políticamente correcta. Téngase en cuenta que incongruente en este contexto es lo mismo que decir que el usuario se encontraba en un estado de estrés para elaborar el discurso.

En una segunda etapa de desarrollo se consideró oportuno aprovechar cada validación por parte del usuario y se incorporaron más preguntas al cuestionario, tal y como muestra la Fig. 2.12. Las nuevas preguntas formuladas eran las siguientes:

- ¿Cuál es el lenguaje de la audición?

- ¿Cuál es el género del locutor?

- ¿Qué edad crees que podría tener el locutor? 


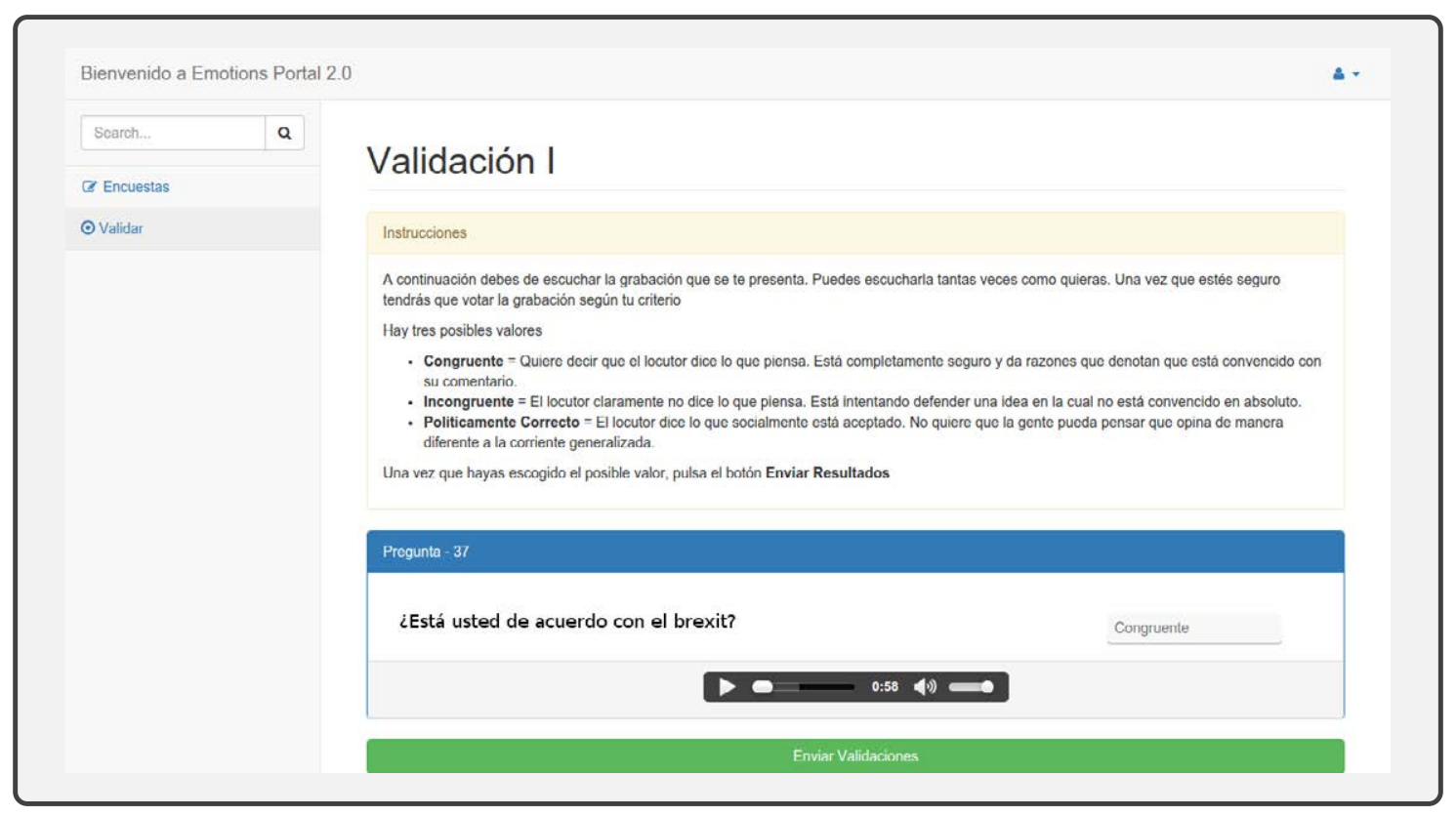

Figura 2.11: Pantalla de validación de emociones.

- ¿En tu opinión es congruente lo que dice el locutor o tal vez está intentando ser políticamente correcto?

- ¿Crees que el usuario está estresado? En caso afirmativo, ¿Cuál es su grado de estrés?

En un siguiente paso en nuestra metodología de validación consideramos la posibilidad de hacer una verificación en dos pasos. Esta nueva característica consiste en presentar al usuario en una segunda pantalla de validación la misma información anteriormente mencionada, más los valores reales que seleccionó el "donante" en el momento de realizar la encuesta. Con este nuevo paso en el proceso de validación se pretende inducir incertidumbre en el validador de forma que se pueda comprobar si está seguro o no de su decisión o en su lugar la valoración realizada en la primera fase era poco consistente. En la Fig. 2.13 se observa como la segunda columna presenta los valores seleccionados por el usuario en el momento de hacer la encuesta. 


\section{Validación I}

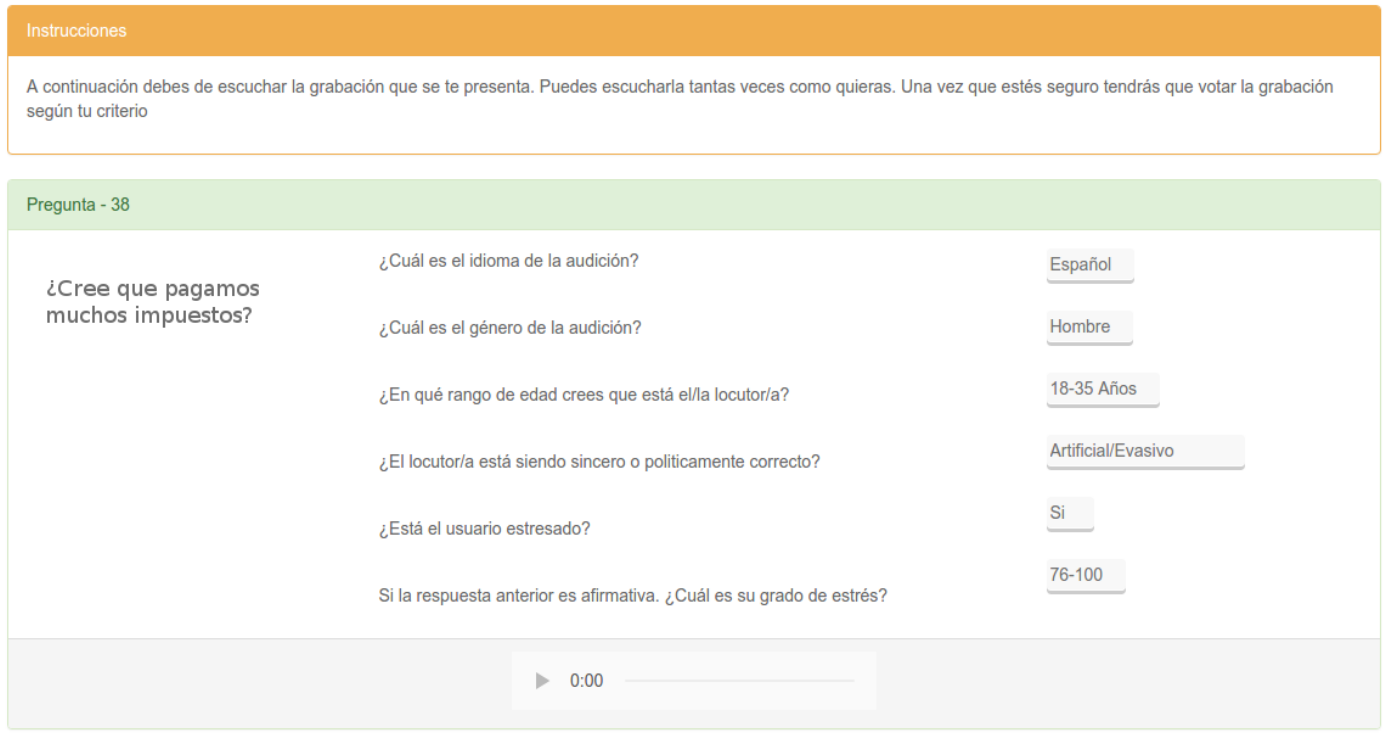

Figura 2.12: Nueva pantalla de validación de muestras.

\section{Validación II}

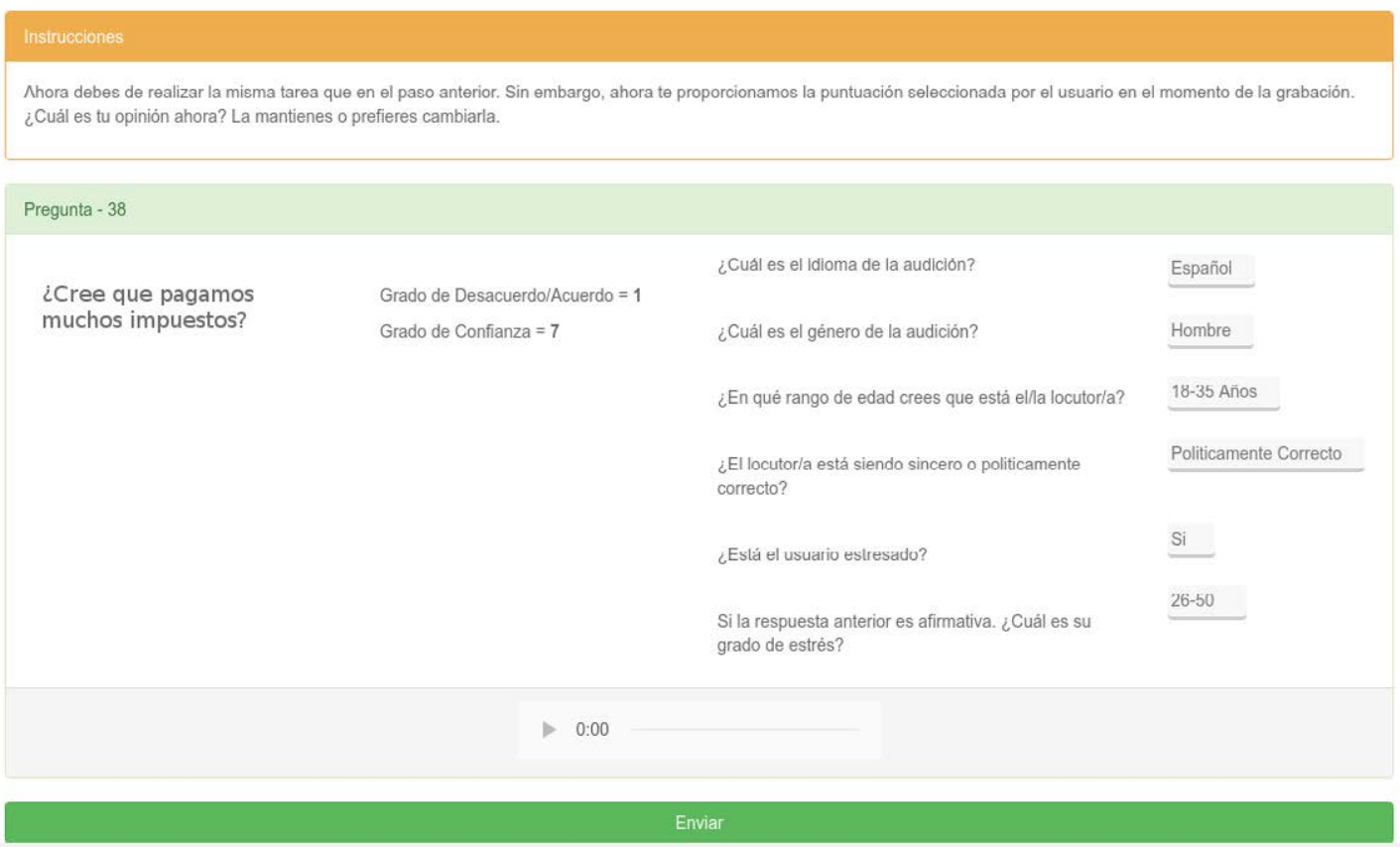

Figura 2.13: Proceso de validación con información adicional sobre la respuesta del informante. 
De forma similar al proceso de grabación se han tenido en cuenta algunas consideraciones en el proceso de validación, como por ejemplo, que el usuario hubiera realizado la actividad de la encuesta antes de comenzar a validar muestras de otros usuarios. Esto es lógico, debido a que si el usuario conoce las preguntas o el cuestionario a priori, después en la fase de validación, las muestras obtenidas no tendrían carácter espontáneo. Por otro lado, cabe comentar que un usuario no está obligado a donar su voz si no quiere, pero sí se le ofrece la oportunidad de ayudar a la comunidad validando muestras de otros usuarios. En la Fig. 2.14 se observa como la aplicación informa al usuario que no ha realizado la encuesta y que si declina la oportunidad en dicho momento, luego ya no podrá realizarla.

\section{Validación I}

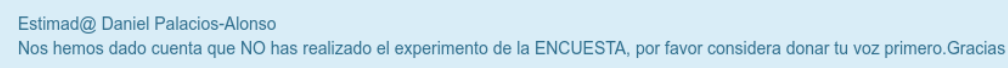

Figura 2.14: Validación de si el usuario ha realizado o no la encuesta.

Finalmente, los registros que el usuario ha escuchado y las respuestas dadas al mismo son almacenados en cada base de datos, de acuerdo con el lenguaje escogido y la emoción evocada al principio del ejercicio.

\subsubsection{Implementación}

El desarrollo de la plataforma se divide en 4 secciones principales o páginas web: Inicio o Home, FAQ, Donar tu Voz, y Validación de Emociones. La primera sección, Inicio, consiste en un pequeño cuadro de mando donde el usuario puede observar el progreso de la información sobre la plataforma. FAQ, Frequently Asked Questions, es una página de ayuda donde el usuario puede encontrar información relacionada con los diferentes procedimientos. La tercera y cuarta página son los casos o procedimientos los cuales han sido explicados anteriormente. Una vista de la página principal se muestra en la Figura 2.15.

Esta plataforma ha sido desarrollada con tecnología open source y no intrusiva, es decir, la plataforma no recolecta ningún tipo de información más allá de la necesaria en los formularios web como se ha mencionado en secciones anteriores.

La aplicación se encuentra actualmente en fase de testeo. No está abierta al público todavía. Por tanto, todas las grabaciones y entrevistas han sido llevadas a cabo en modo offline y en un entorno controlado. El proceso de validación ha sido llevado a cabo por 3 personas pertenecientes al equipo de investigación. Estas 
muestras han sido donadas principalmente por familiares, amigos, estudiantes de la Universidad Politécnica de Madrid y empleados del Instituto de Salud Carlos III. El número de muestras de acuerdo al género está bastante balanceado, teniendo en cuenta que el número de hombres en las universidades técnicas de nuestro país es superior al de mujeres. En la Fig. 2.16 se puede observar el resumen que se presenta al usuario en su página de inicio informando de la situación actual del proyecto. En la Sección 2.3 se hablará en detalle del conjunto de datos utilizado para las fases posteriores de Extracción y Selección de parámetros característicos.

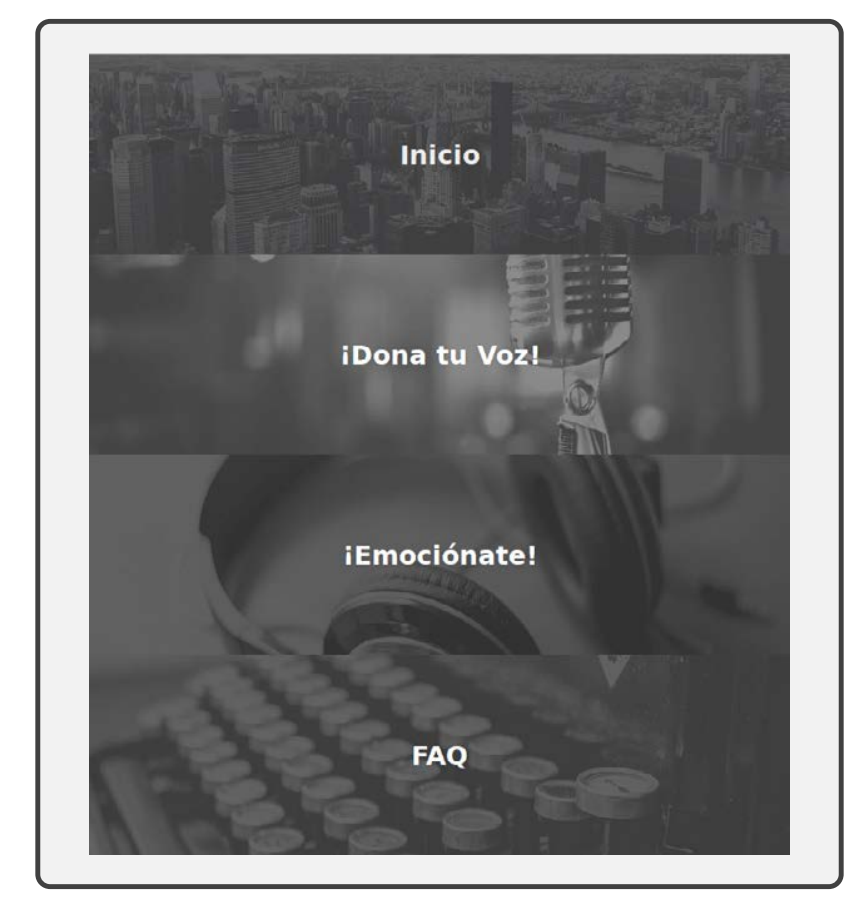

Figura 2.15: Secciones principales de la plataforma implementada. 


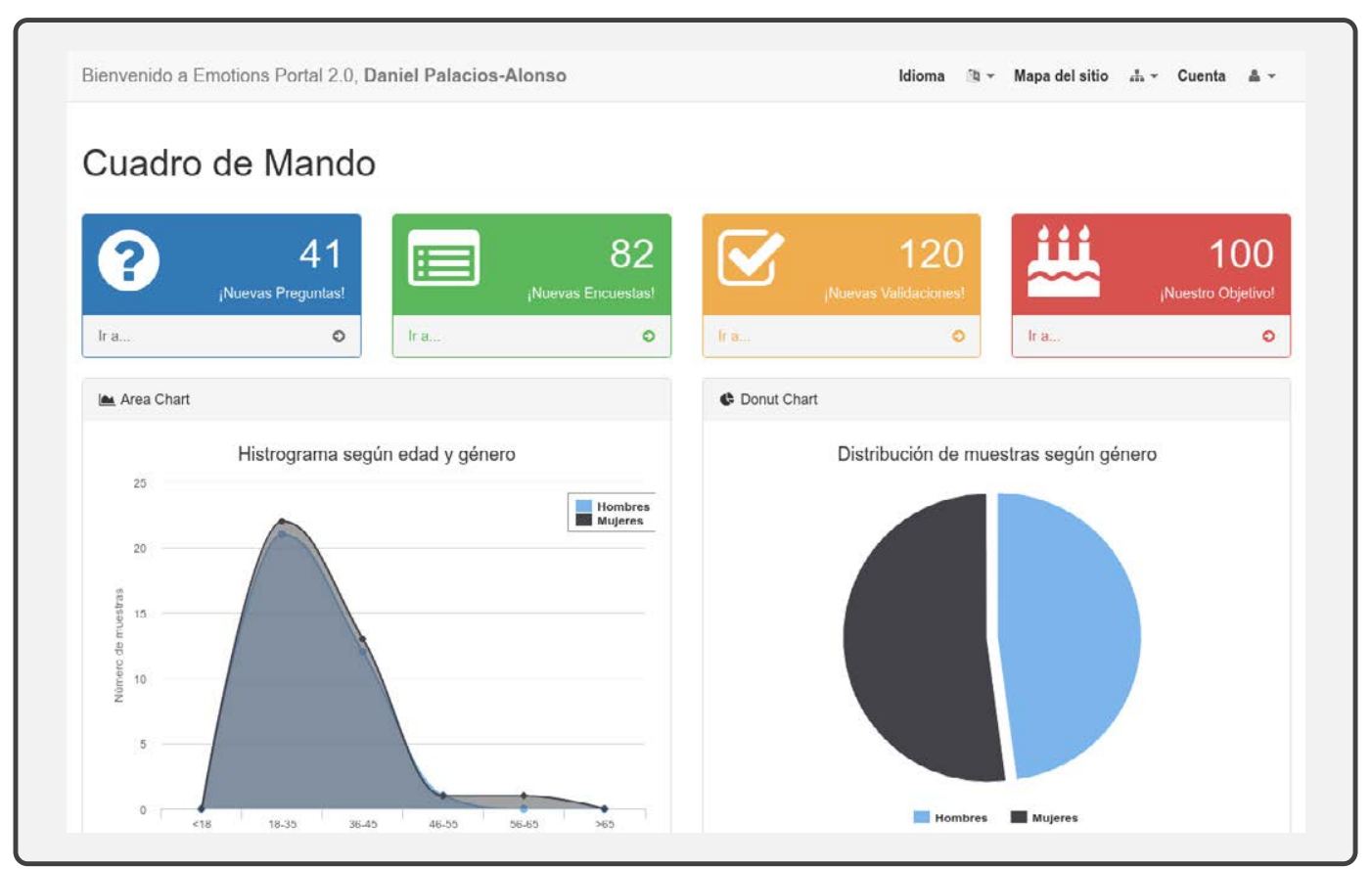

Figura 2.16: Panel principal con las diferentes estadísticas presentadas al usuario.

Por último, cabe destacar que todos los usuarios que han donado sus voces han dado su permiso expreso para realizar este tipo de actividades firmando un consentimiento informado elaborado ad-hoc. En dicho documento se explican los motivos por los cuales se dona la voz, se aclara que no se ofrece contraprestación económica o de otro tipo. Por otro lado, este consentimiento informado está incluido dentro de la sección Términos de Uso en la aplicación web. Este apartado debe de ser aceptado por el usuario en el proceso de alta. Si el usuario no acepta dichas condiciones, no podrá participar, acceder o utilizar la plataforma en ninguna de sus modalidades. En el Apendice D se presenta el texto de dicho consentimiento informado.

\subsection{Adquisición de la colección de datos}

En esta sección, se detallará la estructura de los datos obtenidos para este trabajo, ofreciendo el número de muestras, el género de los sujetos, y la relación entre el donante y las dos respuestas que realizó en el momento de la grabación. Finalmente, se construirán varios conjuntos de muestras con los datos capturados para utilizarlos en la obtención de resultados en los distintos casos de estudio.

\subsubsection{Cuestionario para evocar estrés}

A continuación se presenta la lista de preguntas para evocar estrés que se han utilizado para obtener el conjunto de muestras. Para facilitar la labor a cada pregunta se le ha asignado un código que se utilizará a lo largo del resto de apartados. 


\begin{tabular}{cl}
\hline ID & Descripción \\
\hline \hline Q1 & Relativa a igualdad de salarios entre sexos. \\
\hline Q2 & Relativa a prácticas policiales abusivas. \\
\hline Q3 & Relativa a prácticas bancarias abusivas. \\
\hline Q4 & Relativa a papel laboral de hombres y mujeres. \\
\hline Q5 & Relativa a conciliación familiar de hombres y mujeres. \\
\hline Q6 & Relativa a conciliación doméstica de hombres y mujeres. \\
\hline Q7 & Relativa a papel de los políticos en la sociedad. \\
\hline Q8 & Relativa a igualdad de derechos entre diferentes opciones sexuales. \\
\hline Q9 & Relativa al hecho religioso. \\
\hline Q10 & Relativa a legislación sobre el aborto. \\
\hline Q11 & Relativa a papel de los políticos en la sociedad. \\
\hline Q12 & Relativa a conciliación doméstica de hombres y mujeres. \\
\hline & Tabla 2.1: Lista de preguntas para las encuestas.
\end{tabular}

\subsubsection{Datos por género y tipo de grabación}

El número total de muestras utilizadas para el resto de capítulos han sido 80, donde 40 muestras pertenecían a hombres y las otras 40 a mujeres. Cada individuo realizó dos grabaciones por consiguiente se tendrán dos conjuntos de muestras por género. El primer conjunto de muestras pertenece la respuesta congruente $(\mathrm{P})$, ofrecida por el usuario a la pregunta escogida y la segunda con la respuesta incongruente (C) o "fabricada".

La identificación de las grabaciones se ha expresado en forma de tabla. Donde $\mathrm{F}$ (female) se ha utilizado para el conjunto de mujeres, M (male) para el conjunto de hombres, $\mathrm{C}$ indica una respuesta incongruente, $\mathrm{P}$ identifica una respuesta congruente y Q (question) representa al identificador de pregunta. También se ofrece la duración en segundos y el número de fillers que aparece en el registro. En las Tablas 2.2 y 2.3 se resumen las principales características para el conjunto de las mujeres. 


\begin{tabular}{ccccc}
\hline ID & SUJETO & PREGUNTA & DURACIÓN (“) & FILLERS \\
\hline \hline F1 & $3000-C$ & Q4 & 30 & 3 \\
F2 & $3001-C$ & Q7 & 19 & 1 \\
F3 & $3002-C$ & Q1 & 21 & 3 \\
F4 & $3003-C$ & Q4 & 14 & 2 \\
F5 & $3004-C$ & Q2 & 31 & 2 \\
F6 & $3005-C$ & Q5 & 29 & 2 \\
F7 & $3006-C$ & Q11 & 19 & 6 \\
F8 & $3007-C$ & Q8 & 13 & 1 \\
F9 & $3008-C$ & Q4 & 15 & 2 \\
F10 & $3009-C$ & Q11 & 24 & 3 \\
F11 & $3010-C$ & Q1 & 34 & 4 \\
F12 & $3011-C$ & Q4 & 22 & 2 \\
F13 & $3012-C$ & Q7 & 34 & 4 \\
F14 & $3013-C$ & Q9 & 34 & 3 \\
F15 & $3014-C$ & Q10 & 13 & 1 \\
F16 & $3015-C$ & Q8 & 24 & 1 \\
F17 & $3016-C$ & Q2 & 16 & 1 \\
F18 & $3017-C$ & Q7 & 17 & 8 \\
F19 & $3018-C$ & Q4 & 19 & 4 \\
F20 & 3019-C & Q8 & 20 & 4 \\
\hline \hline TOTAL & 20 & & $\mathbf{4 4 8}$ & $\mathbf{5 7}$
\end{tabular}

Tabla 2.2: Discurso incongruente para el conjunto femenino.

\begin{tabular}{ccccc}
\hline ID & SUJETO & PREGUNTA & DURACIÓN (“) & FILLERS \\
\hline \hline F1 & $3000-P$ & Q2 & 31 & 3 \\
F2 & $3001-P$ & Q4 & 25 & 0 \\
F3 & $3002-P$ & Q4 & 22 & 1 \\
F4 & $3003-P$ & Q11 & 12 & 2 \\
F5 & $3004-P$ & Q8 & 31 & 3 \\
F6 & $3005-P$ & Q7 & 15 & 2 \\
F7 & $3006-P$ & Q4 & 17 & 3 \\
F8 & $3007-P$ & Q4 & 13 & 3 \\
F9 & $3008-P$ & Q1 & 18 & 2 \\
F10 & $3009-P$ & Q2 & 27 & 4 \\
F11 & $3010-P$ & Q10 & 31 & 3 \\
F12 & $3011-P$ & Q1 & 28 & 3 \\
F13 & $2012-P$ & Q1 & 24 & 3 \\
F14 & $3013-P$ & Q2 & 37 & 3 \\
F15 & $3014-P$ & Q2 & 11 & 1 \\
F16 & $3015-P$ & Q8 & 41 & 5 \\
F17 & $3016-P$ & Q2 & 19 & 5 \\
F18 & $3017-P$ & Q3 & 18 & 2 \\
F19 & $3018-P$ & Q4 & 15 & 1 \\
F20 & $3019-P$ & Q1 & 14 & 4 \\
\hline \hline TOTAL & $\mathbf{2 0}$ & & $\mathbf{4 4 9}$ & $\mathbf{5 3}$ \\
\hline
\end{tabular}

Tabla 2.3: Discurso congruente para el conjunto femenino. 
La Figura 2.17 muestra la diferencias entre la duración por individuo entre el discurso fabricado y el congruente. Puede observarse que doce individuos presentan una mayor duración cuando se expresan de forma congruente con sus ideas, mientras que las ocho mujeres restantes presentan el comportamiento contrario. En términos generales, la duración de las dos grabaciones es similar. Los casos excepcionales podrían ser $F 6$ y $F 16$, los cuales utilizan mucho más tiempo en una grabación frente a otra, si bien en sentido contrario. De hecho, F16 casi reduce a la mitad cuando fabrica el discurso que cuando está defendiendo su opinión congruente. Por otro lado, F6 realiza la operación opuesta, es decir, ofrece mayor tiempo de grabación cuando el discurso se supone fabricado que cuando defiende su opinión congruente.

La Figura 2.18 presenta el número de fillers en ambas grabaciones. El número de mujeres que han realizado el mismo número de fillers tanto en su discurso congruente, como incongruente han sido 7 . De igual forma, siete han sido las mujeres que han producido más fillers cuando el discurso era elaborado que cuando defendían su opinión sincera. Finalmente, el conjunto de mujeres que han emitido mayor número de fillers en su discurso coherente que en el otro ha sido seis.

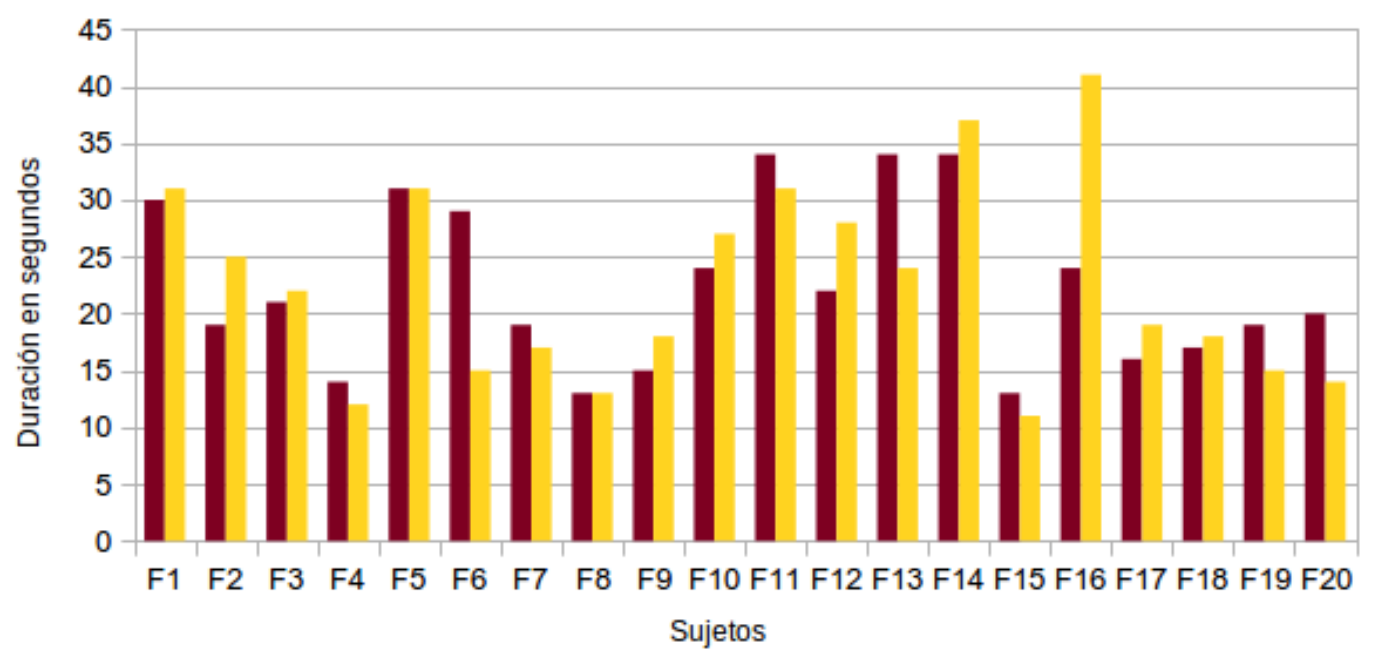

- DURACIÓN EN SEG. (DISCURSO FABRICADO) DURACIÓN EN SEG.(DISCURSO CONGRUENTE)

Figura 2.17: Comparativa entre la duración de las grabaciones para el conjunto femenino. 


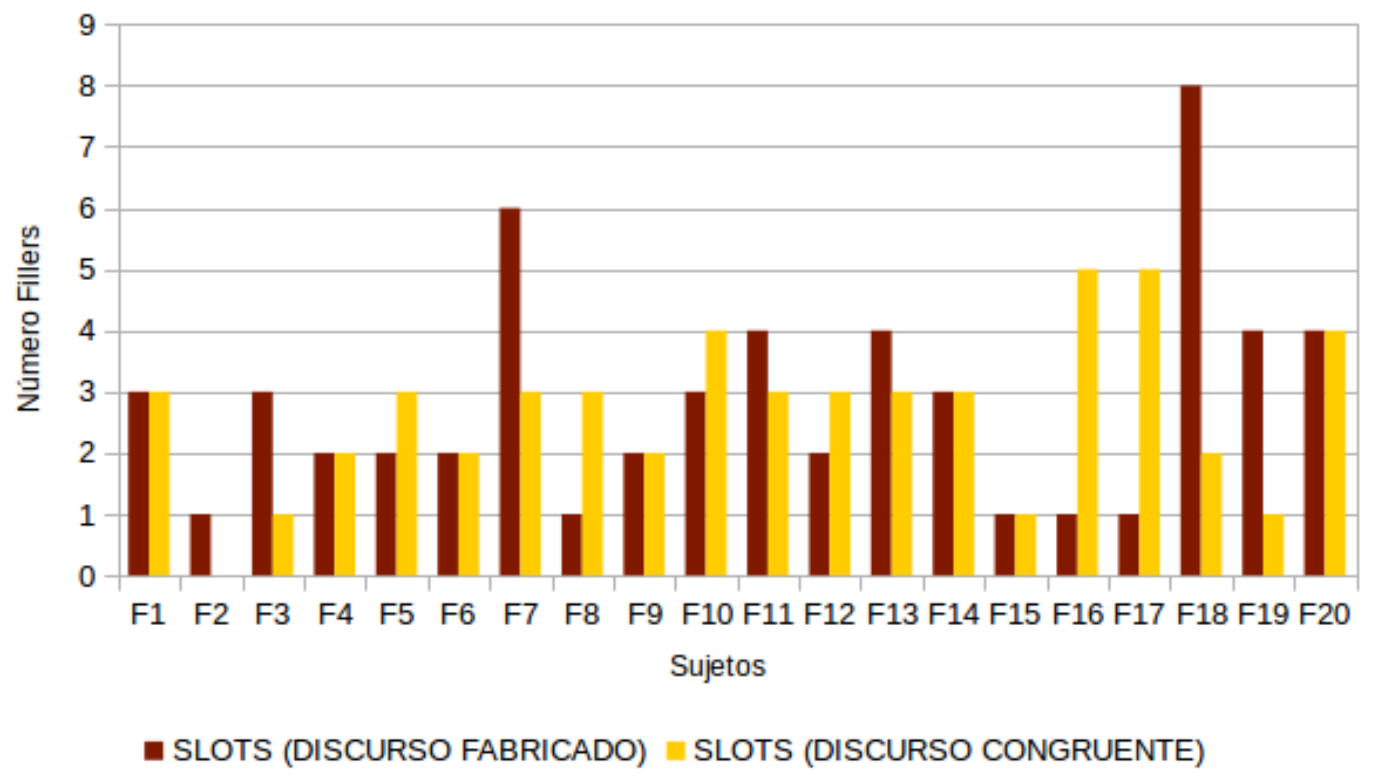

Figura 2.18: Comparativa del número de fillers obtenidos entre ambas grabaciones para el conjunto femenino.

Las Tablas 2.4 y 2.5 resumen el comportamiento de los hombres.

\begin{tabular}{ccccc}
\hline ID & SUJETO & PREGUNTA & DURACIÓN (“) & FILLERS \\
\hline \hline M1 & $2000-C$ & Q7 & 13 & 1 \\
M2 & $2001-C$ & Q1 & 33 & 5 \\
M3 & $2002-C$ & Q7 & 17 & 6 \\
M4 & $2003-C$ & Q3 & 20 & 2 \\
M5 & $2004-C$ & Q7 & 18 & 4 \\
M6 & $2005-C$ & Q2 & 30 & 4 \\
M7 & $2006-C$ & Q8 & 20 & 3 \\
M8 & $2007-C$ & Q7 & 19 & 4 \\
M9 & $2008-C$ & Q4 & 25 & 1 \\
M10 & $2009-C$ & Q3 & 21 & 1 \\
M11 & $2010-C$ & Q1 & 18 & 4 \\
M12 & $2011-C$ & Q3 & 25 & 3 \\
M13 & $2012-C$ & Q9 & 29 & 3 \\
M14 & $2013-C$ & Q2 & 39 & 6 \\
M15 & $2014-C$ & Q7 & 35 & 2 \\
M16 & $2015-C$ & Q4 & 28 & 5 \\
M17 & $2016-C$ & Q2 & 44 & 5 \\
M18 & $2017-C$ & Q3 & 38 & 4 \\
M19 & $2018-C$ & Q2 & 24 & 3 \\
M20 & $2019-C$ & Q4 & 23 & 2 \\
\hline \hline TOTAL & 20 & & $\mathbf{5 1 9}$ & $\mathbf{6 8}$
\end{tabular}

Tabla 2.4: Discurso incongruente para el conjunto de los hombres. 


\begin{tabular}{ccccc}
\hline ID & SUJETO & PREGUNTA & DURACIÓN ( “) & FILLERS \\
\hline \hline M1 & $2000-\mathrm{P}$ & Q8 & 16 & 2 \\
M2 & $2001-\mathrm{P}$ & $\mathrm{Q} 2$ & 31 & 3 \\
M3 & $2002-\mathrm{P}$ & $\mathrm{Q} 1$ & 18 & 5 \\
M4 & $2003-\mathrm{P}$ & $\mathrm{Q} 4$ & 29 & 4 \\
M5 & $2004-\mathrm{P}$ & $\mathrm{Q} 3$ & 23 & 5 \\
M6 & $2005-\mathrm{P}$ & $\mathrm{Q} 10$ & 30 & 5 \\
M7 & $2006-\mathrm{P}$ & $\mathrm{Q} 7$ & 19 & 2 \\
M8 & $2007-\mathrm{P}$ & $\mathrm{Q} 1$ & 19 & 1 \\
M9 & $2008-\mathrm{P}$ & $\mathrm{Q} 8$ & 26 & 1 \\
M10 & $2009-\mathrm{P}$ & $\mathrm{Q} 1$ & 23 & 2 \\
M11 & $2010-\mathrm{P}$ & $\mathrm{Q} 7$ & 15 & 3 \\
M12 & $2011-\mathrm{P}$ & $\mathrm{Q} 5$ & 21 & 4 \\
M13 & $2012-\mathrm{P}$ & $\mathrm{Q} 12$ & 16 & 2 \\
M14 & $2013-\mathrm{P}$ & $\mathrm{Q} 4$ & 26 & 4 \\
M15 & $2014-\mathrm{P}$ & $\mathrm{Q} 4$ & 35 & 1 \\
M16 & $2015-\mathrm{P}$ & $\mathrm{Q} 7$ & 18 & 1 \\
M17 & $2016-\mathrm{P}$ & $\mathrm{Q} 10$ & 39 & 1 \\
M18 & $2017-\mathrm{P}$ & $\mathrm{Q} 2$ & 48 & 4 \\
M19 & $2018-\mathrm{P}$ & $\mathrm{Q} 11$ & 24 & 2 \\
M20 & $2019-\mathrm{P}$ & $\mathrm{Q} 9$ & 24 & 2 \\
\hline \hline TOTAL & $\mathbf{2 0}$ & & $\mathbf{5 0 0}$ & $\mathbf{5 4}$
\end{tabular}

Tabla 2.5: Discurso congruente para el conjunto de los hombres.

Para este conjunto de datos, el tiempo global de grabación es mayor que para el caso de las mujeres. Sin embargo, la diferencia entre los discursos congruentes e incongruentes también son diferentes entre sí en el caso de los hombres, obteniendo casi un punto más de diferencia en el cálculo de la media de la duración total. Análogamente, el número de fillers obtenidos en ambos casos también difieren en mayor medida que para el caso de las locutoras.

Continuando con la tendencia, aquellos donantes masculinos que han dado explicaciones breves en su primera intervención, en la segunda ofrecen más o menos la misma duración. Algunos casos aislados podrían ser el sujeto M1 y el M11, ya que ninguna de las dos grabaciones llega a 20 segundos que es el mínimo establecido. Respecto a la duración en una y otra grabación, el sujeto M18 y M14 destacan frente al resto. El primero ofrece un discurso de mayor duración en la defensa de su opinión congruente, mientras que el locutor M14 se comporta al revés. Por otro lado, once de los veinte hombres produjeron un mayor número fillers cuando el discurso era fabricado que cuando ofrecieron su opinión personal, seis cuando la situación era la contraria y finalmente tan solo en tres ocasiones el número de fillers era idéntico para ambos casos. 


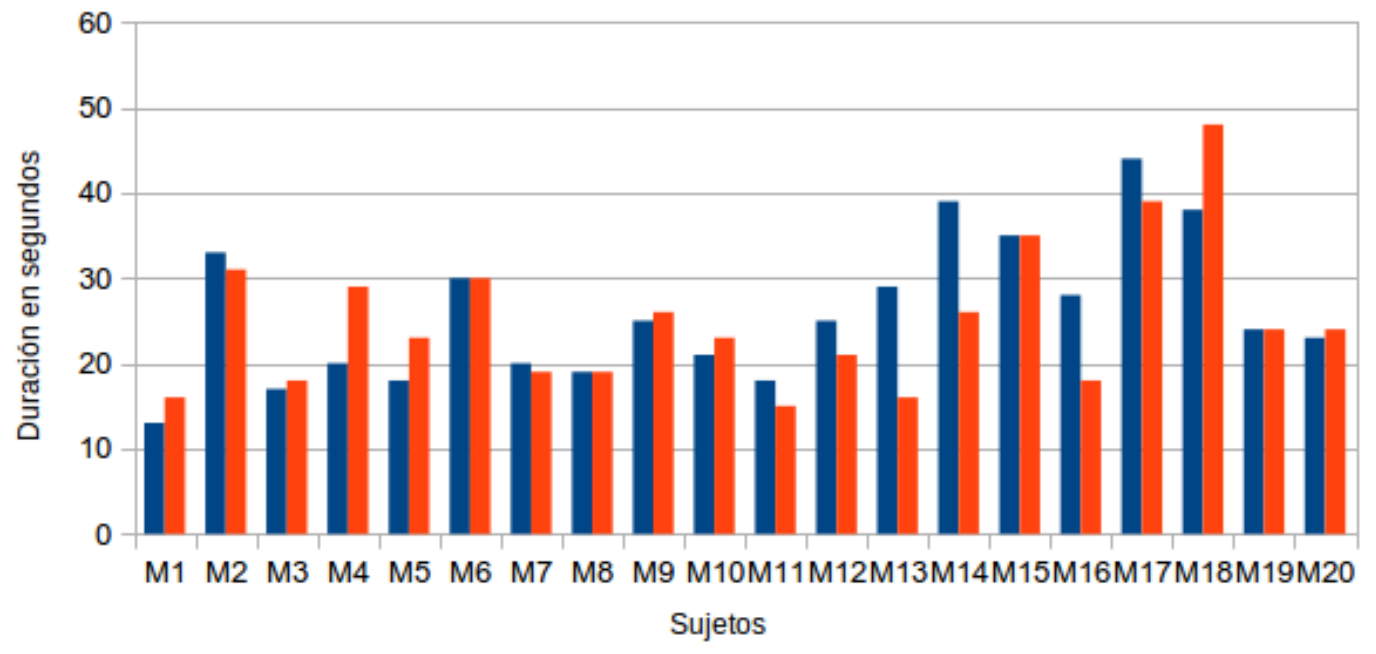

- DURACIÓN EN SEG. (DISCURSO FABRICADO)

- DURACIÓN EN SEG. (DISCURSO CONGRUENTE)

Figura 2.19: Comparativa entre la duración de las grabaciones para el conjunto masculino.

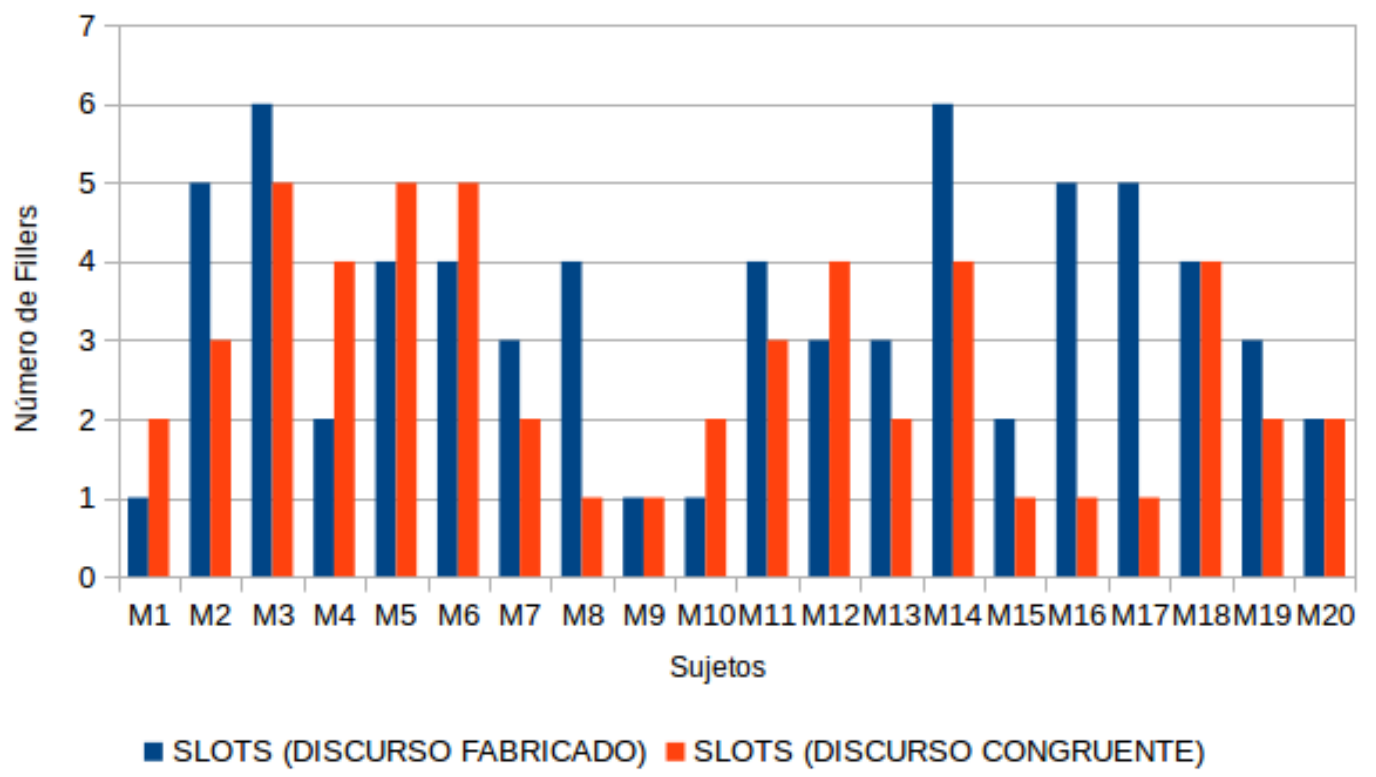

Figura 2.20: Comparativa del número de fillers obtenidos entre ambas grabaciones para el conjunto masculino.

Finalmente, en la Tabla 2.6 se realiza una comparativa de las preguntas seleccionadas por los usuarios y el género de los donantes. Se observa que existen cuatro preguntas que destacan sobre las demás y además relacionadas dos a dos. Por otro lado, las preguntas que se podían considerar de "batalla de sexos" también han sido bastantes veces seleccionadas. 


\begin{tabular}{clccc}
\hline ID & Preguntas & Mujeres & Hombres & Total \\
\hline \hline Q4 & Rol laboral de hombres y mujeres. & 11 & 6 & 17 \\
\hline Q2 & Prácticas policiales abusivas. & 7 & 6 & 13 \\
\hline Q7 & Crisis política. & 4 & 8 & 12 \\
\hline Q1 & Igualdad de salarios entre sexos. & 6 & 5 & 11 \\
\hline Q8 & Igualdad de derechos entre opciones sexuales. & 4 & 3 & 7 \\
\hline Q3 & Prácticas bancarias abusivas. & 1 & 5 & 6 \\
\hline Q11 & Corrupción política. & 3 & 1 & 4 \\
\hline Q10 & Legislación sobre el aborto. & 2 & 2 & 4 \\
\hline Q9 & El hecho religioso. & 1 & 2 & 3 \\
\hline Q5 & Conciliación familiar. & 1 & 1 & 2 \\
\hline Q12 & Igualdad en tareas domésticas entre sexos. & 0 & 1 & 1 \\
\hline \hline & Total & $\mathbf{4 0}$ & $\mathbf{4 0}$ & $\mathbf{8 0}$ \\
\hline
\end{tabular}

Tabla 2.6: Relación de respuestas según género.

\subsubsection{Conjunto de datos por caso práctico}

En esta sección se detallará de forma pormenorizada cada uno de los corpus utilizados para los casos prácticos llevados a cabo en este trabajo. En el ejemplo que se muestra a continuación se presenta una descripción breve de cada uno de las características de los grupos.

- Número total de muestras: se presenta el número total de muestras y su distribución por género.

- Porcentaje de individuos normofónicos/disfónicos: proporción entre cuántos de los locutores se consideran normofónicos (sin patología en la voz) y disfónicos (que poseen alguna alteración o problema en la voz).

- Slots: duración de cada muestra.

- Filler utilizado: las vocales utilizadas para cada caso práctico.

- Metodología utilizada: tipo de metodología que se ha utilizado para obtener el conjunto de datos.

Corpus 1

- Número total de muestras: 200 (100 hombres y 100 mujeres).

- Porcentaje de individuos normofónicos/disfónicos: $50 \%-50 \%$.

- Slots: 2 segundos por muestra.

- Filler utilizado: vocal e - /eh/.

- Metodología utilizada: vocal sostenida. 
- Número de parámetros utilizados: 3 (parámetros cíclicos 1, 2 y 3) (véase sección 3.3.2)

Corpus 2

- Número total de muestras: 50 (10 hombres y 15 mujeres).

- Porcentaje de individuos normofónicos/disfónicos: $100 \%-0 \%$.

- Slots: entre 200 a 500 milisegundos por muestra.

- Filler utilizado: vocal e - /eh/.

- Metodología utilizada: encuesta (véase 2.2.2).

- Número de parámetros utilizados: 68 (todos excepto del p.69 al p.72) (véase sección 3.3.2)

Corpus 3

- Número total de muestras: 68 (16 hombres y 18 mujeres).

- Porcentaje de individuos normofónicos/disfónicos: $100 \%-0 \%$.

- Slots: entre 100 a 200 milisegundos por muestra.

- Filler utilizado: vocal e - /eh/.

- Metodología utilizada: encuesta (véase 2.2.2).

- Número de parámetros utilizados: 72 (todos) (véase sección 3.3.2)

Corpus 4

- Número total de muestras: 4 (1 hombre y 1 mujer).

- Porcentaje de individuos normofónicos/disfónicos: $100 \%-0 \%$.

- Slots: 0.2 segundos por muestra.

- Filler utilizado: vocal e - /eh/.

- Metodología utilizada: encuesta (véase 2.2.2).

- Número de parámetros utilizados: 5 (Body Stiffness, Cover Stiffness, parámetros cíclicos 1, 2 y 3) (véase sección 3.3.2)

Corpus 5

- Número total de muestras: 80 (20 hombres y 20 mujeres).

- Porcentaje de individuos normofónicos/disfónicos: $100 \%-0 \%$. 
- Slots: 400 milisegundos por muestra.

- Filler utilizado: vocal e - /eh/.

- Metodología utilizada: encuesta (véase 2.2.2).

- Número de parámetros utilizados: 68 (todos excepto del p.69 al p.72) (véase sección 3.3.2)

Corpus 6

- Número total de muestras: 80 (20 hombres y 20 mujeres).

- Porcentaje de individuos normofónicos/disfónicos: $100 \%-0 \%$.

- Slots: 500 milisegundos por muestra.

- Filler utilizado: vocal e - /eh/.

- Metodología utilizada: encuesta (véase 2.2.2).

- Número de parámetros utilizados: 1 (rigidez de las cuerdas vocales - p. 37) (véase sección 3.3.2)

Corpus 7

- Número total de muestras: 62 (31 mujeres).

- Porcentaje de individuos normofónicos/disfónicos: $100 \%-0 \%$.

- Slots: mayor a 100 milisegundos por muestra.

- Filler utilizado: vocal e - /eh/.

- Metodología utilizada: encuesta (véase 2.2.2).

- Número de parámetros utilizados: 68 (todos excepto del p.69 al p.72) (véase sección 3.3.2)

Corpus 8

- Número total de muestras: 32 (9 hombres y 12 mujeres).

- Porcentaje de individuos normofónicos/disfónicos: $100 \%-0 \%$.

- Slots: entre 100 a 200 milisegundos por muestra.

- Filler utilizado: vocal e - /eh/.

- Metodología utilizada: encuesta (véase 2.2.2).

- Número de parámetros utilizados: 72 (todos) (véase sección 3.3.2) 


\section{Capítulo 3}

\section{EXTRACCIÓN DE CARACTERÍSTICAS}

Existen muchas características que pueden ser extraídas de la señal acústica. Sin embargo, no existe un consenso, sobre las características que pueden perfilar o definir el estado emocional expresado con la voz. Por consiguiente, surge una pregunta, la cual debe de ser contestada para poder avanzar en este campo. ¿Qué características contribuyen de manera más significativa a la discriminación del estrés y las emociones en la voz?.

Muchos autores han apuntado que el pitch o tono fundamental es una característica preponderante para identificar emociones y estrés en el habla. La desviación típica, el rango y perturbaciones en el pitch, como el conocido jitter, son usados habitualmente, junto a las localizaciones de los formantes en el espectro y la tasa de habla. También son comunes los Mel Frequency Cepstral Coefficients, la potencia del espectro del sonido, la intensidad o también parámetros prosódicos como la duración de las muestras de voz, las pausas o silencios realizados por los informantes, tal y como exponen [29], [67], [96] y [196] en sus correspondientes trabajos y revisiones (véase Tabla 3.1).

Este trabajo intenta ir un paso más allá en la etapa de extracción de características. Además de usar algunos de los rasgos clásicos, también se ha apostado en la estimación de algunos parámetros biomecánicos.

Este capítulo se divide de la siguiente forma. Primeramente, se expondrá el estado del arte sobre las principales características recogidas en la literatura. A continuación se presentará la herramienta, BioMetrßPhon y los principios básicos en los que se basa, y se explicará la lista de los 72 parámetros que se obtienen con ella. Finalmente, se profundizará en la obtención de ciertos parámetros biomecánicos, tales como la rigidez del cuerpo y la cubierta de los pliegues vocales, los parámetros cíclicos, así como el cálculo del temblor. 


\subsection{Aspectos generales}

Los pasos básicos involucrados en la detección e identificación de emoción son la estimación y la selección de las características o rasgos más representativos que caracterizan una emoción específica y encontrar patrones emocionales usando métodos de clasificación diversos.

El conjunto de características o rasgos que identifican las emociones parece ser que están afectados por tres factores fundamentalmente, la selección de las unidades del habla para analizar, las propiedades especificas para extraer de ellas, y el número o la combinación de las mismas para el proceso de identificación. Algunos autores han hecho un arduo ejercicio de recopilación de información para la comunidad científica, como por ejemplo [10], [73] y [92], donde presentan una serie de rasgos y los algoritmos de clasificación utilizados para detectar emociones en la voz con sus correspondientes tasas de reconocimiento.

Las técnicas que se utilizan para la identificación de la emoción se toman del procesamiento del habla [15] y [39]. La literatura clásica centra sus esfuerzos en el análisis de los sonidos del habla desde el punto de vista acústico y fisiológico, incluyendo la producción, la percepción, el ritmo y la entonación en el habla.

La selección de la longitud de las unidades de análisis puede variar desde nivel de frase, fragmento, palabra, vocal y sílaba [52], [53], [133], [188], [196].

Los rasgos acústicos se relacionan principalmente con el tono, los formantes, la energía o intensidad y la tímbrica. Otras singularidades se basan en la caracterización de la señal, imitando el comportamiento de la percepción del sistema auditivo humano; es el caso de los Mel Frequency Cepstral Coefficients (MFCC) [205].

Otras aproximaciones consideran la vibración de las cuerdas vocales incluyendo los parámetros del ciclo glotal [90], [124], como la fase de duración de la apertura y cierre de las cuerdas vocales, los ratios entre la fase de apertura y cierre del ciclo glotal completo, el jitter glotal y el shimmer glotal [125], [196].

Respecto al número de rasgos utilizados existen grandes diferencias en la literatura. Algunos autores utilizan 105 parámetros [52], otros 87 [188] y otros usan un conjunto reducido de 32 [133]. Esto es tan solo un pequeño ejemplo de la falta de uniformidad en los criterios tomados en este tema.

En la mayoría de las ocasiones el esquema utilizado para la extracción de características no lineales de la onda del habla para el estrés se basa en Teager Energy Operator (TEO) [175] y [176]. 


\subsection{Rasgos clásicos más usados}

En esta sección se describirán conceptualmente aquellos rasgos que han sido más recurrentes en la literatura y que varios investigadores han recogido en resúmenes. Hasrul, por ejemplo, agrupa en su trabajo 13 características que han sido utilizadas para la detección de emociones en la voz. Estos parámetros se muestran en la Tabla 3.1 .

\begin{tabular}{ll}
\hline Características utilizadas & Referencias \\
\hline \hline ancho de banda & {$[140]$} \\
\hline áreas del tracto vocal & {$[136],[189]$} \\
\hline características espectrales & {$[154],[190]$} \\
\hline $\begin{array}{l}\text { detección de la actividad del } \\
\text { habla }\end{array}$ & {$[108]$} \\
\hline duración & {$[4],[25],[72],[97],[140],[160],[202]$} \\
\hline energía & {$[2],[11],[25],[71],[72],[95],[97],[108],[131]$,} \\
& {$[140],[160],[163],[189],[190],[193],[202]$} \\
\hline formantes & {$[25],[95],[97],[140],[160],[165],[189],[190]$,} \\
& {$[204]$} \\
\hline intensidad & {$[4],[154],[164],[165]$} \\
\hline LPCs & {$[2],[136]$} \\
\hline MFCCs & {$[2],[11],[71],[72],[95],[131],[189],[193]$} \\
\hline pitch & {$[2],[4],[25],[38],[71],[72],[95],[97]$,} \\
& {$[108],[131],[140],[154],[163],[164],[165]$,} \\
\hline tasa de cruce por ceros & {$[189],[190],[202],[204]$} \\
\hline velocidad del habla $($ speaking & {$[154]$} \\
rate $)$ & {$[164],[189]$} \\
\hline
\end{tabular}

Tabla 3.1: Características usadas en el reconocimiento de emociones en el habla [73].

A continuación se describirán estos rasgos agrupados según se relacionen con la señal en el tiempo, en la frecuencia o constituyan una perturbación.

\subsubsection{Frecuencia}

\section{Frecuencia fundamental}

La frecuencia fundamental, a veces conocida como pitch, se representa como $F_{0}$ y se define como el mínimo divisor común de la serie armónica de una señal compuesta. Dicha frecuencia se produce como resultado de la acción de aducción y abducción de los pliegues vocales [55]. Por consiguiente, la frecuencia fundamental está íntimamente relacionada con la vibración de los pliegues vocales.

Los hombres, normalmente, fonan en su variante modal entre 80 y 150 Hercios, mientras que las mujeres poseen un rango que va desde los 140 a los 250 Hercios. A la vista de estos datos se puede decir que las mujeres suelen tener voces más agudas 
que la de los varones, eso implica que su frecuencia fundamental es más elevada.

¿Por qué es importante este parámetro? Porque el pitch siempre es una variable dependiente en la detección de las emociones o el estrés y no un rasgo característico. Dicho de otra forma, el tono fundamental no será una característica necesaria y suficiente para poder llevar a cabo la misión de detección; siempre será necesario el apoyo o la utilización de otro/s rasgo/s.

\section{Formantes}

Los formantes son frecuencias reforzadas por la reverberación o resonancia en el tracto vocal. El progreso de la onda sonora por las cavidades supraglóticas amplifica unos armónicos específicos. Un menor tamaño en las cavidades supraglóticas y en el tracto vocal, amplifica una mayor frecuencia [101] y [102]. Una analogía con este comportamiento la presentan los instrumentos de cuerda [91]. Por tanto, los formantes están íntimamente relacionados con la fisiología del individuo.

La resonancia se define en [55] como sigue. "La resonancia es el fenómeno por el cual un cuerpo, denominado resonador que posee una tendencia natural a vibrar a determinada frecuencia, experimentará vibraciones de mayor amplitud cuando es puesto en movimiento por otro cuerpo vibrante a una frecuencia similar. Por otro lado, un formante es la zona de la escala de frecuencias en la que un sonido presenta una mayor concentración de energía. También puede definirse como cada una de las resonancias del tracto oro-naso-faríngeo".

El triángulo vocálico es una representación bidimensional de las posiciones del primer y segundo formante, respectivamente. En la Fig. 3.1 se muestra la colocación de las vocales más frecuentes sobre un triángulo vocálico. En la Fig. 3.2 podemos ver la representación de los diferentes armónicos de una vocal gracias a un espectrograma, una representación en el dominio del tiempo obtenida con [19]. En la figura 3.3 y en la 3.4 se pueden observar dos representaciones del triángulo vocálico y las posiciones de los dos primeros formantes obtenidas con [19] para una secuencia que comprende cinco vocales cardinales del español. La primera figura pertenece a un varón, mientras que la segunda pertenece a una mujer.

Normalmente, el triángulo vocálico de las mujeres es más alto que el de los hombres, debido a la producción de frecuencias más altas. Algunas diferencias significativas en los formantes entre hombres y mujeres son por ejemplo que la amplitud de los formantes en los hombres es más alta que en las mujeres, mientras que sucede lo contrario cuando hablamos del ancho de banda [30]. 


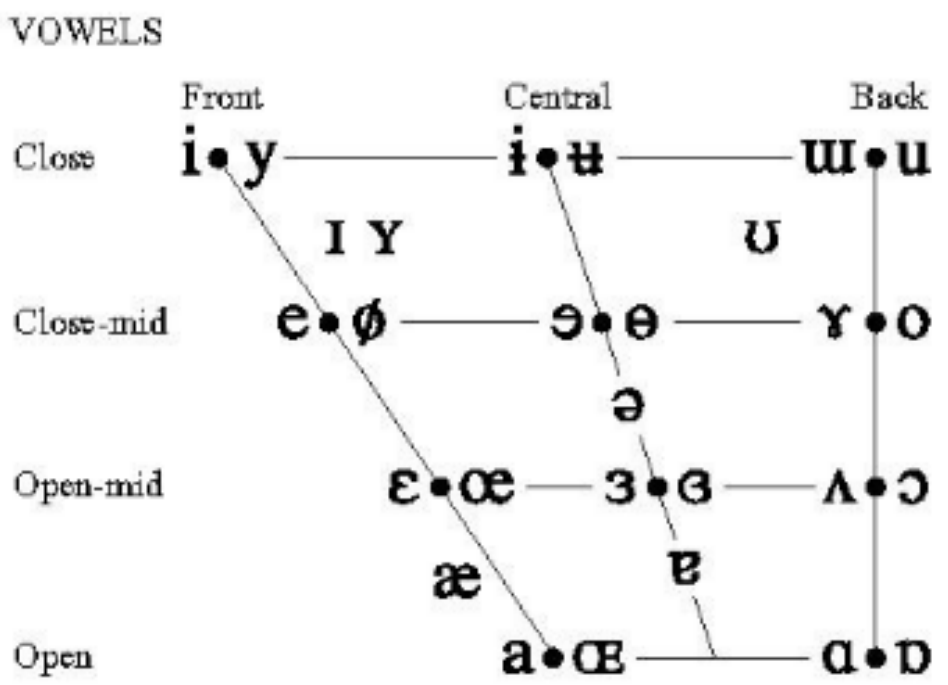

Figura 3.1: Triángulo vocálico según el Alfabeto Fonético Internacional (IPA). Obtenida de ${ }^{\circ}$ IPA 2015.

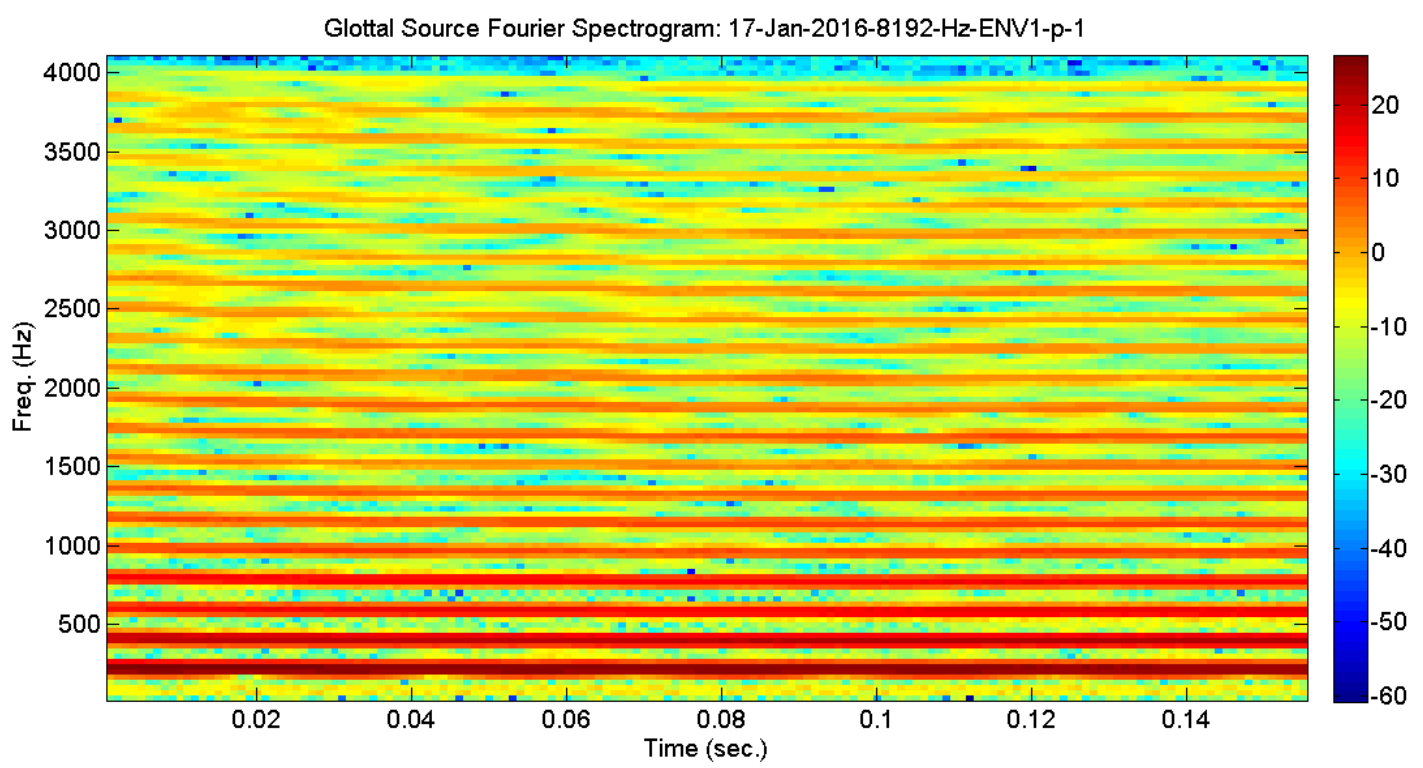

Figura 3.2: Espéctograma representando los diferentes formantes. 

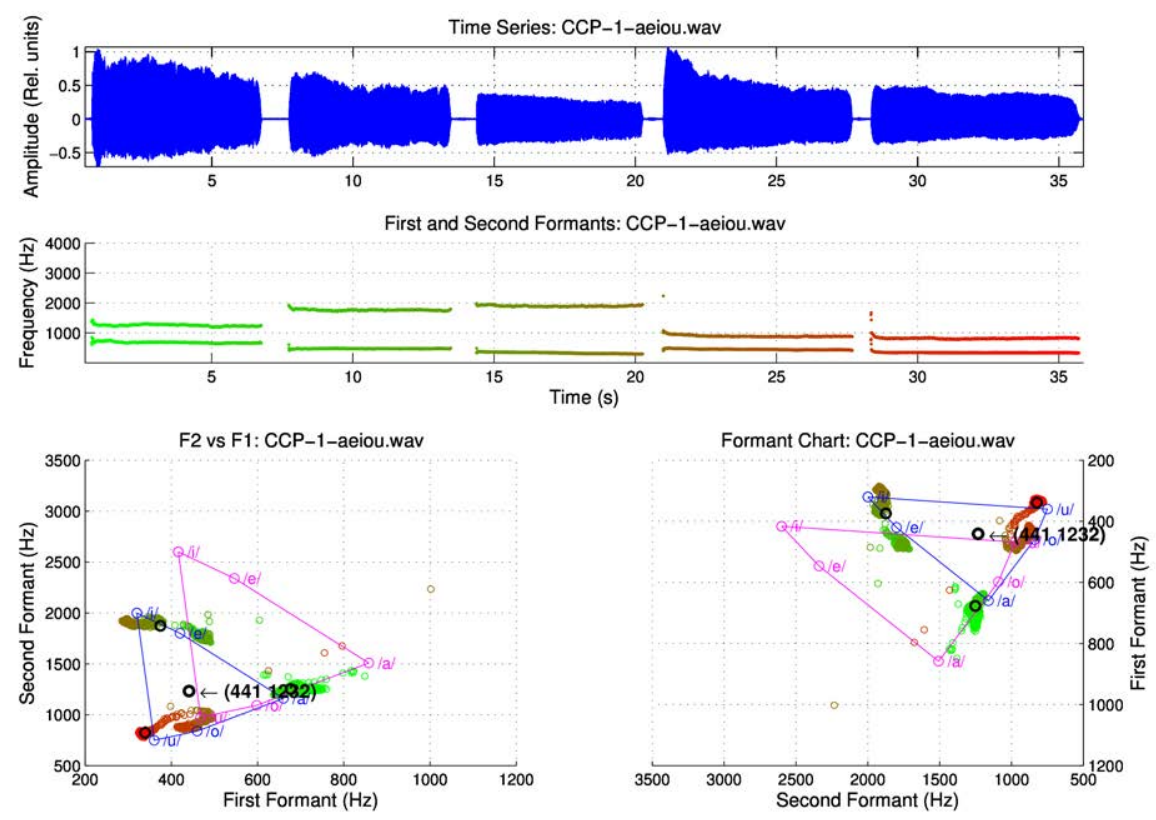

Figura 3.3: Vocales en Español (parte superior), primer y segundo formante (parte intermedia) y triángulo vocálico (parte inferior) de una voz masculina.
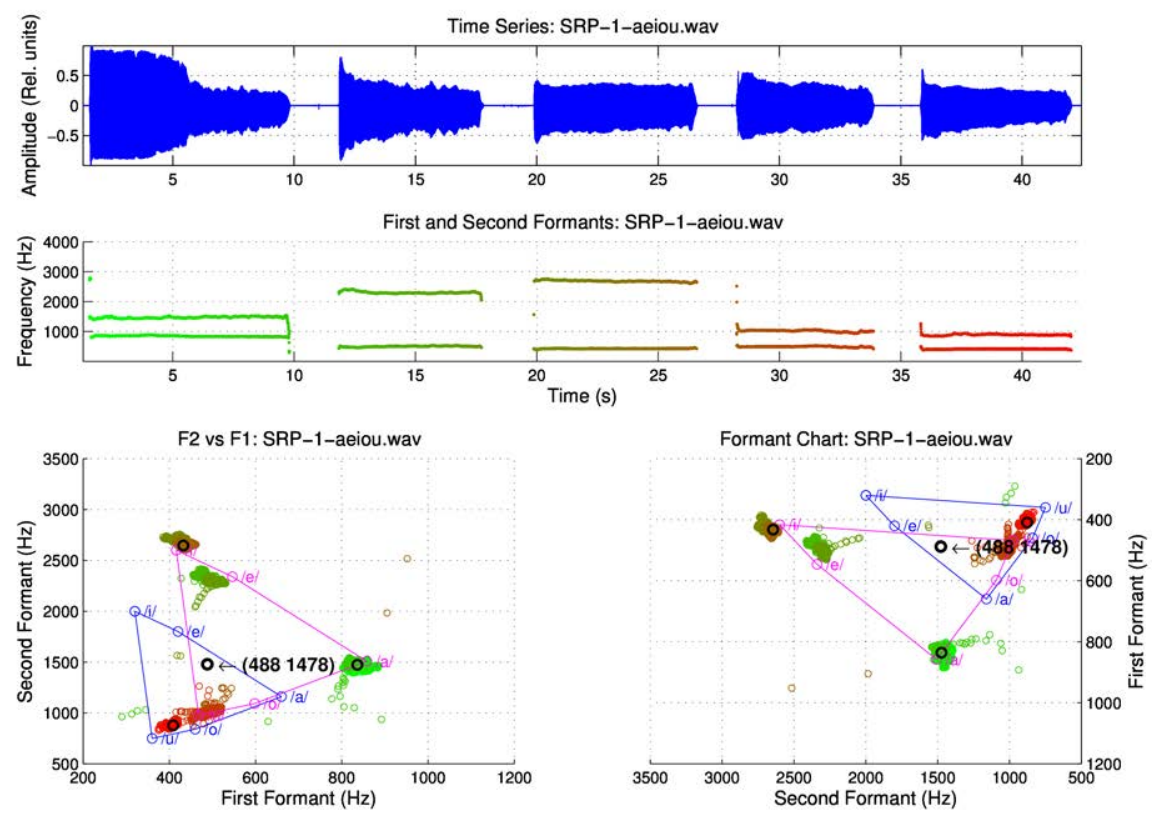

Figura 3.4: Vocales en Español (parte superior), primer y segundo formante (parte intermedia) y triángulo vocálico (parte inferior) de una voz femenina. 


\section{Ancho de banda}

El ancho de banda es la diferencia entre las frecuencias mínimas y máximas presentes en una señal. Este rasgo se mide en Hercios (Hz). En un caso ideal, si la frecuencia mínima es igual a cero, el ancho de banda será equivalente a la frecuencia máxima de la señal. Petrushin en su trabajo [140] utiliza características acústicas básicas tales como la frecuencia fundamental $f_{0}$, los tres primeros formantes y sus anchos de banda correspondientes, la energía y la tasa de habla. A partir de estos parámetros y haciendo uso de estadística descriptiva calcula la media, la desviación estándar, los mínimos y máximos y el rango. Su objetivo es la detección emocional orientada principalmente para su uso en los call centers.

\section{Características espectrales}

Según Ververidis y Kotropoulos en [190] las características espectrales son el contenido energético de ciertas bandas de frecuencia divididas por la longitud de la muestra.

\section{Mel Frequency Cepstrum Coefficients (MFCC)}

La escala de Mel es una de las escalas más conocidas para dividir el espectro en bandas [135]. El análisis por bancos de filtros [141] lo que pretende es dividir el espectro de una señal dadas dos frecuencias "límite", una máxima y una mínima. El objetivo fundamental de esta técnica es fraccionar la señal inicial en un conjunto discreto de bandas espectrales que contienen una información análoga a la que presenta el sistema auditivo humano [126].

\section{Operador Teager}

Tal y como recoge Ververidis en [189] existe un operador que se basa en el número de armónicos ocasionados por el flujo de aire no lineal en el tracto vocal que produce la señal de voz. Algunos ejemplos de la utilización de este rasgo los encontramos cuando se quiere detectar enfado o estrés, puesto que el flujo de aire rápido causa turbulencias localizadas cerca de los estrechamientos del tracto, provocando señales de excitación adicionales diferentes al tono fundamental y de espectro no armónico [176] y [205].

\subsubsection{Tiempo}

\section{Detección de la actividad del habla}

Esta característica trata de controlar cuando el locutor produce o no produce sonido alguno. Se podría decir que esta propiedad define el perfil rítmico del habla. Según la definición de la Real Academia Española, la prosodia es el estudio fonético y fonológico de los elementos que se refieren a unidades superiores al fonema, como las sílabas u otras secuencias de la palabra u oración. Luengo [108] utiliza esta 
técnica para evaluar un corpus en euskera a partir de grabaciones realizadas por una actriz, y realizar un detector de actividad de voz.

\section{Duración}

La duración suele ser la diferencia entre el instante de inicio y de final de una secuencia hablada de muy diversa índole, como por ejemplo, una frase, un sintagma, una palabra o incluso una vocal. Por otro lado, cabe destacar que la duración puede contener silencios o no, dado que algunos autores consideran estos silencios parte de la semántica de las emociones. Lee [97] mide la tasa de duración entre las zonas habladas y las no habladas. Por otro lado, en [25] se contabilizó la tasa de duración entre las sentencias consideradas de tipo emocional y las consideradas neutras.

\section{Velocidad del habla}

Se entiende como velocidad del habla la proporción de unidades segmentales, sílabas y pausas por unidad de tiempo producidas por un locutor [118]. Por ejemplo, según [13] y [38], la velocidad de habla se calculó como la inversa del tiempo medio que el locutor estuvo fonando.

\section{Cruces por Cero}

La tasa de cruces por cero representa cuántas veces la señal cambia de signo pasando por el eje de abscisas. El número total es lo que se conoce como tasa de cruces por cero por unidad de tiempo. Cuando la muestra contiene frecuencias bajas implica que el número de veces que pasa por el eje de abscisas es pequeño, o dicho de otra forma, el número de veces que cambia de signo la señal es bajo. De forma análoga al anterior razonamiento se puede concluir que una muestra contiene frecuencias altas cuando el número cambios de signo es elevado. Por tanto, la tasa de cruces por cero ofrece información sobre la frecuencia de la señal [12].

\section{Energía}

Esta característica representa las variaciones de la energía de la señal en el eje del tiempo. La energía se caracteriza por la siguiente ecuación:

$$
E=\sum_{n=-\infty}^{\infty} x^{2}(n)
$$

Hay que destacar que la extracción de la energía es un proceso sencillo y por tanto su uso es ampliamente extendido. Sin embargo, es muy sensible cuando existe alta concentración de ruido en la señal. Esta característica se utiliza combinada con otros parámetros, tales como Cepstrum, tono fundamental o LPC (Linear Predictive Coding), entre otros [9], [34] y [77].

\section{Intensidad}


La definición estricta de intensidad según la RAE es el valor de la magnitud física que expresa la mayor o menor amplitud de las ondas sonoras. En [164] se presentan tres maneras diferentes de expresar la intensidad, para ello utiliza diferentes métricas, tales como la varianza, la media y el máximo.

\section{Predicción Lineal}

La predicción lineal o estimación por mínimos cuadrados es un procedimiento de medida aproximado, mediante el cual una muestra de una secuencia discreta, puede ser estimada a través de una combinación lineal de las muestras anteriores a ella, realizando un proceso de minimización de la suma de las diferencias al cuadrado (sobre un intervalo finito) entre la muestra actual y la predicha linealmente, determinando así, un grupo de coeficientes único, que caracterizan a la señal [111] y [152].

Aplicado al procesamiento de habla, el término Predicción Lineal se refiere a una gran variedad de formulaciones esencialmente equivalentes para modelizar una forma de onda dada.

\subsubsection{Rasgos de perturbación}

\section{Jitter y Shimmer}

Estas características son calculadas a partir de otros elementos primitivos, la frecuencia fundamental y la amplitud, respectivamente, donde el jitter se define como el cálculo de la variación o perturbación en ciclos consecutivos de la frecuencia fundamental, mientras que el shimmer es el cálculo de la variación o perturbación en ciclos consecutivos de la amplitud.

\section{Áreas del tracto vocal}

De acuerdo con [189], el área del tracto vocal se modifica dependiendo del estado emocional. Muchos autores han intentado modelar dichos cambios a través de otras características, como por ejemplo, los formantes (véase Sección 3.2.1), relacionados con las áreas de sección transversal, definiendo el tracto vocal como una concatenación de tubos sin pérdidas [57].

\section{Tasa de Harmónico/Ruido}

Este rasgo mide la proporción entre la energía de los componentes armónicos de la señal y la del ruido turbulento que acompaña a los mismos. Su origen proviene de una mala adducción u oclusión de los pliegues vocales. 


\subsection{Rasgos propuestos}

Esta sección se dividirá en tres partes. La primera explicará de forma pormenorizada todas las etapas involucradas en el cálculo de la fuente glótica. Seguidamente se presentará la herramienta BioMetr@Phon, la cual ha sido utilizada para extraer los 72 rasgos a lo largo de este trabajo, los cuales se explicarán de forma general. Toda la información hasta este punto se ha extraído de [64], donde se recoge de manera pormenorizada. A continuación se detallará una visión más específica de algunos de los rasgos más relevantes, ofreciendo primeramente la hipótesis inicial en la que se sustenta la detección del estrés.

\subsubsection{La fuente glótica}

Tal y como se vio en el Capítulo 1, una de las etapas para la producción de voz es la Fuente Glótica, la cual se puede definir según el modelo clásico de Fant, reproducido en la Figura 3.5, como "la onda de presión que se genera en el borde supraglótico de los pliegues vocales durante la emisión de una fonación, en que los pliegues vocales modulan el flujo de aire expulsado por los pulmones a través de la laringe". La fuente y el flujo glótico son dos señales que están íntimamente relacionadas, porque en ciertas ocasiones pueden comprenderse como derivada e integral, aunque desde una orientación de estimulación del tracto oro-naso-faríngeo (TONF) es preferible la primera definición, es decir, la presión supraglótica, dado que la cima o cúspide negativa aguda presente en la misma (MFDR: Maximum Flow Declination Rate) se considera el elemento relevante para explicar el despliegue armónico según el modelo de Fant [50]. Estas y otras cuestiones se debatieron en el International Voice Symposium que se celebró en la Universidad de Nueva York en enero de 2014 [61].

El modelo presenta el proceso de producción del habla en forma de un sistema combinado por varias etapas o subsistemas: excitación glótica, excitación turbulenta, combinación de estas dos últimas señales, tracto oro-naso-faríngeo y radiación. Este modelo se puede definir como in-out, es decir, desde dentro hacia el exterior. Este concepto obtendrá más relevancia cuando se defina la hipótesis inicial (véase Sección 3.3.3) de la parametrización de emociones en este trabajo, la cual está explicada como un modelo inverso y que se definirá como out-in. 


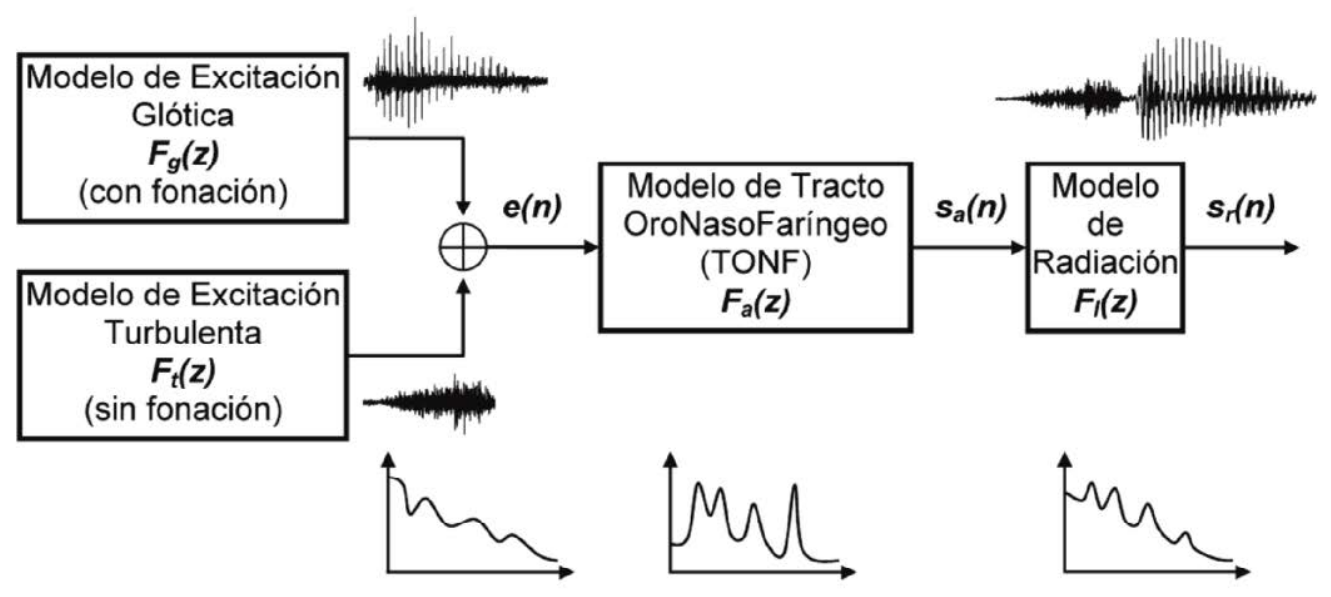

Figura 3.5: Modelo de Fuente-Filtro de Gunnar Fant.

El modelo de excitación glótica denotado por $F_{g}(z)$, representa la fuente fonada obtenida a través de la vibración de los pliegues vocales, mientras que el modelo de excitación turbulenta definido por $F_{t}(z)$ presenta aquellas excitaciones sonoras producidas a causa de las turbulencias ocasionadas en los estrechamientos por los que trascurre el flujo de aire: pliegues vocales, falsos pliegues vocales, zona palatofaríngea, puntos de articulación (labiales, palatales, dento-alveolares), e incluso por las fosas nasales. La señal de excitación $e(n)$ también denominada como "fuente", es la suma de ambas componentes de excitación, la glótica o fonada y la turbulenta sin fonación. Hay que tener en cuenta que la fuente incluirá mayor o menor cantidad de esta última componente dependiendo del tipo de voz asociada, es decir, las voces conocidas como aéreas poseen una mayor cantidad de componente turbulenta que otro tipo de voces. Por consiguiente, este hecho se deberá de tener en cuenta en etapas posteriores. Cuando este fenómeno tiene lugar, el sonido presenta un patrón espectral característico de los sonidos definidos como "sonoros". La tupla armónico-turbulencia es una característica fundamental que se puede ver alterada en voces disfónicas. Éstas se pueden dar en pacientes con enfermedades orgánicas neurodegenerativas tales como Esclerosis Lateral Amiotrófica (ELA) y Parkinson. Hay que destacar que la segunda componente, la turbulenta, siempre se encuentra presente en mayor o menor medida, mientras que la armónica puede que se reduzca o no dependiendo de la función de los pliegues vocales.

Partiendo de los conceptos de resonancia y antirresonancia, la cual se denomina como la amplitud de vibración igual a cero de un sistema mecánico, se puede explicar el comportamiento de la siguiente etapa, el modelo tracto oro-naso-faríngeo. El tracto oro-naso-faríngeo esta dividido en cavidad supráglótica, faringe baja, zona velofaríngea, cavidad nasal y oral. Dichas cavidades presentan unas peculiaridades acústicas, basadas en resonancias que dependiendo de la conexión entre ellas, gobernadas por el "cierre" velofaríngeo, pueden configurarse como resonancias orales y antirresonancias nasales, o como resonancias nasales y antirresonancias orales. Para resumir este modelo, cabe decir que las resonancias y antirresonancias resultantes modifican espectralmente la señal $s_{a}(n)$ que entra a la siguiente etapa que es el mo- 
delo de radiación.

El modelo de radiación (denotado por $F_{l}(z)$ ) es un elemento a tener en cuenta cuando se realizan grabaciones de voz. Tal y como se describió en la sección Objetivos, uno de ellos era realizar una base de datos fiable y de calidad. El sistema o metodología de grabación es crítico para obtener grabaciones con un alto estándar de calidad. El punto de emisión, la distancia de captura y el canal son las condiciones a controlar para una buena grabación. A continuación se explica cada una de las condiciones:

- El punto de emisión se refiere a los puntos donde se está emitiendo o radiando sonido. Los puntos clave de emisión son por orden de importancia los labios, las fosas nasales y su entorno facial, la caja torácica y la zona frontal y temporal del cráneo. Cada una de estas partes influye en la función de transmisión de radiación y en su direccionalidad. Los labios se caracterizan por aportar la mayor propagación de energía, además de un máximo ancho de banda. Las fosas nasales y su entorno facial presentan un aspecto clave en cuanto se habla de canto. La caja torácica constituye un radiador muy eficaz en bajas frecuencias.

- La distancia modifica la intensidad sonora. Otro aspecto interesante de la distancia es que suele influir en la presencia de efectos sonoros indeseados tales como el ruido de ambiente o la reverberación del habitáculo donde se esté realizando la grabación.

- El canal se refiere al medio utilizado para captar la voz. Por lo tanto, aspectos como la placa de audio, la frecuencia de muestreo y el número de bits son características a tener en cuenta. Sin olvidar factores como la sensibilidad del micrófono en amplitud, frecuencia y dirección.

Finalmente, otro aspecto importante a tener en cuenta para la reconstrucción de una buena fuente glótica es la interacción de la fuente y el filtro. Esta interacción se basa en la reverberación de la onda por su paso por los pliegues vocales hasta llegar a la zona de radiación. Las vocales cerradas como son la /i/ y /u/, además de algunas consonantes nasales, ofrecen una mayor alteración en el patrón de fonación de la fuente glótica. Teniendo en cuenta que los procesos de inversión del TONF suelen basarse en filtrado inverso, el cual suele ser más robusto con funciones de transferencia dominadas por resonancias que cuando existen antirresonancias, es conveniente descartar vocales cerradas, como la /i/ o la /u/, o excesivamente nasalizadas. Por este motivo, en el Capítulo 2, conjunto de datos por caso práctico, la selección de vocales utilizadas para extraer los parámetros característicos han sido las vocales /a/ y /e/, dada su mejor predisposición a la hora de reconstruir la fuente glótica.

El procedimiento de inversión del TONF y la reconstrucción de la Fuente Glótica pueden verse en la Figura 3.6 y se explicarán a continuación.

El proceso de inversión iterativo tiene como parámetro de entrada la señal de voz emitida por el locutor y como parámetro de salida se obtiene el residual glótico. 


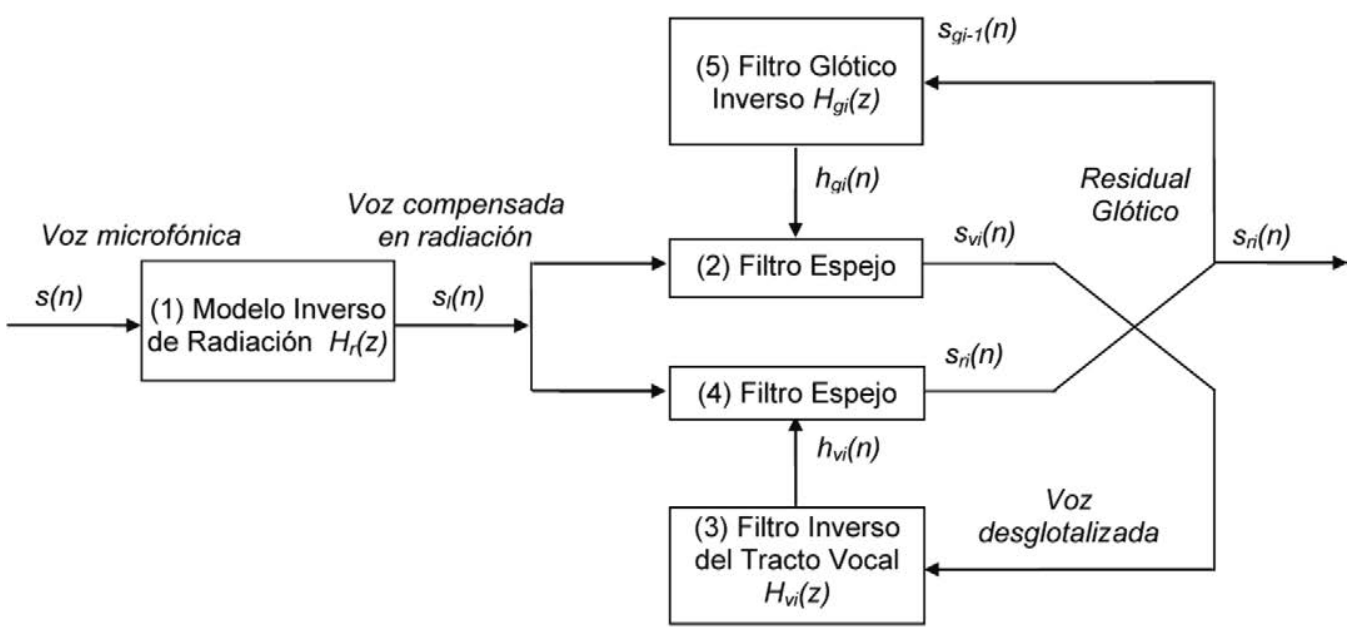

Figura 3.6: Proceso de inversión iterativo basado en filtros inversos y sus filtros espejo, implementados en la aplicación BioMetßPhon.

Dicho proceso se compone de 5 etapas, 4 de ellas iterativas y que se pueden repetir $n$ veces hasta lograr obtener el residuo glótico óptimo. Seguidamente se detallará cada etapa de este proceso.

1. El modelo inverso de radiación denotado por $H_{r}(z)$ tiene como entrada la señal de voz $s(n)$, la cual se obtiene a partir de la señal microfónica. En el proceso de modelado inverso del efecto de radiación se han tenido en cuenta los posibles efectos adversos producidos por los puntos de radiación (oral, nasal), el canal utilizado y la distancia utilizada en el momento de la grabación. Todos ellos son nivelados devolviendo como resultado la señal compensada $s_{l}(n)$.

2. $s_{l}(n)$ posee una gran influencia de la fuente glótica, por consiguiente es necesario realizar un proceso de "desglotalización" utilizando un modelo de hipótesis inicial, definido como $H_{g 0}(z)$, por medio de un filtro de espejo que neutraliza en la medida de lo posible el efecto de la fuente glótica sobre la señal de entrada, $s_{l}(n)$, obteniendo como resultado la señal $s_{v 0}(n)$.

3. Esta nueva señal es modelada mediante filtrado inverso, para producir un modelo inverso del Tracto Oro-Naso-Faríngeo, el cual llamaremos, $H_{v 0}(z)$.

4. El primer residual glótico denominado $s_{r 0}(n)$, se consigue a partir de la aplicación de otro filtro espejo sobre el modelo inverso del TONF y la señal compensada en radiación $s_{l}(n)$.

5. Una vez obtenido residual glótico $s_{r 0}(n)$ se requiere la actualización de la hipótesis inicial $H_{g 0}(z)$ mediante un sistema inverso para generar una función del pulso glótico $H_{g 1}(z)$, momento en el cual las etapas 2 a 5 se repetirán tantas veces como sean necesarias hasta obtener un residual glótico denotado por $s_{r i}(n)$. 
Una vez que se ha obtenido el residual glótico, este se utiliza para obtener la fuente glótica y el flujo glótico. En la Figura 3.7 se representan las diferentes etapas desde la señal de voz radiada $s(n)$ hasta la obtención del flujo glótico. En la Figura 3.7a) se muestra la señal de voz de entrada. Una vez realizado todo el proceso de inversión iterativo explicado anteriormente se obtiene $s_{r i}(n)$, el cual queda representado en la Figura 3.7b). Dicho resultado se basa en todo el proceso ilustrado en la Figura 3.6. A continuación si se realiza un proceso de compensación o nivelado de los efectos de la fuente y el filtro, da como resultado la onda de presión supraglótica, la cual es conocida comunmente como fuente glótica. Esta onda queda ilustrada en la Figura 3.7c). Nuevamente, esta última señal se vuelve a procesar mediante el sistema equivalente de pliegues vocales y tracto oro-naso-faríngeo, dando como resultado el flujo glótico, el cual queda representado en la Figura 3.7d). Las características más importantes de esta onda o patrón son la pendiente inicial, la cual se puede relacionar con la presencia de pérdidas por cierre defectuoso (gap permanente), y la pendiente final, relacionada con el Maximum Flow Declination Rate. El flujo glótico se puede definir como el escape de gas a través de los pliegues vocales, el cual posee forma de pulso triangular. Dicho pulso presenta un arranque desde un mínimo con pendiente moderada, para crecer abruptamente, y disminuir aún más rápido hacia un nuevo mínimo.

a) Input Voice

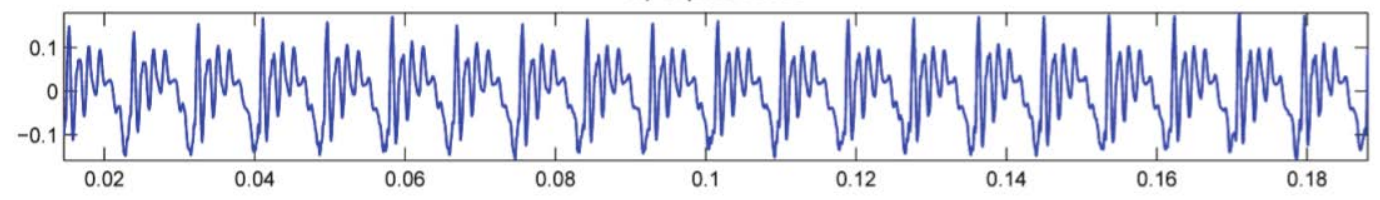

b) Derivative of the Forward Pressure Wave

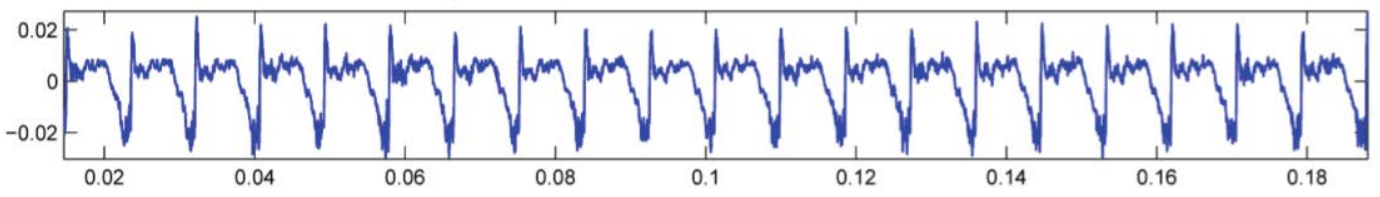

c) Glottal Source

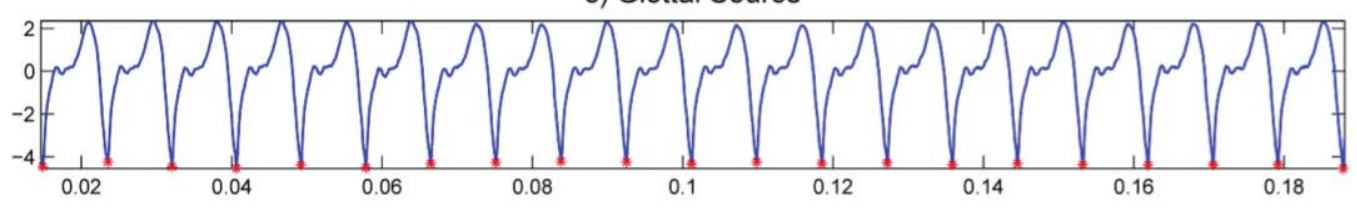

d) Glottal Flow

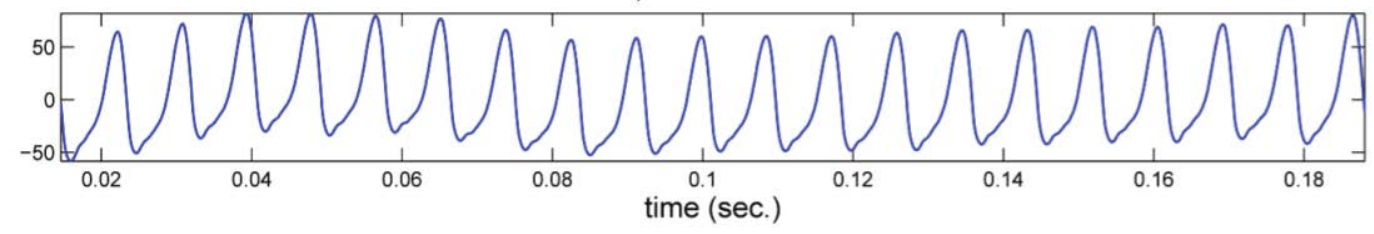

Figura 3.7: Reconstrucción de la Fuente Glótica (c) y el Flujo Glótico (d) a partir de la voz (a).

Dada la relevancia de la fuente glótica, se ha decidido explicar con un poco más de detalle dicho patrón, el cual se ha representado en la Figura 3.8. 

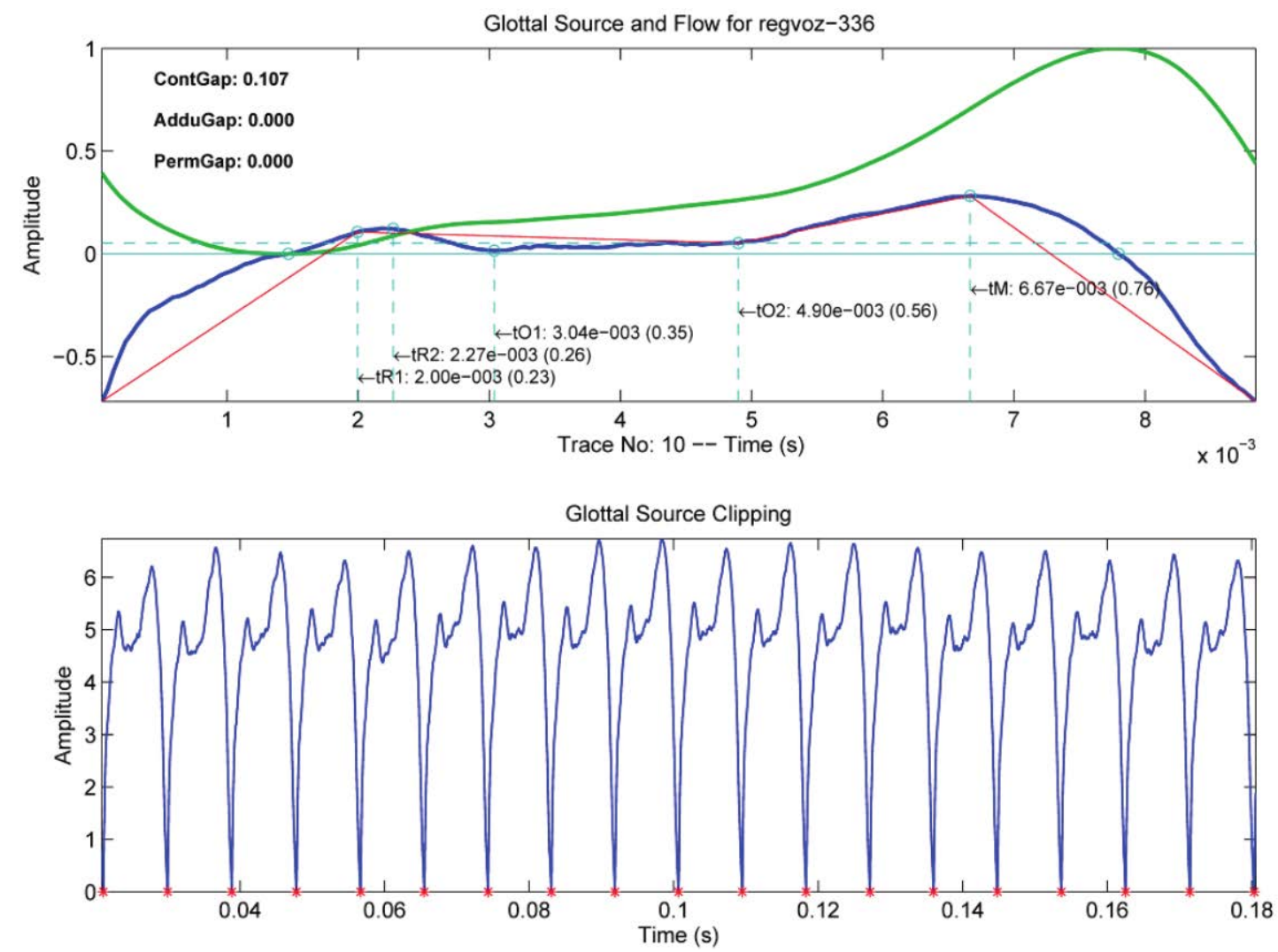

Figura 3.8: Fuente Glótica típica. Parte superior: Reproducción de un ciclo glótico entre dos puntos MFDR (mínimos de presión). Parte inferior: tren de pulsos glóticos consecutivos, uno de los cuales (el central) se presenta en detalle en la parte superior.

En su parte superior se puede observar el patrón normativo de un pulso glótico (patrón L-F o de Liljencrants-Fant [50]), caracterizado por los siguientes segmentos:

1. Tramo de recuperación, el cual corresponde con el intervalo $0-t R 1$ que se basa en que la presión sonora dinámica en la zona supraglótica vuelve a su valor nulo (presión atmosférica) tras una fuerte caída debido al cierre del tracto vocal.

2. Tramo de contacto en reposo, el cual corresponde al intervalo $t_{R 1}-t_{O 2}$ que se sustenta en que la presión sonora dinámica debería ser prácticamente nula, por estar la glotis supuestamente cerrada.

3. Tramo de fuerte inyección de flujo, el cual corresponde con el intervalo $t_{O 2}-t_{M}$ que se corresponde con el aumento de la presión sonora dinámica hasta un máximo por efecto de la apertura de los pliegues vocales (abducción).

4. Tramo de caída de la presión sonora dinámica, debido a la menor tasa de inyección de flujo aéreo por unidad de tiempo, considerando que los pliegues vocales alcanzan un máximo en su separación, a partir del cual vuelven a aproximarse (aducción). Este efecto limita el crecimiento del flujo y condiciona 
su posterior caída. Es importante resaltar que según Titze [180], cuando el flujo desciende a su máximo ritmo se produce el punto MFDR, momento en el cual la presión dinámica alcanza un mínimo, a partir del cual se repite el ciclo glótico. Por otro lado, según la teoría de Fant, la amplitud y agudeza del MFDR son los elementos de referencia para generar un buen despliegue armónico en la voz (número y calidad de los armónicos en el espectro de potencia de la fuente glótica).

\subsubsection{La herramienta BioMetr@Phon}

Es una herramienta versátil que permite grabar y analizar la voz. Además, a partir de fragmentos de voz de diferentes longitudes es capaz de obtener 72 parámetros diferentes, los cuales se pueden dividir en parámetros acústicos, cepstrales, espectrales, biomecánicos y de temblor, entre otros. La interfaz de usuario de dicha herramienta puede verse en la Figura 3.9, donde puede observarse la representación de la fuente glótica, y un tren de pulsos glóticos, la señal en el tiempo, y algunos valores de los parámetros que calcula.

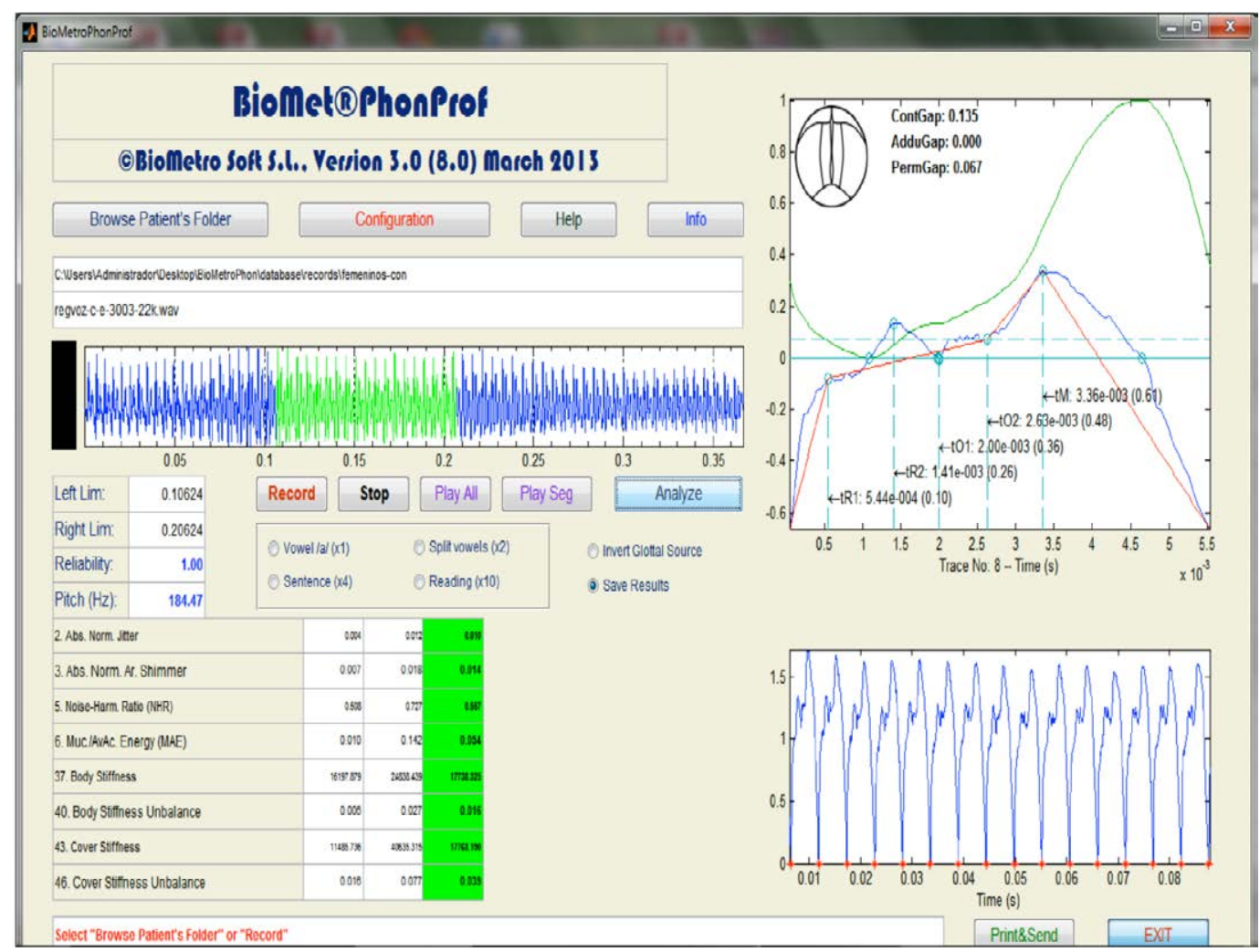

Figura 3.9: Interfaz de usuario de BioMetr@Phon.

No es objeto de este trabajo explicar la interfaz de usuario de dicha herramienta, ni tampoco cada una de sus funcionalidades. Tan solo se van a presentar los diferentes parámetros extraídos:

1. Absolute Pitch. Es la frecuencia de un ciclo glótico, inversa del período 
fundamental. Sirve con otros parámetros para distinguir voz masculina de femenina. Valor dado en Hercios $(\mathrm{Hz})$.

2. Abs. Norm. Jitter. Es el jitter relativo, es decir, el cálculo se basa en el valor inverso de la diferencia entre los periodos de dos ciclos vecinos, dividido por la media aritmética de ambos. Sirve, junto con otros, para detectar inestabilidad en la fonación, y ayuda a caracterizar la disfonía (aplicación en detección y gradación de disfonía).

3. Abs. Norm Ar. Shimmer. Es el shimmer relativo en amplitud media por ciclo glótico, es decir, es la diferencia entre las amplitudes medias de la fuente glótica en dos ciclos vecinos, dividido por la media aritmética de ambas. Sirve, junto con otros, para detectar inestabilidad en la fonación, y ayuda a caracterizar la disfonía (aplicación en detección y gradación de disfonía).

4. Abs. Norm. Min. Sharp. Es el shimmer relativo de área, es decir, la esbeltez del pico del MFDR: amplitud negativa del pico dividida por su anchura. Sirve, junto con otros, para detectar inestabilidad en la fonación, y ayuda a caracterizar la disfonía (aplicación en detección y gradación de disfonía).

5. Noise-Harm. Ratio (NHR). Es la esbeltez del MFDR y mide la agudeza del cierre glótico, es decir, la relación entre las energías de las componentes no armónica y armónica del espectro de potencia de la onda glótica. Sirve, junto con otros, para detectar emocionalidad en la fonación, y ayuda a caracterizar la disfonía (aplicación en detección y gradación de disfonía).

6. Muc./AvAc. Energy (MAE). Es la relación entre la energía de la diferencia de la fuente glótica y su onda acústica promedio. Sirve, junto con otros, para detectar posibles alteraciones neurológicas en un locutor, y ayuda a caracterizar la disfonía (aplicación en detección y gradación de disfonía).

7-20. MWC Cepstral 1 al 14. Forman parte de la firma biométrica del locutor en forma compacta, y junto con otros, ayudan en la identificación y verificación del locutor, tanto en aplicaciones de acceso seguro como en cotejo forense. Estos parámetros van desde el primer coeficiente hasta el decimocuarto de la fuente glótica.

21-34. Parámetros de perfil espectral. Forman parte de la firma biométrica del locutor, así como del comportamiento normativo o no normativo de éste, y junto con otros ayudan en la identificación y verificación del mismo (aplicaciones de acceso seguro o cotejo forense), y en la determinación de la presencia de disfonía de origen orgánico (aplicación en detección y gradación de disfonía).

21. MW PSD 1st Max. ABS. Primer máximo de la densidad espectral de la fuente glótica.

22. MW PSD 1st Min. rel. Primer mínimo de la densidad espectral de la fuente glótica.

23. MW PSD 2nd Max. rel. Segundo máximo de la densidad espectral de la fuente glótica. 
24. MW PSD 2nd Min. rel. Segundo mínimo de la densidad espectral de la fuente glótica.

25. MW PSD 3rd Max. rel. Tercer máximo de la densidad espectral de la fuente glótica.

26. MW PSD End Val. rel. Valor de la energía de la densidad espectral de potencia de la onda glótica a la mitad de la frecuencia de muestreo.

27. MW PSD 1st Max. Pos. ABS. Frecuencia del primer máximo de la densidad espectral de la fuente glótica.

28. MW PSD 1st Min. Pos. rel. Frecuencia relativa del primer mínimo de la densidad espectral de la fuente glótica con respecto al primer máximo.

29. MW PSD 2nd Max. Pos. rel. Frecuencia relativa del segundo máximo de la densidad espectral de la fuente glótica con respecto al primer máximo.

30. MW PSD 2nd Min. Pos. rel. Frecuencia relativa del segundo mínimo de la densidad espectral de la fuente glótica con respecto al primer máximo.

31. MW PSD 3rd Max. Pos. rel. Frecuencia relativa del tercer máximo de la densidad espectral de la fuente glótica con respecto al primer máximo.

32. MW PSD End Val. Pos. rel. Valor relativo de la mitad de la frecuencia de muestreo respecto al primer máximo de la densidad espectral de potencia.

33. MW PSD 1st Min. NSF. Esbeltez del primer valle en " $V$ " en la envolvente espectral de la densidad de potencia de la onda glótica: amplitud negativa del pico dividida por su anchura.

34. MW PSD 2nd Min. NSF. Esbeltez del segundo valle en " $V$ " en la envolvente espectral de la densidad de potencia de la onda glótica: amplitud negativa del pico dividida por su anchura.

35-46. Parámetros biomecánicos. Constituyen un conjunto robusto de descriptores del funcionamiento mecánico de la glotis, y junto con otros, ayudan en la determinación de las posibles causas de una disfonía, y en la cuantificación del grado de la misma (aplicación en detección y gradación de disfonía).

35. Body Mass. Masa dinámica equivalente del cuerpo del pliegue vocal para cada ciclo glótico.

36. Body Losses. Pérdida por fricción equivalente del cuerpo del pliegue vocal para cada ciclo glótico.

37. Body Stiffness. Tensión transversal medida sobre el cuerpo del pliegue vocal para cada ciclo glótico.

38. Body Mass Unbalance. Diferencia entre las masas dinámicas del cuerpo del pliegue observadas en dos ciclos vecinos, dividida por su promedio. En otras palabras, desbalance del parámetro 35 (Body Mass) en dos ciclos vecinos. 
39. Body Losses Unbalance. Diferencia entre las pérdidas por fricción del cuerpo del pliegue vocal observadas en dos ciclos vecinos, dividida por su promedio.

40. Body Stiffnes Unbalance. Desbalance de dos ciclos glóticos vecinos del parámetro 37 (Body Stiffnes). Diferencia entre las tensiones del cuerpo del pliegue vocal observadas en dos ciclos vecinos, divididas por su promedio.

41. Cover Mass. Masa dinámica de la cubierta del pliegue vocal para cada ciclo glótico.

42. Cover Losses. Pérdida por fricción de la cubierta del pliegue vocal para cada ciclo glótico.

43. Cover Stiffnes. Tensión transversal observada sobre la cubierta del pliegue vocal para cada ciclo glótico.

44. Cover Mass Unbalance. Diferencia entre las masas dinámicas de la cubierta del pliegue vocal observadas en dos ciclos vecinos, dividida por su media. En otras palabras, desbalance del parámetro 41 (Cover Mass) entre ciclos vecinos de fonación.

45. Cover Losses Unbalance. Diferencia entre las perdidas por fricción de la cubierta del pliegue medidas en dos ciclos vecinos.

46. Cover Stiffness Unbalance. Desbalance del parámetro 43 (Cover Stiffnes) entre ciclos vecinos de fonación, o lo que es lo mismo, la diferencia entre las tensiones de la cubierta del pliegue observadas en dos ciclos vecinos y dividida por su promedio.

47-58. Parámetros de base temporal. Constituyen un descriptor completo de los instantes de interés del ciclo glótico (cierre, retorno, apertura), y junto con otros sirven en la caracterización de la disfonía (aplicación en detección y gradación de disfonía).

47. Rel. Recov. 1 Time. Relación entre el instante del primer tiempo de recuperación y la duración total del ciclo glótico.

48. Rel. Recov. 2 Time. Relación entre el instante del segundo tiempo de recuperación y la duración total del ciclo glótico.

49. Rel. Open 1 Time. Relación entre el instante del primer tiempo de apertura y la duración total del ciclo glótico.

50. Rel. Open 2 Time. Relación entre el instante del segundo tiempo de apertura y la duración total del ciclo glótico.

51. Rel. Max. Ampl. Time. Relación entre el instante en que se alcanza el máximo de la onda glótica y la duración total del ciclo glótico.

52. Rel. Recov. 1 Ampl.. Relación entre la amplitud en el primer tiempo de recuperación y la amplitud pico a pico de la fuente glótica.

53. Rel. Recov. 2 Ampl.. Relación entre la amplitud en el segundo tiempo de recuperación y la amplitud pico a pico de la fuente glótica. 
54. Rel. Open 1 Ampl. Relación entre la amplitud en el primer tiempo de apertura y la amplitud pico a pico de la fuente glótica.

55. Rel. Open 2 Ampl. Relación entre la amplitud en el segundo tiempo de apertura y la amplitud pico a pico de la fuente glótica.

56. Rel. Stop Flow Time. Relación entre el instante de mínimo flujo y la duración total del ciclo glótico.

57. Rel. Start Flow Time. Relación entre el instante de inicio del flujo y la duración total del ciclo glótico.

58. Rel. Closing Time. Relación entre el instante de máximo flujo y la duración total del ciclo glótico.

59-62. Parámetros de defecto de cierre glótico. Constituyen un descriptor de los defectos de cierre, aducción, abducción y permanente de los pliegues vocales, y junto con otros, sirven en la caracterización de las imperfecciones detectadas en el ciclo glótico.

59. Val. Flow GAP. Relación entre el escape de flujo durante la fase de contacto y el flujo total durante un ciclo glótico (medido sobre el flujo).

60. Val. Contact GAP. Relación entre el escape de flujo durante la fase de contacto y el flujo total durante un ciclo glótico (medido sobre la fuente glótica).

61. Val. Adduction GAP. Relación entre el flujo durante la fase de aducción y el flujo total durante un ciclo glótico.

62. Val. Permanent GAP. Relación entre el flujo durante la fase de recuperación y el flujo total durante un ciclo glótico.

63-72. Parámetros de temblor en la voz. Proporcionan información sobre la presencia de defectos o irregularidades en la actuación del sistema neuromotor vinculado al cierre glótico, puestos de manifiesto por la aparición de temblor en la voz (controlado o incontrolado). Tres de los parámetros sirven de marcadores de la presencia de temblor. Los tres restantes informan sobre su frecuencia, perceptibilidad, y su amplitud relativa.

63. 1st. Order Cyc. Coeff. Primer coeficiente PARCOR en el modelo equivalente autorregresivo de la tensión del cuerpo del pliegue vocal eliminando su media.

64. 2nd. Order Cyc. Coeff. Segundo coeficiente PARCOR en el modelo equivalente autorregresivo de la tensión del cuerpo del pliegue vocal eliminando su media.

65. 3rd. Order Cyc. Coeff. Tercer coeficiente PARCOR en el modelo equivalente autorregresivo de la tensión del cuerpo del pliegue vocal eliminando su media.

66. Physiological Tremor Freq. Primera componente de la tensión del cuerpo del pliegue vocal eliminando su media. Suele distribuirse entre 2-4 $\mathrm{Hz}$ y se atribuye al temblor de carácter fisiológico. 
67. Physiological Tremor Ampl. Amplitud de la primera componente de la tensión del cuerpo del pliegue, en \% respecto al valor medio de la tensión del pliegue.

68. Neurological Tremor Freq. Segunda componente de la tensión del cuerpo del pliegue vocal eliminando su media. Suele distribuirse entre 5-8 $\mathrm{Hz}$ y se atribuye al temblor de carácter neurológico.

69. Neurological Tremor Ampl. Amplitud de la segunda componente de la tensión del cuerpo del pliegue, en \% respecto al valor medio de la tensión del pliegue.

70. Fluttering Tremor Freq. Tercera componente de la tensión del cuerpo del pliegue vocal eliminando su media. Suele distribuirse entre 9-12 Hz y se atribuye al temblor de carácter neurofisilógico.

71. Fluttering Tremor Ampl. Amplitud de la tercera componente de la tensión del cuerpo del pliegue, en \% respecto al valor medio de la tensión del pliegue.

72. Tremor amplitude (rMSA). Valor eficaz de la tensión del pliegue vocal eliminando su media.

\subsubsection{Hipótesis inicial}

Una vez que se ha explicado el modelo de Fuente-Filtro de Gunnar Fant y el proceso de inversión iterativo basado en filtros inversos y sus filtros espejo, llega el momento de explicar la hipótesis inicial, en la cual se basa este trabajo, la detección de emociones y estrés a partir de los 72 rasgos extraídos.

En la Figura 3.10 se ha querido representar el ciclo completo de nuestra hipótesis, la cual se divide en dos partes. La primera, a), es el circuito completo de la producción del habla a partir del modelo de Gunnar Fant [49], donde la producción del habla comienza en el cortex neuromotor, el cual planifica movimientos articularios por medio de la activación de las vías neuromotoras craneales y controla la tensión de los pliegues vocales gracias al alargamiento o acortamiento del musculus vocalis. Los estímulos neuromotores de los músculos trans-cricoaritenoide y oblicuo-cricoaritenoide juntan ambos pliegues vocales produciendo una oclusión en la laringe [195]. El aumento de la presión fuerza a los pliegues vocales a separarse contra los músculos laríngeos [109]. La interacción entre la aducción y abducción del control de flujo glotal produce golpes de fonación que son filtrados por los tractos vocales y nasales, y finalmente se produce lo que conocemos comúnmente como voz. 


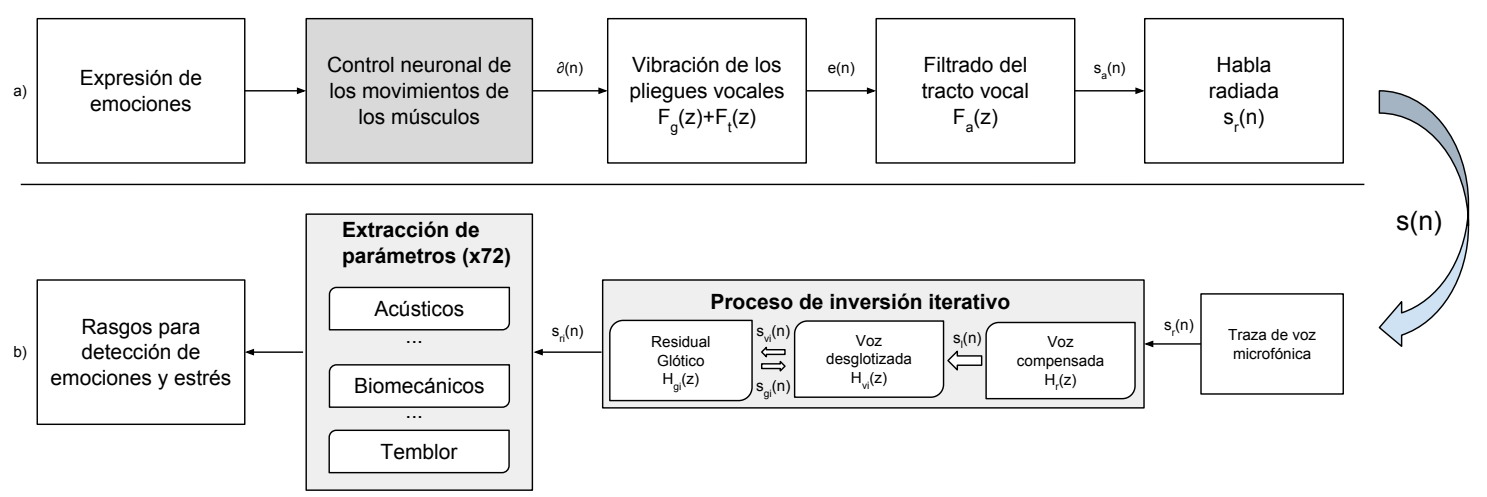

Figura 3.10: Representación de la hipótesis inicial llevada a cabo en este trabajo.

En la parte inferior de la Figura 3.10 se muestra la cadena etiquetada como b), que representa el proceso de deconvolución de una señal de voz previamente grabada y que a través de la realización de un proceso de inversión iterativo y sucesivas etapas se calcula un residual glótico robusto y fiable, como ya se ha visto, $s_{r i}(n)$, el cual se utiliza para obtener una serie de rasgos, que van a ser los descriptores de la fonación, que serán estudiados para intentar esclarecer cuáles de ellos son los más característicos o, los que ofrecen mayor semántica para detectar emociones y estrés en la voz [63]. Todos estos rasgos pueden ser indicadores inconscientes de estados emocionales o estrés.

\subsubsection{Visión específica}

Algunos de los rasgos extraídos tienen una especial relevancia en este trabajo y por tanto van a ser descritos de forma detallada. Estos rasgos son los biomecánicos, los cíclicos y los de temblor.

\subsubsection{Rasgos Biomecánicos}

La fuente glotal se puede considerar como la firma biométrica de la voz y se puede comparar con la misma potencia semántica que un Electrocardiograma (ECG). Si el ECG presenta correlatos entre el tiempo y la amplitud de las señales registradas a partir de los movimientos del corazón, el glotograma señala una semántica similar respecto a la biomecánica de los pliegues vocales.

En la Fig. 3.11 a), se muestra un corte sagital de los pliegues vocales de forma simplificada. Los pliegues vocales son estructuras multicapa, compuestas por un músculo que está recubierto por una mucosa. La estructura multicapa permite a los pliegues vocales alongarse o acortarse. La capa más interna es el músculo tiroaritenoide (musculus vocalis o cuerpo), el cual tiene como función primaria cerrar el paso al aire y a otros fluidos (cierre glótico), y como función secundaria, ejercer la fuerza de restauración del cierre durante la fonación. Alrededor de este músculo hay una funda de tejido mucoso (cubierta), su elasticidad varía desde la capa interna a la externa. La elasticidad de la mucosa depende del estado de contracción de los músculos laríngeos inducidos por el flujo neuromotor procedente del sistema bulbar. 
En la Figura 3.11 b), se puede observar un modelo mecánico del proceso anterior, donde $\mathrm{M}$ representa las masas, $\mathrm{v}$ las velocidades, $\mathrm{K}$ las elasticidades y $\mathrm{f}$ las fuerzas ejercidas por la presión del flujo glotal, b: cuerpo, c: cubierta, l: pliegue vocal izquierdo y r: pliegue vocal derecho. El sistema se puede transformar en un modelo eléctrico equivalente, el cual está representado en la Figura 3.12.

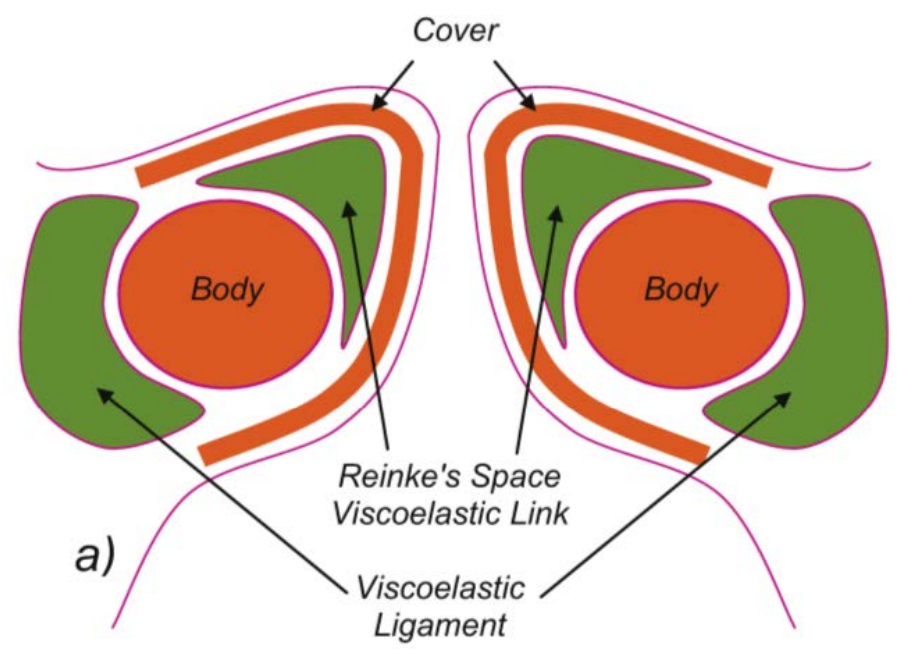

(a) Estructura de los pliegues vocales [151].

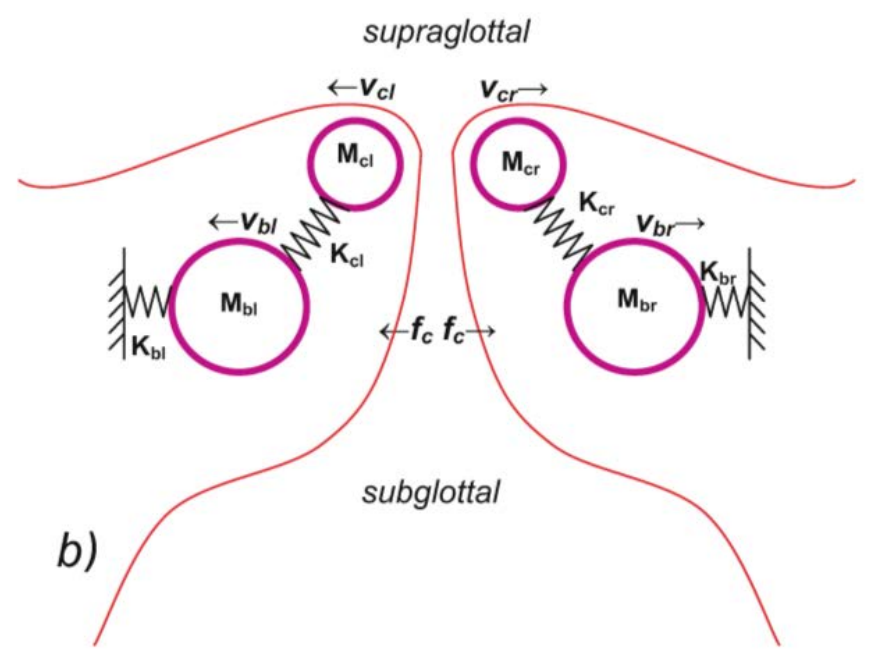

(b) Modelo de dos masas [151].

Figura 3.11: Estructura de los pliegues vocales y su equivalente mecánico.

La interacción entre el flujo glotal y los pliegues vocales es un problema de dinámica de fluidos, el cual requiere soluciones de tipo 3D. Sin embargo, es deseable obtener modelos de estimación más sencillos que reduzcan la complejidad computacional del problema. En este sentido, el funcionamiento de los pliegues vocales se puede modelar como un sistema de masas biomécanico de segundo orden [17] y [172], 
tal y como muestra la Figura 3.12. Este esquema es capaz de explicar la respuesta de los movimientos agonistas y antagonistas de los pliegues vocales debidos a las fuerzas ejercidas sobre ellos [173].

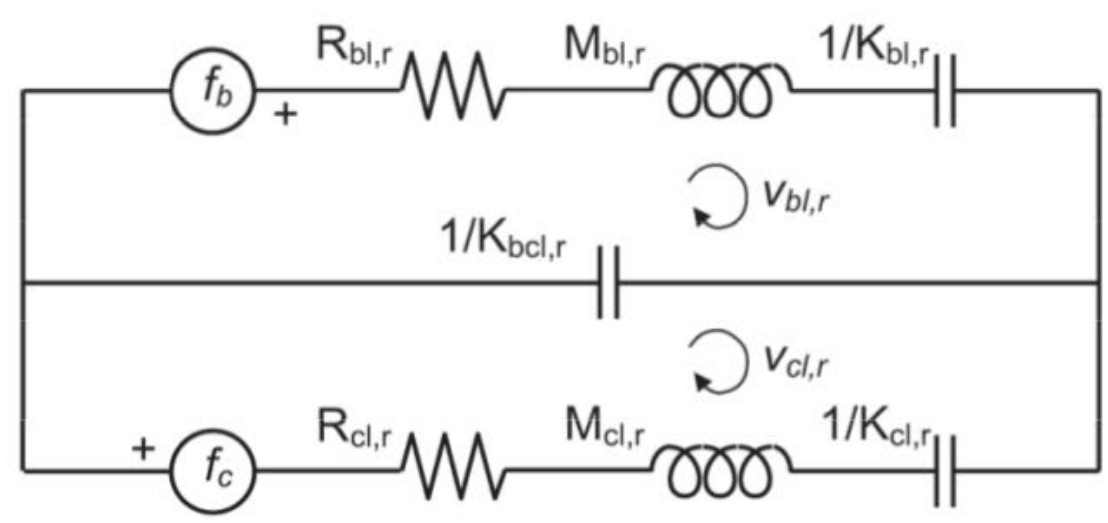

Figura 3.12: Circuito equivalente electromecánico de dos masas.

La estimación de los equivalentes electromecánicos requiere una solución de un problema inverso a partir de la densidad de la potencia espectral de la fuente glotal. Por consiguiente y como se explicó en la Sección 3.3.1, para calcular la señal residual $s_{r}(t)$ es necesario eliminar la onda acústica media, denotada por $s_{a}(n)$ [178] de la fuente glotal $s_{g}(n)$, obteniendo un correlato de la onda mucosa que se desarrolla sobre la cubierta de los pliegues vocales.

$$
s_{r}(t)=s_{g}(t)-s_{a}(t)
$$

definiendo su densidad espectral de potencia como:

$$
\left\|S_{r}(\omega)\right\|=\left|\int_{-\pi}^{\pi} s_{r}(t) e^{-j \omega t} d t\right|
$$

que se puede relacionar con la vibración de la cubierta de los pliegues vocales, introduciendo una función de coste que exprese la diferencia entre la densidad de potencia espectral y la función de transferencia del equivalente electromecánico de las ramas superior e inferior, dada como $T(\omega)$.

$$
L(\omega, \mu, \xi, \sigma)=\oint_{2 \pi}\left(\left\|S_{r}(\omega)\right\|-\left\|T_{c}(\omega, \mu, \xi, \sigma)\right\|\right)^{2} d \omega
$$

donde $\mu, \sigma \mathrm{y} \xi$ representan las estimaciones de cada parámetro biomecánico masivo, viscoso y elástico del cuerpo y la cubierta $\left(R_{b l, r}, M_{b l, r}, K_{b l, r}, R_{c l, r}, M_{c l, r}, K_{c l, r}\right)$.

Suponiendo que T sea una función de segundo orden que relacione la velocidad de la masa dinámica de la cubierta $v_{c}$ con la fuerza aplicada $f_{c}$ en el dominio de la frecuencia donde $Y_{c}$ es una transadmitancia mecánica, el proceso de optimización se podría expresar como:

$$
T_{c}(\omega, \mu, \xi, \sigma)=\left|Y_{c}\right|^{2}=\left|\frac{V_{c}(\omega)}{F_{c}(\omega)}\right|^{2}=\left[\left(\omega \mu_{c}-\omega^{-1} \xi_{c}\right)^{2}+\sigma_{c}^{2}\right]
$$




$$
\frac{\delta L}{\delta \mu_{c}}=0 ; \frac{\delta L}{\delta \xi_{c}}=0 ; \frac{\delta L}{\delta \sigma_{c}}=0 ;
$$

Las soluciones para estas condiciones se pueden encontrar ya sea forzando las derivadas de la función L a cero, obteniendo expresiones para los tres parámetros de ajuste, o por métodos adaptativos basados en técnicas de gradiente. La solución adoptada en el presente enfoque se basa en el ajuste de la densidad de la potencia espectral de la fuente glotal Figura 3.13 (línea continua azul) por la función de transferencia (círculos naranjas) dada por la ecuación (3.6) contra la onda media acústica (triángulos verdes) [62].

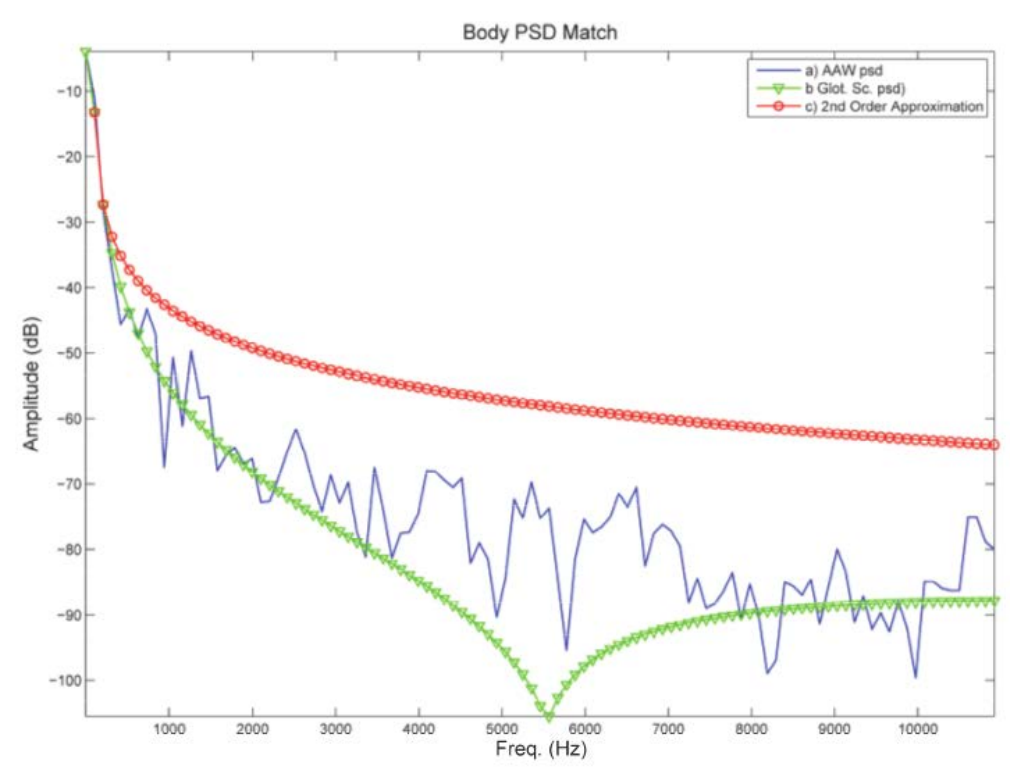

Figura 3.13: Adaptación de la densidad espectral de potencia de la fuente glótica (línea azul fina) ajustada por la densidad espectral de la onda acústica promedio (triángulos verdes) y la función de aproximación (círculos naranjas)

Los resultados obtenidos resolviendo el problema de modelado inverso son compatibles con la vibración de los pliegues vocales. En la Figura 3.14 se muestra el parámetro de la rigidez estimada para el corpus 5. Se puede notar que tanto los valores del cuerpo como de la cubierta son más altos en las mujeres que en los hombres, esta observación nos da una pista para entender que es necesario realizar el estudio separando la población por géneros. 

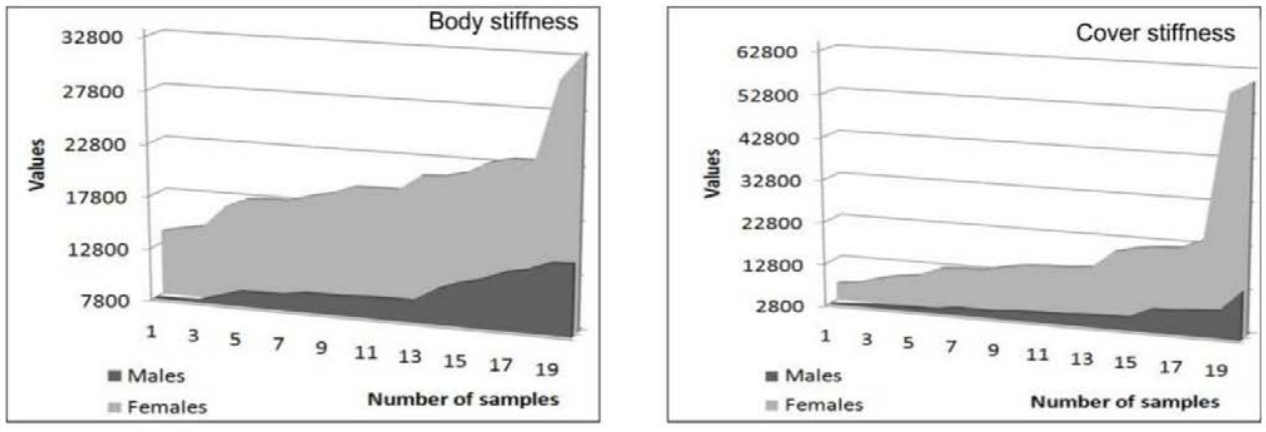

Figura 3.14: Rigidez de cuerpo (body) a la izquierda y de cubierta (cover) a la derecha para hombres y mujeres.

\subsubsection{Coeficientes Cíclicos}

El modelo de la tercera inversión de la fuente glótica se cimienta en el hecho que enfermedades neurológicas como Parkinson o la disfonía espasmódica producen temblores en la voz de manera completamente involuntaria [56] y [139] y pueden causar considerables desórdenes en la fonación. Las señales de temblor en la voz consisten en modulaciones a baja frecuencia y amplitud que se perciben en forma de inestabilidades e intermitencias en la fonación.

El rango del temblor observable para una voz patológica se encuentra entre cuatro y siete Hercios. El temblor en la voz puede ser asociado a aspectos respiratorios, laríngeos y articulatorios. Respecto al aspecto laríngeo, un control neuronal deficiente de los músculos laríngeos puede desembocar en temblores vocales. Por tanto, la hipótesis en este trabajo consiste en que los estados emocionales pueden inducir también algún tipo de temblor y este puede ser apreciado en los correlatos de los parámetros biomecánicos. Específicamente, se hipotetiza que la influencia de las alteraciones emocionales producen fluctuaciones cuasiperiódicas en las estimaciones del parámetro elástico $\xi_{c}$ sobre los pliegues vocales que se aprecian en forma de patrones cíclicos.

La cuestión crucial ahora mismo es cómo estimar el comportamiento cíclico sobre la tensión observada. Un posible enfoque sería con un filtro AR inverso adaptativo [39].

El proceso de estimación se fundamenta en la definición de un modelo predictor autorregresivo de bajo orden sobre el parámetro elástico $\left(\xi_{\mathrm{cm}}\right)$, dado por:

$$
\xi_{m}=\sum_{i=1}^{K} a_{i} \xi_{m-i}+\varepsilon_{m}
$$

donde $\mathbf{a}=\left\{a_{i}\right\}$ son los coeficientes del modelo. La estimación de estos coeficientes se lleva a cabo gracias a un filtro adaptativo de celosía [39] definido como un operador $\Phi_{k n}$ produciendo un error de salida $\varepsilon_{k}(m)$ minimizado en términos del algoritmo 
Least Mean Square o LMS sobre una ventana de tiempo $W_{k}$, a lo largo del ciclo de fonación $m$. En otras palabras, se utiliza un modelo de predicción lineal el cual ofrece un sistema de $\mathrm{K}$ ecuaciones con $\mathrm{K}$ incógnitas y el método utilizado para resolver dicho sistema es el método de correlación parcial.

$$
\left\{\xi_{K m}, \mathbf{c}_{K m}\right\}=\Phi_{K m}\left\{\xi_{c m}, W_{K}, \beta\right\}
$$

Se utilizarán los coeficientes de pivotamiento $\mathbf{c}_{K m}$ como descriptores de ciclicidad, los cuales se definen a través de la iteración de Levinson-Durbin [45].

$$
\mathbf{a}_{k m}=\mathbf{a}_{k-1 m}-c_{k m} \tilde{\mathbf{a}}_{k-1 m}
$$

donde $\tilde{a}$ es la operación de orden inverso sobre el vector a [39].

A continuación y a modo de ejemplo en la Figura 3.15 se muestran los dos primeros coeficientes cíclicos $c_{1}, c_{2}$ para el corpus 5 . En sendas ilustraciones la población de hombres se enfrenta a las de las mujeres y además se ordena de menor a mayor. Es preferible utilizar los coeficientes de pivotamiento ya que estarán pre-normalizados a $(-1,1)$, lo cual permite de forma más fácil contrastar los resultados. En la ilustración de la izquierda se representa $c_{1}$ y en la de la derecha $c_{2}$.
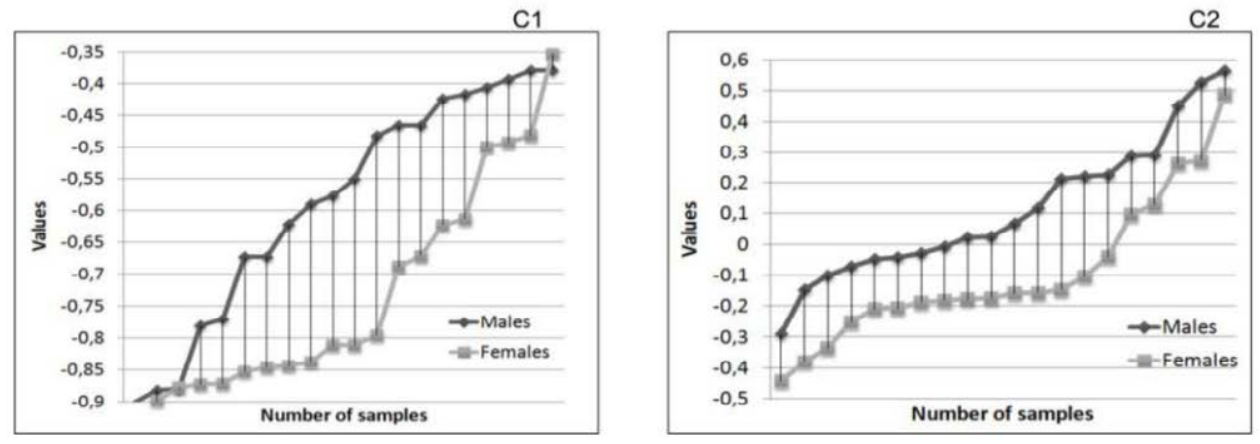

Figura 3.15: Rangos para los parámetros $C_{1}$ y $C_{2}$ para hombres y mujeres.

\subsubsection{Parámetros de temblor}

El temblor puede ser un marcador característico en la detección de estados emocionales y también del estrés, puesto que puede ser una posible respuesta involuntaria.

Anteriormente se ha descrito el proceso de la producción del habla en el capítulo 1. El proceso de ajuste fino de la acción neuromotora de la laringe y los órganos articulatorios (paladar, lengua, mandíbula y máscara orofacial) [107] es muy complejo. Varios bucles de retroalimentación involucran a los córtice prefrontal y frontal, y también al cerebelo y a los ganglios basales [33], [130] y [182]. Se estima que la degradación de las zonas bulbares donde se producen los neurotransmisores dopaminérgicos (substantia nigra pars compacta) es la responsable de un mal funcionamiento del control de retroalimentación, dando como resultado la rigidez o el 
temblor, dependiendo de los retrasos que haya en la retroalimentación.

Es por ello que, en los últimos años un objetivo ha sido estimar el temblor en la fonación de los casos de enfermedad neurodegenerativa. La detección de la modulación de frecuencia en la fonación se ha utilizado para estimar las principales inestabilidades tales como jitter, shimmer, tasa de harmónico ruido, etcétera [113], [127], [119], [120], [167] y [153]. Esta técnica produce estimaciones de las bandas principales encontradas en $f_{0}$ así como de sus respectivas amplitudes. En nuestro caso, en lugar de utilizar $f_{0}$ como señal de referencia, se hará uso de la tensión del pliegue vocal, relacionada con el parámetro, $\xi_{b}$, detectado en el cuerpo de los pliegues vocales como un marcador de actividad neuro-motora. El hecho de preferir el parámetro elástico sobre el tono fundamental para estimar la ciclicidad se basa en dos consideraciones: por un lado $f_{0}$ depende del parámetro elástico, pero también de la masa dinámica del pliegue, y estos parámetros, aun estando correlados, no actúan de igual manera; por otro lado el parámetro elástico está directamente condicionado por la actividad neuromotora. Hay que aclarar que dependiendo del tipo de fonación asociada, los correlatos entre la tensión de la rigidez del cuerpo y la masa dinámica de los pliegues vocales no se van a comportar de igual modo, puesto que esta última $\mu_{b}$ está íntimamente relacionada con el tamaño o proporción del musculus vocalis. Es bien conocido que las capas exteriores de este músculo se mueven más rápido, y consecuentemente participan más en la vibración que las capas más profundas y más cercanas a la unión con el cartílago tiroides. Esta configuración puede sufrir cambios dependiendo del modo de fonación (modal, falsetto, quebrado/creaky, susurrante/whispery) e incluso durante el mismo fragmento de fonación (especialmente si se producen bifurcaciones u otras intermodulaciones fruto de la inestabilidad fonatoria). Por tanto, $f_{0}$ no sería la mejor candidata para estimar el temblor.

La metodología expuesta aquí se basa en la estimación de los parámetros cíclicos que hemos visto en la anterior sección, o dicho de otra forma, en la estimación de la ciclicidad encontrada en los correlatos de tensión neuromuscular $\left(\xi_{b}\right)$ por predicción adaptativa (ver Figura 3.16). 


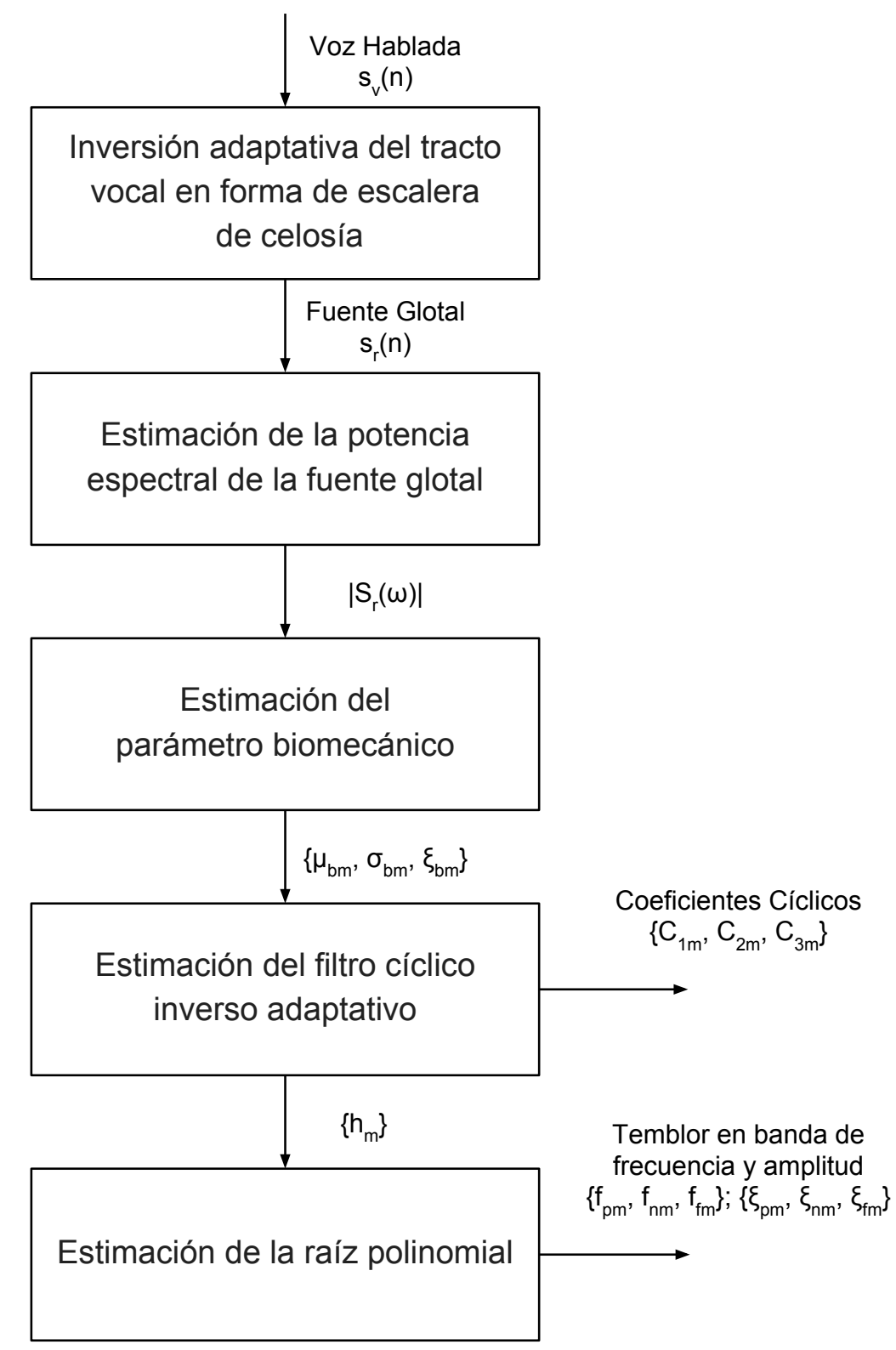

Figura 3.16: Resumen del proceso de estimación del temblor. Las bandas de frecuencia del temblor $f_{p m}, f_{n m}, f_{f m}$ y amplitudes $\xi_{p m}, \xi_{n m}, \xi_{f m}$ son los factores más relevantes

Los coeficientes de pivotamiento $c_{K m}$ se pueden estimar por medio de un filtro de celosía [39] en la siguiente forma:

$$
\begin{gathered}
c_{k m}=\frac{\sum_{m \in W} s_{f k}(m) s_{b k}(m-1)}{\left[\sum_{m \in W} s_{f k}^{2}(m) \sum_{m \in W} s_{b k}^{2}(m-1)\right]^{1 / 2}} \\
s_{f k+1}(m)=s_{f k}(m)+c_{k m} s_{b k}(m-1) \\
s_{b k+1}(m)=c_{k m} s_{f k}(m)+s_{b k}(m-1)
\end{gathered}
$$


donde $s_{f k}(m)$ y $s_{b k}(m)$ son la propagación hacia adelante y hacia detrás de los errores del filtro de celosía, y W es la ventana de observación sobre los ciclos glotales. Los coeficientes de pivotamiento están pre-normalizados entre $(-1,1)$, como se explicó en la sección de parámetros cíclicos. El temblor se puede describir en términos de frecuencia, amplitud y relevancia desde las raíces del modelo inverso de (3.7) en el dominio de z.

$$
H(z)=\frac{1}{1-\sum_{i=1}^{K} a_{i} z^{-i}}=\prod_{i=1}^{K}\left(\frac{z}{z-z_{i}}\right) ; z_{i}=r_{i} e^{j \varphi_{i}}
$$

donde $z=\left\{z_{i}\right\}$ son los polos de la función de transferencia $H(z)$, con el módulo y fase dados por $r_{i}$ y $\varphi_{i}$. La fase de los polos complejos conjugados se relaciona con la banda i-ésima de frecuencia $f_{t i}$ como:

$$
f_{T i}=\frac{\varphi_{i}}{2 \pi} f_{0}
$$

siendo $f_{0}$ la frecuencia fundamental de la fonación. La robustez de la estimación depende del módulo del polo $\left(r_{i}\right)$ como se presentará más adelante. Un parámetro muy relevante relacionado con la importancia del temblor es la amplitud cuadrada media del mismo (rMSA por sus siglas en inglés), la cual se define como:

$$
\eta_{T}=\frac{1}{M_{q}} \frac{\sum_{m=1}^{M_{q}}\left(\xi_{b m}-\bar{\xi}_{b}\right)^{2}}{\bar{\xi}_{b}^{2}}
$$

Otro factor de robustez en las estimaciones es el ancho de banda del temblor. Se puede observar que el ancho de banda de la raíz $z_{i}$ sobre el círculo unidad se puede expresar como:

$$
B W_{3 d B}^{i}=2 \cos ^{-1}\left\{1-\frac{\left(1-r_{i}^{2}\right)}{2 r_{i}}\right\}
$$

Llegados a este punto una pregunta pertinente al presente enfoque puede ser la exactitud de las estimaciones de la raíz $\left\{r_{i}\right\}$ que sirven como marcadores del temblor, en otras palabras, si son suficientemente precisas las estimaciones de los polos dados en (3.13). La precisión ha sido estudiada para el caso de $\mathrm{K}=3$ (orden habitualmente utilizado) en [65], la cual puede ser formulada como sigue:

$$
\begin{aligned}
& z_{2}=r_{2} e^{j \varphi_{2}} ; z_{3}=r_{3} e^{j \varphi_{3}} \\
& r_{2}=r_{3} \in \Re ; r_{2}, r_{3}>0 \\
& 0 \leq \varphi_{2} \leq \pi ; \varphi_{3}=-\varphi_{2}
\end{aligned}
$$

Considerando la verdadera $\zeta$ y la estimada $\hat{\zeta}$ en los vectores de polos y la estimación del error $\varepsilon_{z}$ tenemos:

$$
\begin{aligned}
& \zeta=\left\{z_{2}, z_{3}\right\} ; \hat{\zeta}=\left\{\hat{z}_{2}, \hat{z}_{3}\right\} \\
& \varepsilon_{z}=\hat{\zeta}-\zeta=\left\{\hat{z}_{2}-z_{2} ; \hat{z}_{3}-z_{3}\right\}
\end{aligned}
$$


La estimación relativa del error de una de las raíces se puede definir como la fracción entre el valor absoluto de la estimación del error y el módulo del polo verdadero.

$$
\begin{gathered}
\varepsilon_{r}=\frac{\left\|\varepsilon_{z}\right\|}{\|\zeta\|} \\
\left\|\varepsilon_{z}\right\|=\left[2\left(\hat{r}_{2}^{2}+r_{2}^{2}-2 \hat{r}_{2} r_{2} \cos \left(\hat{\varphi}_{2}-\varphi_{2}\right)\right)\right]^{1 / 2}
\end{gathered}
$$

Este error ha sido calculado para los intervalos $\left(0,5<r_{2}<1\right)$ y $\left(0<\varphi_{2}<\pi\right)$.

Se puede ver que cuanto más cerca está el polo al círculo unidad, el error se hace más pequeño, independientemente de la fase. Esto constituye una garantía de robustez, ya que solo los polos relevantes $\left(r_{i} \longrightarrow 1\right)$ son tenidos en cuenta en este trabajo. 



\section{Capítulo 4}

\section{CLASIFICACIÓN}

En todo problema de reconocimiento de patrones, uno de los pilares angulares es la fase de clasificación. ¿Cómo se puede definir la palabra clasificación? La clasificación parte del supuesto de que existe una colección de objetos o elementos, que poseen rasgos comunes, y que presentan características afines según ciertos grupos o clases. La clasificación no es más que el agrupamiento de dichos elementos según sus características de afinidad, de modo que se asignan a una clase los objetos más afines a los ya existentes en dicha clase que a los existentes en otras clases. En este trabajo se intenta clasificar un conjunto de individuos en dos únicas clases. Estas clases son estrés o ausencia perceptible de estrés, por lo tanto, se trata de un problema de decisión binaria: la detección del estrés. Tal y como se ha visto en el Capítulo 3, ya hemos definido los 72 rasgos que vamos a utilizar para clasificar nuestras muestras.

Pero antes de llegar a poder obtener dicho resultado es importante que el conjunto de pistas o indicios sea reducido, o dicho de otra forma, que con un conjunto mínimo de indicios se garantice la mayor tasa de clasificación posible. Es lo que se conoce como reducción de parámetros.

Cabe destacar que no siempre el conjunto de datos posee una forma estándar o deseada, es decir, la mayoría de las métricas utilizadas en la literatura se basan en la idea preconcebida de que la población sigue una tendencia normal, o dicho de otra forma, conocemos a priori la media y la desviación típica de la muestra. A estos modelos se los conoce como estadísticas paramétricas. En ocasiones esto no ocurre y por tanto no es conveniente utilizar este tipo de modelos. En su lugar se hace uso de frecuencias o número de repeticiones dentro de la población, se comprueban posibles tendencias en los datos y se buscan patrones de comportamiento a partir del numero de repeticiones en ciertos rangos o intervalos creados para tal efecto. A estos modelos se los conoce como no paramétricos.

Este capítulo tendrá la siguiente estructura: en la primera sección, se presentará un breve resumen de las técnicas más utilizadas en la literatura para clasificar emociones y estrés. En la siguiente sección se explicarán los métodos paramétricos utilizados en este trabajo. En la Sección 4.3 se detallarán los métodos no paramétricos llevados a cabo en este estudio. A continuación, se mostrarán los métodos 
relacionados con la reducción de parámetros o dimensionalidad. Finalmente, en la última sección se detallarán los algoritmos de clasificación utilizados para obtener las diferentes tasas de clasificación.

\subsection{Algoritmos más usados}

A lo largo de la literatura podemos encontrar de manera recurrente una serie de algoritmos de clasificación utilizados para el reconocimiento de emociones y de estrés. Tal y como se explica en [10], los más comunmente usados son las cadenas ocultas de Markov (HMM), las máquinas de vectores de soporte (SVM), las redes neuronales artificiales (ANN), y los modelos mixtos Gaussianos (GMM).

HMM es el algoritmo de clasificación de emociones más utilizado o extendido en la literatura. Tal vez, el motivo radique en que HMM es ampliamente utilizado en aplicaciones del habla. Sin embargo, la comunidad científica no acepta un algoritmo universal para la clasificación o detección de emociones. Es obvio pensar que, cada técnica tiene sus virtudes y sus desventajas y por consiguiente dependiendo del problema planteado, el uso del algoritmo es crucial para obtener buenos resultados. Por ejemplo, en este trabajo se ha utilizado SVM por una razón obvia y es que este tipo de algoritmo de clasificación es especialmente eficiente en cuanto a clasificación dicotómica se refiere. Dado que vamos a clasificar estrés o ausencia de estrés, este algoritmo es en nuestra opinión el más indicado.

Se presentan a continuación algunos ejemplos de detección emocional o estrés a título ilustrativo. En [70], la detección automática de estrés en la voz se estudia utilizando TEO (Teager Energy Operator) como característica de extracción y modelos ocultos de Markov como algoritmo de clasificación. Las cadenas ocultas de Markov se basan en un proceso doblemente estocástico, donde se asume que sus estados son desconocidos, los cuales siguen un proceso de Markov. Asociado a cada estado se genera un proceso aleatorio el cual crea una secuencia de observación temporal de símbolos [147]. En [70] se consiguió una tasa de error del $13.1 \%$ y de un $4 \%$ en el estado neutro en el mejor de los casos. Pero como es muy común en el estudio del estrés, el corpus utilizado era muy limitado, contando tan solo con seis muestras de locutores, por lo tanto no recaba suficiente validez estadística por el número de sujetos utilizados. La forma de suscitar estrés en los locutores fue capturando las respuestas que ofrecían los mismos frente a un jurado que evaluaba sus capacidades profesionales.

Lu et al. [106] propusieron una aplicación adaptativa para detectar estrés en tiempo real usando Smartphones con sistema operativo Android. Los parámetros fueron clasificados respecto a si el entorno había sido interior o exterior y el método de clasificación utilizado se basó en modelos mixtos de gausianas (GMMs). Un modelo de mezclas gausiano es una función de densidad de probabilidad paramétrica representada como la mezcla de densidades de distribuciones gaussianas [150], o dicho de otra forma, es un modelo probabilístico para la estimación de densidad usando una combinación convexa de densidades normales multivaribales [194]. GMMs se suele 
utilizar como modelo paramétrico de la distribución de probabilidad de medidas o características continuas. La colección de datos de Lu et al. constaba de 14 muestras en total, 10 mujeres y 4 hombres, todos ellos eran estudiantes universitarios. La metodología utilizada para suscitar estrés en los estudiantes consistió en evaluar a los locutores durante el desarrollo de tareas de marketing para la obtención de un puesto de trabajo. La tasa de acierto en el mejor de los casos no superaba el $81 \%$ para entornos interiores y un $76 \%$ en los exteriores.

Otro conocido clasificador son las redes neuronales artificiales, las cuales son ampliamente utilizadas para reconocimiento de patrones. Existen varios tipos conocidos: redes perceptrón multicapa (MLP), redes con funciones de base radial (RBF), redes neuronales recurrentes (RNN), etc... Las primeras son las más utilizadas para la detección de emociones. Las redes neuronales poseen un mejor rendimiento que GMM y HMM cuando el número de muestras de entrenamiento es relativamente pequeño [20]. Tal y como recopila Hasrul en su trabajo [73], Nicholson utiliza características prosódicas como la intensidad y el tono fundamental, además de características fonéticas, tales como 12 parámetros LPC y parámetros delta LPC [132]. La tasa máxima de clasificación no superaba el $50 \%$ para las emociones de alegría, miedo, tristeza, disgusto, enfado, sorpresa y neutro. Yamada [203] implementa un modelo de emoción para la comunicación de datos sobre la personalidad del individuo. El modelo adecua las conversaciones entre los usuarios por aprendizaje automático. La tasa de reconocimiento cuando se le presentaban datos usados en el entrenamiento era del $100 \%$, y descendía al $70 \%$ para datos desconocidos. Por otro lado, Petrushin [140] ha desarrollado un reconocedor automático de emociones con una tasa de acierto máxima de $77 \%$ para dos únicos estados, agitación y calma.

Respecto a SVM, el cual se explicará con mayor profundidad en la Sección 4.5.1 se puede comentar que es un claro ejemplo de clasificador discriminante de ámbito general [44]. SVM se basa en ciertas funciones de tipo no lineal (kernels), las cuales mapean las características originales sobre un nuevo espacio multidimensional donde los datos pueden ser clasificados utilizando funciones lineales. La forma de separar y/o clasificar los datos es con la creación de hiperplanos. Las tasas de reconocimiento alcanzadas según el trabajo del que se trate [73] son diversas y distintas. El rango va desde $41 \%$ hasta el $90 \%$ en [71], [95] y [108].

\subsection{Algunos recursos paramétricos}

El análisis paramétrico se basa en la suposición de que las poblaciones a estudio son normales. Sus varianzas deben ser homogéneas cuando se estudian dos poblaciones, o dicho de otra forma, las distribuciones o poblaciones deben mostrar distribuciones similares (homocedasticidad). A continuación se recordarán algunos conceptos para centrar las ideas.

\section{Teorema del Limite Central}

Uno de los pilares fundamentales de los que se sustenta la estadística paramétrica 
es el teorema del límite central, en adelante TLC, el cual postula que teniendo una población muestral suficientemente amplia, es decir, un número de muestras mayor a 30 se puede asegurar que dicha población sigue una tendencia normal aunque en inicio no lo sea. Cuanto mayor sea el número de muestras con mayor fuerza se puede asegurar dicha aseveración.

\section{Coeficiente de Correlación de Pearson}

El coeficiente de correlación indica la fuerza y la dirección de una relación lineal entre dos variables [22]. Existen muchas medidas de correlación. Una muy utilizada es el coeficiente de correlación de Pearson.

El rango de valores posibles del coeficiente de correlación es $(-1,1)$. Cualquier valor cercano a -1 y 1 indican una gran relación o fuerza entre ambas variables, mientras que un valor cercano a 0 , indica poca o ninguna relación entre ambas variables.

El signo indica la dirección, o dicho de otra manera, si la relación es directa o indirectamente proporcional entre variables. Si el valor del coeficiente es creciente o cercano a 1, ambas variables aumentan; mientras que si el valor del coeficiente es decreciente o cercano a -1 , cuando una de las variables aumenta, la otra disminuye.

La formula para el cálculo del coeficiente de correlación de Pearson que vamos a usar para nuestro conjunto femenino (f) es la siguiente:

$$
\rho_{f}=\frac{1}{n-1} \sum\left(\frac{\left(x_{a f}-\mu_{a f}\right)\left(y_{d f}-\mu_{d f}\right)}{\sigma_{x_{a f}} \sigma_{y_{d f}}}\right)
$$

donde $n$ es el número de pares de datos, " $a$ " indica acuerdo y " $d$ " desacuerdo, $\mu_{a}$ e $\mu_{d}$ son las medias de la población muestral y $\sigma_{a x}$ y $\sigma_{d y}$ son las desviaciones estándar de los valores x e y, respectivamente [158]. De forma análoga se extrapolaría para el conjunto de datos de los hombres $(\mathrm{m})$.

$$
\rho_{m}=\frac{1}{n-1} \sum\left(\frac{\left(x_{a m}-\mu_{a m}\right)\left(y_{d m}-\mu_{d m}\right)}{\sigma_{x_{a m}} \sigma_{y_{d m}}}\right)
$$

Es importante recordar que el coeficiente de correlación de Pearson es una medida adimensional, es decir, si se cambian las unidades de las variables que se están comparando el resultado sigue siendo el mismo y con la misma proporción. Además, la correlación es inmutable aun cuando se varíe el orden entre las variables a estudio, el resultado de la correlación no se verá afectado.

\section{Coeficiente de Determinación}

El coeficiente de determinación cuantifica cómo de dependiente es una variable al modificar otra variable. Se define como $\rho^{2}$, es decir, es el coeficiente de correlación de Pearson al cuadrado. Este coeficiente ayuda a entender y/o explicar la relación entre las variables. Por ejemplo, si nuestro coeficiente de correlación es 0.9, el coeficiente 
de determinación será igual al $81 \%$, es bien sabido que la correlación no establece relación causa-efecto; únicamente nos dice que $x$ e $y$ varían en una cierta proporción común.

\section{Regresión Lineal}

La regresión lineal se basa en la predicción de una variable dependiente $Y$ a partir de una variable independiente $X$. La fórmula simple que define esta ecuación se denota como $y=m x+b$, donde $m$ es considerada la pendiente o el coeficiente de variación de la variable independiente $x$. Mientras que $b$ es la intersección con el eje $\boldsymbol{y}$, también conocida como variación en el origen [22].

Generalizando la anterior ecuación expresada por una recta, se presenta un modelo lineal que relaciona la variable dependiente $\mathrm{Y}$ con $\mathrm{J}$ variables explícitas (en nuestro caso serían los 72 parámetros extraídos), donde $X_{j}(j=1, \ldots J)$, o cualquier modificación de éstas que construyen un hiperplano de parámetros $\beta_{j}$ desconocidos:

$$
Y=\sum \beta_{j} X_{j}+\varepsilon
$$

donde $\varepsilon$ es el error debido a factores no controlables o dicho de otra manera, el posible azar del proceso, lo cual le otorga al modelo carácter estocástico.

\section{Prueba t-Student}

La prueba t-Student se utiliza para comparar la distribución de una población muestral con una población conocida. La hipótesis nula, $H_{0}$, asume que no existe diferencia entre la distribución de la población de la que se extrajo la muestra y la de la población conocida [22]. Dicho de otra manera, esta prueba evalúa si dos poblaciones varían entre sí de manera importante respecto a sus distribuciones de sus poblaciones.

Esta prueba se utiliza para realizar un contraste de una hipótesis para una media poblacional que cumpla las siguientes características [159]:

1. La población debe ser pequeña. Se entiende por población pequeña aquella que no supere las 30 muestras.

2. La desviación estándar de la distribución teórica, denotada por $\sigma$, se desconoce, y por consiguiente hay que calcularla a partir de la desviación estándar de la muestra.

Las expresiones de dichos tests para los conjuntos muestrales masculino (m) y femenino (f) serían las siguientes:

$$
t_{m}=\frac{\bar{x}_{m}-\mu_{0}}{\frac{\sigma_{m}}{\sqrt{n}}} ; t_{f}=\frac{\bar{x}_{f}-\mu_{0}}{\frac{\sigma_{f}}{\sqrt{n}}}
$$


donde $\bar{x}_{m}$ ó $\bar{x}_{f}$ es la media de la muestra, $\mu_{0}$ es la media de referencia, $\sigma_{m}$ ó $\sigma_{f}$ es la desviación estándar de la muestra y $n$ es el tamaño de la población.

Cabe destacar que existen otras pruebas basadas en distribuciones paramétricas como la normal o la chi cuadrada, que no se comentan por no ser de utilidad en el presente estudio.

\subsection{Estadística No Paramétrica}

Los modelos no parámetricos son procedimientos descriptivos que no presuponen una forma determinada para la función de distribución, es decir, no requieren que la distribución sea expresable como una función conocida. Las variables no tienen por qué seguir un modelo dado y pueden analizarse datos numéricos o categóricos. Es común referirse a ellas como pruebas de distribución libre. Si se quiere trabajar con estas en forma de agrupaciones o intervalos es necesario hacer un pre-procesamiento para asignar los datos a categorías discretas. Por consiguiente estas métricas, técnicas o modelos son aplicables a cualquier variable.

Tal y como se explica en [16], las pruebas no paramétricas reúnen las siguientes características:

1. Son más fáciles de utilizar.

2. Son aplicables a datos jerarquizados.

3. Se pueden usar cuando dos series de observaciones provienen de distintas poblaciones.

4. Son la única alternativa cuando el tamaño de muestra es pequeño (menor de 30 muestras).

5. Son útiles dentro de un intervalo de significancia previamente especificado.

Es importante destacar que existen técnicas de estadística no paramétrica equivalentes a técnicas de estadística parámetrica. Por ejemplo, la t-Student anteriormente citada, puede ser sustituida por la prueba de Wilcoxon, cuando la población muestral tan solo tiene dos conjuntos de observaciones o dicho en otras palabras dos poblaciones muestrales. Por otro lado, si el número de poblaciones muestrales es superior a dos, se suele utilizar la prueba $U$ de Mann-Whitney.

\subsubsection{Prueba de Kolmogorov-Smirnov}

Existen dos métodos para esta prueba. Se puede utilizar para una sola muestra; o por el contrario con dos muestras independientes [16]. En el caso que nos ocupa, utilizaremos esta prueba para comprobar si dos muestras pertenecen a la misma población, es decir, la prueba de K-S para dos muestras. 
El método para dos muestras independientes busca contrastar en su hipótesis si dos distribuciones siguen o no el mismo patrón, o dicho de otro modo, proceden de la misma población. Para ello, calcula la máxima diferencia absoluta entre las funciones de distribución acumuladas observadas para ambas muestras. Suele denotarse a este estadístico como Z.

Partiendo del conjunto de datos masculino, $m$, donde el conjunto de muestras de la población perteneciente al estado de congruencia, estado neutro o acuerdo, $a$, denotado como $X_{a}$ y el conjunto de muestras para la población relacionada con el estado de estrés, incongruencia o desacuerdo, $d$, denotado como $X_{d}$ se calculan las funciones de distribución para ambas poblaciones muestrales, como $F_{a m}\left(X_{j}\right)$ y $F_{d m}\left(X_{j}\right)$, siendo $J$ el conjunto de 72 parámetros y $j$ cada uno de ellos.

Para obtener las funciones de distribución para cada grupo, ordenamos de menor a mayor los valores de cada población muestral por separado y lo dividimos por el número total de muestras de cada población. Para ello, se realiza una asignación de rangos por población, en caso de empates se realizará el promedio de los rangos de las observaciones. Una vez establecidos los rangos de ambas muestras, la función de distribución para estas se obtiene como: $F_{a j m}\left(X_{s}\right)=s / n_{\text {ajm }}$ y $F_{d j m}\left(X_{s}\right)=s / n_{d j m}$, donde $s$ es cada una de las observaciones del vector de la población muestral y $n$ el número total de observaciones por cada conjunto muestral. Normalmente en la literatura, una de las muestras se considera la teórica y otra de ellas la empírica. En nuestro caso, diremos que $X_{a m}$ es la muestra teórica y $X_{d m}$ será la muestra empírica.

Seguidamente se calcula la diferencia entre ambas muestras quedando definida de la siguiente forma: $\left|D_{j s m}\right|=\left|F_{a j m}\left(X_{s}\right)-F_{d j m}\left(X_{s}\right)\right|$. Una vez obtenidas las diferencias, la hipótesis se contrasta a partir de la diferencia más grande en valor absoluto, como se puede ver en la siguiente ecuación [168], [169]:

$$
Z_{m j}=\max _{j}\left|D_{j}\right| \sqrt{\frac{n_{a j m} n_{d j m}}{n_{a j m}+n_{d j m}}}
$$

Esta prueba al contrario que la de Mann-Whitney-Wilcoxon es sensible a cualquier característica diferenciadora entre las muestras, tales como simetría, variabilidad o tendencia central, entre otras posibilidades. Para el conjunto de datos femenino, las relaciones serían similares a las anteriores, salvo que vendrían identificadas por el subíndice $f$.

\subsubsection{Prueba de Mann-Whitney-Wilcoxon}

Esta técnica no paramétrica fue enunciada en 1945 por Frank Wilcoxon para poblaciones muestrales de igual tamaño o lo que es lo mismo $n_{a f}=n_{d f}$ ó $n_{a m}=n_{d m}$ [199]. Sin embargo, fue en 1947 cuando Henry B. Mann y Donald R. Whitney generalizaron el método para muestras con diferentes tamaños [112]. Es por ello que, este método se puede encontrar descrito de muchas formas diferentes en cuanto a autoría se refiere. 
Partiendo del conjunto de datos femenino, $f$, donde la población perteneciente al estado de congruencia (estado neutro, o acuerdo, " $a$ "), denotado como $X_{a f}$, con un tamaño $n_{a f}$ y el conjunto de muestras para la población relacionada con el estado de estrés o incongruencia (desacuerdo, " $d$ "), denotado como $X_{d f}$, donde el cardinal de las muestras se describe como $n_{d f}$. Además, cada parámetro se denota por la letra, $j$. Por lo tanto, cada subconjunto quedaría de la siguiente forma $X_{a j f}$ y $X_{d j f}$, respectivamente. Realizamos la suma de ambas poblaciones muestrales, quedando $n_{j f}=n_{a j f}+n_{d j f}$ observaciones y considerando ambas poblaciones como una sola, generando una serie de rangos $R_{j f}$ para las $n_{j f}$ observaciones, donde se le asigna el valor 1 a la más pequeña, 2 a la siguiente, 3 a la siguiente y así sucesivamente hasta la más grande que se le otorga un valor $n$. Si existiera algún empate, éste se resuelve realizando el promedio de ambas muestras. Por consiguiente, tendremos $R_{a j f}$ para los $n_{a f}$ rangos correspondientes a las observaciones de la población muestral $X_{a f}, \mathrm{y}$ $R_{d j f}$ para los $n_{d f}$ rangos correspondientes a las observaciones de la población muestral $X_{d f}$.

Calculamos la suma de los rangos asignados a la población muestral, $X_{a f}$, y hacemos exactamente la misma operación con los rangos asignados a la otra población muestral, $X_{d f}$. Ambas sumas se definirán como $W_{a f}$ y $W_{d f}$, respectivamente. El estadístico de Mann-Whitney quedará de la siguiente forma para cada una de las poblaciones muestrales para cada parámetro $j$ :

$$
\begin{aligned}
& U_{a j f}=n_{a j f} n_{d j f}+\frac{n_{a j f}\left(n_{a j f}+1\right)}{2}-W_{a j f} \\
& U_{d j f}=n_{a j f} n_{d j f}+\frac{n_{d j f}\left(n_{d j f}+1\right)}{2}-W_{d j f}
\end{aligned}
$$

Esta técnica permite contrastar la hipótesis de igualdad entre dos medianas poblacionales donde los conjuntos de datos $X_{a f}$ y $X_{d f}$ son independientes. La hipótesis inicial se basa en que ambas poblaciones son aproximadamente iguales si $U_{a j f} \mathrm{y}$ $U_{d j f}$ lo son. Si $U_{a j f}$ y $U_{d j f}$ son muy diferentes, se puede concluir que proceden de poblaciones distintas. Por consiguiente, la hipótesis nula de que ambos promedios poblaciones son iguales podría rechazarse si $U_{a j f}$ o $U_{d j f}$ son demasiado grandes o pequeños.

Las fórmulas para el conjunto de datos masculino, serían las mismas, cambiando el subíndice $f$ por $m$. En [51] se ponen de manifiesto algunas de las reglas de decisión para escoger el método parámetrico (t-Student) o el no parámetrico ( $U$ Mann-Whitney).

\subsubsection{Distancia de Kullback-Leibler}

La entropía relativa (o también conocida como la divergencia de Kullback-Leibler [94]), en adelante $D K L$, es una medida no-simétrica de la diferencia entre dos distribuciones de probabilidad $\Omega_{1}$ y $\Omega_{2}$. 
La entropía relativa para una variable aleatoria, $j$, discreta se define como:

$$
D K L\left(\Omega_{1} \| \Omega_{2}\right)=\sum_{j} \Omega_{1}(j) \log \frac{\Omega_{1}(j)}{\Omega_{2}(j)}
$$

\subsection{Reducción de Parámetros}

Existen multitud de técnicas para reducir la dimensionalidad de un conjunto de datos determinado, tales como análisis de componentes principales, análisis de componentes independientes, análisis de correspondencias, análisis discriminante lineal, análisis factorial, análisis multidimensional, análisis de regresión y análisis de varianza, entre otros. Sin embargo, en este trabajo, tan solo se describen aquellos que se han utilizado.

\subsubsection{Principal component analysis (PCA)}

La técnica de análisis de componentes principales es una de las más utilizadas en lo que a reducción de dimensionalidad se refiere. Según [21] existen dos definiciones aceptadas. La primera ofrecida por Karl Pearson en 1901, la cual define PCA como la proyección lineal que minimiza el coste de proyección media, definida como la distancia al cuadrado media entre los puntos de datos y sus proyecciones [138]. La segunda definición la enunció Hotelling en 1993 y es equivalente a la anterior definición, es decir, PCA es la proyección ortogonal sobre un espacio lineal con menor número de dimensiones, conocido como, subespacio principal, tal que la varianza de los datos proyectados sea máxima [79].

Partiendo de la segunda definición de PCA, varianza máxima y aplicado a nuestros datos a partir de la explicación del algoritmo recogido por Bishop en [21] presentamos la siguiente definición para PCA basado en los datos específicos del corpus 2:

Teniendo unos conjuntos de datos definidos como $X_{m}$ y $X_{f}$ para los grupos masculino y femenino respectivamente, donde $m$ y $f$ son el número de sujetos por cada conjunto de datos, donde cada $x_{m}$ y $x_{f}$ corresponde a un vector fila que posee $J$ parámetros o dicho de otra forma posee $J$ dimensiones. La idea fundamental de este algoritmo es obtener un subespacio donde el número de dimensiones o parámetros, $Z$, sea menor, $Z<J$. Las componentes principales no presentan correlación alguna y se obtienen en orden decreciente de relevancia. Por consiguiente, la primera componente principal es aquella que conserva la mayor cantidad de información significativa de los datos, la segunda componente principal recoge el resto de la información más relevante y así sucesivamente.

Esta técnica busca la combinación lineal de las variables que maximiza la varianza entre ellas. En un primer paso se definirá la proyección sobre un espacio unidimensional o lo que es lo mismo $J=1$. A continuación asignaremos $v_{1}$, el cual 
será un vector unitario, por lo que $v_{1}^{T} v_{1}=1$ (sin perdida de generalidad). Es importante recalcar que lo que se busca con este método es la dirección de este vector y no tanto su magnitud. Ahora cada $x_{m}$ o $x_{f}$ se proyectan sobre un valor del escalar $v_{1}^{T} x_{m}$ o $v_{1}^{T} x_{f}$, o en otras palabras, la combinación lineal del vector unitario sobre cada variable de la matriz de origen. La media de los datos proyectados se denota como $v_{1}^{T} \bar{x}_{m}$ o $v_{1}^{T} \bar{x}_{f}$, esta media $(\bar{x})$, se calcula como la suma de todos los valores de la matriz original dividido entre el número total de individuos. En adelante y para abreviar se utilizará solo el conjunto de datos femenino, aunque como en el resto de casos es directamente trasladable al conjunto de datos masculino.

En este punto se calculará la varianza proyectada según la expresión.

$$
v_{1}^{T} S v_{1}=\frac{1}{N_{f}} \sum_{n_{f}=1}^{N_{f}}\left\{v_{1}^{T} x_{f}-v_{1}^{T} \bar{x}_{f}\right\}^{2}
$$

donde $S$ es la matriz de covarianza, la cual se define como puede verse a continuación.

$$
S=\frac{1}{N_{f}} \sum_{n_{f}=1}^{N_{f}}\left(x_{f}-\bar{x}\right)\left(x_{f}-\bar{x}\right)^{T}
$$

Seguidamente debemos maximizar la varianza proyectada, $v_{1}^{T} S v_{1}$, respecto del vector de coeficientes $v_{1}$. Es necesario acotar la solución y como tenemos infinitos vectores de dirección, generamos una restricción de normalización, la cual se denota como $v_{1}^{T} v_{1}=1$ o dicho de otra forma que tenga norma 1 . Para ello será necesario utilizar un multiplicador de Lagrange, el cual lo definiremos como $\lambda_{1}$. Por consiguiente la varianza proyectada queda de la siguiente forma:

$$
v_{1}^{T} S v_{1}+\lambda_{1}\left(1-v_{1}^{T} v_{1}\right)
$$

Realizando la derivada parcial a la anterior ecuación respecto a $v_{1}$ e igualada a cero, tendrá un punto estacionario cuando $S v_{1}=\lambda_{1} v_{1}$, donde $\lambda$ es un valor propio de la matriz de covarianzas y $v$ el vector propio asociado. Además, si multiplicamos a la izquierda por $v_{1}^{T}$ y hacemos uso de la condición inicial $v_{1}^{T} v_{1}=1$ la varianza se ve reducida a:

$$
v_{1}^{T} S v_{1}=\lambda_{1}
$$

y por consiguiente se puede concluir que la varianza será máxima siempre y cuando asignemos al vector $v_{1}$ el autovector con el autovalor $\lambda_{1}$ más grande. Finalmente, este vector propio se le conoce con el nombre de primera componente principal.

Esta descripción para un espacio unidimensional se puede extrapolar a $J$ componentes principales escogiendo nuevos vectores dirección, los cuales deben de hacer máxima la varianza proyectada entre todas las posibles direcciones ortogonales que hayan sido consideradas. Si se considera el caso general del espacio de proyección J-dimensional, la proyección lineal óptima para la varianza de los datos proyectados será máxima si se define un autovector con los j-ésimas dimensiones o parámetros del tipo $v_{1}, \ldots, v_{j}$ de la matriz de covarianza $S$ correspondiente a los autovalores más 
grandes $\lambda_{1}, \ldots, \lambda_{j}$.

Dejando a un lado la explicación matemática del método, se puede explicar la reducción de parámetros PCA como el proceso iterativo que evaluá con cada uno de los parámetros del conjunto dado $(\mathrm{J}=72)$, si el residual calculado a partir de la varianza acumulada es menor que un umbral dado. Si la condición anterior se cumple, la iteración se detiene, en caso contrario se pasa al siguiente parámetro y se vuelve a ejecutar el proceso. PCA y otros métodos derivados de esta técnica han sido ampliamente utilizados en trabajos de clasificación tales como [105], [104] y [170].

\subsubsection{Independent component analysis (ICA)}

La diferencia fundamental entre PCA e ICA es que la primera busca correlación entre sus variables o lo que es lo mismo la máxima varianza, mientras que la segunda busca máxima independencia estadística. PCA intenta reconstruir un subespacio más pequeño que el inicial pero con el mayor contenido de significado. Sin embargo, la técnica ICA, tan solo busca la máxima independencia en su nuevo subespacio vectorial o dicho de otra forma, intenta encontrar la combinación lineal del conjunto de características inicial en un nuevo subespacio de características, donde estas sean mutuamente independientes (que su información mutua sea nula). Esta técnica se ha utilizado en multitud de áreas y trabajos, como por ejemplo [3], [85], [86], [114] y [177].

Siendo un poco más estrictos, tal y como se define en [81], [82] y [84], ICA se basa en un modelo estadístico de "variables latentes". El concepto latente hace referencia a que existen variables (que serán las componentes independientes (ICs)) que no han sido directamente observadas o estimadas, o dicho de otra forma, que son desconocidas a priori. Por consiguiente, teniendo $n$ variables aleatorias observadas $x_{1}, x_{2}, \ldots, x_{n}$, las cuales pueden ser modeladas como combinación lineal de $n$ variables aleatorias $s_{1}, s_{2}, \ldots, s_{n}$, el modelo queda definido por la siguiente ecuación:

$$
x_{i}=a_{i 1} s_{1}+a_{i 2} s_{2}+\ldots+a_{i n} s_{n}, \text { para todo } i=1, \ldots, n
$$

donde $a_{i j}, i, j=1, \ldots, n$ son los coeficientes de la mezcla y $s_{i}$ son lo que se conocen como componentes independientes. Hay que tener en cuenta que, por definición, las variables aleatorias $s_{i}$ son mutuamente independientes estadísticamente hablando.

Siguiendo la definición estricta anterior se puede decir que, a partir de una matriz de muestras de observación $x_{i}$ (en nuestro caso será $x_{f}$ y $x_{m}$ para el conjunto de hombres y mujeres) debemos de ser capaces de estimar una serie de coeficientes denotados por $a_{i j}$ y de obtener componentes independientes $s_{i}$. Para llegar a esta combinación lineal es necesario cumplir una serie de restricciones.

1. Las ICs se consideran estadísticamente independientes. Dicho en otras palabras que la información mutua entre cada una de las componentes es igual a cero.

2. Las componentes independientes deben de tener distribuciones no gaussianas. 
3. Por simplicidad, se asume que la matriz de mezcla es cuadrada, es decir, que se deben estimar tantas componentes independientes como variables observadas.

ICA es una técnica que está íntimamente relacionada con el método conocido como "separación ciega de fuentes". Normalmente, la ecuación 4.12 suele presentarse en forma matricial por comodidad, quedando:

$$
x=A s
$$

donde $x$ hace referencia al conjunto de datos femeninos o al conjunto de datos masculinos $x_{f}$ o $x_{m}$, respectivamente, los cuales son los vectores de muestras observadas, A es la matriz de coeficientes de mezclado $a_{i j}$, los cuales toman un conjunto de valores que garanticen que la matriz A sea invertible y $s_{i}$ es el vector aleatorio de variables ocultas o componentes independientes. Por consiguiente, se puede asumir que existe una matriz $W$ con coeficientes $w_{i j}$ que nos permite obtener las componentes independientes denotados como $s_{i}$, quedando:

$$
s_{i}=w_{i 1} x_{1}+s_{i 2} w_{2}+\ldots+s_{i n} w_{n}, \text { para todo } i=1, \ldots, n
$$

o en forma matricial:

$$
s=W x
$$

Existe una implementación de este algoritmo llamado FastICA, el cual ofrece resultados más rápidamente que otros métodos, como se puede ver en [59]. Esta modificación se cimienta en algoritmos adaptativos basados en descenso por gradiente. La convergencia es normalmente baja, y depende de la elección de los parámetros. Algunos trabajos que utilizan esta técnica se pueden encontrar en [80] y [83].

\subsubsection{Partial Least Squares (PLS)}

Tal y como se define en [155], la idea que subyace en todos los métodos PLS es que el conjunto de datos observados se ha obtenido a partir de un conjunto de variables desconocidas o que no hayan sido observadas directamente, las cuales reciben el nombre de variables latentes. El algoritmo PLS por el cual las estructuras latentes proyectadas dan como resultado los datos observados fue desarrollado por Herman Wold [201]. En términos generales, PLS genera vectores ortogonales de puntuación (vectores latentes) gracias a la maximización de la covarianza entre diferentes conjuntos de variables. PLS se basa en dos matrices, una de predicción y otra de respuestas. Existen varios métodos conocidos para PLS, todos ellos dependen del número de variables de respuesta que utilicen, es decir, PLS1 significa que tiene una variable de respuesta, mientras que PLS2, tiene dos. Los métodos PLS se puede utilizar de forma similar a como se procede con PCA, es decir, como herramienta para la reducción de dimensiones, aunque también tiene múltiples usos en diversas áreas, tales como quimiometría (área de Herman Wold), psicología, bioinformática, medicina, etcétera. Además, existen trabajos que han utilizado la combinación PLS y SVM [156]. Por consiguiente, este método es una posible alternativa a la utilización de PCA. 
Considerando que PLS es un modelo que relaciona dos conjuntos de datos, donde $X_{m}$ o $X_{f} \subset \Re^{J}$ un espacio $j$-dimensional de variables que representan el primer bloque, también llamado de predictores y de forma similar $Y_{m}$ o $Y_{f} \subset \Re^{Z}$ un espacio que representa el segundo bloque de vectores o respuestas, donde la función que realiza PLS es modelar las relaciones entre estos dos conjuntos de datos mediante unos vectores latentes. Habiendo observado $n$ individuos de cada conjunto de datos, PLS genera una matriz de desviación o lo que es lo mismo una matriz con media igual a cero de tipo $(n \times J)$ para la matriz X, análogamente para la matriz Y de la forma $(n \times Z)$, quedando la siguiente combinación lineal:

$$
\begin{aligned}
& \mathbf{X}=\mathbf{T P}^{T}+\mathbf{E} \\
& \mathbf{Y}=\mathbf{U Q}^{T}+\mathbf{F}
\end{aligned}
$$

donde $\mathrm{T}$ y $\mathrm{U}$ son las matrices de proyección de $\mathbf{X}$ e $\mathbf{Y}$, respectivamente. Estas son de la forma $(n \times p)$ donde $p$ son los vectores latentes extraídos. $\mathbf{P}(J \times p)$ y $\mathbf{Q}(Z \times p)$ representan las matrices de carga ortogonal y $\mathbf{E}$ y $\mathbf{F}(n \times J)$ son las matrices de residuos o de error. La finalidad de la descomposición de $\mathbf{X}$ e $\mathbf{Y}$ es obtener la máxima covarianza de $\mathbf{T}$ y $\mathbf{U}$. El método clásico PLS se basa en el algoritmo nonlinear partial least squares (NIPALS) [200], el cual estima unos vectores de pesos $w, c$ tales que:

$$
\left[\operatorname{cov}(t, u)^{2}\right]=[\operatorname{cov}(X w, Y c)]^{2}=\max _{|r|=|s|=1}[\operatorname{cov}(X r, Y s)]^{2}
$$

donde $\operatorname{cov}(t, u)=t^{T} u / n$ denota la muestra de la covarianza entre el vector latente t y u. A continuación se presenta el flujo del algoritmo NIPALS, el cual comienza con la inicialización aleatoria del vector latente $\mathbf{u}$ perteneciente al espacio $Y$. El algoritmo no para de ejecutar hasta que finalmente converge:

1. $w=X^{T} u /\left(u^{T} u\right)$

2. $\|w\| \longrightarrow 1$

3. $t=X w$

4. $c=Y^{T} /\left(t^{T} t\right)$

5. $\|c\| \longrightarrow 1$

6. $u=Y c$

Obsérvese que $u=y$ si $Z=1$, es decir, $\mathbf{Y}$ es un vector unidimensional que se denota como y. En este supuesto NIPALS convergería en la primera iteración.

\subsection{Algoritmos de Clasificación}

Como ya se comentó al inicio de este capítulo, existen muchos algoritmos de clasificación, por ejemplo, los modelos de mezclas gausianas (GMM), las redes neuronales artificiales (ANN), o las máquinas de vector de soporte (SVM), entre otros. Sin embargo, tan solo se describen en este apartado aquellos algoritmos que se han 
escogido para clasificar el conjunto de datos. SVM, es idóneo para clasificar conjuntos dicotómicos de datos. Por otro lado, el ratio de máxima verosimilitud logarítmica es la opción acertada cuando se quiere validar el comportamiento de un individuo sobre una población muestral.

\subsubsection{Support Vector Machine (SVM)}

El objetivo fundamental de las máquinas de vectores de soporte o SVM es definir un hiperplano que clasifique todos los vectores de datos en 2 clases, en nuestro caso particular, estrés y carencia de estrés [23] y [198]. Siendo más formales se podría decir que SVM construye una función del tipo $f: \Re^{n} \longrightarrow \pm 1$ a partir de un conjunto de datos $X_{a f}, X_{d f}, X_{a m}, X_{d m}$, siendo $a$ acuerdo o estado neutro, $d$ desacuerdo o estado de estrés, $m$ representando a los hombres y $f$ a las mujeres, que tendrán un cardinal $n_{a f}$ o $n_{a m}$ o $n_{d f}$ o $n_{d m}$ y de unas etiquetas predefinidas con la clase a la que pertenecen y que se denotarán como $y_{i}$. Cada fila de la matriz del conjunto de datos tendrá los $J$ parámetros extraídos para cada uno de los individuos. Por consiguiente la ecuación que define nuestro problema inicial será para el conjunto masculino (o el femenino en su caso):

$$
\left(x_{m 1}, y_{m 1}\right),\left(x_{m 2}, y_{m 2}\right), \ldots,\left(x_{m n}, y_{m n}\right) \in\left(\Re^{n} \times \pm 1\right)
$$

por lo tanto la función, $f$, debe de ser capaz de clasificar correctamente nuevas muestras $\left(x_{m}, y_{m}\right)$.

En nuestro caso tendremos $(n \times 2)-1$ muestras como matriz de entrenamiento o lo que es lo mismo $\left(X_{a m}+X_{d m}\right)-1$, para el conjunto de datos masculino; mientras que $\left(X_{a f}+X_{d f}\right)-1$ será para el conjunto femenino, donde cada fila corresponderá a un vector de un individuo que tendrá $j$ características o parámetros. Cada individuo $x_{i}$ tendrá una etiqueta asociada $y_{i}$ que equivaldrá al estado de estrés o carencia de estrés. Esta forma de entrenar el algoritmo se denomina leave-one-out, y será comentada en detalle en el Capítulo 5, Resultados.

La fórmula que define el hiperplano y trata de separar los datos etiquetados se denota como sigue:

$$
g(x)=w^{T} x+w_{0}
$$

donde $w$ se conoce como el vector de pesos y $w_{0}$ como el umbral. Este hiperplano hace máxima la distancia entre ambas clases (denominado como el hiperplano de margen máximo). Este margen viene definido por la distancia entre el hiperplano y los elementos más cercanos respecto a él, donde se tiene en consideración la siguiente regla de decisión:

$$
w^{T} x+w_{0}\left\{\begin{array} { l } 
{ \text { si } > 0 } \\
{ \text { si } < 0 }
\end{array} \Rightarrow x \in \left\{\begin{array}{ll}
w_{1} & \text { corresponde con } y_{i}=+1 \\
w_{2} & \text { corresponde con } y_{i}=-1
\end{array}\right.\right.
$$


Todos los puntos de entrenamiento se clasificarán correctamente si:

$$
y_{i}\left(w^{T} x_{i}+w_{0}\right)>b \text { para todo } i
$$

Por consiguiente, una posible solución para que todos los puntos $x_{i}$ estén a una distancia mayor que $b /|w|$ sería si para un $b=1$ y sin pérdida de generalidad generásemos dos hiperplanos del tipo $H_{1}: w^{T} x+w_{0}=+1$ y $H_{2}: w^{T} x+w_{0}=-1$. Donde a estos planos se les denominan hiperplanos canónicos que hacen ciertas las expresiones siguientes:

$$
\begin{aligned}
& w^{T} x+w_{0} \geq+1 \text { para } y_{i}=+1 \\
& w^{T} x+w_{0} \leq-1 \text { para } y_{i}=-1
\end{aligned}
$$

Llamamos margen total a la suma de los márgenes obtenidos a partir de $H_{1}$ y $H_{2}$. Estos márgenes vienen definidos como $h=\frac{|g(x)|}{|w|}=\frac{1}{|w|}$. La distancia entre $H_{1} \mathrm{y}$ $\mathrm{H}_{2}$ y el hiperplano de separación, $A$, la cual se define como margen que hace cierta la ecuación, $g(x)=0$. Por tanto, la maximización del margen es la búsqueda de una solución que minimiza $|w|$ para la restricción, $R_{1}$ :

$$
R_{1}: y_{i}\left(w^{T} x_{i}+w_{0}\right) \geq 1, \text { donde } i=1, \ldots, n
$$

Por lo tanto, la forma de conseguir la máxima distancia es minimizando el módulo del vector de pesos, $|w|$. Para mininimizar el vector de pesos es necesario llevar a cabo una tarea de optimización no lineal, la cual se basa en las condiciones de Karush-Kuhn-Tucker o (KKT) [93]. Para ello es necesario utilizar multiplicadores de Lagrange $\lambda_{i}$, teniendo en cuenta una restricción adicional $\sum_{i=1}^{n} \lambda_{i} y_{i}=0$ y obteniendo la ecuación de vectores de soporte, $w$, mostrada en la siguiente ecuación:

$$
w=\sum_{i=1}^{n} \lambda_{i} y_{i} x_{i}
$$

SVM tiene una serie de kernels o funciones muy populares para generar el cálculo de los hiperplanos a partir de los conjuntos de entrenamiento. Por ejemplo en Matlabß podemos encontrar algunos de los siguientes:

Polinomial:

$$
K\left(x_{1}, x_{2}\right)=\left(x_{1}^{\top} x_{2}+1\right)^{\rho}
$$

Función de base radial:

$$
K\left(x_{1}, x_{2}\right)=\exp \left(-\frac{\left\|x_{1}-x_{2}\right\|^{2}}{2 \sigma^{2}}\right)
$$

donde $\rho$ es el orden del polinomio y $\sigma$ es el ancho del kernel. Cuando $\rho$ adquiere los valores que a continuación se presentan, el kernel de entrenamiento se convierte en:

- $\rho=1 \Rightarrow$ kernel lineal. 
- $\rho=2 \Rightarrow$ genera un kernel de tipo cuadrático, que es uno de los más utilizados.

En la fase de test o clasificación, un SVM utiliza:

$$
f(x)=\sum_{i} \alpha_{i} k\left(s_{i}, x\right)+b
$$

donde $\alpha_{i}$ son los pesos, $s_{i}$ son los vectores de soporte, $b$ es el umbral y $k$ es el kernel utilizado. Obsérvese que, si el kernel es lineal, $k$ es el producto escalar. Entonces, si $f(x)>0$, x será clasificado como la primera clase, mientras que si $f(x)<0$, x será de la segunda clase.

\subsubsection{Log-likelihood Ratio}

Hemos implementado un algoritmo propio a partir del cual se obtiene unos indicadores que validan el conjunto de datos, basándonos en la verosimilitud logarítmica o log-likelihood [74]. Este método trata de comprobar si el sujeto $i$ muestra congruencia en caso de defender su opinión sincera, respecto de su opinión personal e incongruencia cuando se trata de defender la opinión contraria cuando se le solicita.

Partiendo del corpus 3 y de su definición exhaustiva en la sección 2.3.3, obtenemos las medias y las desviaciones típicas por cada vector columna $j$ de cada matriz de observación $X_{a m}, X_{d m}, X_{a f}$ y $X_{d f}$, las cuales serán estimadas como $\mu_{a m j}, \mu_{a f j}, \mu_{d m j}, \mu_{d f j} ; \sigma_{a m j}, \sigma_{a f j}, \sigma_{d m j}, \sigma_{d f j}$, respectivamente.

Estas estimaciones serán usadas en la evaluación de la capacidad de discriminación individual de cada característica [186] por cada subconjunto de hombres y mujeres como:

$$
\begin{gathered}
f_{m j}=\frac{\left(\mu_{m a j}-\mu_{m d j}\right)^{2}}{\sigma_{m a j}^{2}-\sigma_{m d j}^{2}} \\
f_{f j}=\frac{\left(\mu_{f a j}-\mu_{f d j}\right)^{2}}{\sigma_{f a j}^{2}-\sigma_{f d j}^{2}}
\end{gathered}
$$

Las medias estimadas para cada locutor $i$ compondrán las medias de los vectores fila $\mu_{a m}, \mu_{a f}, \mu_{d m}$ y $\mu_{d f}$. Además, las matrices de covarianzas para cada subconjunto vendrán estimadas también como $S_{a m}=E\left\{X_{a m} X_{a m}^{T}\right\}, S_{a f}=E\left\{X_{a f} X_{a f}^{T}\right\}$, $S_{d m}=E\left\{X_{d m} X_{d m}^{T}\right\}$ y $S_{d f}=E\left\{X_{d f} X_{d f}^{T}\right\}$, donde $E$ se refiere a la esperanza estadística, y $\left({ }^{T}\right)$ a la matriz traspuesta.

A continuación se supondrá que las observaciones son producidas por procesos Gaussianos, por tanto los modelos Gaussianos serán $\Gamma_{a m}=\left\{\mu_{a m}, S_{a m}\right\}, \Gamma_{a f}=$ $\left\{\mu_{a f}, S_{a f}\right\}, \Gamma_{d m}=\left\{\mu_{d m}, S_{d m}\right\}$ y $\Gamma_{d f}=\left\{\mu_{d f}, S_{d f}\right\}$.

En el presente enfoque, cada característica de los vectores individuales $\mathbf{x}_{a m i}, \mathbf{x}_{d m i}$, $\mathbf{x}_{a f i} \mathrm{y}_{d f i}$, será comparada contra su correspondiente modelo Gaussiano simplificado 
usando la tasa de verosimilitud logarítmica definida como:

$$
\begin{aligned}
\lambda_{a m i j} & =\log \frac{p\left(x_{a m i j} \mid \Gamma_{s a m}\right)}{p\left(x_{a m i j} \mid \Gamma_{s d m}\right)} \\
\lambda_{d m i j} & =\log \frac{p\left(x_{d m i j} \mid \Gamma_{s a m}\right)}{p\left(x_{d m i j} \mid \Gamma_{s d m}\right)} \\
\lambda_{a f i j} & =\log \frac{p\left(x_{a f i j} \mid \Gamma_{s a f}\right)}{p\left(x_{a f i j} \mid \Gamma_{s d f}\right)} \\
\lambda_{d f i j} & =\log \frac{p\left(x_{d f i j} \mid \Gamma_{s a f}\right)}{p\left(x_{d f i j} \mid \Gamma_{s d f}\right)}
\end{aligned}
$$

donde las probabilidades condicionadas se definen como:

$$
\begin{aligned}
p\left(x_{a m i j} \mid \Gamma_{s a m}\right) & =\frac{1}{\sqrt{2 \pi} \sigma_{a m j}} e^{-\frac{\left(x_{a m i j}-\mu_{a m j}\right)^{2}}{2 \sigma_{a m j}^{2}}} \\
p\left(x_{a m i j} \mid \Gamma_{s d m}\right) & =\frac{1}{\sqrt{2 \pi} \sigma_{d m j}} e^{-\frac{\left(x_{a m i j}-\mu_{d m j}\right)^{2}}{2 \sigma_{d m j}^{2}}} \\
p\left(x_{d m i j} \mid \Gamma_{s a m}\right) & =\frac{1}{\sqrt{2 \pi} \sigma_{a m j}} e^{-\frac{\left(x_{d m i j}-\mu_{a m j}\right)^{2}}{2 \sigma_{a m j}^{2}}} \\
p\left(x_{d m i j} \mid \Gamma_{s d m}\right) & =\frac{1}{\sqrt{2 \pi} \sigma_{d m j}} e^{-\frac{\left(x_{d m i j}-\mu_{d m j}\right)^{2}}{2 \sigma_{d m j}^{2}}} \\
p\left(x_{a f i j} \mid \Gamma_{s a f}\right) & =\frac{1}{\sqrt{2 \pi} \sigma_{a f j}} e^{-\frac{\left(x_{a f i j}-\mu_{a f j}\right)^{2}}{2 \sigma_{a f j}^{2}}} \\
p\left(x_{a f i j} \mid \Gamma_{s d f}\right) & =\frac{1}{\sqrt{2 \pi} \sigma_{d f j}} e^{-\frac{\left(x_{a f i j}-\mu_{d f j}\right)^{2}}{2 \sigma_{d f j}^{2}}} \\
p\left(x_{d f i j} \mid \Gamma_{s a f}\right) & =\frac{1}{\sqrt{2 \pi} \sigma_{a f j}} e^{-\frac{\left(x_{d f i j}-\mu_{a f j}\right)^{2}}{2 \sigma_{a f j}^{2}}} \\
p\left(x_{d f i j} \mid \Gamma_{s d f}\right) & =\frac{1}{\sqrt{2 \pi} \sigma_{d f j}} e^{-\frac{\left(x_{d f i j}-\mu_{d f j}\right)^{2}}{2 \sigma_{d f j}^{2}}}
\end{aligned}
$$

Explicando con un poco más de detalle las ecuaciones se puede decir que los correlatos estimados de frases emitidas de forma congruente (supuestamente libres de estrés - $a$ ) son contrastadas contra las emitidas de forma incongruente (potencialmente afectadas por estrés - $d$ ). Donde, si el resultado de la probabilidad logarítmica resulta positivo, indicaría que el sujeto está diciendo lo que realmente piensa. Sin embargo, si el resultado de la probabilidad logarítmica es negativo podría interpretarse en el sentido que el individuo no está diciendo lo que realmente piensa.

Análogamente, los correlatos estimados de frases emitidas de forma incongruente (potencialmente afectadas por estrés) son contrastadas contra las emitidas de forma 
congruente (supuestamente libres de estrés). Donde, si los registros hablados fueran congruentes se debería obtener una probabilidad resultante negativa para este caso. Asimismo estos datos no serían aparentemente coherentes con el tipo de respuesta dada.

Como las tasas de verosimilitud logarítmica han sido estimadas para cada característica ha sido necesario un método para fusionar todas las tasas de características individuales para cada locutor. Esto se ha realizado combinando las tasas de verosimilitud logarítmica de las funciones individuales ponderadas por los factores discriminantes que se muestran en 4.31 .

$$
\begin{aligned}
\vartheta_{a m i} & =\sum_{1}^{J} f_{m j} \lambda_{a m i j} \\
\vartheta_{d m i} & =\sum_{1}^{J} f_{m j} \lambda_{d m i j} \\
\vartheta_{a f i} & =\sum_{1}^{J} f_{f j} \lambda_{a f i j} \\
\vartheta_{d f i} & =\sum_{1}^{J} f_{f j} \lambda_{d f i j}
\end{aligned}
$$

Para resumir, cuando una muestra pertenece al conjunto de datos $X_{a f}$ o $X_{a m}$, el resultado de evaluar la ecuación 4.29 debería de ser mayor que cero o positivo. Mientras que las muestras pertenecientes al conjunto de datos de estrés, es decir, $X_{d f}$ o $X_{d m}$ deberían producir un valor menor que cero o negativo. De esta forma cada sujeto habría realizado de forma congruente el caso propuesto de dos grabaciones, una para el estado de calma y otra para el de estrés.

La validación de los datos se puede ver en el Capítulo 5, Resultados, y más concretamente en la sección 5.3, donde se pone en práctica este algoritmo. 


\section{Capítulo 5}

\section{RESULTADOS}

A lo largo de los capítulos expuestos hasta el momento se ha intentado ofrecer una panorámica del estado del arte actual, las bases de datos más significativas, los parámetros más representativos y finalmente los algoritmos de clasificación más utilizados. En este capítulo se presentan los resultados alcanzados a partir de los datos obtenidos para este estudio y los instrumentos y métodos descritos en los capítulos anteriores de acuerdo con los objetivos de este trabajo.

Partiendo de la intención de adquirir un conocimiento genérico y de amplio espectro sobre el problema en cuestión, el siguiente paso lógico fue recolectar un conjunto de datos con el cual poder comenzar a trabajar, es decir, la primera sección de este capítulo presenta la relación entre los diferentes corpora mostrados en el capítulo 2 en conjunción con la obtención de ciertos parámetros característicos (véase capítulo 3) haciendo uso de las técnicas de reducción de parámetros y los diferentes algoritmos de clasificación (véase capítulo 4).

En la siguiente sección, se comprobó la utilidad del cálculo de ciertos rasgos para la detección y caracterización del estrés en el cambio de estados emocionales. Estos rasgos fueron los biomecánicos (véase sección 3.3.4.1), los cíclicos (véase sección 3.3.4.2) y los de temblor (véase sección 3.3.4.3).

Tal y como se explicó en el capítulo 2, además de capturar muestras de voz con cierta metodología de inducción al estrés, también se validaron de forma subjetiva dichas muestras. Por consiguiente, la siguiente acción a realizar para dar veracidad al resto de etapas fue comprobar si los datos obtenidos eran o no fiables. Por lo tanto, se ideó una técnica basada en el ratio de verosimilitud logarítmica (véase sección 4.5.2) para comprobar si los sujetos participantes en el estudio realizaron de forma adecuada los casos de estrés y carencia de estrés elicitados.

En la cuarta sección de este capítulo se presenta una primera clasificación muy simple de un conjunto de datos de mujeres. La idea fundamental en este caso era realizar una primera aproximación al método de clasificación SVM (véase sección 4.5.1), comprobando los parámetros de configuración de las funciones de entrenamiento, utilizando diversos kernels en la función de test y la visualización de dos 
características en un eje cartesiano. La técnica llevada a cabo con este conjunto de datos era perfectamente extrapolable al conjunto de datos masculino, tan solo se quería ver la idoneidad del método de clasificación para conjunto de datos dicotómicos. Además, la relevancia de los parámetros se calculó a partir del coeficiente de correlación de Pearson (véase sección 4.2), haciendo uso también del coeficiente de determinación (véase sección 4.2) y los parámetros más representativos se utilizaron para clasificar el conjunto de datos femenino.

En este punto del estudio se tenían todos los ingredientes para dar respuesta a algunos de los objetivos más importantes planteados en este trabajo. ¿Cuáles de los 72 parámetros extraídos eran los más significativos? ¿Cómo de bien o de mal clasificaban el estrés y la calma? Es por ello que en la siguiente sección se utilizaron técnicas tales como PCA (véase 4.4.1) o ICA (véase 4.4.2) para obtener las mejores tasas de clasificación utilizando el algoritmo SVM (véase sección 4.5.1).

Dado que el conjunto de datos obtenido era reducido, surgió la necesidad de buscar nuevas formas de validar el conjunto de datos de forma completamente objetiva. Los corpora reducidos son muy sensibles a los posibles artefactos o individuos anómalos dentro de una población muestral. Es por ello que, se investigó la utilización de técnicas de estadística no paramétrica, las cuales se basan en el uso de la función de densidad de probabilidad, en lugar del uso de estadísticos de segundo orden. En la última sección de este capítulo se utilizaron las técnicas de Kolmogorov-Smirnov (véase sección 4.3.1) y la prueba de U-Mann-Whitney-Wilcoxon (véase sección 4.3.2) para ver cómo se comportaban los parámetros en cada caso de estudio, es decir, si las magnitudes obtenidas en el caso de congruencia e incongruencia de las dos poblaciones presentaban valores significativamente distintos.

\subsection{Conjunto de Datos}

Debido al carácter multidisciplinar de este trabajo es necesario aportar información del conjunto de datos utilizado para cada caso de estudio y los métodos llevados a cabo con el mismo. Por consiguiente, el esquema utilizado será el siguiente:

- Validación de los rasgos biométricos como indicadores del estado emocional: se busca comprobar si ciertos rasgos de índole biométrico pueden ser suficientemente robustos como para poder describir estados emocionales, partiendo de una hipótesis inicial de condiciones emocionales neutras. Para llevar a cabo este estudio se utilizaron los corpora 1 y 4.

- Comportamiento de los rasgos biométricos según el género: una vez presentadas las evidencias con un conjunto de muestras muy pequeño se extrapoló el estudio con un conjunto más amplio y se observó cómo se comportaban los hombres y las mujeres dado un escenario emocional evocado. Para este caso se utilizó el corpus 5 .

- Metodología para monitorizar estrés emocional: se intentó profundizar en la utilización de la rigidez de los pliegues vocales a partir de la utilización de 
la técnica de las encuestas para evocar cambios de estados emocionales en los sujetos. Para este caso se utilizó el corpus 6 y el estadístico parámetrico t-test (véase sección 4.2), con el cual se intenta ver si existen diferencias evidentes entre las muestras congruentes frente a las incongruentes, o dicho de otra forma, si se pueden distinguir ambas distribuciones muestrales o en su lugar no hay suficientes evidencias como para poder asegurar que pertenecen a la misma distribución.

- Validación de la coherencia del conjunto de datos: dado que se han observado ciertas diferencias entre hombres y mujeres cuando se les sitúa en escenarios emocionales adversos, parece lógico pensar que es necesario validar el conjunto de datos de partida. Para ello se ha diseñado una técnica basada en el ratio de verosimilitud logarítmica (véase sección 4.5.2) y se ha utilizado el corpus 3 , subconjunto del corpus 5 para validar de forma objetiva si cada individuo responde al estudio de forma congruente o lo hace de forma políticamente correcta a las preguntas de la encuesta (véase sección 2.2.2).

- Primera selección de parámetros: tras obtener evidencias de que existen algunos rasgos capaces de detectar el estrés emocional y una técnica que ayuda a validar si un conjunto de datos es apto para trabajar con él; ahora es el momento de empezar a clasificar un conjunto de datos a partir de rasgos significativos o relevantes. Por consiguiente, se va a utilizar una interpretación geométrica, la cual se basa en el coeficiente de correlación de Pearson (véase sección 4.2) y el coeficiente de determinación (véase sección 4.2). Después de seleccionar estos parámetros, se realizará una clasificación del conjunto de datos utilizando tan solo dos parámetros cada vez y el algoritmo SVM (véase sección 4.5.1). De esta forma se podrá representar los resultados de clasificación en un eje cartesiano. En este caso de estudio se ha utilizado el corpus 7.

- Optimización del conjunto de parámetros: una vez realizada la primera selección de rasgos y un pequeño proceso de clasificación de muestras, ahora se busca obtener los rasgos que caractericen mejor el estrés con tasas de clasificación elevadas. Además, se busca a partir de un conjunto de 68 rasgos seleccionar un máximo de 20 de ellos y clasificar el conjunto de datos con el algoritmo SVM. Este caso de estudio se llevó a cabo con el corpus 2.

- Validación de rasgos de forma no paramétrica: tras haber obtenido ciertos rasgos relevantes a partir de funciones de selección y reducción dimensional, parece conveniente validarlos a través de otras técnicas. Para llevar a cabo la siguiente acción se van a utilizar pruebas no parámetricas tales como la de Kolmogorov-Smirnov (véase sección 4.3.1) y la de U-Mann-Whitney (véase sección 4.3.2). La primera se utiliza para comprobar si dos distribuciones muestrales pertenecen a una misma población, mientras que la segunda es la versión no paramétrica de la t-Student. Además, cada una de las técnicas llevan asociadas dos enfoques. El primero se basa en realizar un estudio de todos los rasgos de forma global entre las poblaciones de congruencia (calma) frente a la incongruencia (estrés), mientras que el segundo enfoque se cimienta en realizar un estudio de tipo pair-wise de la población, es decir, de un individuo 
sobre si mismo. Para el primer enfoque, ambas técnicas se llevan a cabo con el corpus 3, mientras que el segundo enfoque utiliza el corpus anteriormente citado en primera instancia y luego utiliza el corpus 8 .

\subsection{Rasgos biométricos: indicadores del estado emocional}

El comportamiento afectivo es multimodal y complejo [99]. Las emociones pueden ser expresadas a través de gestos, posturas y voz, entre otros comportamientos. En este trabajo se hace hincapié en el uso de la voz para poder discernir comportamientos o patrones emocionales. En la sección 3.2 del capítulo 3 se detallaron los parámetros clásicos utilizados en la literatura. Sin embargo, no hay que olvidar nuevas fuentes de inspiración, como por ejemplo las ofrecidas por Airas y Alku en [1] que analizan el flujo glotal en segmentos de vocales o el trabajo de Moore et al. que analizan las características glotales en pacientes diagnosticados con depresión [125]. La depresión es un estado anímico o emocional que conlleva unos síntomas asociados tales como, apatía, tristeza, etcétera.

Nuestro enfoque radica en realizar una analogía inversa, es decir, igual que el comportamiento de incongruencia lleva al estrés y se manifiesta hacia el exterior, también debe reflejarse de forma interna. Por lo tanto, la producción del habla no debe ser ajena a este efecto por ello consideramos la hipótesis que el temblor es un comportamiento característico del estrés, como una de sus posibles manifestaciones.

\subsubsection{Estimación de la Rigidez de las Cuerdas Vocales}

El experimento realizado consiste en el seguimiento de los correlatos emocionales presentes en la voz. La idea fundamental de este caso es definir marcas biomecánicas como la rigidez en la cubierta y en el cuerpo de las cuerdas vocales para estimar patrones de la dispersión y ciclicidad.

\subsubsection{Hipótesis Inicial}

La hipótesis inicial asumida en este estudio se basa en la idea a priori de que los parámetros cíclicos no aportan ningún tipo de información diferenciadora dada una población de individuos cuando las condiciones emocionales son neutras.

Para llevar a cabo la refutación o la ratificación de la hipótesis inicial se ha utilizado el corpus número uno (véase sección 2.3.3), el cual puede considerarse un conjunto de datos balanceado. Los correlatos de la fuente glotal se obtuvieron de los segmentos de voz de la vocal /a/, y se utilizó la tensión biomecánica para la estimación de los coeficientes cíclicos $c_{1}, c_{2}$ y $c_{3}$ como se explicó de forma pormenorizada en las secciones 3.3.4.1 y 3.3.4.2. 
Los histogramas de estos tres parámetros referidos a una población normativa de 50 individuos masculinos y 50 femeninos validados por los servicios de ORL del Hospital Universitario Gregorio Marañón de Madrid se presentan en la Figura 5.1 para los hombres y en la Figura 5.2 para las mujeres. Tal y como se puede ver en dichas figuras, el solapamiento entre las distribuciones normofónicas y disfónicas para ambos géneros muestra que la hipótesis realizada en párrafos anteriores tiene una base fundamentada en relación a las condiciones emocionales neutras de los estados emocionales, es decir, que no existe diferencia significativas entre individuos con o sin patologías neurodegenerativas para ambos géneros.

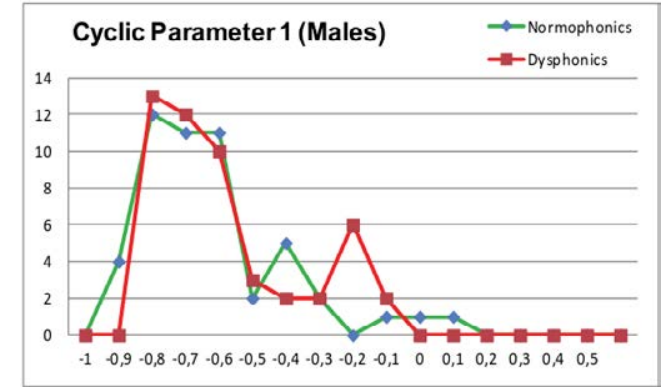

(a)

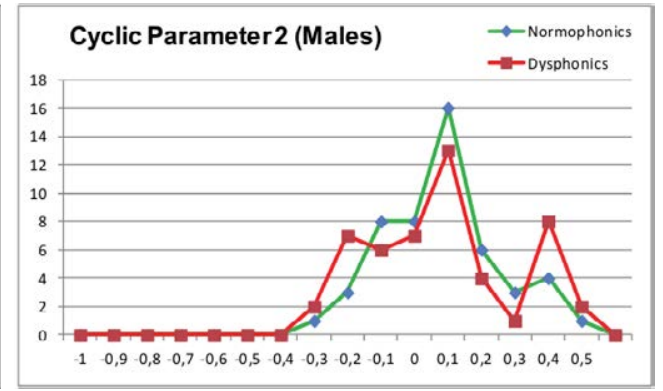

(b)

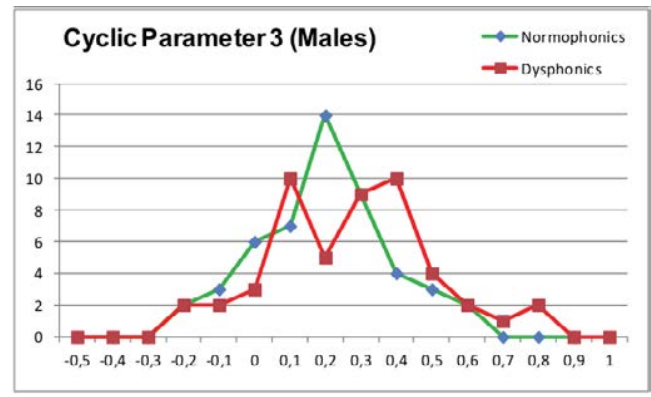

(c)

Figura 5.1: Distribución de los tres primeros parámetros cíclicos para conjunto masculino. 


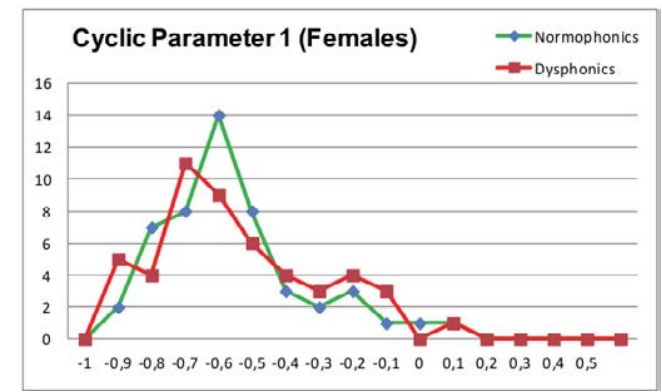

(a)

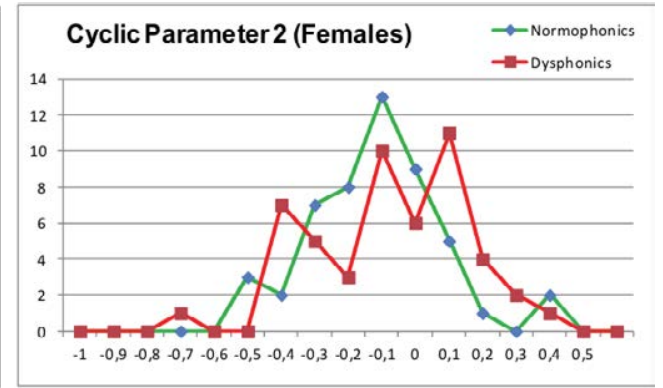

(b)

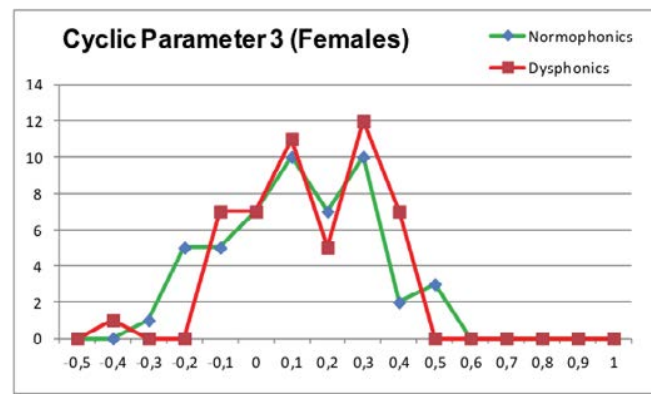

(c)

Figura 5.2: Distribución de los tres primeros parámetros cíclicos para conjunto femenino.

\subsubsection{Casos de Estudio}

Para mostrar que estos rasgos dejan marcas significativas en la voz para caracterizar estados emocionales alterados se han utilizado algunos casos de estudio fenomenológicos. Estos ejemplos corresponden a la estimación de los rasgos de ciclicidad con un pequeño conjunto de locutores de ambos géneros en ciertas condiciones emocionales casi imperceptibles para el locutor. La forma de suscitar estas condiciones emocionales se describió en el capítulo 2 y más concretamente en la sección 2.2.2, Encuestas, la cual se basa en el trabajo de Arciuli [6].

Como primera observación al proceso de grabación sería que los sujetos (en su mayoría) presentan un discurso más espontáneo y por consiguiente más fluido. Esto es debido a que el locutor está defendiendo su supuesto punto de vista y por consiguiente su discurso es interiorizado, o definido "a priori", mientras que en la grabación no congruente se mostraría un mayor grado de dubitación en su discurso, donde los individuos realizarían un mayor número de pausas fonadas. A este segundo fenómeno se le denomina filler o "relleno", y se genera frecuentemente cuando un individuo "fabrica" o "construye" su discurso sobre la marcha.

Los fillers más reconocidos son las vocales y más concretamente los fonemas /ah/, /uh/ y /eh/. El uso de estos fonemas es muy útil para el análisis del estrés manifestado en la rigidez y la cubierta de las cuerdas vocales. En el caso de la lengua castellana el fonema /eh/ es utilizado de forma más amplia que el /ah/. Por consiguiente, el análisis se concentra en el uso del fonema /eh/ más que en el /ah/. 
La base de datos se ha validado con el fonema /ah/ pero no existe incompatibilidad con la validación explicada en el apartado anterior, debido a que los patrones de articulación se han eliminado durante la inversión del tracto vocal para ambos tipos de emisión, por lo tanto se puede considerar compatible en lo que concierne a las estimaciones de rigidez (véase sección 3.3.1). Se muestran cuatro casos de estudio contrapuestos durante la locución de la vocal /eh/ sostenida desde la Figura 5.3 a la Figura 5.6 para hombres y mujeres, respectivamente.
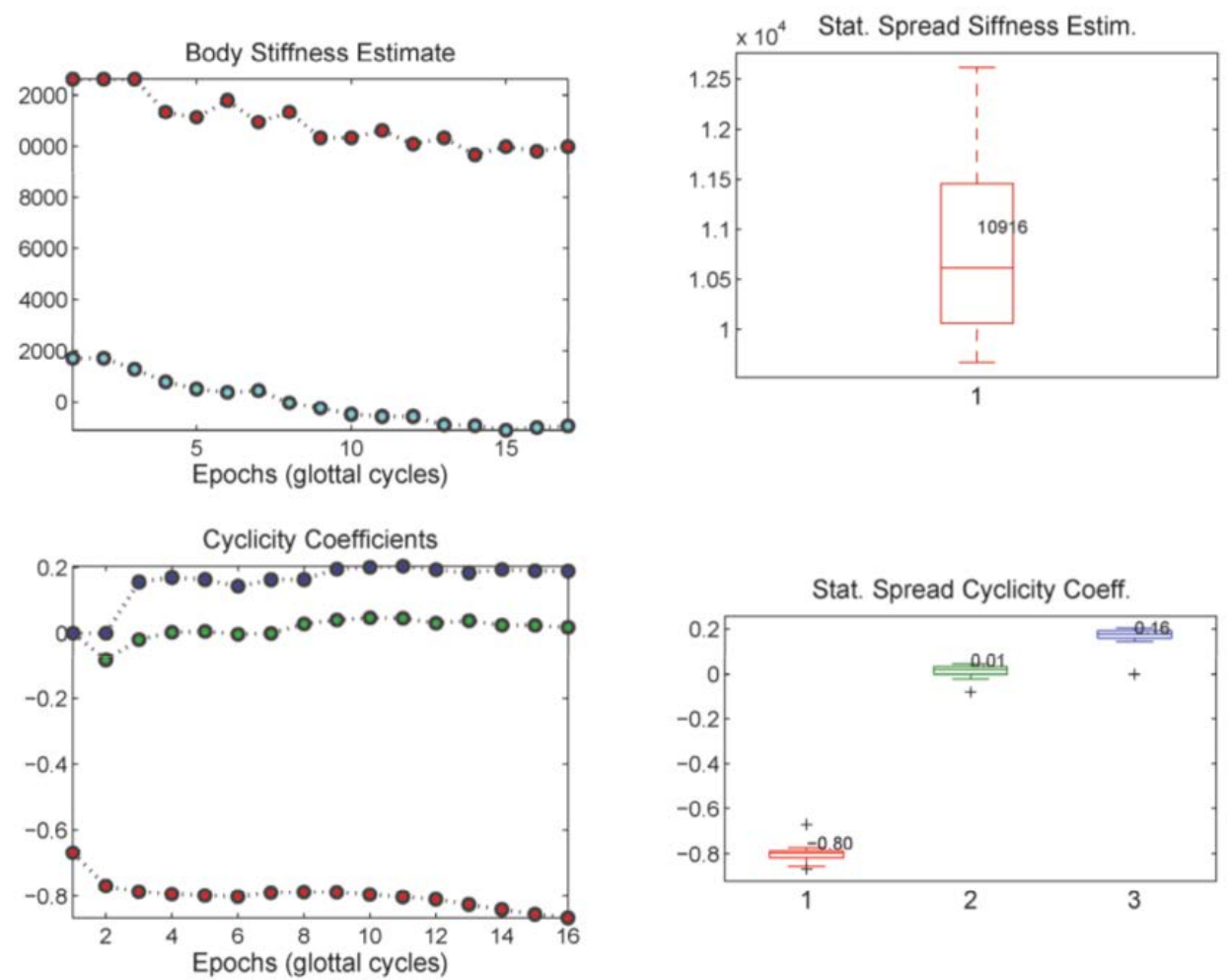

Figura 5.3: Análisis del filler /eh/ para los locutores masculinos expresando su opinión congruente o espontánea. 

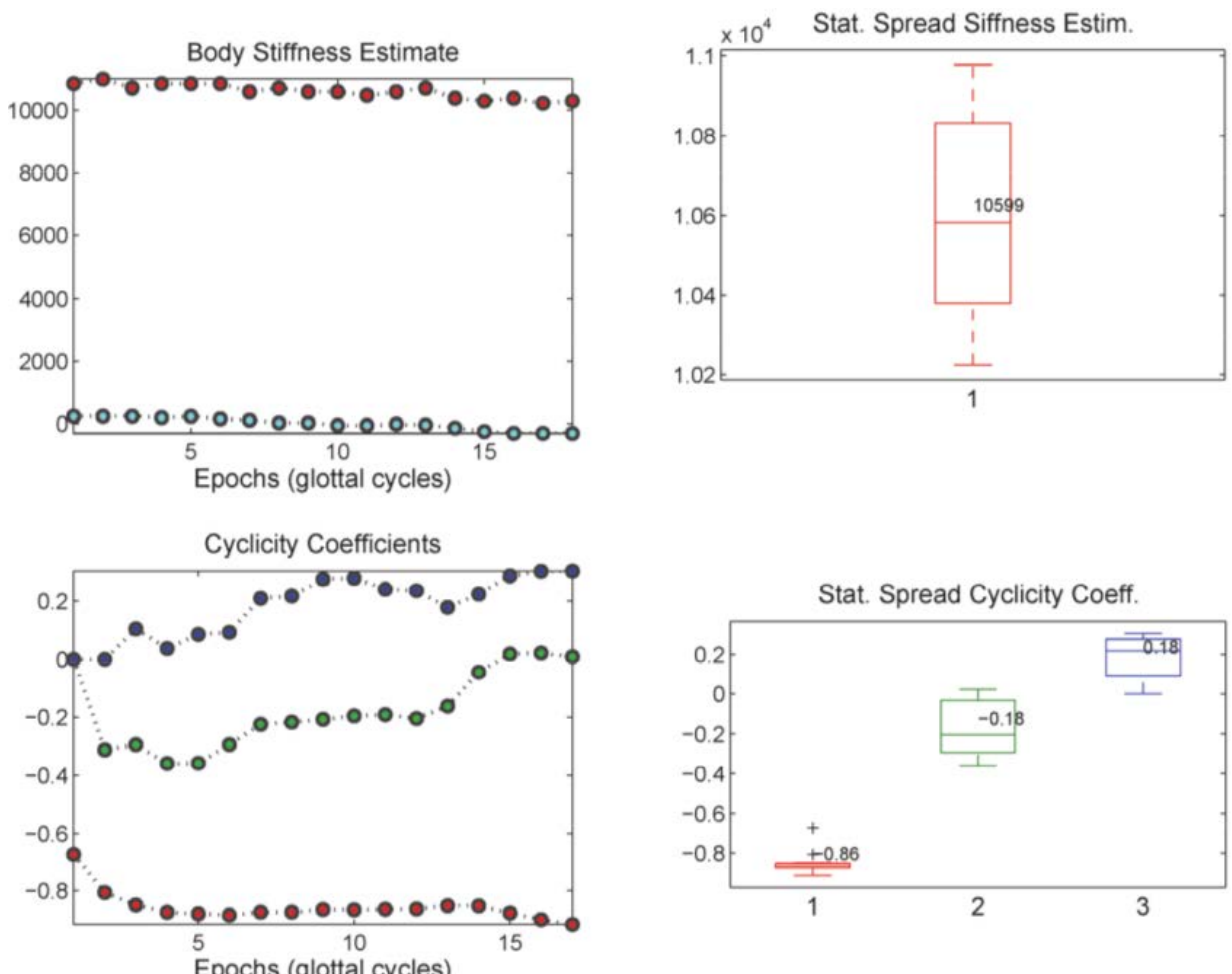

Figura 5.4: Análisis del filler/eh/ para los locutores masculinos expresando su opinión opuesta.
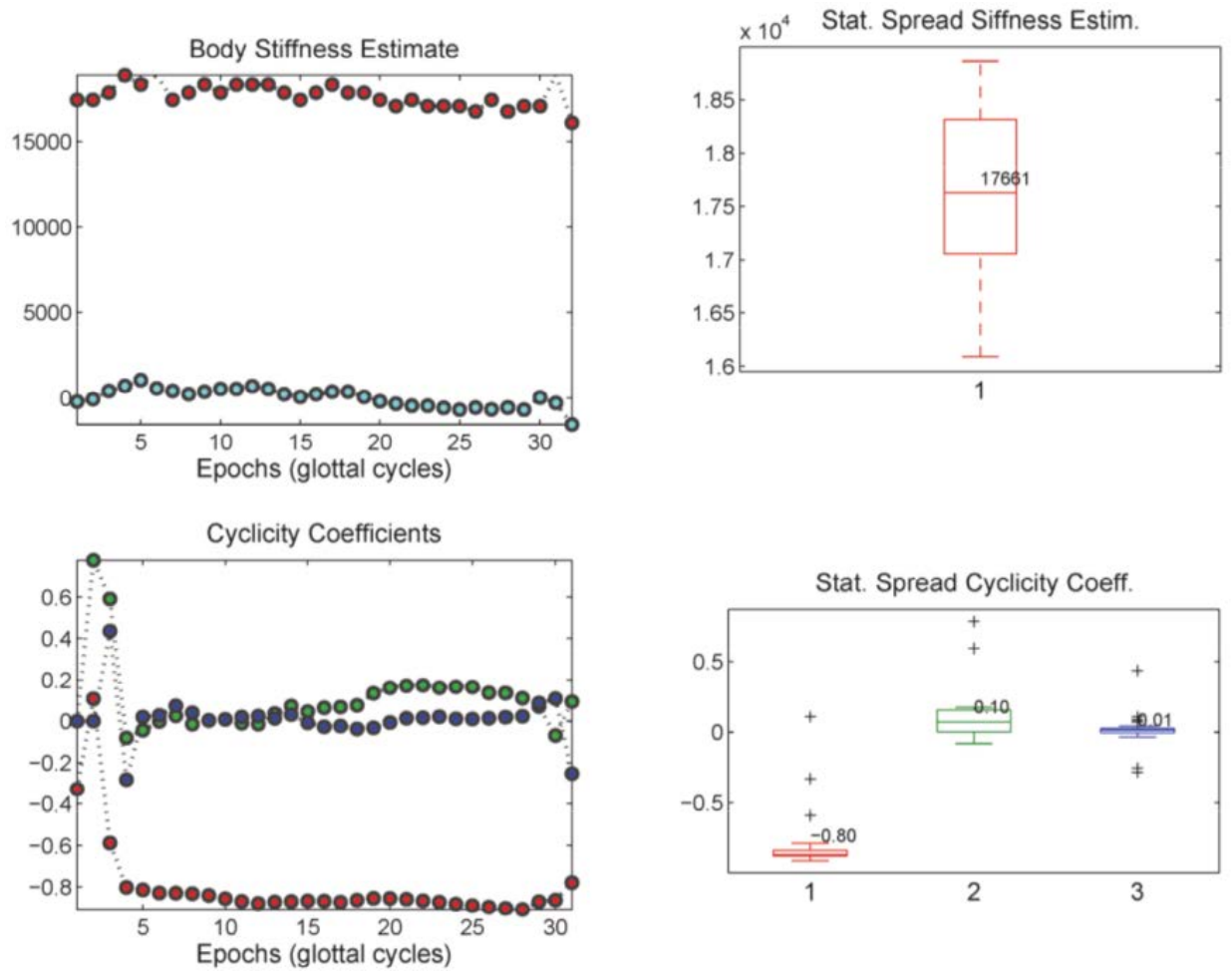

Figura 5.5: Análisis del filler /eh/ para los locutores femeninos expresando su opinión congruente o espontánea. 

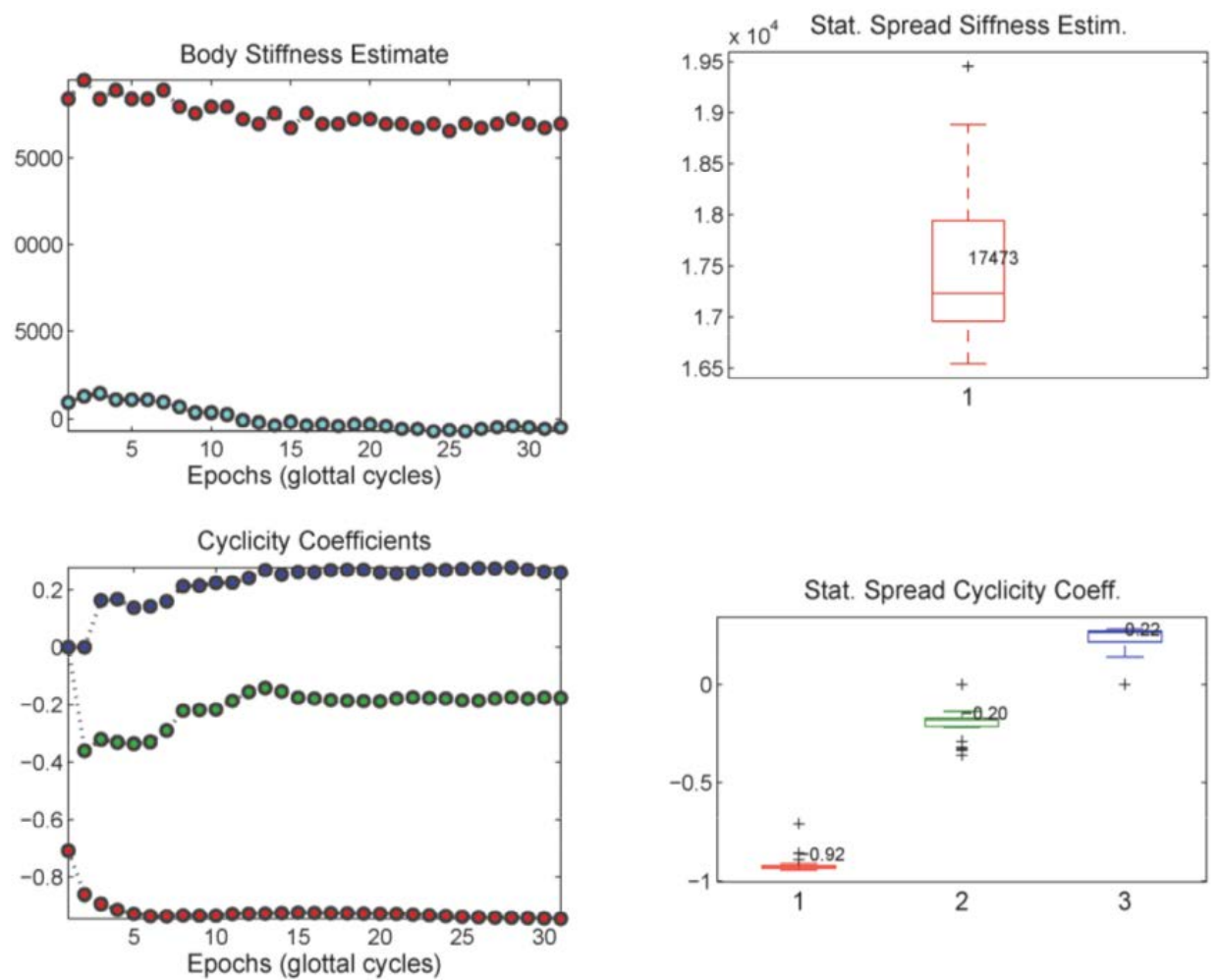

Figura 5.6: Análisis del filler / eh/ para los locutores femeninos expresando su opinión opuesta.

Estas imágenes muestran la opinión congruente sobre la pregunta que se le ha realizado, frente a la defensa de su opinión contraria sobre el tema en cuestión. En todas ellas, la imagen superior izquierda se muestra la evolución de la rigidez de las cuerdas vocales en unos 0.2 segundos y con color rojo, mientras que en color azul se representa la misma traza habiendo eliminado su media. El diagrama de caja de la distribución estadística de la rigidez de las cuerdas vocales de la muestra eliminada su media se representa en la parte superior derecha de la imagen. De forma análoga en la parte inferior izquierda se representa la evolución de los tres parámetros cíclicos (aportando sus medias) y sus distribuciones estadísticas respectivamente, representadas en la parte inferior de la imagen.

Los resultados anteriormente mencionados para los cuatro casos de estudio se han representado en la Tabla 5.1, donde MSS/FSS representa las locuciones congruentes con la opinión personal para hombres y mujeres, respectivamente, mientras que MSO/FSO muestran los valores obtenidos cuando el sujeto defiende una idea opuesta a su opinión personal, también separados por hombres y mujeres. Los valores presentados en la tabla son los siguientes: tiempo en el que comienza y termina el filler utilizado, la media de la rigidez de la tensión del cuerpo y la cubierta de las cuerdas vocales, denotado por $\mu K b$ y $\mu K c$, respectivamente y las correspondientes desviaciones típicas, $\sigma K b$ y $\sigma K c$. Finalmente, se presentan los valores de los tres parámetros cíclicos c1, c2 y c3. 


\begin{tabular}{|c|c|c|c|c|c|c|c|c|c|}
\hline Segmento & Inicio (s) & Fin $\mathbf{( s )}$ & $\left.\boldsymbol{\mu K b} \mathbf{~ ( g . s ~}^{-1}\right)$ & $\left.\boldsymbol{\mu K c} \mathbf{~ ( g . s ~}^{-\mathbf{1}}\right)$ & $\boldsymbol{\sigma K b}$ & $\boldsymbol{\sigma K c}$ & $\mathbf{c 1}$ & $\mathbf{c 2}$ & $\mathbf{c 3}$ \\
\hline MSS & 15.21 & 15.41 & 10,916 & 8,230 & 941 & 1,529 & -0.80 & -0.01 & 0.16 \\
\hline MSO & 3.40 & 3.60 & 10,599 & 7,267 & 213 & 321 & -0.86 & -0.18 & 0.18 \\
\hline FSS & 12.40 & 12.60 & 17,661 & 9,432 & 621 & 2,096 & -0.80 & 0.10 & 0.01 \\
\hline FSO & 7.80 & 8.00 & 17,473 & 9,917 & 758 & 997 & -0.92 & -0.20 & 0.22 \\
\hline
\end{tabular}

Tabla 5.1: Rigidez de las cuerdas vocales y coeficientes cíclicos. De izquierda a derecha: Inicio y fin de los fillers, medias del cuerpo y la cubierta, desviaciones típicas del cuerpo y la cubierta y los tres parámetros de ciclicidad.

A continuación se quiere incidir en algunos detalles a tener en cuenta a partir de los las figuras presentadas para los locutores masculinos. Lo primero es que la rigidez de la cubierta parece menos estable y decae de forma más significativa en las muestras espontáneas. Esto puede ser confirmado por la desviación típica del parámetro $(\sigma K b)$ en la Tabla 5.1 y se podría asociar con una condición menos estresada en la fonación cuando el sujeto está en proceso espontáneo que cuando está construyendo un discurso. Sin embargo, la media de la tensión del pliegue vocal $(\mu K b)$ es casi igual. La situación en el caso de las mujeres difiere respecto de la de los hombres en lo concerniente a la rigidez del cuerpo. Por otro lado, si la dispersión de la tensión de la cubierta $(\sigma K c)$ se examina en los hombres y en las mujeres cuando están defendiendo sus puntos de vista congruentes y se compara con las muestras no espontáneas se puede apreciar una diferencia sustancial en ambos géneros, siendo mucho más grande en las muestras congruentes que en las incongruentes.

La comparación de los rasgos cíclicos entre las muestras congruentes y las incongruentes es que el parámetro c1 muestra una tendencia decreciente hacia - 1 que es casi el doble de grande en las mujeres (-0.8 a -0.92) que en el caso de los hombres (-0.8 a -0.86), mientras que el segundo parámetro cíclico, c2, desciende en ambos casos, del (-0.001 a -0.18) para las muestras masculinas, y del (0.1 al -0.2) para las locutoras femeninas. El tercer y último parámetro cíclico, c3, no muestra una orientación tan clara, aunque se obtienen valores más grandes cuando los locutores defienden discursos "fabricados".

El hecho que la dispersión de la rigidez de cubierta, $K c$, sea más grande en la fonación espontánea se podría interpretar como que el locutor deja las cuerdas vocales más "sueltas" en condiciones de menor estrés que bajo situaciones controladas y con un nivel de estrés superior suscitado bajo las condiciones de las preguntas realizadas.

Una segunda observación es que la tensión media tanto del cuerpo como la cubierta $(K b$ y $K c)$ no están demasiado alteradas respecto de una situación de calma o espontánea que en una situación alterada o estresada. Sin embargo, su dispersión sí que se ve afectada, siendo más baja cuando son situaciones alteradas. Además, los dos primeros parámetros cíclicos (c1 y c2) muestran diferencias en ambas situaciones. Las razones para estas variaciones donde el valor obtenido es más grande en el caso de las mujeres que, en el de los hombres no tiene que deberse explícitamente al género. Tal vez respondan a un comportamiento idioléctico (de causa desconocida) específico del locutor, aunque este problema se debe de contrastar por medio de un estudio más amplio fuera del alcance del presente estudio. 
Resumiendo, este trabajo se basa en la definición de ciertos rasgos biomecánicos, entre ellos el temblor en todas sus variantes, la rigidez o tensión de los pliegues vocales y el comportamiento cíclico de los rasgos estimados, los cuales hipotetizamos que son marcadores de correlatos neurológicos que están íntimamente relacionados con las emociones y el estrés; y además con enfermedades neurológicas degenerativas relacionadas con el control muscular, tales como el Parkinson, Esclerosis Lateral Amiotrófica o incluso la enfermedad de Alzheimer, puesto que las alteraciones de dichos correlatos son manifestaciones de comportamiento anómalo en estas situaciones.

Otra observación interesante es que el modelo de cadena (véase Figura 3.16) desde la voz a la estimación de los parámetros biomecánicos y cíclicos de los locutores, parece coincidir con las hipótesis inicialmente planteadas. Estas asumen que el temblor inducido por la metodología utilizada para la elicitación de estrés en la voz pudiera dejar correlatos en los diferentes rasgos biomecánicos.

A partir de esta observación se puede concluir también que la metodología para estimar la fuente glótica, los correlatos biomecánicos y los parámetros de ciclicidad parece ser suficientemente robusta para ampliar dicho estudio con una base de datos más extensa, con un mayor número de individuos, la cual ayudará a obtener un mejor contraste de los resultados obtenidos.

\subsubsection{Comportamiento de los parámetros biométricos fren- te al género}

Este trabajo intenta focalizar sus esfuerzos en mostrar la relación existente entre la firma biométrica de la voz basada en la caracterización de la biomecánica glotal y las perturbaciones en la rigidez de las cuerdas vocales que se manifiesta en forma de temblor. Este a su vez puede ser usado como descriptor de emociones.

Continuando con lo mencionado en la sección anterior, se ha aumentado el número de individuos. Para este caso de estudio se ha utilizado el corpus 5 (véase sección 2.3.3). Nuevamente se ha evaluado la elicitación del estrés emocional [58].

La nomeclatura utilizada para explicar las variaciones obtenidas respecto de los datos neutros es la siguiente: H (High) implica un incremento en el valor del parámetro cuando el discurso es no congruente, mientras que L (Low) significa una disminución, y S (the Same) una variación no significativa. Se etiqueta como S cuando los valores están por debajo de un $20 \%$ cuando se sustrae el valor contradictorio frente al valor consistente.

En la Tabla 5.2 se pueden ver los resultados obtenidos. Se puede observar que los valores estimados para la rigidez del cuerpo han sufrido una disminución en catorce de las mujeres, es decir, el $70 \%$ de la población femenina, y un incremento en tres mujeres, o dicho de otra forma, el $15 \%$ mientras que otro $15 \%$ (tres mujeres) permanece invariable o aproximadamente igual. 
La rigidez de la cubierta muestra la misma tendencia que la rigidez del cuerpo, y muestra una disminución en once de las veinte mujeres, o lo que es lo mismo en un $55 \%$, un incremento en siete mujeres $(35 \%)$ y finalmente dos casos que no han sufrido grandes cambios $(10 \%)$.

Sin embargo, $c_{1}$ y $c_{2}$ presentan un comportamiento opuesto al de la tensión. $c_{1}$ aumenta en quince de los casos $(75 \%)$ y disminuye tan solo en cinco casos $(25 \%)$, mientras que $c_{2}$ aumenta en doce de los veinte casos $(60 \%)$ y disminuye en ocho $(40 \%)$.

\begin{tabular}{rrrrrrrrrrrrrrrrrrrrrr}
\hline Women & $\mathbf{1}$ & $\mathbf{2}$ & $\mathbf{3}$ & $\mathbf{4}$ & $\mathbf{5}$ & $\mathbf{6}$ & $\mathbf{7}$ & $\mathbf{8}$ & $\mathbf{9}$ & $\mathbf{1 0}$ & $\mathbf{1 1}$ & $\mathbf{1 2}$ & $\mathbf{1 3}$ & $\mathbf{1 4}$ & $\mathbf{1 5}$ & $\mathbf{1 6}$ & $\mathbf{1 7}$ & $\mathbf{1 8}$ & $\mathbf{1 9}$ & $\mathbf{2 0}$ \\
\hline Body & H & L & L & L & L & L & L & S & H & L & L & S & S & L & L & H & L & L & L & L \\
Cover & H & L & H & H & L & L & S & H & H & L & L & L & L & H & L & H & S & L & L & L \\
C1 & H & H & H & H & H & H & L & L & L & H & H & H & H & H & H & H & L & H & H & L \\
C2 & H & H & L & H & H & H & L & L & L & H & H & H & L & H & H & L & L & H & H & L \\
\hline
\end{tabular}

Tabla 5.2: Variaciones de los parámetros para mujeres.

A partir de estos resultados se puede inferir que el estrés en la mayoría de las mujeres implica una disminución en la rigidez del cuerpo y la cubierta, y un incremento en los coeficientes cíclicos. Por consiguiente, parece que su tendencia es a relajar las cuerdas vocales y a aumentar el temblor en su discurso.

Los resultados para los hombres se muestran en la Tabla 5.3, y a simple vista muestran un comportamiento inverso al mostrado por las mujeres en la Tabla 5.2. En los hombres, los valores de la rigidez del cuerpo aumentan en un $60 \%$ de los casos, mientras que disminuyen en un $30 \%$, y un $10 \%$ permanecen sin variación.

La rigidez de la cubierta se incrementa en el $50 \%$ de los casos, mientras que disminuye en casi la totalidad del resto de casos (45\%), y finalmente tan solo un $5 \%$ permanece sin variaciones.

El primer coeficiente cíclico, $c_{1}$, disminuye en un $65 \%$ de los casos y aumenta en el resto de casos $35 \%$. Y finalmente, el segundo parámetro cíclico tiene el mismo comportamiento que el primero, donde el $75 \%$ de los casos sufre una disminución y el $25 \%$ restante aumenta.

Para concluir, desde el punto de vista de una situación de estrés emocional anteriormente descrita, la tendencia de la población masculina es a aumentar los valores de rigidez como consecuencia de una tensión en sus cuerdas vocales, y disminuir sus parámetros cíclicos, $c_{1}$ y $c_{2}$, lo cual se traduce en un menor nivel de temblor. 


\begin{tabular}{rrrrrrrrrrrrrrrrrrrrrr}
\hline Men & $\mathbf{1}$ & $\mathbf{2}$ & $\mathbf{3}$ & $\mathbf{4}$ & $\mathbf{5}$ & $\mathbf{6}$ & $\mathbf{7}$ & $\mathbf{8}$ & $\mathbf{9}$ & 10 & 11 & 12 & 13 & 14 & 15 & 16 & 17 & 18 & 19 & 20 \\
\hline Body & H & H & H & H & L & L & H & H & S & L & H & L & S & L & H & H & H & H & H & L \\
Cover & H & H & S & H & L & H & H & H & H & L & L & L & H & L & L & H & H & L & L & L \\
C1 & H & L & L & L & L & L & L & H & L & L & H & H & H & L & L & H & L & L & L & H \\
C2 & H & L & L & L & H & H & L & L & L & H & L & L & L & L & L & L & L & L & L & H \\
\hline
\end{tabular}

Tabla 5.3: Variaciones de los parámetros para hombres.

En esta primera aproximación, los rasgos biométricos propuestos parecen ser indicadores adecuados para caracterizar el estrés emocional en el habla. En las mujeres, los resultados reflejan una variabilidad del $85 \%$ en la rigidez del cuerpo de las cuerdas vocales y un $90 \%$ en la rigidez de su cubierta. En los hombres, la rigidez del cuerpo y la cubierta presentan un $5 \%$ más de variabilidad que en las mujeres. En ambos géneros la variabilidad es de un $100 \%$ en los parámetros cíclicos. Sin embargo, la tendencia de la variabilidad de los parámetros (el incremento o la disminución) parece presentar un patrón más definido en las mujeres que en los hombres.

La dificultad para obtener datos fiables es el mayor problema en este trabajo, las muestras no pueden ser tomadas una segunda vez para el mismo locutor con el protocolo utilizado para evocar estrés, porque la espontaneidad de las respuestas se pierde. Por otro lado, las preguntas realizadas son muy controvertidas y comprometidas, por consiguiente algunas personas pueden haber contestado de forma políticamente correcta, en lugar de contestar lo que realmente piensen o ser consecuentes con sus puntos de vista personales.

\subsubsection{Metodología para Monitorizar Estrés Emocional}

Una vez que se ha mostrado que el estrés emocional se puede estimar a partir de los correlatos biomecánicos expresados por la tensión y el temblor [65], se continua probando la metodología de las encuestas (véase sección 2.2.2) aunada con otros métodos para poder comprobar si tiene validez estadística.

Para este caso, se utilizó el corpus 6 [14]. Los valores de las estimaciones de la rigidez de los pliegues vocales (tensión media biomecánica expresada en $10^{-3} \mathrm{~N} / \mathrm{m}$ a lo largo de todos los ciclos de fonación producidos en un segmento) a partir de las muestras de tipo congruente (en calma) y las muestras de incongruencia (bajo estrés) dadas en la Tabla 5.4 en el caso de los hombres y en la Tabla 5.5 para las mujeres. 


\begin{tabular}{ccc}
\hline Locutor & Body St. pro $\left(10^{-3} \mathrm{~N} / \mathrm{m}\right)$ & Body St. $\operatorname{con}\left(10^{-3} \mathrm{~N} / \mathrm{m}\right)$ \\
\hline \hline M1 & 8.557 & 9.488 \\
\hline M2 & 7.894 & 9.095 \\
\hline M3 & 12.401 & 13.637 \\
\hline M4 & 14.595 & 18.001 \\
\hline M5 & 13.695 & 12.969 \\
\hline M6 & 9.831 & 9.572 \\
\hline M7 & 13.262 & 14.558 \\
\hline M8 & 9.684 & 9.840 \\
\hline M9 & 7.893 & 8.015 \\
\hline M10 & 14.492 & 13.097 \\
\hline M11 & 9.627 & 10.819 \\
\hline M12 & 11.117 & 10.220 \\
\hline M13 & 9.658 & 9.579 \\
\hline M14 & 9.802 & 9.150 \\
\hline M15 & 9.266 & 9.994 \\
\hline M16 & 9.221 & 9.684 \\
\hline M17 & 7.958 & 10.806 \\
\hline M18 & 11.884 & 12.679 \\
\hline M19 & 9.281 & 10.087 \\
\hline M20 & 9.841 & 9.053 \\
\hline
\end{tabular}

Tabla 5.4: Valores medios obtenidos para la rigidez del cuerpo body stiffness para las situaciones de congruencia ( $\mathrm{pro}=\mathrm{a}$ favor) e incongruencia (con=en contra) para el conjunto de los hombres.

\begin{tabular}{ccc}
\hline Locutor & Body St. $\operatorname{pro}\left(10^{-3} \mathrm{~N} / \mathrm{m}\right)$ & Body St. con $\left(10^{-3} \mathrm{~N} / \mathrm{m}\right)$ \\
\hline \hline F1 & 17.615 & 18.388 \\
\hline F2 & 23.300 & 20.820 \\
\hline F3 & 23.288 & 21.480 \\
\hline F4 & 19.635 & 15.117 \\
\hline F5 & 17.809 & 12.821 \\
\hline F6 & 14.724 & 13.307 \\
\hline F7 & 13.954 & 12.477 \\
\hline F8 & 21.715 & 21.674 \\
\hline F9 & 18.422 & 22.493 \\
\hline F10 & 33.220 & 23.297 \\
\hline F11 & 19.682 & 15.307 \\
\hline F12 & 18.838 & 18.554 \\
\hline F13 & 21.222 & 21.354 \\
\hline F14 & 30.758 & 19.522 \\
\hline F15 & 19.700 & 17.281 \\
\hline F16 & 14.354 & 21.277 \\
\hline F17 & 16.725 & 16.059 \\
\hline F18 & 17.794 & 16.488 \\
\hline F19 & 21.136 & 16.248 \\
\hline F20 & 22.799 & 20.228
\end{tabular}

Tabla 5.5: Valores medios obtenidos para la rigidez del cuerpo body stiffness para las situaciones de congruencia ( $\mathrm{pro}=\mathrm{a}$ favor) e incongruencia (con=en contra) para el conjunto de las mujeres.

El análisis estadístico utilizado fue un test de emparejado de la prueba $t$-Student 
también conocido como pair-wise test, donde la hipótesis nula, $H_{0}$ se evalúa como la diferencia entre las estimaciones medias de la rigidez del cuerpo de los pliegues vocales para las muestras de congruencia e incongruencia, las cuales pueden ser modeladas como si fueran la misma distribución estadística. En otras palabras, que no hay diferencias significativas entre las estimaciones tomadas bajo diferentes condiciones (en calma y de estrés) siempre que el p-value obtenido sea mayor del 0.05 si se ha establecido dicho nivel de significación.

El cálculo de la rigidez biomecánica de los pliegues vocales se ha realizado a través del proceso explicado en el capítulo 3 y más concretamente en la sección 3.3.4.1. Cabe incidir en que el interés específico de la tensión biomecánica de los pliegues vocales es debido al hecho que este rasgo está directamente relacionado con la tasa de disparos neuromotores que actúan sobre los músculos laríngeos, y acusa el estrés emocional en marcas de baja y alta tensión biomecánica, al igual que el temblor [65]. Estos correlatos significativos cuantifican el estrés en los pliegues vocales, y el temblor, expresados en frecuencia y valor eficaz (amplitude rms) relativo a su valor medio.

En la Tabla 5.6 se muestran los resultados del test pair-wise llevado a cabo, donde la media de las diferencias entre las muestras congruentes e incongruentes se presentan en la primera línea de la tabla con la etiqueta media. La desviación media es positiva para los hombres $(0.519 \mathrm{~N} / \mathrm{m})$ mientras que es negativa para las mujeres $(-2.125 \mathrm{~N} / \mathrm{m})$. Esto indicaría una relajación de la rigidez de los pliegues vocales en situaciones contradictorias como la marca de comportamiento en las mujeres, donde los resultados indican un incremento en el mismo rasgo para los hombres, como ya se ha mencionado en el apartado anterior.

\begin{tabular}{lrr}
\hline Estadístico & Hombres & Mujeres \\
\hline \hline media & 0.519 & -2.125 \\
\hline desviación típica & 1.208 & 4.079 \\
\hline EEN & 0.382 & 1.29 \\
\hline estadístico-t & 1.36 & 1.65 \\
\hline p-value & $\mathbf{0 . 0 3 4 8}$ & $\mathbf{0 . 0 1 5 5}$ \\
\hline Rechazo $H_{0}$ & SI & SI \\
\hline
\end{tabular}

Tabla 5.6: Diferentes estadísticos para los tests de la t-Student

Otro parámetro de interés es el error estándar normalizado EEN, para los tamaños de las muestras, donde el conjunto de las mujeres triplica el valor obtenido por el conjunto masculino. Partiendo de estos valores los resultados de la prueba t se muestran en la fila con el mismo nombre, junto con su p-value asociado. Se puede comprobar que en ambos casos la hipótesis nula $\left(H_{0}\right)$ resulta ser rechazada, puesto que el valor obtenido es menor de 0.05, validando que la metodología de evocación de estrés es estadísticamente significativa para ambos conjuntos de datos (hombres y mujeres). 
Los resultados obtenidos y comentados en las tablas 5.4 y 5.5 para hombres y mujeres se han representado en las figuras 5.7 y 5.8 , respectivamente. Se ha realizado una regresión lineal (véase sección 4.2) con ambos conjuntos de datos y se ha calculado la ecuación del coeficiente de determinación para sendos conjuntos. Se puede observar que los resultados obtenidos para el conjunto de datos masculino son menos dispersos que los resultados para el conjunto femenino, o dicho en otros términos, los valores obtenidos para las condiciones de congruencia e incongruencia son bastante más similares en el caso de los hombres que en el caso de las mujeres. Aun así, confirmamos este hecho, realizando la raíz cuadrada del coeficiente de determinación para obtener el coeficiente de correlación de Pearson para cada uno de los conjuntos, arrojando un valor mucho más grande para los hombres que para las mujeres (0.87 frente a 0.56$)$.

La hipótesis nula $\left(H_{0}\right)$ se ha dibujado, en las figuras anteriormente mencionadas, como una línea discontinua roja correspondiente a la suposición de que la tensión media de los pliegues vocales para las condiciones de congruencia sea igual a la tensión media de los pliegues vocales para las condiciones de incongruencia. Además, se presentan en sendas figuras dos líneas de delimitación (guiones de color malva) alrededor de la hipótesis nula, las cuales representan el error estándar normalizado. Las muestras que se encuentran dentro de las líneas de delimitación se consideran de baja sensibilidad para el test. Por otro lado, las muestras por encima (en rojo oscuro) han experimentado un incremento de tensión en el pliegue, mientras que las muestras que se encuentran por debajo han experimentado una disminución en la tensión de sus pliegues vocales.

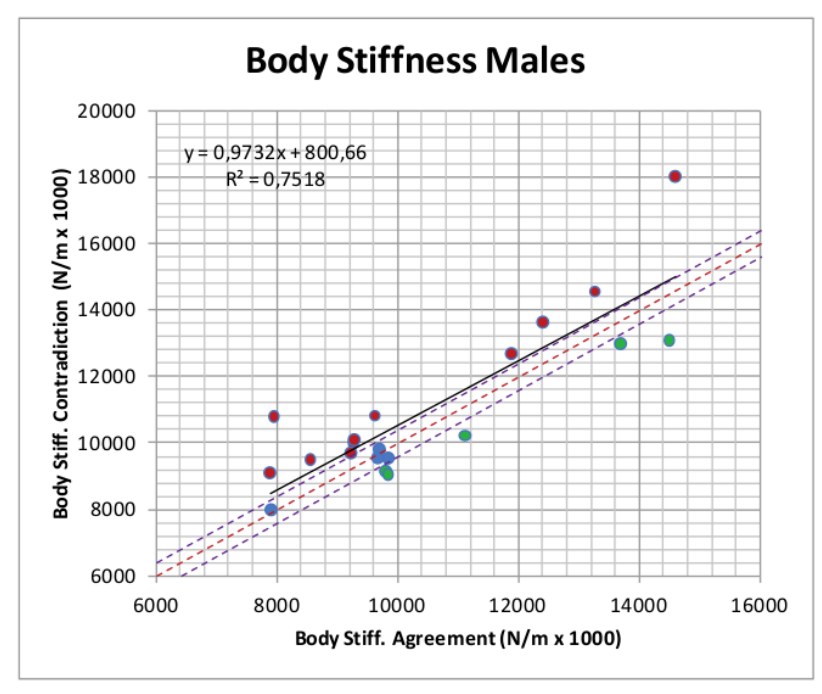

Figura 5.7: Comparación de la rigidez del cuerpo de las cuerdas vocales entre las muestras con versus pro para el conjunto de muestras masculinas. La expresión de la regresión lineal se muestra con una línea negra sólida. 


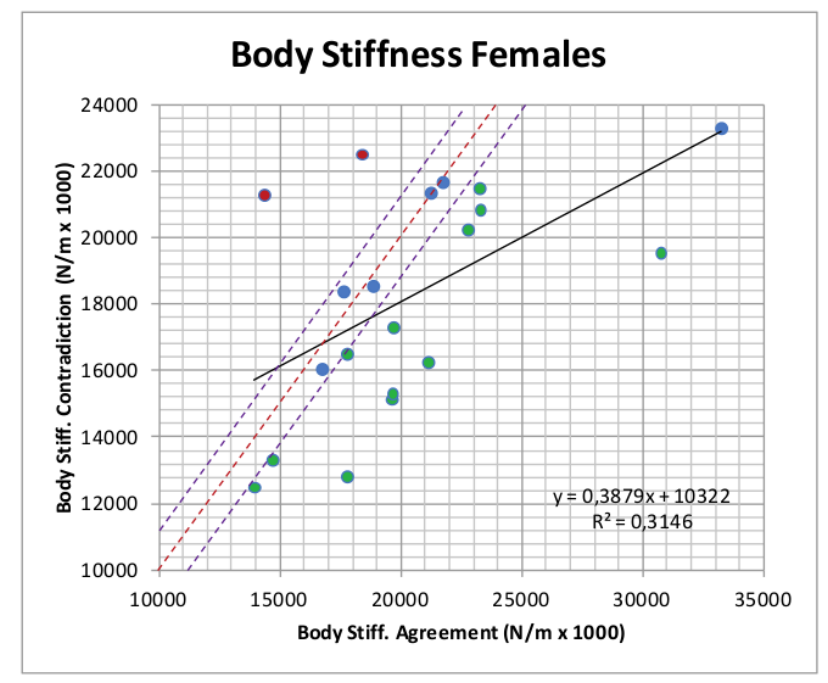

Figura 5.8: Comparación de la rigidez del cuerpo de las cuerdas vocales entre las muestras con versus pro para el conjunto de muestras femeninas. La expresión de la regresión lineal se muestra con una línea negra sólida.

\subsection{Validación de la coherencia de datos}

La detección de la coherencia (verdad) y la incoherencia (mentira) en un discurso oral es una tarea muy difícil, la cual siempre ha sido un tema de controversia, ya que hay personas que tienen especial habilidad para modificar su discurso manteniendo una tesis y la contraria sin mostrar alteración aparente. El engaño deja marcas en muchos parámetros físicos que son reflejos inconscientes y por tanto completamente involuntarios, tales como actividad ocular, facial, la conductancia de la piel, sudor, sonrojo, el ritmo cardíaco y respiratorio entre otros [41]. Sin embargo, queda mucho por hacer para llegar a obtener resultados significativos de forma automática.

El presente enfoque muestra una posible aplicación de la detección del estrés para poder validar conjuntos de datos derivados de estados emocionales alterados por la congruencia del discurso. El estrés se manifiesta en la prosodia, la articulación y los correlatos de fonación. Muchos trabajos en la literatura relacionan la detección del estrés emocional en el habla; la mayoría de ellos, proponen sistemas de detección independientes al lenguaje utilizado. La propuesta realizada por Lefter [98] separa el discurso considerado neutro del discurso emocional gracias a un conjunto de características prosódicas basadas en el nivel de las palabras y las características espectrales a nivel de trama. El conjunto de datos se derivó de grabaciones procedentes de un call center.

El trabajo propuesto por Demenko [40] se centra en la variabilidad y analiza su comportamiento respecto de la base de datos proporcionada por la policía con muestras espontáneas de llamadas de emergencias.

Otros autores completan la toma de voz con un conjunto de señales adiciona- 
les obtenidas a través de biosensores, como la conductancia de la piel [75], análisis químicos, o electrocardiogramas. En [116] se presenta una relación entre el estrés y las microfluctuaciones de temblor en las cuerdas vocales, las cuales se analizan en [100].

El objetivo de este caso de estudio es identificar alteraciones en el discurso causadas por el estrés en individuos de una población, es decir, dado un conjunto de individuos se calcula cómo de congruentes o incongruentes están siendo, respecto del resto de individuos de su población. Esta estimación se usa como indicador para detectar incoherencia en el discurso a partir del cálculo del ratio de máxima verosimilitud logarítmica.

La utilización de un método logarítmico viene cimentado por las diferencias de los valores obtenidos en las distribuciones individuales por cada característica o parámetro extraído y la inversión de la matriz de covarianza que reproduce casos bastantes inestables. Un ejemplo de lo anteriormente comentado se puede observar en la característica 66 (frecuencia del temblor fisiológico) en la Figura 5.9. En esta ilustración se puede ver que la distribución bajo situación de incongruencia o estrés coloreada en azul es más dispersa que la distribución bajo condición de congruencia o calma coloreada en color rojo y que la media de la frecuencia del temblor es también mayor (alrededor de 4.7 Hercios para la distribución de estrés respecto a los 4.5 Hercios para la distribución neutra).

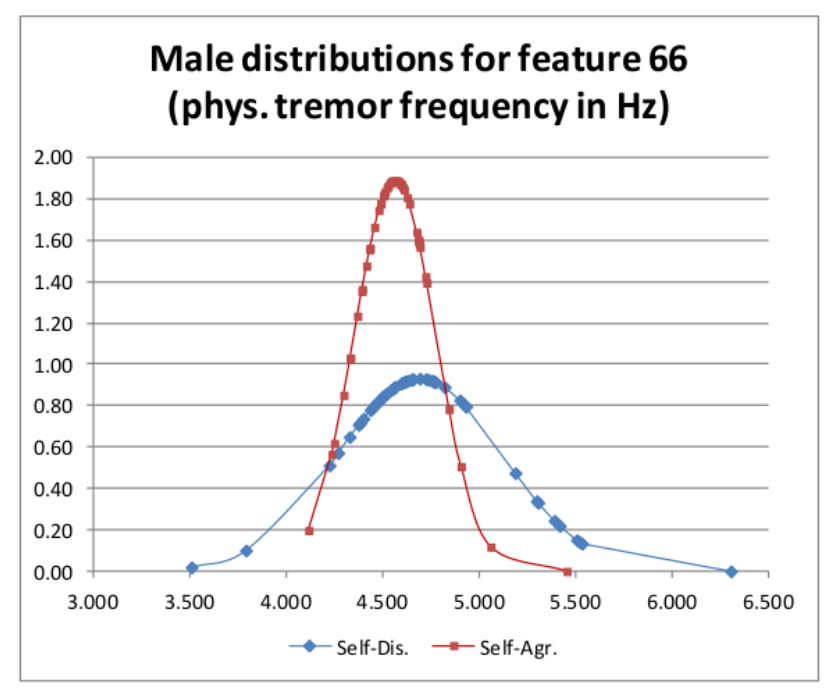

Figura 5.9: Distribuciones del parámetro 66 (frecuencia del temblor fisiológico) relativo a la distribución neutra o congruente (azul - diamante) y la distribución de estrés o engaño (rojo - cuadrados). El eje de abscisas representa los Hercios de la frecuencia y el eje de ordenadas están los recuentos normalizados. Ambas distribuciones se pueden representar como distribuciones cuasi-Gaussianas.

Los resultados de clasificación pertenecientes a los dieciséis hombres con sus 72 parámetros extraídos se muestran en la Tabla 5.7, dadas las expresiones 4.31 
presentadas en la Sección 4.5.2 y que se reproducen a continuación:

$$
\begin{aligned}
\vartheta_{a m i} & =\sum_{1}^{J} f_{m j} \lambda_{a m i j} \\
\vartheta_{d m i} & =\sum_{1}^{J} f_{m j} \lambda_{d m i j} \\
\vartheta_{a f i} & =\sum_{1}^{J} f_{f j} \lambda_{a f i j} \\
\vartheta_{d f i} & =\sum_{1}^{J} f_{f j} \lambda_{d f i j}
\end{aligned}
$$

la cual indica que un resultado positivo explica un estado neutro mientras que un resultado negativo expresa un estado de estrés. En esta tabla puede observarse que la tasa de clasificación obtenida para las muestras neutras o carentes de estrés es del $100 \%$, mientras que esta tasa desciende hasta un $56 \%$ en el caso de las muestras bajo estrés. En una primera interpretación, los resultados obtenidos para el discurso o muestras de estrés son muy pobres porque el $44 \%$ de las muestras teóricamente producidas en una situación bajo estrés son identificadas como neutras. Sin embargo, la forma en que el estrés ha sido elicitado en los individuos puede soportar una segunda interpretación de los resultados.

\begin{tabular}{ccc}
\hline Hombres & Neutro $\left(\vartheta_{a m}\right)$ & Estrés $\left(\vartheta_{d m}\right)$ \\
\hline \hline M1 & 0,327 & $-1,268$ \\
M2 & 0,081 & $-2,288$ \\
M3 & 0,343 & $-0,510$ \\
M4 & 0,595 & 0,290 \\
M5 & 0,168 & $-1,002$ \\
M6 & 0,654 & $-7,323$ \\
M7 & 0,387 & 0,008 \\
M8 & 0,808 & 0,621 \\
M9 & 0,422 & $-5,965$ \\
M10 & 0,370 & 0,310 \\
M11 & 2,094 & $-0,218$ \\
M12 & 0,335 & 0,322 \\
M13 & 0,272 & $-0,823$ \\
M14 & 0,289 & 0,589 \\
M15 & 1,118 & $-1,562$ \\
M16 & 0,536 & 0,461 \\
\hline \hline Clasificación & $\mathbf{1 0 0 \%}$ & $\mathbf{5 6 \%}$ \\
\hline
\end{tabular}

Tabla 5.7: Resultados de la probabilidad logarítmica para los hombres.

Las muestras de voz fueron obtenidas de dos temas, ambos de plena actualidad 
en el momento de las grabaciones, los cuales evocaron en la persona altos niveles de valencia y excitación. Los temas fueron escogidos de entre una "bolsa" de temas controvertidos. Por consiguiente, pudiera darse el caso de que los individuos respondieran de forma políticamente correcta en lugar de ofrecer su opinión sincera sobre el tema. Para analizar este problema, los resultados neutros y de estrés para el mismo sujeto deben ser estudiados como un todo. Finalmente, se ha decidido optar por esta segunda interpretación a la hora de mostrar los resultados numéricos representados en la Figura 5.10, donde el eje " $x$ " representa los valores neutros y el eje " $y$ " muestra los valores de estrés.

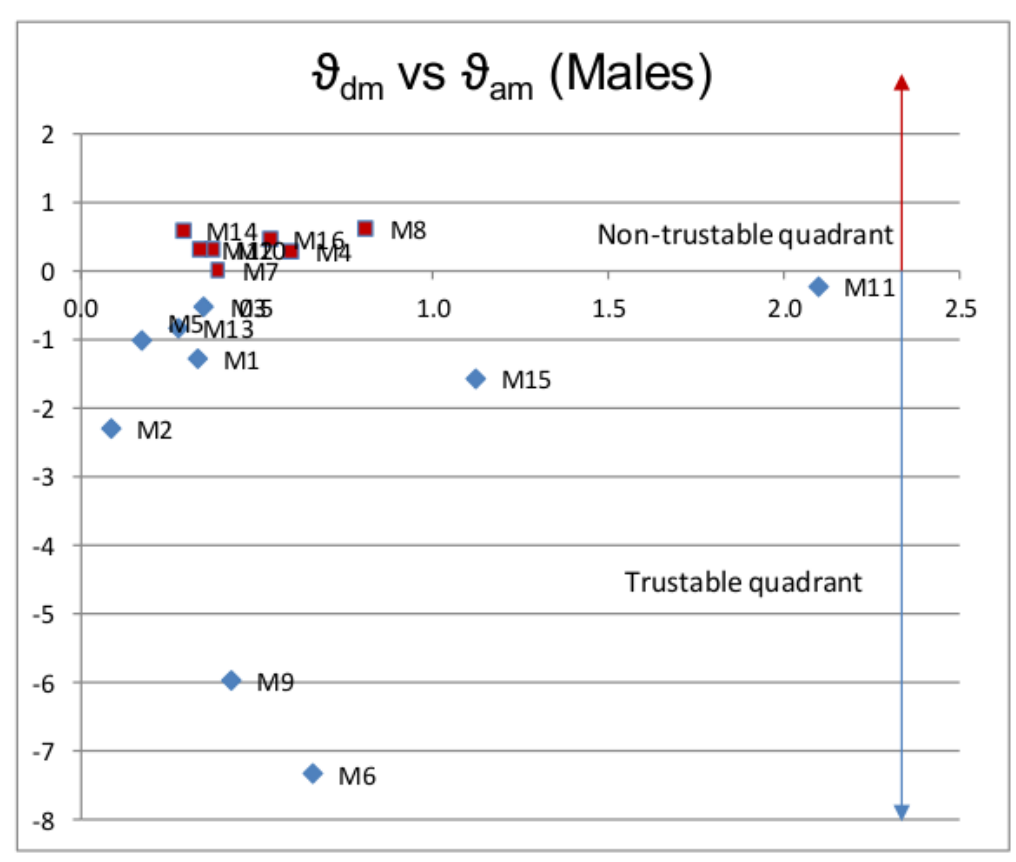

Figura 5.10: Locutores masculinos representados en dos áreas: confiable - diamantes y no-confiable - cuadrados.

Los resultados mostrados presentan dos áreas bien definidas, la confiable y la no confiable. La parte inferior incluye aquellos individuos que han contestado congruentemente según el protocolo de adquisición de datos, es decir, ellos han dado su opinión sincera y su contraria justo cuando se le solicitaba realizar dicha acción en cada fase de la metodología. Las muestras que se pueden consideran "confiables" son las etiquetadas como M1, M2, M3, M5, M6, M9, M13 y M15. En la parte superior de la Figura 5.10 se representan los individuos que siempre muestran un estado neutro y que son sospechosos de emitir respuestas políticamente correctas en lugar de responder en congruencia con sus propias ideas. Esta área se la define como zona no-confiable o (non-trustable area). Las muestras que se colocan en esta zona son M4, M8, M10, M12, M14 y M16. Tras obtener estos resultados se volvió a realizar una escucha de estas grabaciones en cuestión, dándose el caso de que la mayoría de estas respuestas versan sobre problemas de género (véase el apartado - cuestionario de preguntas en 2.3.1 en el capítulo 2), tales como "igualdad en tareas domésticas entre sexos" e "igualdad de salarios entre sexos". Las muestras M7 y M11 están 
localizadas a ambos lados de la línea fronteriza entre ambas áreas. Estos dos últimos sujetos contestaron a la misma pregunta cuando la situación era de congruencia, "crisis politica", mientras que las respuestas para el caso de incongruencia fueron distintas. M7 contestó a la pregunta "igualdad de derechos entre opciones sexuales" y M11 a la pregunta "igualdad de salarios entre sexos", ambas preguntas ligadas íntimamente con el género. Dado que ambos individuos se encuentran cercanos a la línea divisoria, cabe pensar que M7 y M11 realizaron de manera correcta la primera parte de la metodología, sin embargo en la segunda parte, M7 no respondió acorde a la pregunta realizada.

Se ha realizado un estudio similar para el grupo de las 18 mujeres. Los resultados de clasificación utilizando los 72 parámetros se muestran en la Tabla 5.8. La clasificación para el estado neutro falla tan solo en un caso de los 18, dando una tasa cercana al $100 \%$, muy similar a la tasa obtenida con los hombres, mientras que la clasificación para el estado de estrés falla en seis de los dieciocho casos posibles, alcanzando una tasa de predicción del $67 \%$, que es mejor resultado que el obtenido para la distribución masculina.

\begin{tabular}{ccc}
\hline Mujeres & Neutro $\left(\vartheta_{a f}\right)$ & Estrés $\left(\vartheta_{d f}\right)$ \\
\hline \hline F1 & 0,206 & $-0,222$ \\
F2 & 0,020 & $-1,435$ \\
F3 & 0,251 & $-0,860$ \\
F4 & 0,148 & 0,167 \\
F5 & 0,227 & $-0,548$ \\
F6 & 0,172 & $-0,313$ \\
F7 & 0,042 & $-0,108$ \\
F8 & 0,200 & 0,027 \\
F9 & 0,190 & 0,127 \\
F10 & 0,145 & $-0,096$ \\
F11 & 0,210 & $-0,093$ \\
F12 & 0,066 & $-0,007$ \\
F13 & $-0,235$ & 0,064 \\
F14 & 0,374 & $-1,041$ \\
F15 & 0,172 & 0,105 \\
F16 & 0,292 & $-0,121$ \\
F17 & 0,255 & $-0,215$ \\
F18 & 0,081 & 0,129 \\
\hline \hline Clasificación & $\mathbf{9 4 \%}$ & $\mathbf{6 7 \%}$ \\
\hline
\end{tabular}

Tabla 5.8: Resultados de la probabilidad logarítmica para las mujeres.

Los resultados numéricos se han presentado gráficamente en la Figura 5.11. En la misma se puede ver que el área más poblada es la confiable. Los casos que se sitúan en esta zona son: F1, F2, F3, F5, F6, F7, F10, F11, F14, F16 y F17. La zona noconfiable tiene cuatro casos claros: F4, F9, F15 y F18. Y la frontera entre ambas áreas contiene dos casos: el F8 y el F12. El caso F13 se comporta de manera completamente 
contraria a lo establecido en el protocolo, es decir, cuando se le solicitó que dijera lo que verdaderamente pensaba sobre un tema, contestó lo contrario y viceversa. Tal vez, esta locutora no entendió bien la dinámica del ejercicio o simplemente no se le explicó de manera adecuada.

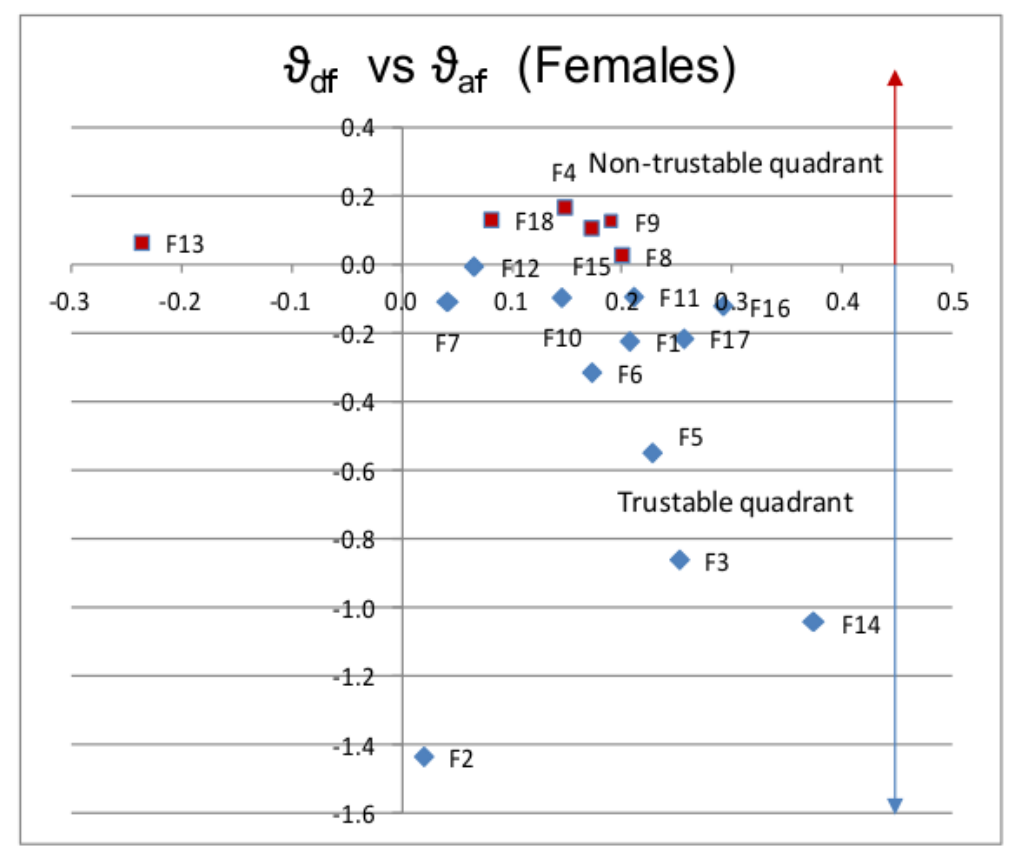

Figura 5.11: Locutoras femeninas representadas en dos áreas: confiable - diamantes y no-confiable - cuadrados.

Como se ha explicado en párrafos anteriores cada individuo se comporta de una forma única ante este tipo de estudio. Es por ello que esta metodología intenta compensar la desviación inducida por tales comportamientos tanto como sea posible utilizando mecanismos de verificación por varios modos o (cross-check). Por tanto cada respuesta de un sujeto se evaluá frente a la distribución completa de estado neutro/congruencia o el estado de estrés/incongruencia dado el género. Después de examinar los resultados comentados en las Tablas 5.7 y 5.8 y representados en las Figuras 5.10 y 5.11 su interpretación quedó mucho más clara.

Es interesante comprobar que algunas de las locutoras que se sitúan en la zona no confiable respondieron a preguntas tales como "igualdad en tareas domésticas entre sexos", "igualdad de salarios entre sexos", "legislación sobre el aborto". Por ejemplo, F4, F9 y F12 contestaron a la misma pregunta cuando se les solicitaba que defendieran la idea contraria a su opinión personal. F12 se situó en la frontera entre ambas zonas, por consiguiente no se aleja demasiado respecto del resto de locutoras " $n o$ confiables". Además, F9 y F12 contestaron a las mismas preguntas en los mismos casos. Por otro lado, otras preguntas contestadas por este conjunto de locutoras que se situaron en la zona no confiable estaban relacionadas con la política y cuestiones de género, nuevamente. Estas últimas líneas quieren destacar el hecho que diversas locutoras contestando a las mismas preguntas, cada una de ellas se posicionan en cuadrantes diferentes debido a que sus contestaciones pueden ser congruentes con 
su opinión personal, mientras que en otras ocasiones la respuesta ofrecida pudiera ser considerada como políticamente correcta.

En la Figura 5.12 se pueden observar las interpretaciones a las que se ha llegado a partir de los resultados por pares obtenidos para ambos géneros. En primer lugar, el área que hemos llamado "de confianza", la cual se encuentra en el cuarto cuadrante $(+,-)$, donde los resultados son congruentes con respecto al comportamiento que se esperaba dada la metodología, de modo que, cuando un locutor responde congruentemente debe haberse obtenido un valor positivo al compararse frente al resto de individuos de la distribución y similarmente debe de haberse obtenido un valor negativo cuando el sujeto responde de modo incongruente.

\section{Self-disagree}

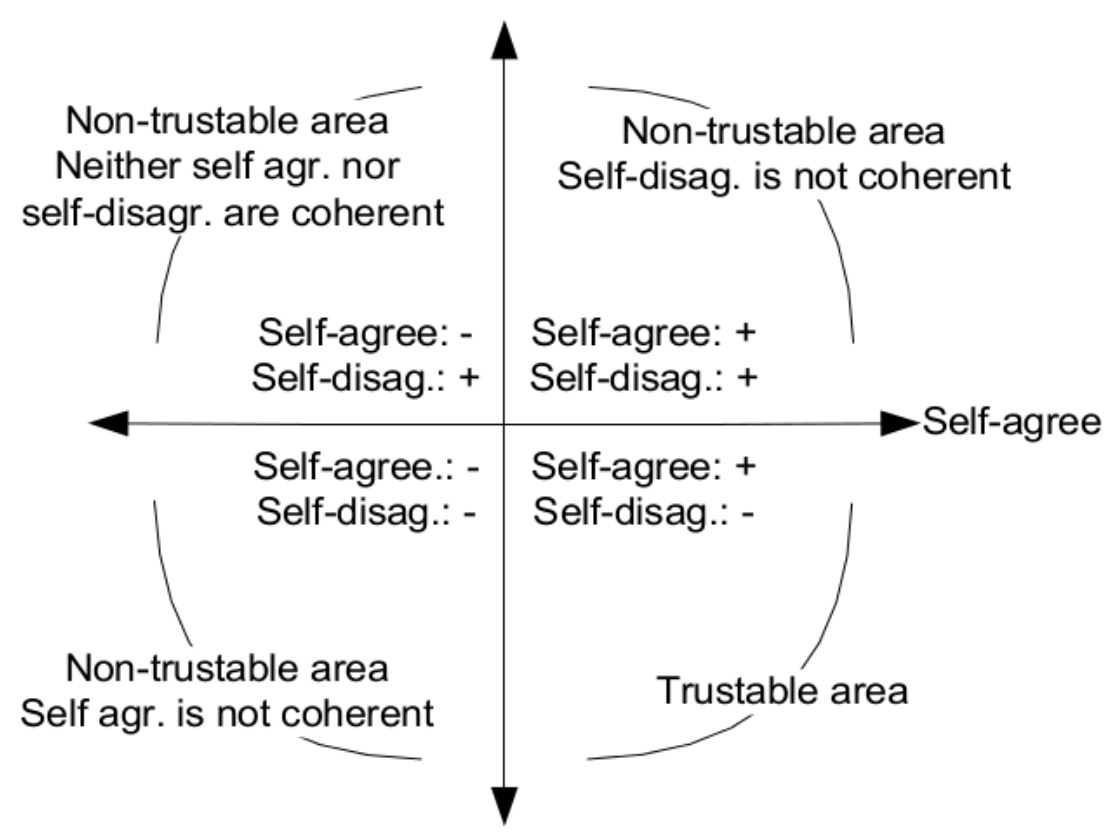

Figura 5.12: Áreas específicas para la detección de la coherencia de los datos.

El primer cuadrante $(+,+)$ representa aquellos individuos que son congruentes o coherentes en la primera parte del ejercicio, es decir, el resultado obtenido es positivo cuando responden congruentemente, sin embargo el valor obtenido cuando se supone que tienen que defender la idea contraria a sus opiniones o ideas vuelve a ser positivo.

El tercer cuadrante (-,-) opuesto al anterior, contiene aquellos individuos que cuando tienen que expresar sus opiniones o ideas "propias" obtienen un valor negativo mostrando incongruencia, mientras que cuando se supone que tienen que defender la idea contraria a sus opiniones el resultado obtenido vuelve a ser negativo. Podría definir a ese grupo que nunca está de acuerdo con nada. En este cuadrante no se ha situado ninguno de los sujetos analizados.

Finalmente, el segundo cuadrante $(-,+)$ y el más conflictivo, pertenece a aquellos 
individuos que van a contracorriente, o dicho en otras palabras, producen justo los valores contrarios a lo esperado, es decir, cuando se les solicita que digan sus opiniones el valor que se obtiene es negativo, cuando en realidad debería de ser positivo y viceversa, cuando se supone que deben de obtener un valor negativo por responder de forma incongruente, producen un valor positivo. El único caso en que se ha observado este comportamiento fue con la locutora número 13 (F13), aunque también es cierto que su valor está muy cercano al valor cero en el caso de la expresión de incongruencia.

Como conclusión de este apartado se puede decir que las muestras analizadas se mueven en los cuadrantes que indican la coherencia de las respuestas y lo políticamente correcto, por lo tanto son datos validados.

En cualquier caso, este estudio permitiría hacer un primer filtro de los datos para eliminarlos del conjunto de estudio de cara a una futura ampliación de la base de datos.

\subsection{Prospectiva inicial para la selección de rasgos característicos}

Una vez que se ha mostrado que los rasgos biomecánicos son relevantes a la hora de detectar estrés en el habla y que se ha diseñado una técnica con la que validar de forma objetiva las muestras obtenidas en un conjunto de datos emocional, el siguiente paso lógico sería empezar a concretar el grado de validez estadística de estos rasgos. Para ello se quiere realizar una primera selección de rasgos a baja escala y con una orientación completamente semántica, es decir, no se buscó una tasa de acierto per se, si no cómo de bien estos rasgos se comportan a la hora de clasificar muestras emocionales.

Para abordar una primera selección de parámetros se utilizó el coeficiente de correlación de Pearson y el coeficiente de determinación, los cuales fueron introducidos en la sección 4.2. Por otro lado, para clasificar las muestras se utilizó el algoritmo SVM (véase sección 4.5.1) y el conjunto de datos utilizado fue el corpus 7 .

El objetivo de este caso de estudio se basa en una interpretación geométrica del conjunto de datos femenino, definido como $f$, de entre las muestras congruentes, denotadas por $a$, frente a las de incongruencia, denotadas por $d$, donde el coeficiente de Pearson de cada característica denotado como $P_{j}$ puede ser interpretado como el coseno del ángulo entre los vectores de la característica $j$ en las grabaciones neutras $x_{f a j}$ y el vector para la misma característica de las grabaciones consideradas de estrés $x_{f d j}$.

$$
P_{j}\left(x_{f a j}, x_{f d j}\right)=\cos \beta_{j}
$$

La interpretación del coeficiente de correlación que se va a utilizar es la siguiente: 
- $P_{j}=1$ cuando $\beta_{j}=0$. Los vectores están alineados y mirando en la misma dirección. Estos rasgos presentan la máxima correlación positiva.

- $P_{j}=0$ cuando $\beta_{j}=\pi / 2$. Los vectores son ortogonales y no hay correlación entre ellos.

- $P_{j}=-1$ cuando $\beta_{j}=\pi$. Los vectores están alineados y mirando en direcciones opuestas. Estos parámetros muestran máxima correlación negativa.

Un posible criterio para establecer un mínimo coeficiente de correlación para la selección de rasgos podría establecerse a partir de un vector neutro, cuando $\beta_{j}=\pi / 4$, entonces $P_{\text {min }_{j}}=0,707$. Este criterio encierra el conjunto de valores con alta correlación positiva dentro de un cono como se muestra en la Figura 5.13. La interpretación de este criterio se basa en que con un ángulo de 45 grados se justifica un nivel de relevancia suficiente entre muestras neutras y de estrés. Este criterio puede considerarse muy estricto, ya que hay autores que afirman que con un valor del coeficiente de correlación superior a 0.3 puede ya afirmarse que existe una correlación apreciable [121].

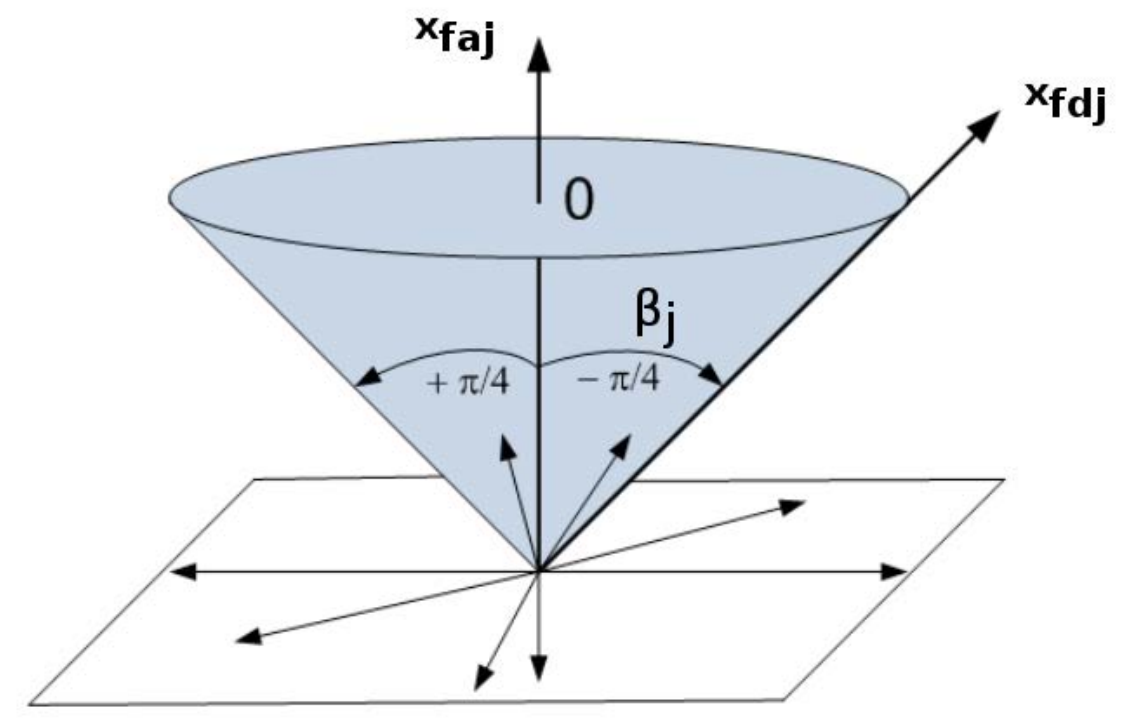

Figura 5.13: Interpretación geométrica del máximo y mínimo coeficiente de correlación de Pearson.

El coeficiente de Determinación $\left(D_{j}\right)$ se denota como:

$$
D_{j}=P_{j}^{2}
$$

De acuerdo a los límites prefijados por el coeficiente de correlación de Pearson $[\cos (\pi), \cos (\pi / 4)]$, los valores de D estarán comprendidos entre [1, 0.5]. Este coeficiente explica la proporción de variabilidad que comparte $x_{f a j}$ y $x_{f d j}$. Por consiguiente, para tener en cuenta un parámetro será necesario que el coeficiente de determinación 
obtenga un valor $D_{j} \geq 0,5$.

En la Tabla 5.9 se presentan tan solo los seis rasgos con los coeficientes de determinación más representantivos en orden descendente. Los rasgos que cumplen con el criterio de selección fueron Body Mass, la frecuencia fundamental $F_{0}$, Cepstral 3, y Body Stiffness. El resto de rasgos tuvieron coeficientes de determinación menores al 0,5. Del conjunto de cuatro rasgos relevantes, dos de ellos la tensión del cuerpo de los pliegues vocales y la masa del cuerpo de los pliegues vocales son rasgos biomecánicos. Aparece también el rasgo Cepstral 3, y fuera de criterio los Cepstral 2 y 4 que también son indicadores de la biometría del locutor, pero ocupando posiciones significativas en la clasificación. Estos rasgos están relacionados con el control neuromotor de los pliegues vocales [63].

\begin{tabular}{lcc}
\hline Parámetro & Coef. Pearson & Coef. Determinación \\
\hline \hline 35. Body Mass & 0,760 & $\mathbf{0 , 5 7 8}$ \\
\hline 1. Absolute Pitch & 0,741 & $\mathbf{0 , 5 4 8}$ \\
\hline 9. MWC Cepstral 3 & 0,740 & $\mathbf{0 , 5 4 7}$ \\
\hline 37. Body Stiffness & 0,715 & $\mathbf{0 , 5 1 2}$ \\
\hline 8. MWC Cepstral 2 & 0,671 & 0,450 \\
\hline 10. MWC Cepstral 4 & 0,619 & 0,383 \\
\hline
\end{tabular}

Tabla 5.9: Rasgos relevantes en orden descendente.

Finalmente, los parámetros más relevantes fueron testeados con un algoritmo de clasificación tipo SVM básico (véase la Sección 4.5.1). La finalidad del caso era intentar clasificar un conjunto pequeño de muestras usando solo dos rasgos, para que los resultados obtenidos pudieran ser representados gráficamente en un eje de coordenadas cartesianas. Para realizar esta última operación se utilizó un toolbox de Matlabß para la clasificación SVM con la configuración básica.

La función de aprendizaje fue una base radial de tipo Gaussiana (RBF) y el algoritmo de optimización secuencial mínima (SMO) para resolver el problema cuadrático (QP) durante el entrenamiento del SVM. El algoritmo fue entrenado con un vector de 25 muestras congruentes y otro vector de 25 muestras incongruentes. A continuación seis muestras neutras y seis muestras estresadas fueron utilizadas en clasificación.

En las Figuras 5.14 y 5.15, las muestras congruentes fueron codificadas con color azul, mientras que las muestras incongruentes estaban representadas con color rosa. En la Figura 5.14 se representa la clasificación de las muestras utilizando dos parámetros exclusivamente, Body Mass y Body Stiffness. En la Figura 5.15 se han utilizado otros dos parámetros, la frecuencia fundamental $F_{0}$ y el Body Stiffness. En ambas imágenes se puede observar que las 12 muestras utilizadas quedan clasificadas de manera eficiente puesto que las muestras de color azul (muestras congruentes) y las rosas (muestras incongruentes) quedan perfectamente separadas en dos agrupaciones. 


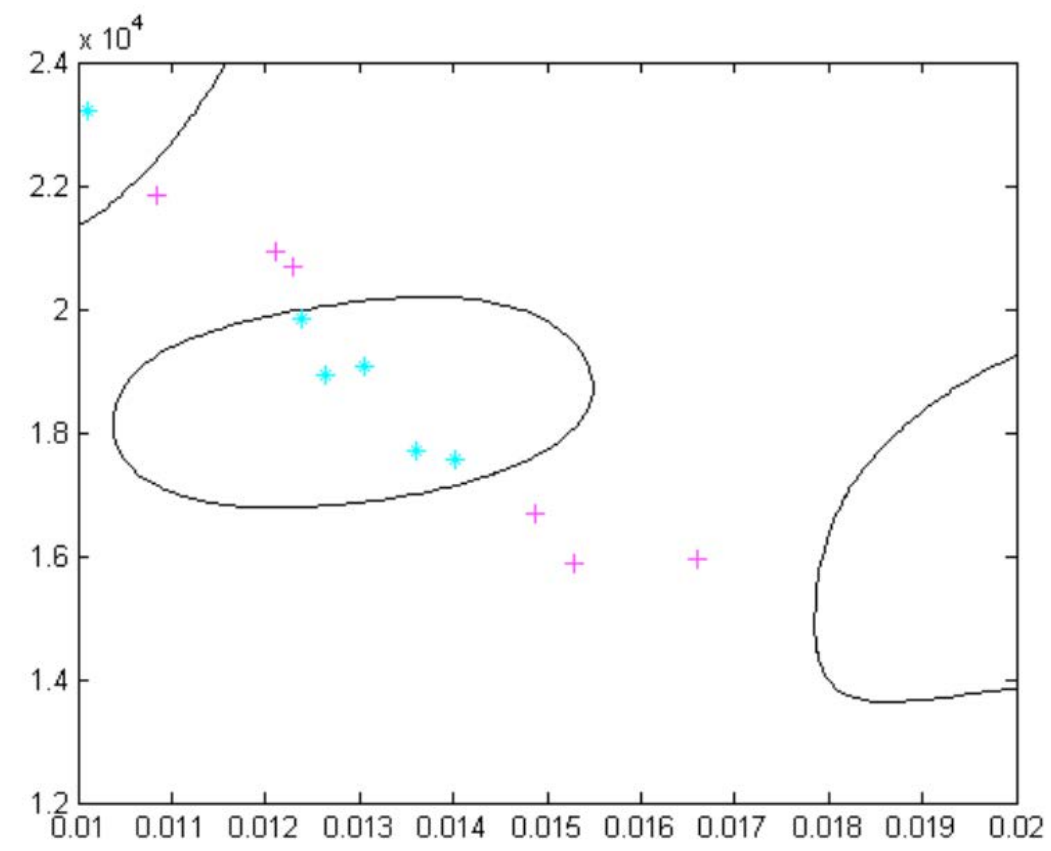

Figura 5.14: Clasificación utilizando los parámetros Body Mass y Body Stiffness.

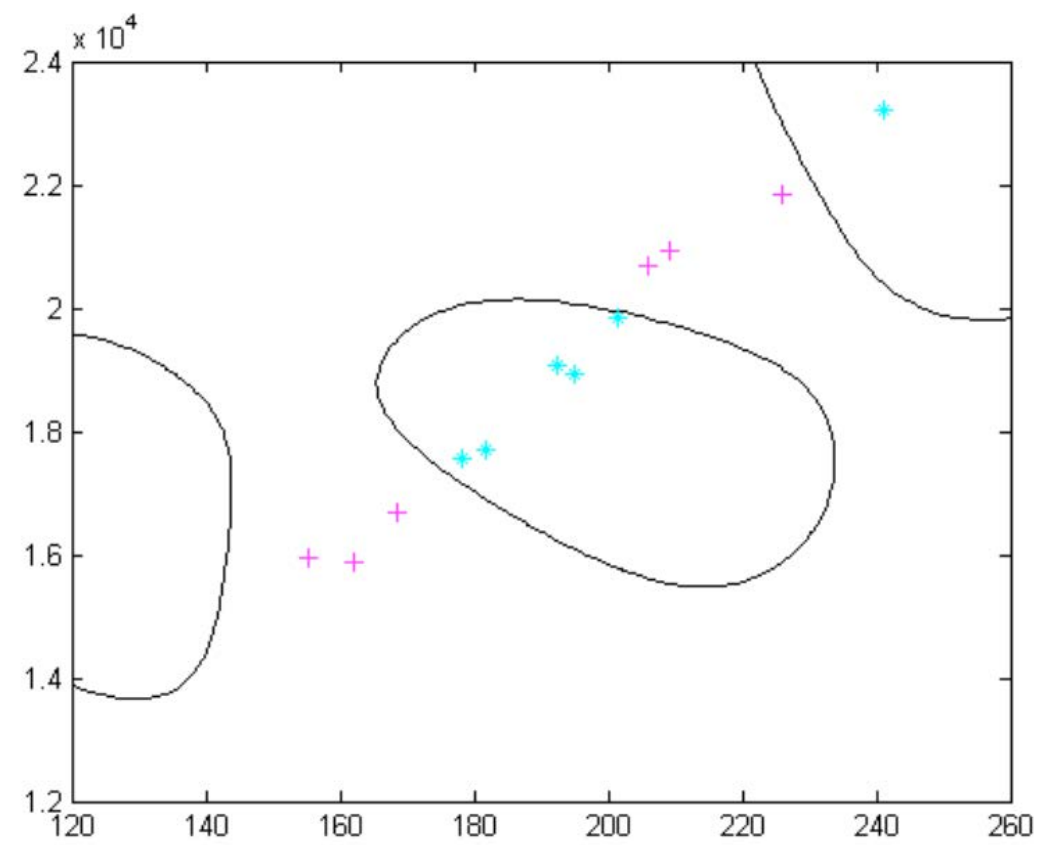

Figura 5.15: Clasificación utilizando los parámetros Frecuencia Fundamental y Body Stiffness.

Resumiendo todo lo anteriormente expuesto, se ha presentado un criterio de selección de características basado en el coeficiente de correlación de Pearson que se puede utilizar como herramienta para la caracterización de emociones. Los resultados ofrecidos, mostraban un conjunto muy reducido de rasgos para caracterizar el estrés. Los rasgos biomecánicos de masa y rigidez del cuerpo de los pliegues vocales (body 
mass y body stiffness), parecen ser muy significativos (véase capítulo 3, sección 3.3.2). También su relevancia es coherente con el comportamiento de la fuente glotal, porque ofrece una descripción precisa de las condiciones de la fonación de la laringe, y aporta también información sobre las condiciones de las vías neuromotoras que inervan la laringe, por el flujo de activación procedente del hipotálamo dirigido desde el neocortex del habla (véase sección 3.3.1). Estos centros de procesamiento pueden verse alterados cuando una persona es forzada a fabricar un discurso "artificial", el cual está en contra de sus opiniones o sentimientos. Finalmente, una vez más, el problema fundamental es que estos resultados obtenidos no son contrastables con ningún otro, puesto que estos rasgos no han sido utilizados para caracterizar emociones hasta el momento. Aún así, los resultados no pueden explicarse en su totalidad, puesto que los parámetros cepstrales todavía no poseen una semántica clara en este ámbito (véase sección 3.2.1), aunque sean buenos descriptores de la biometría del locutor.

\subsection{Modelos Paramétricos}

La elección de las mejores características para desarrollar cualquier sistema de clasificación artificial es una decisión crítica. Algunas veces, se escogen los rasgos por ensayo (prueba/error) seleccionando los mejores resultados. En otras ocasiones, los rasgos se escogen utilizando enfoques puramente estadísticos.

En este trabajo se busca determinar los rasgos más relevantes (de 1 a 20 de los 68/72 utilizados según la versión de BioMetr@Phon) y con ese grupo reducido de rasgos obtener las mejores tasas de clasificación. Dicho de manera más formal, dado un espacio $j$-dimensional, donde $J=68 / 72$ intentamos construir otro subespacio $k$-dimensional, donde $K \leq 20$ para obtener las tasas de clasificación más elevadas. El corpus 2 fue el utilizado para llevar a cabo diferentes casos de estudio. Este corpus contiene ya los datos normalizados y libres de outliers.

Una vez realizada la media de todos los valores obtenidos para cada individuo y para cada rasgo se realizó un cribado con objeto de comprobar los dos puntos siguientes:

1. Toda muestra de una categoría congruente debía de tener alguna muestra también en la categoría incongruente para ese mismo individuo. Es decir, si por ejemplo, el individuo regvoz-3001-P (siendo $\mathrm{P}$ - neutra) tenía 3 fillers para las muestras de tipo neutra, pero no se había podido obtener ningún filler de grabación incongruente (duración insuficiente), ese locutor quedaba descartado del conjunto de datos a procesar.

El motivo se debía a que el experimento consistía en hacer una clasificación de tipo pair-wise de cada uno de los individuos y por consiguiente, carecía de interés mantener una muestra de un locutor para la que no se pudiese disponer de una muestra de tipo contrario.

2. Por otro lado, se eliminaron todos aquellos outliers de entre las muestras de 
un mismo individuo. Por ejemplo, se dio el caso de que alguna de las muestras obtenidas mostrase valores muy elevados en algunos rasgos por artefactos en la estimación. Por consiguiente, al realizar la media con el resto de los rasgos obtenidos en otros fragmentos de la misma muestra se distorsionaba el valor final del rasgo que se utilizaba en los cálculos, contaminando los datos.

\subsubsection{Metodología}

Los pasos básicos involucrados en el proceso de extracción de los mejores rasgos para caracterizar estrés en la fonación se muestran en la Figura 5.16. Los experimentos fueron realizados separando por género a los individuos. El sistema y los experimentos fueron desarrollados gracias al paquete de bioinformática y redes neuronales de MATLABR.

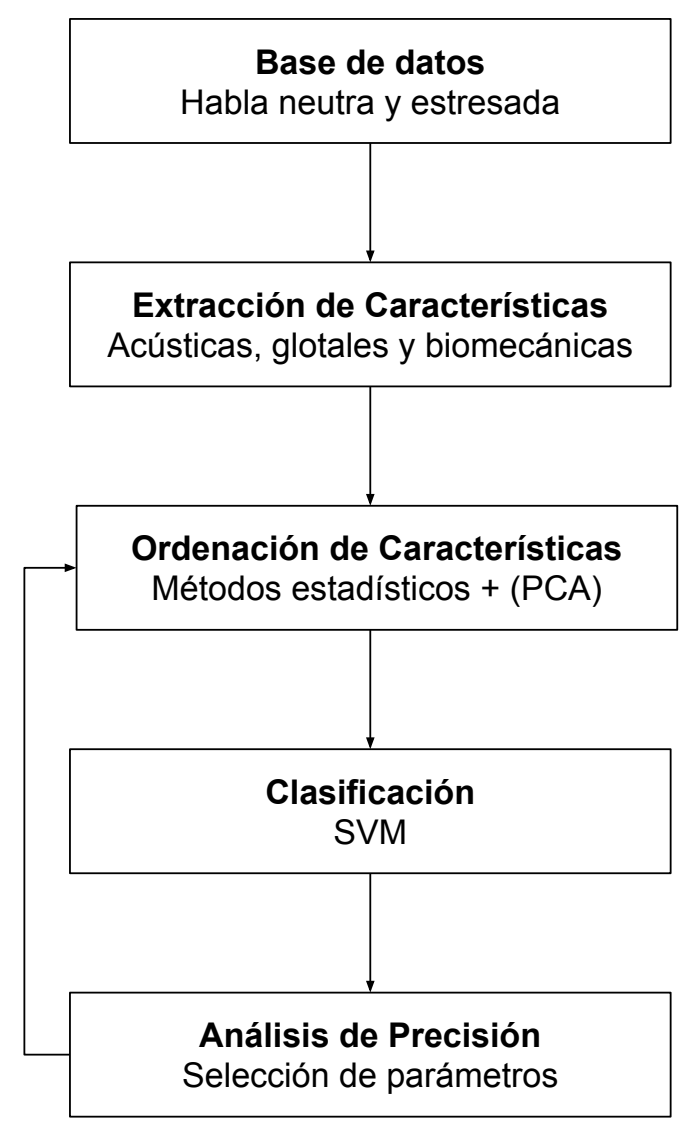

Figura 5.16: Etapas básicas para la selección de características utilizando PCA y SVM.

Tal y como se muestra en la Figura 5.16, la siguiente acción una vez que el conjunto de datos era considerado "óptimo" según los criterios citados, fue realizar la reducción de rasgos.

Este proceso se llevó a cabo de dos formas distintas: 
1. Realizar una selección de rasgos a partir de paquetes estadísticos y métodos de clasificación. Los rasgos más relevantes fueron ordenados por su significancia según cuatro criterios, los cuales fueron Student t-test, relación de entropía, ROC y Wilcoxon [22]. Esta etapa se llevó a cabo con la función estadística, Rank Features, perteneciente a los toolboxes de Matlabß.

2. La segunda etapa representada entre paréntesis es la reducción de dimensionalidad del conjunto de datos a partir de PCA (Principal Component Analysis, véase sección 4.4.1) [88] y [183]. Se quiso representar entre paréntesis para expresar los dos experimentos a realizar. El primero sin PCA (caso anterior) y el segundo incluyendo PCA. Por otro lado, tan solo se tuvieron en consideración los 20 parámetros mejor posicionados.

Finalmente, la última etapa del algoritmo fue realizar la clasificación, para ello se utilizó SVM (véase sección 4.5.1) [21], [74] y [184]. La precisión de clasificación fue evaluada con cuatro diferentes kernels [104] y [143], los cuales fueron:

- Lineal.

- Polinomial.

- Cuadrático.

- Función de Base Radial $(R B F)$.

Debido a que el número de muestras era reducido se decidió implementar una estrategia de validación por cruce del tipo leave-one-out o lo que es lo mismo, se entrena el algoritmo con todas las muestras menos una $(n-1)$, siendo $n$ el número de muestras totales. La muestra restante se utiliza para realizar el test de clasificación. Esta estrategia se repite tantas veces como muestras se tiene en el conjunto de datos (véase Figura 5.17).

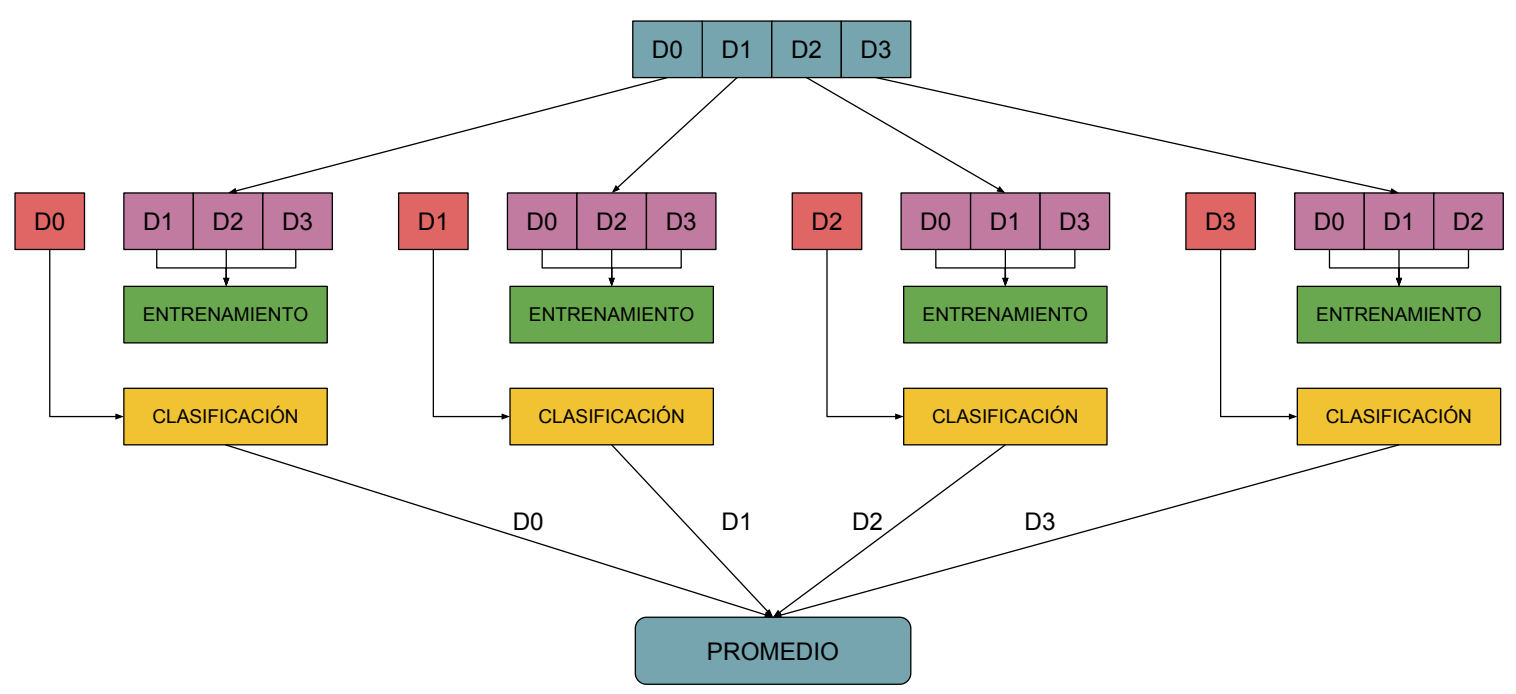

Figura 5.17: Ejemplo de (leave-one-out) para $\mathrm{N}=4$. 
Finalmente, la tasa de media de precisión se calcula acumulando todos y cada uno de los test realizados por el algoritmo de clasificación, es decir, 30 veces (15 muestras) para el caso de las mujeres y 20 veces (10 muestras) para el caso de los hombres.

Esta estrategia no es tan rigurosa como otras, pero es comprensible y adecuada debido a que el conjunto de datos es realmente pequeño. Si se utilizara un número más grande para realizar la clasificación, el número de muestras sobrantes para entrenar el algoritmo sería insuficiente y las tasas de precisión serían demasiado bajas.

\subsubsection{Resultados}

El conjunto de datos disponible contiene $N$ locutores, dos estados (congruente, incongruente), 68 rasgos por estado ordenados como una matriz $\mathrm{X}$ de $2 N \times 68$, donde en la primera mitad de la matriz se encuentran las muestras etiquetadas como incongruentes y en la segunda mitad las muestras congruentes (véase corpus 2).

A partir de una serie de criterios de evaluación independientes, la matriz X es ordenada según sus características más relevantes. Cada columna de la matriz $X_{f}$ o $X_{m}$ contiene estimaciones de un rasgo de los 68 totales y cada fila se corresponde con un individuo. Cada uno de los criterios puede escoger un máximo de 20 características a lo sumo, es decir, genera una submatriz con 20 columnas.

Los criterios utilizados para evaluar la relevancia de cada característica o parámetro fueron:

- t-test $=$ Prueba de la t-Student de dos muestras de valor absoluto con estimación de varianza agrupada (véase 4.2).

- Entropía = Entropía relativa (véase 4.3.3).

- ROC o (Receiver Operating Characteristic) = Tal y como explica la documentación del software bioinformático Matlabß, este operador mide el área entre la curva empírica ROC y la pendiente del clasificador aleatorio. Se basa en un intervalo dicotómico o lo que es lo mismo [0,1]. Cada agrupación recibe una clasificación que puede o no coincidir con su verdadera etiqueta o valor de clase, por tanto se calculan dos valores, la Tasa de Positivos Ciertos (TPC) y la Tasa de Falsos Positivos (TFP). Partiendo de una agrupación $c$, el TPC es el número de resultados cuya clase real y la detectada es $c$, dividida por el número de resultados cuya agrupación detectada es $c$. Análogamente, TFP es el número de resultados cuya agrupación real no es la $c$, pero la clase detectada es la clase $c$, dividido por el número de resultados cuya agrupación detectada no es la clase $c$.

- Wilcoxon = Valor absoluto del estadístico U-Mann-Whitney (véase 4.3.2). 
Una vez que se han seleccionado los rasgos más relevantes, estos se introducen como argumentos en la etapa de entrenamiento del algoritmo de clasificación SVM, usando la técnica leave-one-out.

La relevancia de los rasgos se evaluá con un bucle de 20 iteraciones (el número máximo de parámetros a elegir), y en cada iteracion $\mathrm{M}$, se recalcula la tasa de clasificación según SVM.

A continuación se presentan, en la Tabla 5.10, los resultados de los parámetros obtenidos para los distintos kernels utilizados.

\begin{tabular}{l|l|l}
\hline Criterio & $\begin{array}{l}\text { Conjunto parámetros } \\
\text { (mujeres) }\end{array}$ & $\begin{array}{l}\text { Conjunto parámetros } \\
\text { (hombres) }\end{array}$ \\
\hline \hline t-test & $66,27,68,62,24,9,5,32$, & $23,60,22,28,29$ (Total: \\
& 61,58 (Total: 10) & 5 ) \\
\hline Entropía & $27,32,62,25$ (Total: 4$)$ & $27,64,25,5,45,23,22$, \\
& & $\begin{array}{l}28,31,7,58,60,30,61, \\
41,29,68 \text { (Total: } 17)\end{array}$ \\
\hline ROC & $66,27,5,46,9,68,23,28$, & $27,62,60,28,29,22,23$, \\
& $51,14,25$ (Total: 11) & $\begin{array}{l}10,68,17,42,6,64,66, \\
12,18 \text { (Total: 16) }\end{array}$ \\
\hline Wilcoxon & $66,5,46,58,9,28,51,68$, & $60,28,29,22,23,42,10$, \\
& 27,23 (Total: 10) & $\begin{array}{l}68,6,12,64,58,34,66 \\
(\text { Total: } 14)\end{array}$ \\
& &
\end{tabular}

Tabla 5.10: Características para los resultados con mejor precisión.

En la Tabla 5.10 se lista la totalidad de los rasgos más relevantes por orden de relevancia. En el conjunto de datos pertenecientes a las mujeres se puede observar que los rasgos 66 (Temblor Fisiológico - Frecuencia), 68 (Temblor Neurológico Amplitud), 9 (Cepstral - 3) y 5 (Relación armónico/ruido) aparecen en 3 de los 4 criterios utilizados ( $t$-test, ROC y Wilcoxon) y el rasgo 27 (perfil espectral) aparece en todos ellos (véase sección 3.3.2 para una explicación en detalle de cada uno de los parámetros).

Por tanto, se puede concluir que t-test, ROC y Wilcoxon son métodos que destacan claramente la importancia de la frecuencia y la amplitud del temblor en las mujeres.

Respecto a los resultados obtenidos en las muestras masculinas, todos los métodos incluyen los rasgos 60 (defecto del cierre glótico), 22, 23, 28 y 29 (todos relacionados con el perfil espectral) pero no en el mismo orden de relevancia. Se debe hacer la apreciación de que el caso que mejores resultados ofrece se basa en el criterio de ROC con una precisión del $75 \%$, incluyendo los rasgos 66 y 68, los cuales se relacionan con el temblor. Además, el rasgo 68 se repite en todos los criterios, exceptuando en el t-test. Si se comparan los rasgos determinados entre ambos géneros, 
se puede concluir que no comparten resultados significativos en común, exceptuando el parámetro 68, el cual aparece en un $75 \%$ de las ocasiones para ambos géneros. Adicionalmente puede observarse que el número de rasgos del conjunto masculino, en todos los casos, es mayor que el del femenino.

Los resultados de clasificación obtenidos se muestran en las Tablas 5.11 y 5.12 para las mujeres y los hombres, respectivamente.

\begin{tabular}{lcccc}
\hline Kernel (SVM) & t-test & Entropía & ROC & Wilcoxon \\
\hline \hline Lineal & $80 \%$ & $80 \%$ & $76.67 \%$ & $73.33 \%$ \\
\hline Polinomial & $63,33 \%$ & $83,33 \%$ & $66,67 \%$ & $73,33 \%$ \\
\hline Cuadrático & $63,33 \%$ & $83,33 \%$ & $63,33 \%$ & $66,67 \%$ \\
\hline RBF & $66,67 \%$ & $86,67 \%$ & $56,67 \%$ & $60 \%$ \\
\hline
\end{tabular}

Tabla 5.11: Resultados de clasificación para las mujeres.

\begin{tabular}{lcccc}
\hline Kernel (SVM) & t-test & Entropía & ROC & Wilcoxon \\
\hline \hline Lineal & $65 \%$ & $65 \%$ & $60 \%$ & $55 \%$ \\
\hline Polinomial & $60 \%$ & $55 \%$ & $55 \%$ & $45 \%$ \\
\hline Cuadrático & $70 \%$ & $60 \%$ & $75 \%$ & $70 \%$ \\
\hline RBF & $60 \%$ & $50 \%$ & $60 \%$ & $60 \%$ \\
\hline
\end{tabular}

Tabla 5.12: Resultados de clasificación para los hombres.

Analizando los resultados para las mujeres en la Tabla 5.11, se puede observar que los mejores obtenidos lo son utilizando el criterio de selección basado en el t-test y con el kernel de entrenamiento lineal utilizando diez de los 68 rasgos, dando una precisión de hasta el $80 \%$. Para el criterio de la relación de entropía estos resultados mejoran hasta un $86,67 \%$ usando el kernel basado en RBF y con tan solo cuatro rasgos de los 68 totales. Sin embargo, la tasa de precisión disminuye al 76,67\% cuando la combinación se basa ROC, lineal y once rasgos. Finalmente, el test de Wilcoxon produce una tasa de clasificación de 73,33\% sobre el mismo conjunto de datos para un kernel de tipo lineal y polinomial. La diferencia estriba en el número de rasgos necesarios para haber alcanzado dicha tasa. En el caso del kernel lineal este número fue de diez, mientras que en el caso del kernel polinomial fue suficiente utilizar un solo rasgo. Este fue el primero de los diez utilizados en el caso lineal, correspondiente al número 66, perteneciente al grupo de rasgos relacionados con la estimación del temblor. Se ha querido destacar la opción del kernel lineal porque parece más robusta para caracterizar fragmentos de voz usando diez rasgos en lugar de tan solo uno. Por consiguiente, el rango de los mejores resultados para las mujeres en esta primera etapa estaría comprendido entre un 73,33\% (10 parámetros) y un $86,67 \%$ (4 parámetros), aunque en este último caso los rasgos seleccionados como relevantes no concuerdan con el resto de criterios utilizados. Estos rasgos fueron 25, 27 y 32, los cuales están relacionados con el perfil espectral y el 62 con el GAP. 
Respecto los resultados de los hombres que se muestran en la Tabla 5.12, los porcentajes de exactitud son más bajos que los resultados obtenidos para las mujeres, variando de un $45 \%$ a un $75 \%$. El t-test ofrece un porcentaje del $70 \%$ (5 rasgos) y el ROC que da el mejor resultado requiere 16 rasgos.

En las relaciones 5.4 y 5.5 se muestran el número de iteraciones para esta primera fase del experimento por cada uno de los conjuntos de datos iniciales (mujeres y hombres):

$$
\begin{aligned}
& M=30 \text { muestras } \times 20 \text { params } \times 4 \text { kernels } \times 4 \text { criterios }=9600 \text { iteracs } \\
& H=20 \text { muestras } \times 20 \text { params } \times 4 \text { kernels } \times 4 \text { criterios }=6400 \text { iteracs }
\end{aligned}
$$

A continuación se representan las Figuras 5.18 y 5.19 donde se plasma el número de rasgos necesarios por cada criterio y por cada kernel para alcanzar los niveles máximos de precisión, mostrando únicamente las cuatro combinaciones con mejores resultados.

En la Figura 5.18 para el conjunto de datos femenino se puede observar que cuando el criterio seleccionado es la relación de entropía, la tasa de clasificación es más elevada siempre que el número de rasgos escogidos no supere los nueve. A partir de ese momento la tasa de acierto cae estrepitosamente hasta alcanzar valores cercanos al cero absoluto. En el caso de Wilcoxon, sus valores son bastante constantes quedando siempre en la franja entre el $50 \%$ y el $60 \%$, aunque con diez rasgos consiga su máximo valor, 73,33\%. Por otro lado, t-test ofrece una imagen cuasi sinusoidal, es decir, comienza en un punto intermedio, decrece y luego crece hasta alcanzar su cota máxima situada en el $80 \%$ de exactitud, para luego volver a caer y situarse al final casi en la misma tasa de acierto que cuando había comenzado. Finalmente, ROC ofrece una tendencia parecida a la anterior, pero con tasas de precisión más elevadas en media, permaneciendo en dos iteraciones consecutivas (con once y doce rasgos) en su tasa de éxito más elevada, del 76,67\%. 


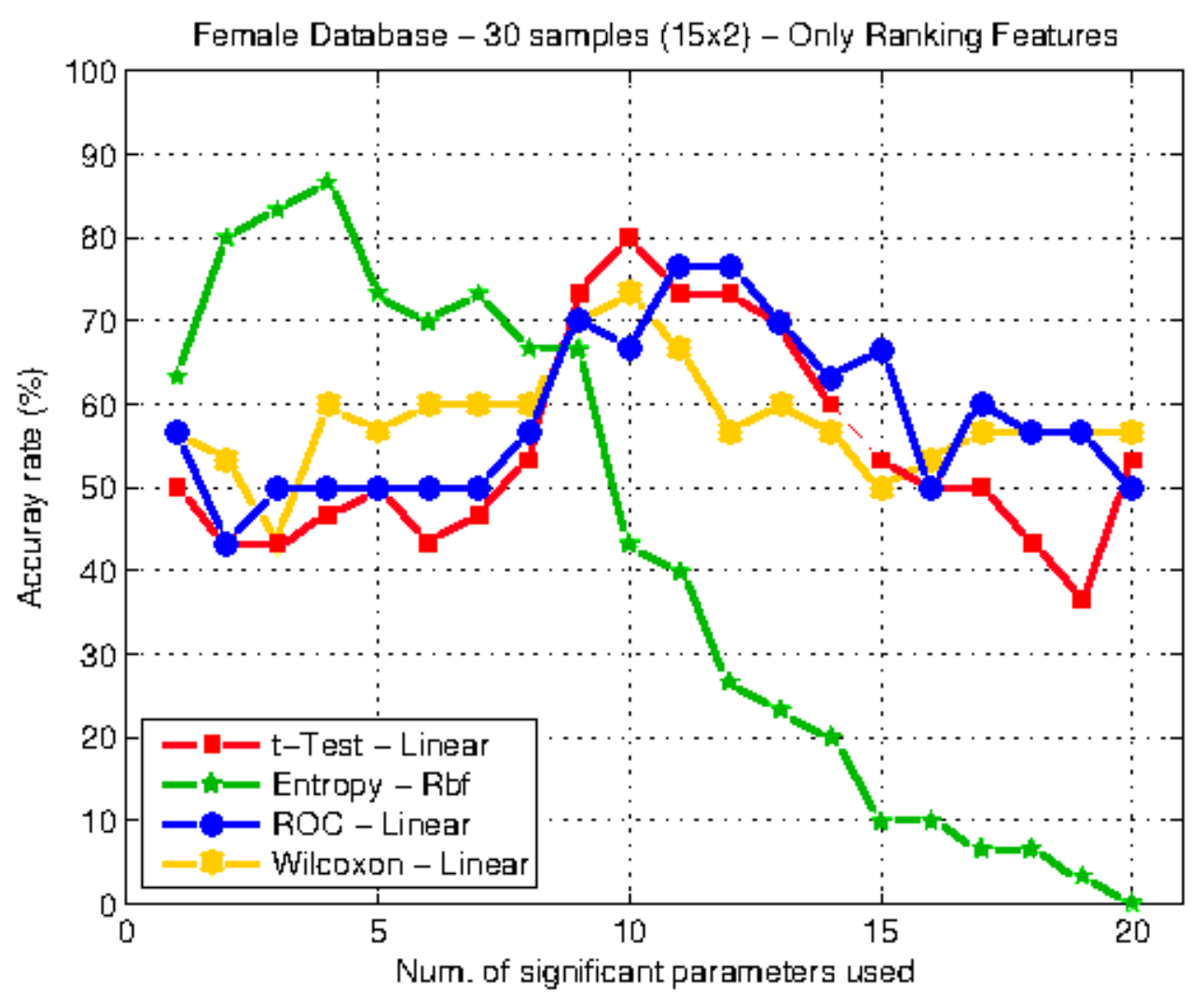

Figura 5.18: Resumen de las ejecuciones realizadas para jerarquizar los parámetros más relevantes para el conjunto de datos femenino.

En la figura 5.19 relativa al conjunto de datos masculino se puede ver que las curvas presentadas ofrecen mayor número de picos que en la anterior, es decir, que de una iteración a la siguiente la tasa de precisión puede cambiar de forma bastante abrupta. Como se comentó con anterioridad, tan solo se alcanza el $75 \%$ cuando el criterio elegido es ROC y el kernel utilizado es de tipo cuadrático. Además, para alcanzar esta tasa fue necesario utilizar dieciséis rasgos de los 68. La siguiente tasa de éxito más elevada fue de $70 \%$ y fue alcanzada por dos kernels, Wilcoxon y $t$ test, la diferencia fundamental es que con uno tan solo fueron necesario cuatro o cinco rasgos (t-test), mientras que el otro necesitó de catorce rasgos para alcanzar la misma tasa. Finalmente, la peor clasificación la encontramos cuando el kernel es la relación de entropía, alcanzando una tasa del $65 \%$ con diecisiete rasgos. 


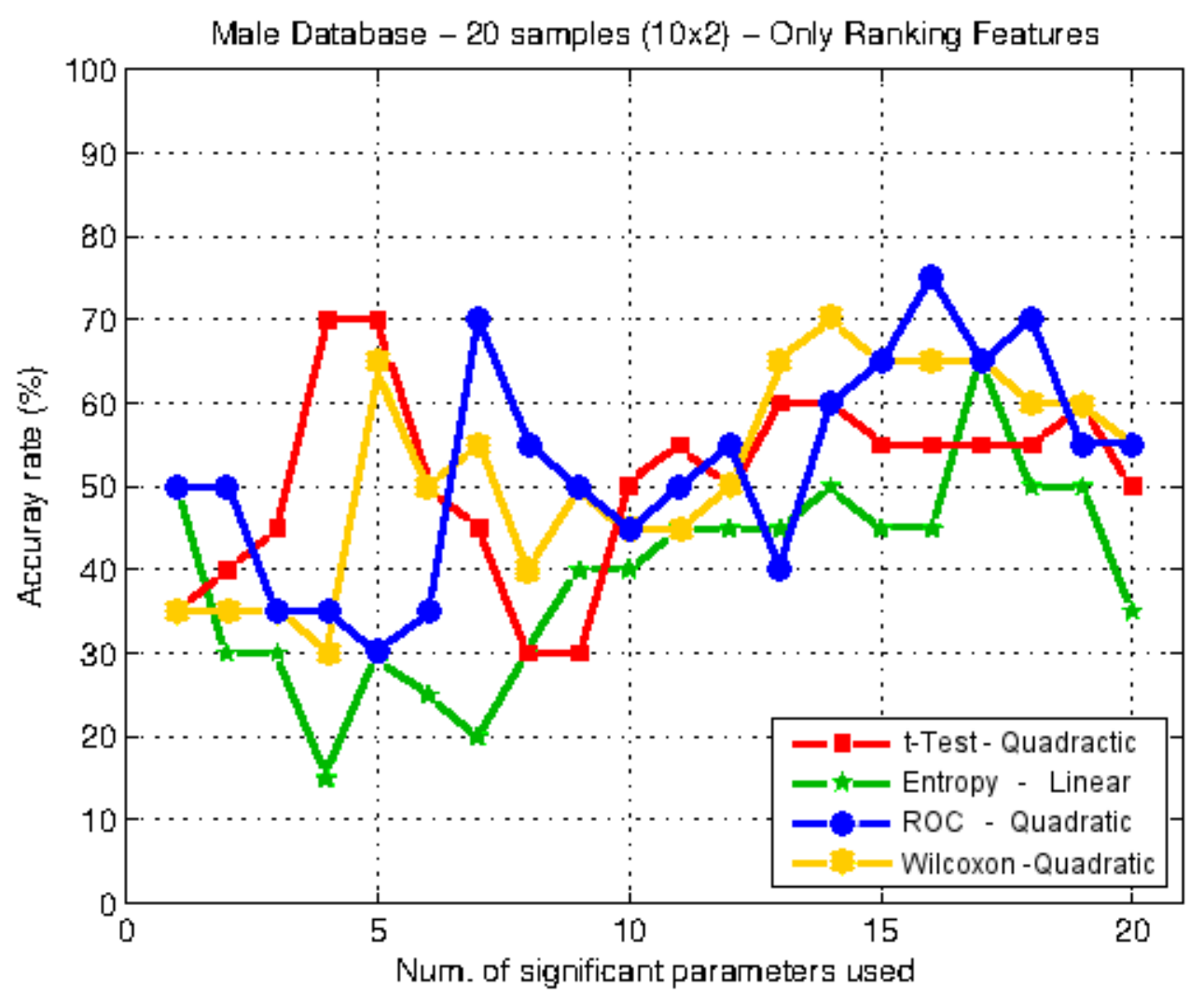

Figura 5.19: Resumen de las ejecuciones realizadas para jerarquizar los parámetros más relevantes para el conjunto de datos masculino.

Se realizó una segunda etapa para intentar mejorar las tasas de precisión anteriormente alcanzadas, tal y como se presentó en la Figura 5.16. Se consideró la fusión del caso anterior y un procesado adicional sobre los datos utilizando la técnica PCA (véase sección 4.4.1). Este estudio consistió en usar los primeros 20 rasgos más relevantes $(M)$ como parámetros de entrada para el procedimiento de análisis de componentes principales, los cuales seleccionarían $N$ parámetros de los $M$ anteriores, por tanto, $N$ siempre era un subconjunto de $M$, de acuerdo con el grado de relevancia reorganizando el espacio vectorial por PCA. La complejidad de esta combinación viene dada por la siguiente expresión:

$$
\text { Complejidad }=\sum_{M=1}^{20} \sum_{N=1}^{20} M \times N-\frac{M \times(N-1)}{2}=210 \text { combinaciones }
$$

Obsérvese que en ella 5.6 no se ha tenido en cuenta, ni el número de muestras, ni el número de criterios, ni el número de kernels utilizados.

Es importante destacar que aunque este estudio se realizó para mejorar las tasas de precisión del anterior caso, éste es completamente independiente de aquel. 


$$
\begin{aligned}
\text { Mujeres }= & 30 \quad \text { muestras } \times 210 \text { combinaciones } \\
& \times 4 \text { kernels } \times 4 \text { criterios }=100800 \text { iteraciones }
\end{aligned}
$$

$$
\begin{aligned}
\text { Hombres }= & 20 \text { muestras } \times 210 \text { combinaciones } \\
& \times \quad 4 \text { kernels } \times 4 \text { criterios }=67200 \text { iteraciones }
\end{aligned}
$$

Finalmente, la matriz de resultados se organizó de manera descendente, es decir, arriba los mejores resultados y abajo los peores. La mejor tasa de clasificación para este segundo estudio se obtuvo para la combinación $M=14$ y $N=10$. Esta combinación alcanzó una precisión de hasta el $90 \%$ para el conjunto de muestras de mujeres, tal y como se muestra en la Tabla 5.13.

\begin{tabular}{lcccc}
\hline Kernel (SVM) & t-test & Entropía & ROC & Wilcoxon \\
\hline \hline Lineal & $86,67 \%$ & $86,67 \%$ & $73,33 \%$ & $70 \%$ \\
\hline Polinomial & $76,67 \%$ & $86,67 \%$ & $73,33 \%$ & $76,67 \%$ \\
\hline Cuadrático & $73,33 \%$ & $90 \%$ & $73,33 \%$ & $66 \%$ \\
\hline RBF & $73,33 \%$ & $86,67 \%$ & $66,67 \%$ & $60 \%$ \\
\hline
\end{tabular}

Tabla 5.13: Resultados de clasificación para las mujeres incluyendo PCA.

Estos resultados en términos generales se puede decir que mejoran considerablemente los resultados obtenidos anteriormente mostrados en la Tabla 5.11. Sin embargo, se obtuvieron peores resultados cuando el criterio a utilizar fue ROC, descendiendo a un 73,33\% respecto al 76,67\% anteriormente obtenido. Este es un caso particular puesto que los resultados son similares en tres de los cuatro criterios utilizados. Tal y como se explicó unos párrafos más arriba, se decidió escoger los primeros resultados (ROC-lineal), porque estos parecían ser más robustos y estables. Esta tasa de precisión se alcanzó en tres ocasiones de las 210 iteraciones entre el método de reorganización de características (rank features) y la estrategia PCA. Los dos criterios (polinomial y cuadrático) produjeron la misma tasa de clasificación, pero esta tasa de clasificación fue alcanzada tan solo una vez. Además, la combinación entre $M$ y $N$ fue muy similar en ambos casos.

En la Tabla 5.14 se resumen los mejores resultados obtenidos con esta combinación de estrategias para el conjunto de datos de los hombres. Análogamente al caso anterior, se puede concluir que los resultados obtenidos son mejores que los presentados en la Tabla 5.12. Tanto el límite superior, como el límite inferior mejoran, moviéndose la tasa de clasificación entre el $60 \%$ y el $80 \%$. Se puede observar en la Tabla 5.14 que cuando se habla del criterio de Wilcoxon en tres de los cuatro kernels utilizados la tasa de clasificación es idéntica, del $70 \%$. En esta situación, se hace bastante complicado seleccionar o elegir cuál de estos kernels es más ventajoso respecto a los demás. Finalmente, se decidió eliminar este kernel por los siguientes motivos: 
- El tiempo de computación medio oscilaba entre los 90 y los 130 minutos.

- La mejora obtenida no fue tan sustancial respecto de los anteriores resultados.

\begin{tabular}{lcccc}
\hline Kernel (SVM) & t-test & Entropía & ROC & Wilcoxon \\
\hline \hline Lineal & $80 \%$ & $70 \%$ & $70 \%$ & $70 \%$ \\
\hline Polinomial & $60 \%$ & $75 \%$ & $65 \%$ & $65 \%$ \\
\hline Cuadrático & $70 \%$ & $72 \%$ & $65 \%$ & $70 \%$ \\
\hline RBF & $65 \%$ & $60 \%$ & $65 \%$ & $70 \%$ \\
\hline
\end{tabular}

Tabla 5.14: Resultados de clasificación para los hombres incluyendo PCA.

En la Tabla 5.15, se muestran los rasgos que produjeron mejores resultados aplicando ambas estrategias. Para el conjunto de datos femenino, los parámetros 68 (Temblor Neurológico - Amplitud), 66 (Temblor Fisiológico - Frecuencia), 27 (perfil espectral) y 5 (Relación ruido/armónico) aparecen en todos los resultados independientemente del criterio de precisión usado.

Analizando los resultados del conjunto de datos masculino, se puede concluir que el número total de rasgos necesarios para mejorar la precisión (entre 17 y 20) y el número de rasgos en común para todos los métodos es más grande que en el caso femenino. Por ejemplo, los rasgos comunes que se presentan son 22, 23, 28, 58, 60, 64 y el 68. Una vez más, la influencia del temblor se manifiesta gracias a la presencia del rasgo 68 en la selección.

Estos resultados muestran claramente que hombres y mujeres tienen el rasgo 68 en común cuando se utiliza las dos estrategias conjuntas en el proceso de clasificación.

\begin{tabular}{|c|c|c|}
\hline Criterio & $\begin{array}{l}\text { Conjunto } \\
\text { (mujeres) }\end{array}$ & $\begin{array}{ll}\begin{array}{l}\text { Conjunto } \\
\text { (hombres) }\end{array} & \text { parámetros }\end{array}$ \\
\hline t-test & $\begin{array}{l}66,27,68,62,24,9,5,32, \\
61,58,23 \text { (Total:11) }\end{array}$ & $\begin{array}{l}23,60,22,28,29,68,58, \\
6,42,41,27,46,64,4, \\
10,33,45,66,57,34 \text { (To- } \\
\text { tal:20) }\end{array}$ \\
\hline Entropía & $\begin{array}{l}27,32,62,25,5,61,19 \\
4,45,68,66,46,60,44 \\
\text { (Total:14) }\end{array}$ & $\begin{array}{l}27,64,25,5,45,23,22, \\
28,31,7,58,60,30,61, \\
41,29,68,33 \text { (Total:18) }\end{array}$ \\
\hline $\mathrm{ROC}$ & $\begin{array}{l}66,27,5,46,9,68,23,28 \\
51,14,25 \text { (Total:11) }\end{array}$ & $\begin{array}{l}27,62,60,28,29,22,23, \\
10,68,17,42,6,64,66, \\
12,18,34,58,33 \text { (To- } \\
\text { tal:19) }\end{array}$ \\
\hline Wilcoxon & $\begin{array}{l}66,5,46,58,9,28,51,68, \\
27,23,14,36,29,3,56, \\
20,34,47 \text { (Total:18) }\end{array}$ & $\begin{array}{l}60,28,29,22,23,42,10, \\
68,6,12,64,58,34,66, \\
33,17,18 \text { (Total:17) }\end{array}$ \\
\hline
\end{tabular}

Tabla 5.15: Características para los resultados con mejor precisión incluyendo PCA. 


\subsubsection{Comparando algoritmos de clasificación}

A continuación se ha profundizado en la cuestión de la tasa de clasificación de muestras, más concretamente, en los aspectos de comparar técnicas, tiempo de ejecución y tasa de precisión. Como ya se adelantó unas líneas más arriba, algunos de los criterios utilizados tardaban en producir resultados un tiempo demasiado elevado y por consiguiente estas técnicas no parecen adecuadas para realizar un clasificador en tiempo real; es por ello que Wilcoxon, no será tenido en cuenta en esta comparación.

Para que sea posible comparar los resultados obtenidos aquí con los del apartado anterior es necesario que el conjunto de datos sea el mismo, así como el entorno de trabajo.

Se van a realizar dos estudios. En el primer estudio se trata de utilizar la técnica de reorganización de información, Rank Features, pero esta vez, concatenarla con otro algoritmo, Partial Least Squares (ver sección 4.4.3), la cual se basa en la construcción de un nuevo espacio vectorial a partir de las covarianzas de sus matrices de origen para resolver un problema de tipo regresión lineal. El segundo se basa en la utilización de ICA (véase sección 4.4.2), la cual obtiene las componentes independientes de los 68 rasgos de entrada.

Por consiguiente, la idea de este apartado es comparar los resultados obtenidos con dos tipos de enfoque. El primero con una técnica compuesta y el segundo con una técnica única.

\subsubsection{Rank Features y PLS}

Los resultados para los hombres y las mujeres se muestran en las Tablas 5.16 y 5.17, respectivamente. Estas tablas ofrecen los resultados obtenidos utilizando el algoritmo de clasificación SVM y sus cuatro kernels. En la Tabla 5.18 se muestran los rasgos más relevantes obtenidos para las tasas de clasificación más elevadas combinadas con los rasgos escogidos por PLS.

\begin{tabular}{lccc}
\hline Kernel & t-test & Entropía & ROC \\
\hline \hline Lineal & $70 \%$ & $70 \%$ & $70 \%$ \\
\hline Polinomial & $75 \%$ & $75 \%$ & $80 \%$ \\
\hline Cuadrático & $70 \%$ & $70 \%$ & $70 \%$ \\
\hline RBF & $75 \%$ & $70 \%$ & $65 \%$ \\
\hline
\end{tabular}

Tabla 5.16: Resultados de clasificación utilizando Rank Features y Partial Least Squares para el conjunto de datos masculino. 


\begin{tabular}{lccc}
\hline Kernel & t-test & Entropía & ROC \\
\hline \hline Lineal & $66,67 \%$ & $73,33 \%$ & $60 \%$ \\
\hline Polinomial & $63,33 \%$ & $66,67 \%$ & $66,67 \%$ \\
\hline Cuadrático & $66,67 \%$ & $63,33 \%$ & $66,67 \%$ \\
\hline RBF & $66,67 \%$ & $63,33 \%$ & $63,33 \%$ \\
\hline
\end{tabular}

Tabla 5.17: Resultados de clasificación utilizando Rank Features y Partial Least Squares para el conjunto de datos femenino.

\begin{tabular}{lll}
\hline Criterio & Mujeres & Hombres \\
\hline t-test & $66,27,68,62,24,9$ (Total: 6$)$ & $23,60,22,28,29,68,58,6$, \\
& & $42,41,27$ (Total: 11) \\
\hline Entropía & $27,32,62,25,5,61,19,4,45$, & $27,64,25,5,45,23,22,28$, \\
& $68,66,46,60,44,63,24,26$, & $31,7,58,60,30,61,41,29$, \\
& $9,56,20$ (Total: 20) & 68,33 (Total: 18) \\
\hline ROC & $66,27,5,46,9,68,23,28,51$, & $27,62,60,28,29,22,23,10$, \\
& $14,25,17,58$ (Total: 13$)$ & 68,17 (Total: 10) \\
\hline
\end{tabular}

Tabla 5.18: Características para los resultados con mayor tasa de clasificación incluyendo PLS.

Analizando los resultados para los hombres en la Tabla 5.16, se puede observar que los valores alcanzados rondan en media el $70 \%$ de precisión, siendo todos menos uno, iguales o superiores a dicha tasa. La combinación $R O C$ polinomial logró alcanzar su mejor tasa de clasificación. Es de destacar que en los casos lineal y cuadrático, la estabilidad de resultados se hace patente, puesto que en todas las combinaciones la tasa es idéntica, del $70 \%$. El kernel con peores prestaciones en este conjunto de resultados se podría decir que ha sido $R B F$ porque en una de sus combinaciones (ROC x RBF) tan solo alcanzó el 65\%. Sin embargo, el mejor ha sido el kernel polinomial, el cual ha alcanzado la tupla $(75 \%, 75 \%, 80 \%)$, pero aun así no supera la barrera del $80 \%$ alcanzado por PCA según se muestra en la Tabla 5.14.

Por otro lado, los resultados para el conjunto de datos de las mujeres disminuyen sus tasas de clasificación si se comparan con los resultados anteriores de la Tabla 5.13. Esto es así, porque la tasa de clasificación más elevada asciende al 73,33\% cuando se utiliza el kernel lineal, el criterio de la relación de entropía y 20 rasgos. La tónica general de los resultados ronda entre el $63,33 \%$ y el $66,67 \%$ siendo esta última tasa la más repetida (6 veces) entre los 12 resultados obtenidos por las diferentes combinaciones. Sin embargo en un único caso la tasa de clasificación desciende hasta el $60 \%$ ( $R O C$ y lineal).

Finalmente, en la Tabla 5.18, se presentan los parámetros más relevantes para ambos géneros en combinación con el algoritmo PLS. Comenzando por el conjunto de las mujeres, los rasgos 66, 68, 9 y 27 se repiten en todas las combinaciones. Cabe recordar que tanto el rasgo 66, como el 68 son rasgos biomecánicos que tienen relación directa con el temblor. Es interesante destacar que tan solo cuando el 
criterio utilizado es el t-test el número de rasgos utilizadas para alcanzar la mayor tasa de clasificación correspondiente a cualquiera de sus combinaciones es más bajo de diez, puesto que tanto la relación de entropía como ROC necesitan de veinte y trece rasgos, respectivamente para alcanzar sus mayores tasas. Por otro lado, para el conjunto masculino en todos los casos son necesarios diez o más rasgos para alcanzar sus tasas de clasificación más elevadas; once rasgos en el caso de t-test, dieciocho para la relación de entropía y diez para ROC. Los rasgos que se repiten en todos los criterios para el caso de los hombres es mayor que para el caso de las mujeres, aunque disminuyen respecto del caso de PCA mostrado en la Tabla 5.15. Los rasgos son los siguientes $22,23,27,28,60$ y 68 . Nuevamente el rasgo 68 vuelve a aparecer en todas las combinaciones, tanto en hombres como en mujeres.

Resumiendo, cuando utilizamos la técnica de Rank Features con otro reductor de parámetros, PLS (véase Sección 4.4.3), los resultados obtenidos fueron distintos si los comparamos con la combinación híbrida o compuesta (RF y PCA). El mejor resultado obtenido para el conjunto de las mujeres tan solo alcanzó 73,33\% en (RF y PLS) frente al $90 \%$. Además, si hablamos del número de rasgos utilizados para estas tasas de clasificación, también empeora sustancialmente, exceptuando la combinación t-test y lineal.

Sin embargo, los resultados para el conjunto de los hombres mejoran en media, es decir, la mayoría de las combinaciones dan tasas más elevadas respecto al anterior caso para este conjunto de datos. Pero, la tasa máxima alcanzada sigue siendo $80 \%$ y tan solo se alcanza cuando la combinación utilizada es ROC y el kernel polinomial. Respecto al número de parámetros también mejora, por lo menos en los casos que los criterios utilizados son $t$-test y ROC.

Aunque cada caso es independiente, se ha querido hacer un promedio de las matrices de resultados tanto por filas, como por columnas, es decir, criterios por un lado y kernels por otro; diferenciando, por supuesto, el género en ambas. En las Tablas 5.19 y 5.20 se presenta la relación de las medias calculadas para el conjunto de datos de los hombres.

\begin{tabular}{lccc}
\hline Estudio & t-test & Entropía & ROC \\
\hline \hline RF + PCA & $68,75 \%$ & $69,25 \%$ & $66,25 \%$ \\
\hline \hline RF + PLS & $72,5 \%$ & $71,25 \%$ & $71,25 \%$ \\
\hline \hline
\end{tabular}

Tabla 5.19: Relación media de tasas de clasificación para el conjunto de datos masculino para los dos casos con Rank Feautres según los criterios utilizados.

Analizando las conclusiones presentadas en las Tablas 5.19 y 5.20 se puede observar que en el caso de los criterios tanto t-test como la relación de entropía tienen unos rendimientos muy parecidos para ambos casos, mientras que ROC es claramente el peor de los tres criterios utilizados cuando se utiliza la combinación (RF y PCA). En términos generales, para el conjunto de datos masculino el rendimiento obtenido con 


\begin{tabular}{lcccc}
\hline Estudio & Lineal & Polinomial & Cuadrático & RBF \\
\hline \hline RF + PCA & $73,33 \%$ & $66,67 \%$ & $69 \%$ & $63,33 \%$ \\
\hline \hline RF + PLS & $70 \%$ & $76,67 \%$ & $70 \%$ & $70 \%$ \\
\hline
\end{tabular}

Tabla 5.20: Relación media de tasas de clasificación para el conjunto de datos masculino para los dos casos con Rank Feautres según los kernels utilizados.

cualquiera de los criterios utilizados nunca baja del $71 \%$ cuando la combinación utilizada es (RF y PLS). Por otro lado, si se habla de los kernels de entrenamiento para el algoritmo de clasificación SVM, se puede observar que el rendimiento obtenido cuando se utiliza PLS es bastante mejor que cuando se utiliza PCA. El kernel lineal resulta ser robusto frente a los demás produciendo tasas del $70 \%$ como mínimo.

En las Tablas 5.21 y 5.22 se presentan la confrontación de rendimientos cuando los casos son las combinaciones para (RF y PCA) y (RF y PLS) para el conjunto de datos femenino.

\begin{tabular}{lccc}
\hline Estudio & t-test & Entropía & ROC \\
\hline \hline RF + PCA & $77,5 \%$ & $87,5 \%$ & $71,67 \%$ \\
\hline \hline RF + PLS & $65,84 \%$ & $66,67 \%$ & $64,17 \%$ \\
\hline \hline
\end{tabular}

Tabla 5.21: Relación media de tasas de clasificación para el conjunto de datos femenino para los dos casos con Rank Features según los criterios utilizados.

\begin{tabular}{lcccc}
\hline Estudio & Lineal & Polinomial & Cuadrático & RBF \\
\hline \hline RF + PCA & $82,22 \%$ & $78,89 \%$ & $78,89 \%$ & $75,56 \%$ \\
\hline \hline RF + PLS & $66,67 \%$ & $65,56 \%$ & $65,56 \%$ & $64,44 \%$ \\
\hline \hline
\end{tabular}

Tabla 5.22: Relación media de tasas de clasificación para el conjunto de datos femenino para los dos casos con Rank Features según los kernels utilizados.

Analizando los resultados de las Tablas 5.21 y 5.22 se puede comprobar a simple vista que el primer caso, es decir, la combinación de (RF y PCA) es claramente superior en ambas tablas. Sin embargo, yendo al detalle se puede decir que la relación de entropía es el criterio vencedor y en el caso de los kernels el más estable en media ha sido el lineal. Es cierto que la tasa más alta se obtuvo con la combinación entropía y kernel cuadrático, aunque lo que estamos valorando es la estabilidad y los mejores resultados en promedio. Respecto de los rendimientos obtenidos tanto para los diferentes criterios, como para los distintos kernels se obtiene un peor rendimiento para el segundo caso (RF y PLS) que en el primero (RF y PCA).

Finalmente, se podría concluir que aunque PCA y PLS son métodos relativamente parecidos, como ya se comentó en el Capítulo 4, la forma que tiene de reducir la dimensionalidad PCA favorece en gran medida a los datos del conjunto femenino, 
mientras que PLS lo hace para el conjunto de datos masculino, siendo éste un aspecto que merecería posterior consideración si se dispusiese de una base de datos más amplia.

\subsubsection{Independent Component Analysis - ICA}

A continuación se presentan en las Tablas 5.23 y 5.24 los valores obtenidos utilizando ICA y SVM para hombres y mujeres, respectivamente. Las funciones de no linealidad utilizadas en el algoritmo de ICA fueron pow3 y skew. La primera se basa en una función de orden tres, $g(x)=x^{3}$, mientras que la segunda es una función de orden dos, $g(x)=x^{2}$ (véase sección 4.4.2). Este caso se ha llevado a cabo con el toolbox de Matlabß, FastICA, el cual ha sido desarrollado por Erkki Oja y su grupo de colaboradores de la Universidad Aalto en Finlandia [80], [83].

Analizando los valores obtenidos para el conjunto de datos masculino (Tabla 5.23), se puede observar que en la mitad de los casos, la tasa de precisión alcanzada es del $70 \%$, siendo está a su vez la cota más alta de clasificación para dicho conjunto. Sin embargo, cuando la combinación utilizada es pow3 y $R B F$ la tasa cae hasta el $55 \%$, siendo esta la tasa más baja de las 8 calculadas. Finalmente, existen dos combinaciones, (lineal, skew) y (polinomial, pow3) que alcazan una precisión del $65 \%$.

\begin{tabular}{lcc}
\hline Kernel & Skew & Pow3 \\
\hline \hline Lineal & $65 \%$ & $70 \%$ \\
\hline Polinomial & $70 \%$ & $65 \%$ \\
\hline Cuadrático & $70 \%$ & $70 \%$ \\
\hline RBF & $70 \%$ & $55 \%$ \\
\hline
\end{tabular}

Tabla 5.23: Resultados de clasificación utilizando ICA para el conjunto de datos masculino.

Dado que existen cinco combinaciones para los hombres que alcanzan el máximo de precisión, del 70\%, se ha decidido presentar en la Figura 5.20(a) todas las combinaciones de las funciones de no linearidad que producen las tasasa máximas, donde se puede observar el número de componentes independientes estimadas por cada iteración. Además, se puede apreciar que utilizando la función de no linearidad pow3 tan solo se alcanza la cota máxima en una ocasión por cada kernel, mientras que en el caso de las combinaciones skew con los kernels cuadrático y $R B F$, dicho máximo se alcanza más de una vez. 


\begin{tabular}{lcc}
\hline Kernel & Skew & Pow3 \\
\hline \hline Lineal & $70 \%$ & $73,33 \%$ \\
\hline Polinomial & $66,67 \%$ & $66,67 \%$ \\
\hline Cuadrático & $60 \%$ & $70 \%$ \\
\hline RBF & $60 \%$ & $70 \%$ \\
\hline
\end{tabular}

Tabla 5.24: Resultados de clasificación utilizando ICA para el conjunto de datos femenino.

De forma análoga, los resultados para el conjunto femenino se presentan en la Tabla 5.24, donde se puede observar que las tasas de precisión alcanzadas son en términos generales más altas que para el conjunto masculino. Las tasas de clasificación más bajas han sido las combinaciones de la función skew y los kernels cuadrático y $R B F$, alcanzando un $60 \%$. Por otro lado, el kernel polinomial devuelve una tasa idéntica para ambas funciones de no linearidad, del 66,67\%. Se puede decir que los resultados más estables para el conjunto femenino se han alcanzado cuando la combinación utiliza la función de no linearidad pow3, consiguiendo un $70 \%$ para los kernels cuadrático y $R B F$. Por último, la mejor tasa de clasificación se obtiene cuando se utiliza pow3 y un kernel de tipo lineal, obteniendo un 73,33\%. En la Figura 5.20 (b) se representan las dos mejores combinaciones con sus respectivas iteraciones para alcanzar las tasas máximas de clasificación. En general, los resultados no son buenos, puesto que más de la mitad de ellos en cada una de las iteraciones para cada función de contraste están por debajo del $50 \%$ de tasa de clasificación.

Por consiguiente, si comparamos los resultados obtenidos en los estudios desarrollados con Rank Features e ICA para el conjunto de datos femenino, se puede observar que las tasas alcanzadas en términos generales son peores para ICA, que cuando se utilizó únicamente Rank Features. La tasa máxima alcanzada fue 73,33\% cuando la combinación fue (pow3, lineal), mientras que se alcanzó un 83,33\% en media cuando el criterio utilizado con Rank Features fue la relación de entropía. Hay que destacar que el kernel lineal tiene un comportamiento bastante estable, puesto que su tasa máxima de clasificación no baja del $70 \%$. La función de contraste pow3 obtiene mejores tasas de clasificación en media para el conjunto de datos femenino. Por otro lado, para el conjunto masculino sí se ve una mejora en casi todas las combinaciones de las funciones de contraste con los kernels de entrenamiento, respecto de la técnica Rank Features. En cuatro de los ocho resultados posibles el algoritmo ICA obtiene una tasa de precisión del $70 \%$. Tres de ellos para la función de contraste fue skew. Sin embargo, cuando la técnica utilizada fue Rank Features solo se obtuvieron tasas parecidas con el kernel cuadrático, alcanzándose incluso el $75 \%$. Todas las demás combinaciones ni siquiera alcanzaron un $70 \%$ de tasa de clasificación. Por lo tanto, la función de contraste con mejores conclusiones sería en este caso skew. En términos generales el kernel con mejores resultados para el conjunto masculino sería el cuadrático, mientras que para el femenino sería el lineal. Ambos, obtuvieron en media un rendimiento igual o superior al $70 \%$. 


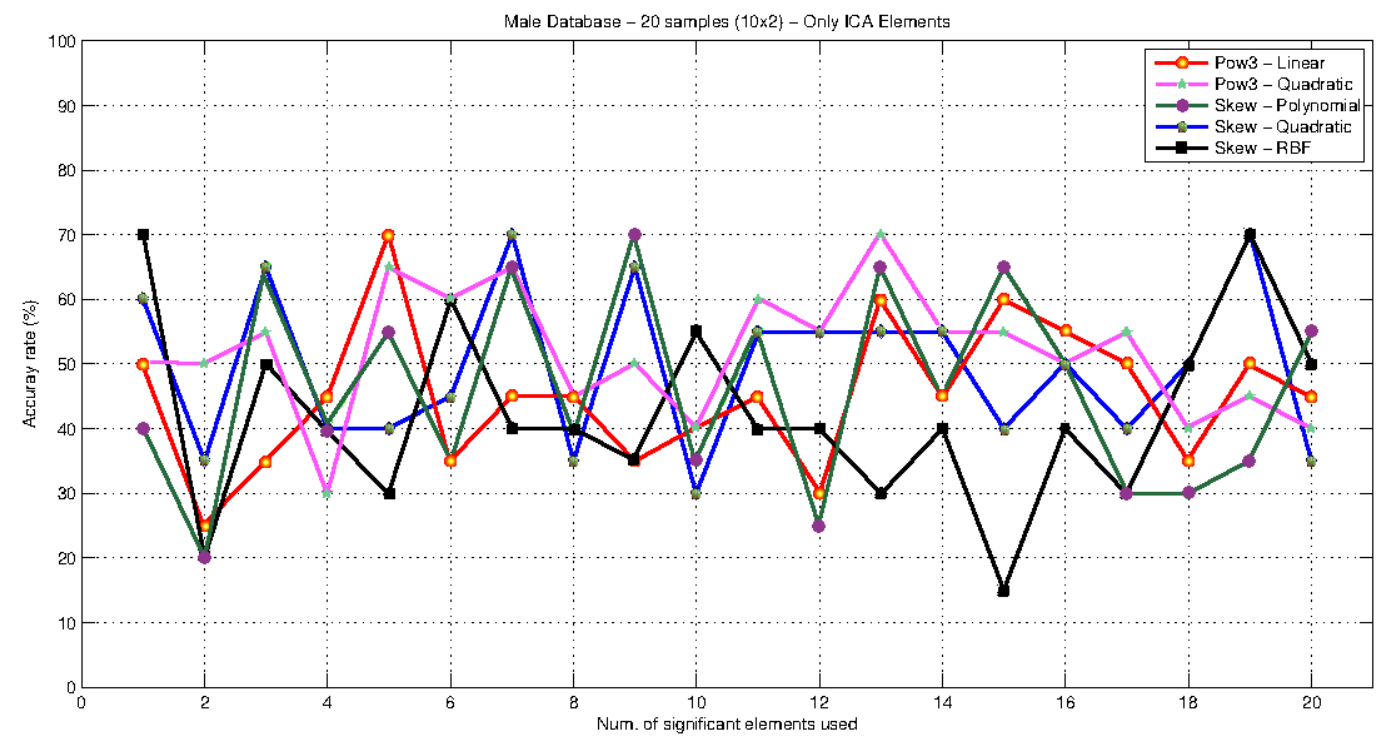

(a)

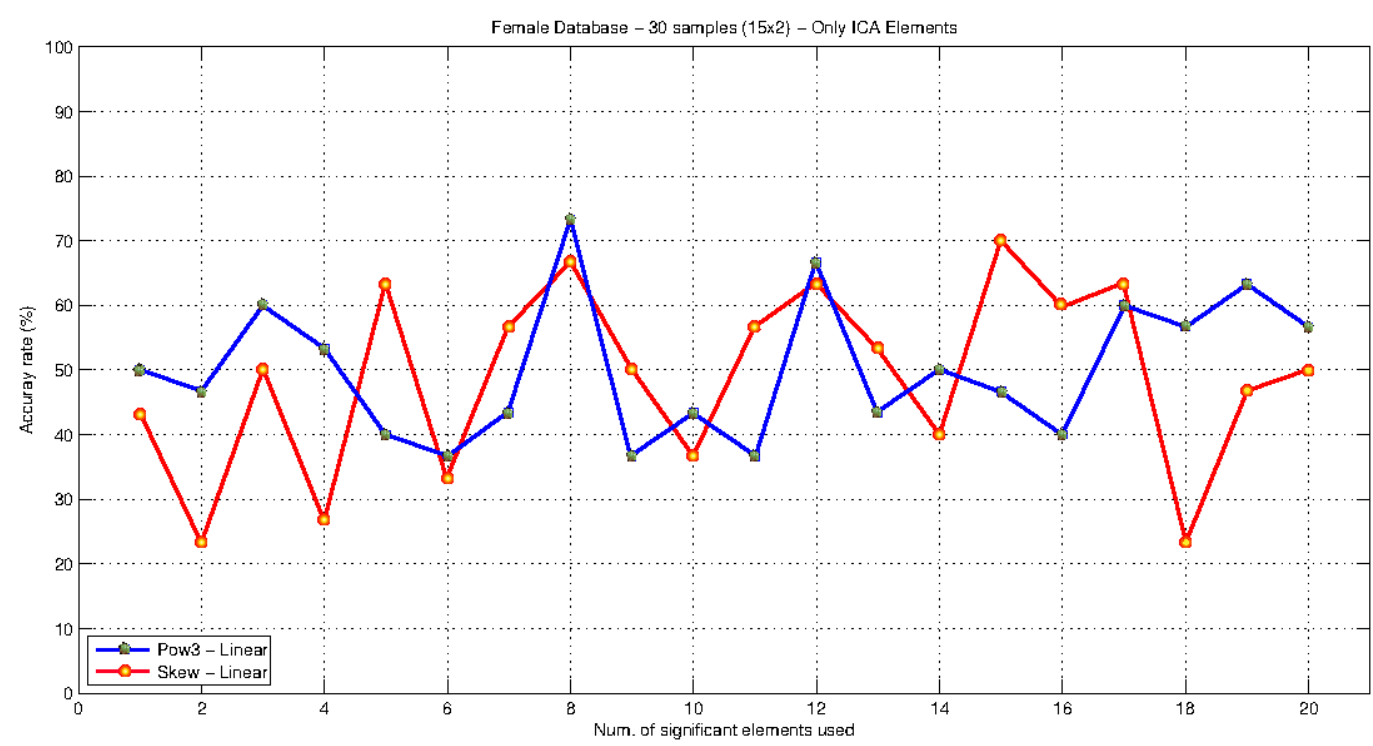

(b)

Figura 5.20: Resumen de las ejecuciones realizadas para jerarquizar los componentes independientes más relevantes en el caso del conjunto (a) - masculino. (b) - femenino.

\subsection{Modelos no paramétricos}

En esta sección se intentará dar un nuevo enfoque al estudio de los rasgos y estimación del estrés, pero esta vez desde un punto de vista no parámetrico. ¿Cuál es el motivo de este enfoque? Debido a que el número de muestras de los conjuntos iniciales de datos es pequeño, y por consiguiente muy sensible al cálculo de las medias estadísticas o varianzas lo que hace que estos datos sean poco robustos en cuanto 
alguna muestra se desvíe de la población o distribución a considerar. La estadística no paramétrica utiliza frecuencias o funciones de densidad, es decir, intervalos disjuntos de datos y generación de rangos.

A continuación se va a estudiar qué rasgos destacan claramente por su capacidad de clasificación desde esta nueva aproximación. Utilizaremos dos técnicas no paramétricas, explicadas en las Secciones 4.3.1 y 4.3.2, consistentes en el cálculo de la función de contraste de Kolmogorov-Smirnov y de la función de contraste de UMann-Whitney para la suma de rangos. El conjunto de datos utilizado es el corpus 3 .

\subsubsection{Validación de rasgos}

Aquí se trata de comparar cada una de las características extraídas entre las distribuciones neutras contra las distribuciones de estrés. Esta acción ofrecerá como resultado qué rasgos difieren en forma, simetría o tendencia, cuando el discurso establecido es neutro o congruente o por el contrario existen rasgos de estrés o incongruencia.

El estudio se planteó bajo dos puntos de vista:

- El primer enfoque radica en comparar las dos poblaciones muestrales, congruencia (neutro) frente a incongruencia (estrés) para cada uno de los rasgos. Se busca contrastar la población muestral en cada situación para cada uno de los rasgos, sin tener en cuenta los individuos de forma separada, sino como si todos pertenecieran a un único individuo. El método consiste en comparar los datos de congruencia/neutro de parámetro $x_{a j}$ con los de ese mismo parámetro en incongruencia/estrés $x_{d j}$ para todos los individuos de la población, como puede verse en la Figura 5.21.

- El segundo enfoque realiza un estudio de pares o pair-wise, un individuo sobre si mismo, enfrentando todas las muestras de estado neutro ( $a$ : congruencia), para el rasgo $j$ del individuo $i, x_{a i j}$ contra todas las muestras de estado alterado ( $d$ : incongruencia), para el rasgo $j$ del individuo $i, x_{d i j}$. En la Figura 5.22 se presenta el segundo enfoque de manera gráfica. Con esta comparación se intenta comprobar si dicho rasgo se ve alterado entre un estado u otro para un individuo $i$. Una vez se hayan contrastado todos los individuos para cada uno de los rasgos, se contabilizará cuántas veces dicho rasgo ha rechazado la hipótesis nula, $H_{0}$.

En sendos enfoques, los rasgos que hayan rechazado la hipótesis nula, se ordenarán y se compararán con los rasgos seleccionados de la sección anterior, por métodos de estadística paramétrica (véase sección 5.5). 


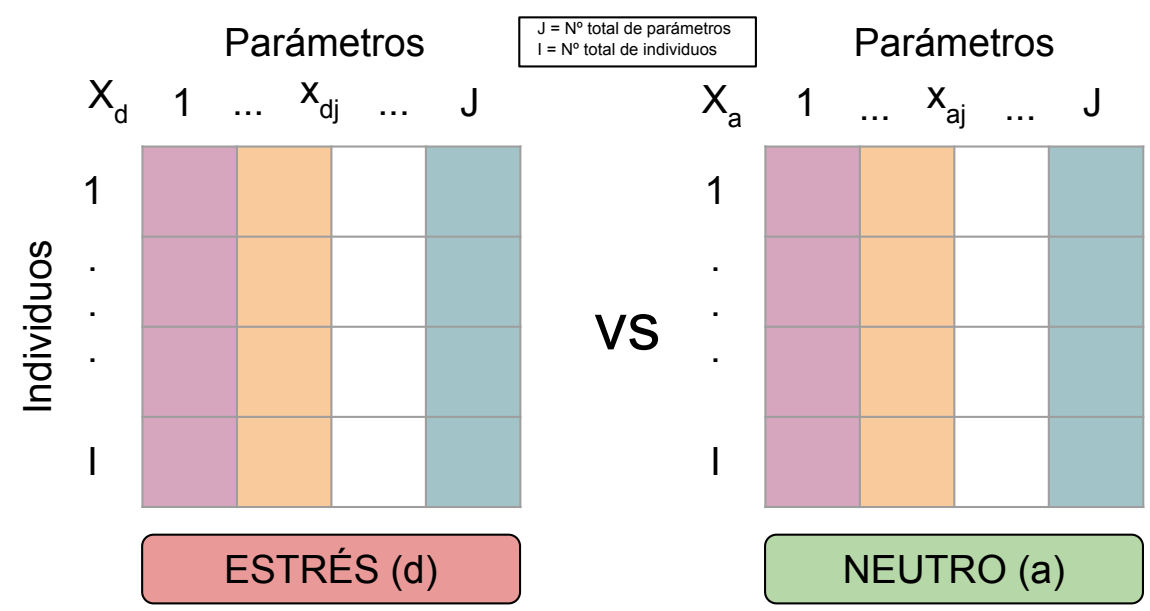

Figura 5.21: Prueba sobre la colección completa de datos según cada parámetro.
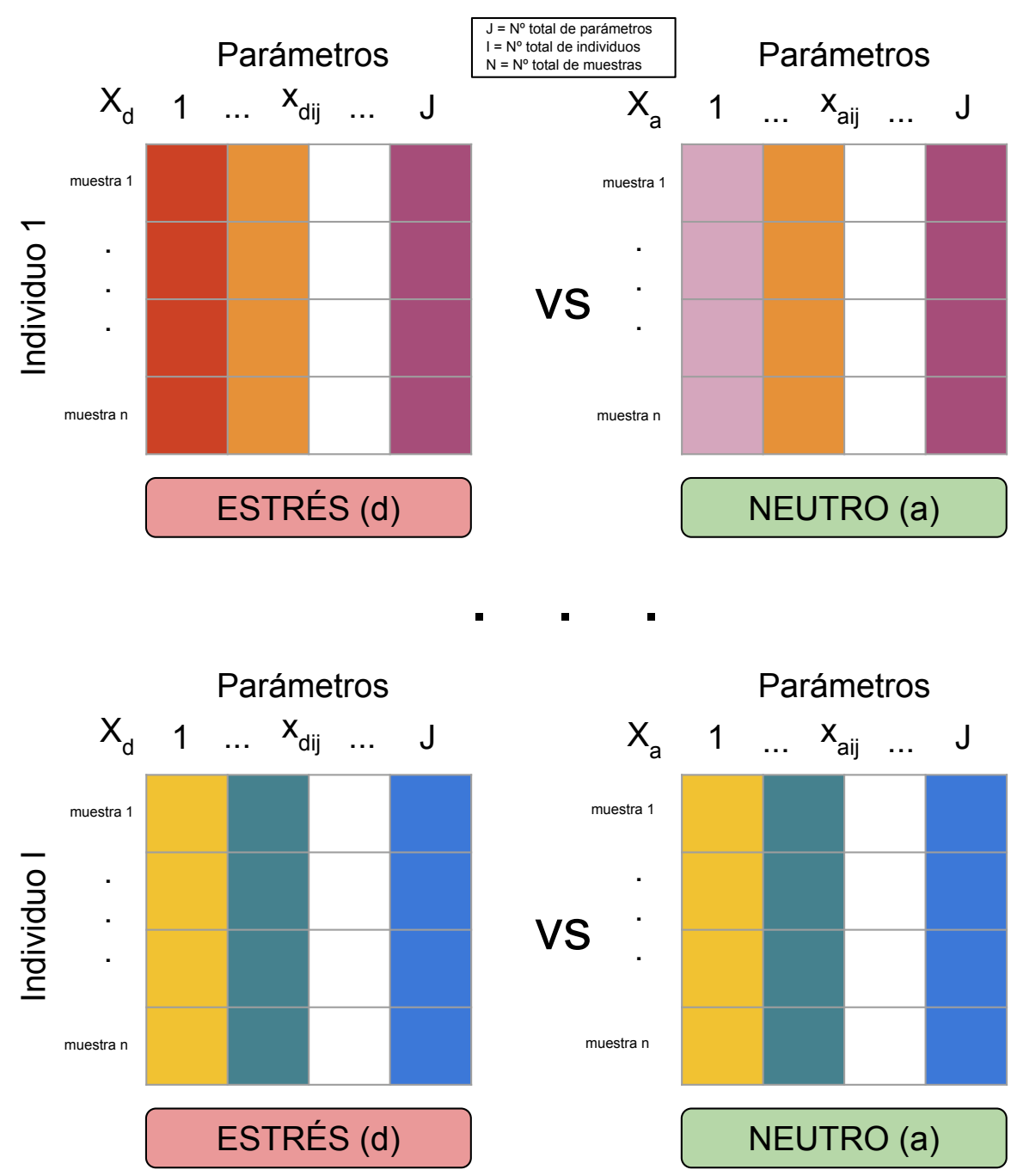

Figura 5.22: Prueba pair-wise sobre la colección completa de datos según cada individuo. 


\subsubsection{Prueba de Kolmogorov-Smirnov}

La prueba de contraste de Kolmogorov-Smirnov (en adelante $K S$ ) devuelve como resultado dos variables. La primera indica el $p$-value obtenido al enfrentar dos vectores $x_{1}$ y $x_{2}$ de distintas distribuciones, considerando que ambas muestras son independientes en su origen y pertenecientes a la misma población. La segunda variable es de tipo lógico y devuelve 0 cuando no se rechaza la hipótesis nula y devuelve 1 cuando dicha hipótesis sí es rechazada.

La prueba de $K S$ se centra en las diferencias entre las frecuencias relativas acumuladas, comprobando no solo la tendencia central de las distribuciones, sino también la asimetría de la distribución. Básicamente, cuando las diferencias encontradas entre ambas distribuciones es grande, la hipótesis nula resulta rechazada.

Partiendo de lo anteriormente descrito, si el resultado de la comparación fuese que no se rechaza la hipótesis nula $\left(H_{0}=0\right)$, significa que no existen evidencias suficientes como para que los dos vectores contrastados no procedan de la misma población. Dicho en otras palabras, no existe evidencia plausible para poder distinguir los valores obtenidos de una distribución de estrés, respecto de una distribución neutra para ese parámetro $j$. Sin embargo, si el resultado obtenido fuese que se rechaza la hipótesis nula $\left(H_{0}=1\right)$, significa que ambos vectores poseen valores realmente distintos en ambos casos y por lo tanto este parámetro se podría considerar significativo desde un punto de vista empírico.

La función utilizada para realizar los cálculos pertenece al conjunto de estadística del programa Matlabß y se basa en el trabajo de [115], [122] y [197].

\section{Primera Parte - Todos vs Todos}

Se quiso realizar dos comprobaciones adicionales por cada conjunto de datos, tanto en el masculino, como en el femenino. Esta comprobación se basa en la utilización de dos niveles de relevancia. El estándar para este tipo de pruebas es el $95 \%$, en otras palabras, un $\alpha=0,05$ dejando en cada cola de la distribución un 0,25 si la distribución se considerase normal. El otro nivel de relevancia relativamente generalizado es cuando $\alpha=0,1$.

En las Tablas B.1, B.2, B.3 y B.4 pertenecientes a la Sección B.1 del Apéndice $\mathrm{B}$ se presentan los resultados correspondientes al conjunto de datos masculino y femenino para esta primera parte del caso (Todos vs Todos) de forma íntegra. Sin embargo, en las próximas líneas, tan solo se presentarán los resultados más relevantes, es decir, los rasgos que hayan rechazado la hipótesis nula $\left(H_{0}\right)$. De esta forma, nos centramos solo en los rasgos que se han manifestado relevantes.

En las Tablas 5.25 y 5.26 se presentan los resultados obtenidos para $\alpha=0,05$ y $\alpha=0,1$, respectivamente para el grupo de los hombres:

Analizando los resultados de las Tablas 5.25 y 5.26 se puede observar que los 
rasgos obtenidos cuando el nivel de confianza es estricto, $\alpha=0,05$, son tan solo dos, el rasgo 8 y el 68, siendo el rasgo 8 el segundo Cepstral para la descripción de la fuente glotal y el rasgo 68, el cual ha surgido en muchas ocasiones a lo largo de este capítulo, la amplitud de la estimación del temblor. Por otro lado, cuando la exigencia es un poco más laxa, $\alpha=0,1$, los rasgos que rechazan la hipótesis nula son siete. Los dos anteriormente mencionados, por supuesto, y además los rasgos 20, 30, 31, 50 y 66 (véase sección 3.3.2). Como se puede comprobar, nuevamente, los rasgos 66 y 68 están relacionados con la estimación del temblor.

\begin{tabular}{lcc}
\hline Rasgos & p-value & Hipótesis \\
\hline \hline 8. MWC Cepstral 2 & 0,032 & 1 \\
\hline 68. NeurTremor Frequency $(\mathrm{Hz})$ & 0,014 & 1 \\
\hline
\end{tabular}

Tabla 5.25: Rasgos que rechazan la hipótesis nula para la prueba de contraste de Kolmogorov-Smirnov en el conjunto masculino cuando enfrentamos todas las muestras neutras frente a las muestras de estrés, teniendo en cuenta un $\alpha=0,05$.

\begin{tabular}{lcc}
\hline Rasgos & p-value & Hipótesis \\
\hline \hline 8. MWC Cepstral 2 & 0,032 & 1 \\
\hline 20. MWC Cepstral 14 & 0,096 & 1 \\
\hline 30. MW PSD 2nd Min. Pos. rel. & 0,099 & 1 \\
\hline 31. MW PSD 3rd Max. Pos. rel. & 0,075 & 1 \\
\hline 50. Rel. Open 2 Time & 0,093 & 1 \\
\hline 66. PhysTremor Frequency (Hz) & 0,070 & 1 \\
\hline 68. NeurTremor Frequency (Hz) & 0,014 & 1 \\
\hline
\end{tabular}

Tabla 5.26: Rasgos que rechazan la hipótesis nula para la prueba de contraste de Kolmogorov-Smirnov en el conjunto masculino cuando enfrentamos todas las muestras neutras frente a las muestras de estrés, teniendo en cuenta un $\alpha=0,1$.

A continuación y de forma análoga se presentan las Tablas 5.27 y 5.28 pertenecientes al grupo de las mujeres:

Repasando los rasgos obtenidos en el conjunto de las mujeres cuando se enfrentan todas las muestras entre sí, podemos observar que el número de rasgos obtenidos cuando el nivel de relevancia es del $95 \%$ es más amplio que en el caso de los hombres, concretamente, se seleccionan 7 rasgos. Estos no coinciden en ningún caso con los rasgos obtenidos para el conjunto masculino. Continuando con el estudio del caso y ampliando la selección se puede ver que se obtienen diecisiete rasgos, es decir, se aumenta la lista en diez rasgos más. Algunos de estos están relacionados con la biomecánica de los pliegues vocales y más específicamente con la rigidez del cuerpo y cubierta de los mismos. Estamos hablando de los rasgos 35, 37, 41 y 42. 


\begin{tabular}{lcc}
\hline Rasgos & p-value & Hipótesis \\
\hline \hline 2. Abs. Norm. Jitter & 0,020 & 1 \\
\hline 3. Abs. Norm. Ar. Shimmer & 0,005 & 1 \\
\hline 4. Abs. Norm. Min. Sharp. & 0,006 & 1 \\
\hline 14. MWC Cepstral 8 & 0,001 & 1 \\
\hline 19. MWC Cepstral 13 & 0,043 & 1 \\
\hline 35. Body Mass & 0,026 & 1 \\
\hline 41. Cover Mass & 0,006 & 1 \\
\hline
\end{tabular}

Tabla 5.27: Rasgos que rechazan la hipótesis nula para la prueba de contraste de Kolmogorov-Smirnov en el conjunto femenino cuando enfrentamos todas las muestras neutras frente a las muestras de estrés, teniendo en cuenta un $\alpha=0,05$.

\begin{tabular}{lcc}
\hline Rasgos & p-value & Hipótesis \\
\hline \hline 1. Absolute Pitch & 0,054 & 1 \\
\hline 2. Abs. Norm. Jitter & 0,020 & 1 \\
\hline 3. Abs. Norm. Ar. Shimmer & 0,004 & 1 \\
\hline 4. Abs. Norm. Min. Sharp. & 0,006 & 1 \\
\hline 5. Noise-Harm. Ratio (NHR) & 0,080 & 1 \\
\hline 6. Muc./AvAc. Energy (MAE) & 0,062 & 1 \\
\hline 10. MWC Cepstral 4 & 0,059 & 1 \\
\hline 14. MWC Cepstral 8 & 0,001 & 1 \\
\hline 19. MWC Cepstral 13 & 0,043 & 1 \\
\hline 32. MW PSD End Val. Pos. rel. & 0,097 & 1 \\
\hline 34. MW PSD 2nd Min NSF & 0,076 & 1 \\
\hline 35. Body Mass & 0,026 & 1 \\
\hline 37. Body Stiffness & 0,054 & 1 \\
\hline 41. Cover Mass & 0,006 & 1 \\
\hline 42. Cover Losses & 0,088 & 1 \\
\hline 55. Rel. Open 2 Ampl. & 0,095 & 1 \\
\hline 57. Rel. Start Flow Time & 0,071 & 1 \\
\hline
\end{tabular}

Tabla 5.28: Rasgos que rechazan la hipótesis nula para la prueba de contraste de Kolmogorov-Smirnov en el conjunto femenino cuando enfrentamos todas las muestras neutras frente a las muestras de estrés, teniendo en cuenta un $\alpha=0,1$.

Entrelazando los resultados obtenidos con este caso de estudio y los rasgos seleccionados utilizando estadística paramétrica (véase sección 5.5) y más concretamente con la técnica Rank Features, podemos observar que para el conjunto de los datos masculinos los rasgos 66 y 68, relativos a la estimación del temblor, aparecerían como relevantes como mínimo en tres de las cuatro pruebas. De hecho, el rasgo 68 resultó seleccionado con todos los criterios utilizados. Por consiguiente, se puede decir que existen diferencias significativas entre el conjunto de muestras (congruentes/neutras) y las de (incongruencia/estrés) que hacen que se puedan diferenciar ambas distribuciones y afirmar que no pertenecen a la misma distribución poblacio- 
nal cuando los rasgos son el 66 y el 68.

Análogamente, para el conjunto de datos femenino, el rasgo 5 (tasa del HarmónicoRuido) también aparece en todos y cada uno de los posibles criterios de selección en la técnica Rank Features. Sin embargo, este rasgo resulta relevante para un $\alpha=0,1$. Otros rasgos que han rechazado la hipótesis nula, también aparecen en algún momento seleccionados con la anterior metodología, pero no de forma tan notable. Por ejemplo, los rasgos 14 y 32 aparecen seleccionados en dos ocasiones, mientras que los rasgos 3, 4, 19 y 34 tan solo han sido seleccionados en una ocasión con alguno de los criterios utilizados. Por otro lado, los rasgos 1, 10, 35 y 37 también rechazaron la hipótesis nula, de modo relevante cuando se realizó una primera selección de rasgos gracias al coeficiente de correlación de Pearson utilizando el algoritmo SVM (véase sección 5.4). De hecho, el rasgo 35 (la masa del cuerpo de los pliegues vocales) rechazó la hipótesis nula con un $\alpha=0,05$.

\section{Segunda Parte - Pair-Wise}

A parte de lo que ya se ha explicado, en este segundo enfoque se realizó una tarea "extra", la cual consistió en realizar un post-procesado de los datos. Este proceso consistió en eliminar todos aquellos individuos que tuviesen una o ninguna muestra en alguno de sus emparejamientos. Es evidente que trabajando con frecuencias si no se tiene muestras en alguno de los conjuntos, carece de sentido realizar la prueba.

Teniendo en cuenta lo anterior, el número de individuos incluidos varía de la siguiente forma:

\begin{tabular}{lcc}
\hline Dataset & Hombres & Mujeres \\
\hline \hline Inicial & 20 & 20 \\
Primer Procesado & 16 & 18 \\
Segundo Procesado & 9 & 12 \\
\hline
\end{tabular}

Tabla 5.29: Número de individuos para el conjunto de datos masculino y femenino para el estudio del segundo caso, pair-wise.

En las expresiones 5.9 y 5.10 se presenta la forma de calcular el tanto por cierto (\%) del total de rasgos que contribuyen en la detección del estrés, respecto del conjunto total de los 72 rasgos para la población utilizada (véase Tabla 5.29). La hipótesis inicial se basa en el hecho que todos los rasgos podrían rechazar la hipótesis nula y por consiguiente todos ellos serían rasgos significativos de cara a discernir de manera clara la detección del estrés. Por consiguiente, el máximo es el producto entre el número de individuos de la población a estudio, y el número total de rasgos extraídos. Una vez calculado el máximo, el factor de mérito se obtiene del cociente entre el número total de veces que se han seleccionado los rasgos y el máximo de posibilidades de haber rechazado la hipótesis nula.

$$
\text { Máximo }=N^{\mathrm{o}} \text { Individuos de la Población } \times N^{\mathrm{o}} \text { Total de Parámetros }
$$




$$
\text { Factor de Mérito }(\%)=\frac{\text { Total }}{\text { Máximo }}
$$

Por ejemplo, en el caso del conjunto masculino y utilizando el primer procesado, el número inicial de individuos era de 16. Se extrajeron 72 rasgos por cada individuo, por consiguiente el número máximo de ocasiones en que se podría haber rechazado la hipótesis nula era de 1152. Sin embargo, tan solo en 63 ocasiones se ha rechazado la hipótesis nula de las 1152 posibles, por consiguiente el factor de mérito fue del 5,47\%.

En las Tablas 5.30 y 5.31 aparece el resumen del cálculo del factor de mérito para el conjunto de los hombres y en las Tablas 5.32 y 5.33 el cálculo similar para el conjunto de las mujeres, respecto de los niveles de confianza utilizados.

\begin{tabular}{llr}
\hline TOTAL & & 63 \\
\hline \hline \multirow{3}{*}{ Primer Procesado } & Emparejamientos & 16 \\
& Máximo & 1152 \\
& Factor de mérito & $5,47 \%$ \\
\hline \multirow{3}{*}{ Segundo Procesado } & Emparejamientos & 9 \\
& Máximo & 648 \\
& Factor de mérito & $9,72 \%$ \\
\hline
\end{tabular}

Tabla 5.30: Resultados para el conjunto masculino, cuando realizamos un estudio de tipo pair-wise para la prueba KS con un $\alpha=0,05$.

\begin{tabular}{llr}
\hline TOTAL & & 153 \\
\hline \hline \multirow{3}{*}{ Primer Procesado } & Emparejamientos & 16 \\
& Máximo & 1152 \\
& Factor de mérito & $13,28 \%$ \\
\hline \multirow{3}{*}{ Segundo Procesado } & Emparejamientos & 9 \\
& Máximo & 648 \\
& Factor de mérito & $23,61 \%$ \\
\hline
\end{tabular}

Tabla 5.31: Resultados para el conjunto masculino, cuando realizamos un estudio de tipo pair-wise para la prueba KS con un $\alpha=0,1$.

Analizando los resultados de las tablas anteriormente citadas, se puede observar que el número de rasgos que han rechazo la hipótesis nula es reducido respecto del total de posibilidades. Más concretamente, cuando $\alpha=0,05$, ninguno de los conjuntos de datos en cualquiera de los dos postprocesados superan el 10\%, aunque en el caso de los hombres en el segundo procesado casi lo alcanza. Por otro lado, cuando el nivel de confianza aumenta, los valores resultantes casi alcanzan un cuarto del total en el caso de los hombres, o dicho de otra forma casi el $25 \%$ de los parámetros ha rechazado la hipótesis nula en alguna ocasión, mientras que en el caso de las mujeres, no se supera el $15 \%$. 


\begin{tabular}{llr}
\hline TOTAL & & 59 \\
\hline \hline \multirow{3}{*}{ Primer Procesado } & Emparejamientos & 18 \\
& Máximo & 1296 \\
& Factor de mérito & $4,55 \%$ \\
\hline \multirow{3}{*}{ Segundo Procesado } & Emparejamientos & 12 \\
& Máximo & 864 \\
& Factor de mérito & $6,83 \%$ \\
\hline
\end{tabular}

Tabla 5.32: Resultados para el conjunto femenino, cuando realizamos un estudio de tipo pair-wise para la prueba KS con un $\alpha=0,05$.

\begin{tabular}{llr}
\hline TOTAL & & 127 \\
\hline \hline \multirow{3}{*}{ Primer Procesado } & Emparejamientos & 18 \\
& Máximo & 1296 \\
& Factor de mérito & $9,80 \%$ \\
\hline \multirow{3}{*}{ Segundo Procesado } & Emparejamientos & 12 \\
& Máximo & 864 \\
& Factor de mérito & $14,70 \%$ \\
\hline
\end{tabular}

Tabla 5.33: Resultados para el conjunto femenino, cuando realizamos un estudio de tipo pair-wise para la prueba KS con un $\alpha=0,1$.

A continuación y para dejar patente qué rasgos han rechazado la hipótesis nula en alguna ocasión o incluso más de una vez, se presentan las Tablas B.5 y B.6 para el conjunto de los hombres y las Tablas B.7 y B.8 para el caso de las mujeres, las cuales se encuentran todas ellas en el apéndice B.1.

En ellas se puede observar que el número máximo de veces que un rasgo ha rechazado la hipótesis nula es de tres veces cuando $\alpha=0,05$ y cinco veces cuando $\alpha=0,1$. Por consiguiente, se puede decir que estos rasgos que han rechazado en más de una ocasión la hipótesis nula tienen valores considerablemente diferentes entre ambas distribuciones para un mismo individuo, es decir, al rechazar la hipótesis nula se puede decir que estas distribuciones no pertenecen a la misma distribución. De forma similar, en las Tablas B.7 y B.8 se observa que cuando $\alpha=0,05$ el número máximo de rasgos que rechazan la $H_{0}$ en más de una ocasión es de cuatro. Mientras que si $\alpha=0,1$ el número asciende a cinco.

Resumiendo este segundo enfoque, se puede decir que el factor de mérito alcanzado es debido a que el número de hipótesis nulas rechazadas es bajo porque existen individuos en ambos conjuntos de datos que no han rechazado la hipótesis nula en ningún momento, incluso relajando el nivel de relevancia. Por consiguiente, a la vista de estos resultados, cuando se enfrentan ambas muestras (neutro vs estrés) para este conjunto de individuos, ambas distribuciones podrían perfectamente pertenecer a la misma población, ya que sus valores son muy similares. Además, el factor de mérito aumenta cuando se realiza el segundo procesamiento de datos debido a que los individuos que permanecen, poseen distribuciones poblaciones algo diferentes y 
se han eliminado aquellos que eran bastante análogos y no proporcionaban información adicional. Aun así, hay otro punto de vista a tener en cuenta y es que todos los individuos no aportan información por igual. Por ese motivo se ha querido presentar gráficamente la contribución de cada individuo al conjunto total.

En las Figuras 5.23 y 5.24 se puede observar la cantidad de rasgos que han rechazado la hipótesis nula por individuo para ambos géneros según los dos niveles de relevancia.

Null Hyphotesis Rejected by Males (Kolmogorov-Smirnov)

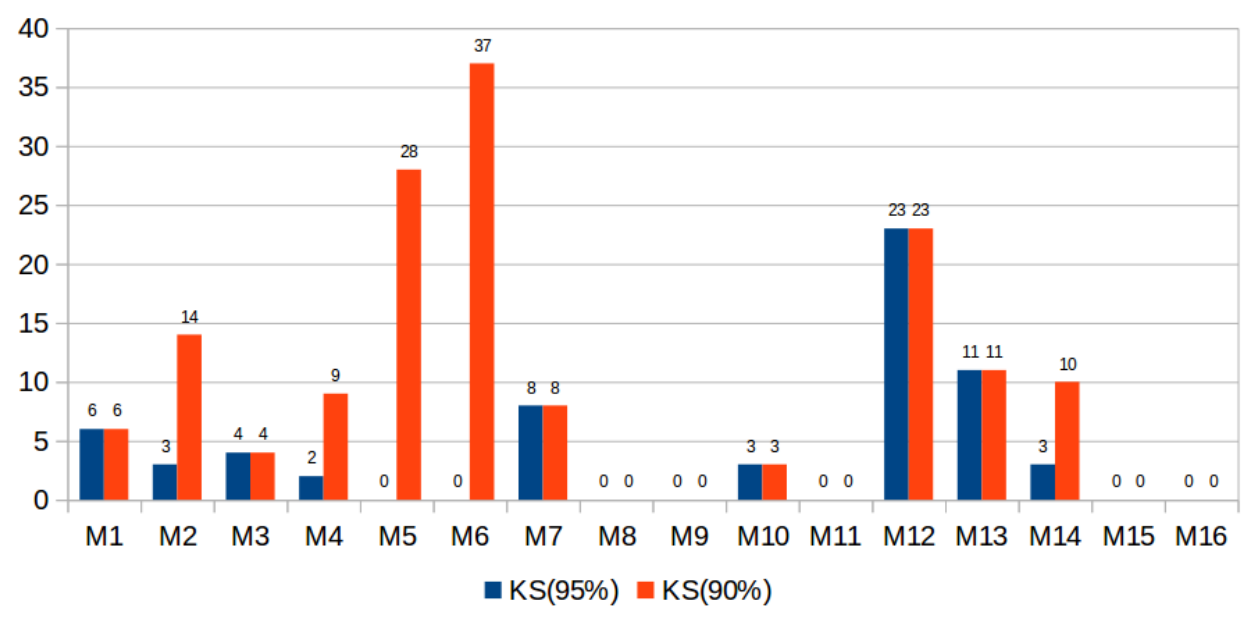

Figura 5.23: Resumen del número de veces en que es rechazada la hipótesis nula por individuo para el conjunto de datos masculino según la prueba $K S(5 \%)$ y $K S(10 \%)$.

Analizando la Figura 5.23 se puede observar que el individuo M12 genera 23 rasgos que rechazan la hipótesis nula con un $\alpha=0,05$. Esto significa que este individuo genera valores distintos cuando se enfrentan sus muestras neutras y sus muestras de estrés. Además, cuando el nivel de relevancia es $\alpha=0,1$ el número de rasgos que rechazan la hipótesis nula permanece constante, por consiguiente se puede concluir que estos rasgos son realmente significativos para este individuo. Casos análogos como el individuo M12 pueden ser M1, M3, M7, M10 y M13, pero estos generan una menor cantidad de rasgos significativos. Otros dos casos "curiosos" serían los individuos M5 y $M 6$, los cuales alcanzan un número muy elevado de rechazos de hipótesis nula cuando el nivel de relevancia se relaja. Sin embargo, no generan rechazo alguno cuando el nivel de relevancia es estricto. Por otro lado, los individuos M2 y M $_{4}$ presentan un comportamiento similar, es decir, con un $\alpha=0,05$ han rechazado $H_{0}$ en alguna ocasión, pero relajando el nivel de relevancia, generan más del doble de rechazos que en la anterior situación. Finalmente, el número de individuos que no han rechazado la hipótesis nula en ninguna ocasión ha sido cinco, (M8, M9, M11, M15 y M16).

En la Figura 5.24 se observan los resultados para el conjunto femenino. Los casos F1 y $F 8$ se comportan de manera análoga a $M 12$, pero para una menor cantidad de rasgos. En este caso sí que existe mayor número de diferencias entre los niveles de 
relevancia, aumentando la cuantía de rechazos de $H_{0}$ que se generan al relajar el nivel de relevancia. Los casos $F 5$ y en menor medida $F 10$ presentan un comportamiento similar a los de $M 5$ y $M 6$, es decir, los rechazos de $H_{0}$ tan solo se producen cuando el nivel de relevancia se relaja, en cualquier otro caso el número de rechazos es nulo. El número de casos que no han rechazado en ningún caso la hipótesis nula, asciende a seis (F2, F6, F7, F14, F16 y F17). Finalmente, los últimos siete casos por comentar (F3, F4, F9, F11, F12, F13 y F18) presentan un comportamiento parecido al de M2 y $M 4$, ya que en ambos casos se ha rechazado $H_{0}$ en alguna ocasión.

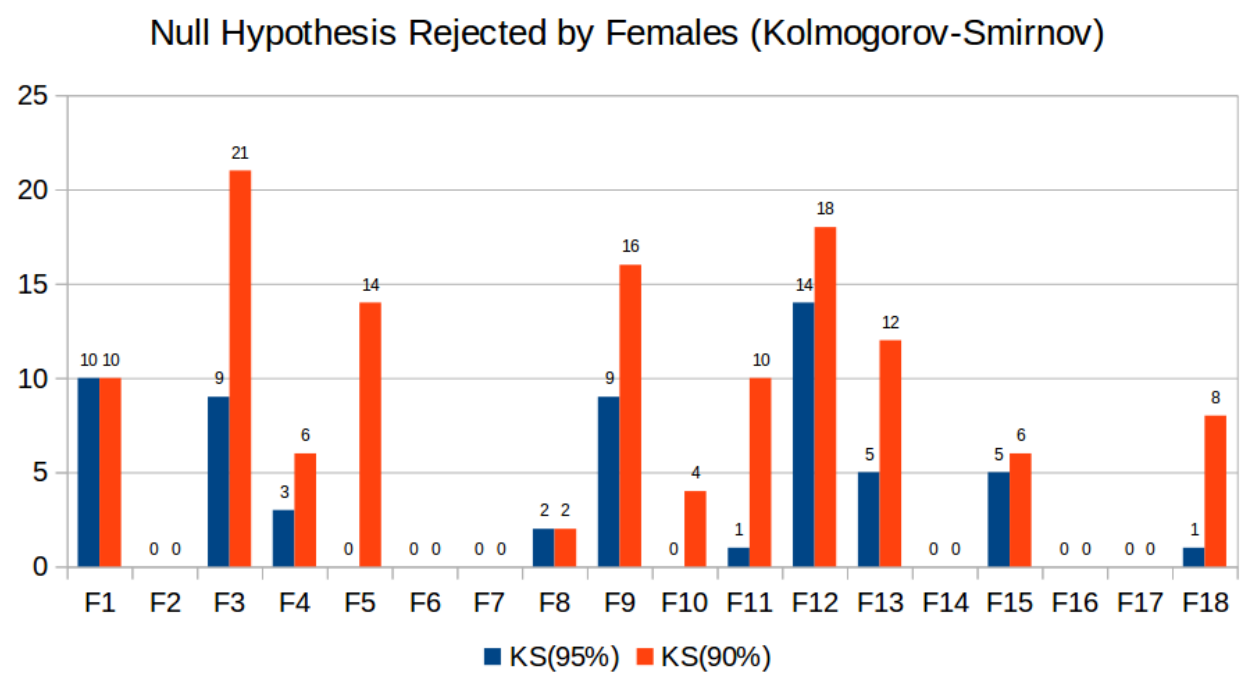

Figura 5.24: Resumen del número de veces en que es rechazada la hipótesis nula por individuo para el conjunto de datos femenino según la prueba $K S(5 \%)$ y $K S(10 \%)$.

\subsubsection{Prueba de U-Mann-Whitney}

La prueba de contraste de Mann-Whitney (en adelante $M W$ ) devuelve exactamente las dos mismas variables que en el caso de la función de $K S$. Sin embargo, la función de $M W$ calcula la esperanza matemática entre dos vectores $x_{1}$ y $x_{2}$ que pertenecen a dos distribuciones continuas e independientes, donde $x_{1}$ y $x_{2}$ pueden tener longitudes diferentes. La hipótesis nula supone que ambas distribuciones poseen la misma mediana. Este test es considerado la variante no paramétrica de la prueba t-Student para la diferencia de dos medias cuando las muestras son independientes pero no puede suponerse la normalidad de las poblaciones de origen.

Este tipo de prueba se utiliza para comprobar hipótesis en casos como la comparación de sueldos en dos ciudades distintas del mundo, las puntuaciones medias de los estudiantes de un mismo curso, etcétera. De esta forma se puede comprobar si ambas distribuciones son similares si su esperanza matemática lo es, por lo tanto la hipótesis nula no se rechaza, mientras que si el resultado obtenido es considerablemente distinto se rechaza la hipótesis nula.

En el caso que nos ocupa el test de la hipótesis nula pretende comprobar la diferencia entre las distribuciones de ambos supuestos (congruente e incongruente). Si 
se rechazara la hipótesis nula significaría que entre ambas distribuciones para dicho parámetro existen diferencias evidentes cuando el sujeto o individuo realiza uno u otro discurso lo que constituye la esencia de nuestro estudio.

La función utilizada para realizar los cálculos pertenece al conjunto de estadística del programa Matlab® y se basa en el trabajo de [60] y [78].

\section{Primera Parte - Todos vs Todos}

De forma similar al estudio anterior, los resultados completos se encuentran en las Tablas B.9, B.10, B.11 y B.12 incluidos en el Apéndice B.

En las Tablas 5.34 y 5.35 se pueden observar los resultados obtenidos cuando se comprueban todas las muestras del supuesto estado neutro con todas las muestras del supuesto estado de estrés para el parámetro $j$ para el conjunto de datos masculino.

Analizando estos resultados se puede ver que el número de rasgos con medianas diferentes y que por consiguiente rechazan la hipótesis nula tan solo es uno cuando el nivel de relevancia es de $\alpha=0,05$. El único rasgo resultante fue el 7, (primer Cepstral).

\begin{tabular}{lcc}
\hline Rasgos & p-value & Hipótesis \\
\hline \hline 7. MWC Cepstral 1 & 0,041 & 1 \\
\hline
\end{tabular}

Tabla 5.34: Rasgos que rechazan la hipótesis nula para la prueba de contraste de Mann-Whitney en el conjunto masculino cuando enfrentamos todas las muestras neutras frente a las muestras de estrés, teniendo en cuenta un $\alpha=0,05$. 


\begin{tabular}{lcc}
\hline Rasgos & p-value & Hipótesis \\
\hline \hline 7. MWC Cepstral 1 & 0,041 & 1 \\
\hline 8. MWC Cepstral 2 & 0,066 & 1 \\
\hline 20. MWC Cepstral 14 & 0,058 & 1 \\
\hline 52. Rel. Recov. 1 Ampl. & 0,056 & 1 \\
\hline 68. NeurTremor Frequency $(\mathrm{Hz})$ & 0,060 & 1 \\
\hline
\end{tabular}

Tabla 5.35: Rasgos que rechazan la hipótesis nula para la prueba de contraste de Mann-Whitney en el conjunto masculino cuando enfrentamos todas las muestras neutras frente a las muestras de estrés, teniendo en cuenta un $\alpha=0,1$.

Sin embargo, cuando el nivel de relevancia es $\alpha=0,1$, los rasgos que rechazan la hipótesis nula aumentan hasta cinco. El rasgo 7, evidentemente, y además los rasgos $8,20,52$ y 68 . Como se puede comprobar los rasgos 8,20 y el 68 vuelven a aparecer, al igual que en el caso de $K S$. Por consiguiente, el rasgo 68 es determinante para el conjunto de datos masculino, puesto que aparece en todos y cada uno de los criterios utilizados en las pruebas paramétricas (Rank Features), pero además en las dos pruebas no paramétricas $(K S$ y $M W)$.

Por otro lado, en las Tablas 5.36 y 5.37 se presentan los resultados para el conjunto femenino:

\begin{tabular}{lcc}
\hline Rasgos & p-value & Hipótesis \\
\hline \hline 1. Absolute Pitch & 0,041 & 1 \\
\hline 2. Abs. Norm. Jitter & 0,022 & 1 \\
\hline 3. Abs. Norm. Ar. Shimmer & 0,006 & 1 \\
\hline 4. Abs. Norm. Min. Sharp. & 0,035 & 1 \\
\hline 10. MWC Cepstral 4 & 0,026 & 1 \\
\hline 14. MWC Cepstral 8 & 0,0003 & 1 \\
\hline 19. MWC Cepstral 13 & 0,041 & 1 \\
\hline 32. MW PSD End Val. Pos. rel. & 0,034 & 1 \\
\hline 35. Body Mass & 0,042 & 1 \\
\hline 37. Body Stiffness & 0,042 & 1 \\
\hline 41. Cover Mass & 0,005 & 1 \\
\hline 57. Rel. Start Flow Time & 0,017 & 1 \\
\hline
\end{tabular}

Tabla 5.36: Rasgos que rechazan la hipótesis nula para la prueba de contraste de Mann-Whitney en el conjunto femenino cuando enfrentamos todas las muestras neutras frente a las muestras de estrés, teniendo en cuenta un $\alpha=0,05$. 


\begin{tabular}{lcc}
\hline Rasgos & p-value & Hipótesis \\
\hline \hline 1. Absolute Pitch & 0,041 & 1 \\
\hline 2. Abs. Norm. Jitter & 0,022 & 1 \\
\hline 3. Abs. Norm. Ar. Shimmer & 0,006 & 1 \\
\hline 4. Abs. Norm. Min. Sharp. & 0,035 & 1 \\
\hline 10. MWC Cepstral 4 & 0,026 & 1 \\
\hline 14. MWC Cepstral 8 & 0,0003 & 1 \\
\hline 19. MWC Cepstral 13 & 0,041 & 1 \\
\hline 32. MW PSD End Val. Pos. rel. & 0,034 & 1 \\
\hline 34. MW PSD 2nd Min NSF & 0,078 & 1 \\
\hline 35. Body Mass & 0,042 & 1 \\
\hline 37. Body Stiffness & 0,042 & 1 \\
\hline 39. Body Losses Unbalance & 0,056 & 1 \\
\hline 40. Body Stiffness Unbalance & 0,076 & 1 \\
\hline 41. Cover Mass & 0,005 & 1 \\
\hline 42. Cover Losses & 0,076 & 1 \\
\hline 57. Rel. Start Flow Time & 0,017 & 1 \\
\hline 58. Rel. Closing Time & 0,086 & 1 \\
\hline 66. PhysTremor Frequency $(\mathrm{Hz})$ & 0,082 & 1 \\
\hline
\end{tabular}

Tabla 5.37: Rasgos que rechazan la hipótesis nula para la prueba de contraste de Mann-Whitney en el conjunto femenino cuando enfrentamos todas las muestras neutras frente a las muestras de estrés, teniendo en cuenta un $\alpha=0,1$.

Se puede observar que el número de rasgos que generan rechazo de $H_{0}$ con un nivel de relevancia del $5 \%$ es mucho más amplio que en el caso de los hombres. De hecho, se constata que doce rasgos generan rechazo, frente a uno en el caso masculino. Comparando los resultados obtenidos en esta prueba con los obtenidos en la prueba $K S$, podemos ver que todos y cada uno de los rasgos destacados cuando $\alpha=0,05$ son idénticos en sendas pruebas. Analizando los resultados cuando $\alpha=0,1$ podemos observar que este número aumenta hasta dieciocho. Los rasgos que rechazan la hipótesis nula coinciden casi en su mayoría con el caso anterior $(K S)$. Sin embargo, aparecen nuevos rasgos interesantes, como es el caso del rasgo 66 (frecuencia del temblor), además de los rasgos biomecánicos que se comentaron con anterioridad. De hecho, el rasgo 66 apareció en tres de los cuatro criterios de selección con la técnica de Rank Features, sin olvidar que en las tres ocasiones fue el rasgo con mayor relevancia por ser elegido en primer lugar. Un aspecto curioso a destacar es que el rasgo 5 (la tasa de Harmónico-Ruido) no aparece entre los rasgos seleccionados con ninguno de los niveles de relevancia supuestos. Sin embargo otros rasgos tales como el 1, 10, 35,37 y 41 aparecen tanto en la prueba de $K S$, como en esta prueba. Sin olvidar, por supuesto, que fueron rasgos determinantes en otros casos de estudio como por ejemplo, el realizado en la Sección 5.4. Nuevamente, se constata que existen rasgos que ya han aparecido en otras pruebas parámetricas (Rank Features), tales como el 4, 14, 19 y 32. Además, teniendo en cuenta que la prueba de U-Mann-Whitney es equivalente en variante no paramétrica a la prueba t-Student, podemos corroborar que los datos obtenidos en la sección 5.2.3 coinciden con los valores alcanzados 
con esta prueba, puesto que el rasgo 37 (Body Stiffness) ha rechazado la $H_{0}$ en sendas ocasiones. Por lo tanto, existen rasgos determinantes para el conjunto de datos femenino, tales como $1,4,10,14,19,32,35,37$ y 41 , aunque tal vez no tan sobresalientes como en el caso del conjunto masculino.

\section{Segunda Parte - Pair-Wise}

Nuevamente, el proceso a seguir parte de la misma idea que en el enfoque de $K S$ y por consiguiente las Ecuaciones 5.9 y 5.10 están vigentes para este enfoque también. En las Tablas 5.38 y 5.39 se presentan los resultados de los dos procesamientos de los datos para el conjunto masculino:

\begin{tabular}{llr}
\hline TOTAL & & 11 \\
\hline \hline \multirow{3}{*}{ Primer Procesado } & Emparejamientos & 16 \\
& Máximo & 1152 \\
& Factor de mérito & $0,95 \%$ \\
\hline \multirow{3}{*}{ Segundo Procesado } & Emparejamientos & 9 \\
& Máximo & 648 \\
& Factor de mérito & $1,70 \%$ \\
\hline
\end{tabular}

Tabla 5.38: Resultados para el conjunto masculino, cuando realizamos un estudio de tipo pair-wise para la función de contraste de Mann-Whitney para un $\alpha=0,05$.

\begin{tabular}{llr}
\hline TOTAL & & 26 \\
\hline \hline \multirow{3}{*}{ Primer Procesado } & Emparejamientos & 16 \\
& Máximo & 1152 \\
& Factor de mérito & $2,26 \%$ \\
\hline \multirow{3}{*}{ Segundo Procesado } & Emparejamientos & 9 \\
& Máximo & 648 \\
& Factor de mérito & $4,01 \%$ \\
\hline
\end{tabular}

Tabla 5.39: Resultados para el conjunto masculino, cuando realizamos un estudio de tipo pair-wise para la función de contraste de Mann-Whitney para un $\alpha=0,1$.

Analizando los resultados del grupo de datos masculino se puede observar que los valores alcanzados son bastante menores en esta función de contraste que en el anterior enfoque, KS. Cuando $\alpha=0,05$, el factor de mérito no alcanza ni el $2 \%$ en el segundo procesado de los datos. Incluso, cuando $\alpha=0,1$, los resultados tampoco cambian demasiado, puesto que en el mejor de los casos no se llega siquiera al $5 \%$ de rasgos que rechazan la hipótesis nula.

En las Tablas 5.40 y 5.41 se presentan los resultados para la función de contraste $M W$ para el conjunto femenino: 


\begin{tabular}{llr}
\hline TOTAL & & \\
\hline \hline \multirow{3}{*}{ Primer Procesado } & Emparejamientos & 18 \\
& Máximo & 1296 \\
& Factor de mérito & $3,32 \%$ \\
\hline \multirow{2}{*}{ Segundo Procesado } & Emparejamientos & 12 \\
& Máximo & 864 \\
& Factor de mérito & $4,98 \%$ \\
\hline
\end{tabular}

Tabla 5.40: Resultados para el conjunto femenino, cuando realizamos un estudio de tipo pair-wise para la función de contraste de Mann-Whitney para un $\alpha=0,05$.

\begin{tabular}{llr}
\hline TOTAL & & 86 \\
\hline \hline \multirow{3}{*}{ Primer Procesado } & Emparejamientos & 18 \\
& Máximo & 1296 \\
& Factor de mérito & $6,64 \%$ \\
\hline \multirow{2}{*}{ Segundo Procesado } & Emparejamientos & 12 \\
& Máximo & 864 \\
& Factor de mérito & $9,95 \%$ \\
\hline
\end{tabular}

Tabla 5.41: Resultados para el conjunto femenino, cuando realizamos un estudio de tipo pair-wise para la función de contraste de Mann-Whitney para un $\alpha=0,1$.

Observando los resultados para el conjunto femenino, se puede decir que el número de rasgos que rechazan la hipótesis nula es mayor que en el caso masculino. Cuando $\alpha=0,05$, los resultados son similares, salvando las distancias, puesto que ninguno de ellos alcanza el $5 \%$. Sin embargo, cuando $\alpha=0,1$, el factor de mérito alcanzado asciende hasta casi alcanzar el $10 \%$, lo cual es bastante más que en el caso de los hombres.

En las Tablas B.13 y B.14 del Apéndice B.2 se presentan los rasgos que en alguna ocasión han rechazado la hipótesis nula para el conjunto masculino.

Tan solo una vez el rasgo 7 rechazó dos veces la hipótesis nula para el conjunto masculino. El resto de los nueve rasgos restantes tan solo rechazaron la hipótesis nula en una ocasión cuando $\alpha=0,05$. Los resultados obtenidos cuando $\alpha=0,1$ no mejoran demasiado, aunque el rasgo 7 rechaza la hipótesis nula en tres ocasiones y el rasgo 9 en dos ocasiones. Los 21 rasgos restantes rechazaron la hipótesis nula en tan solo una ocasión.

En las Tablas B.15 y B.16 del Apéndice B.2 se presentan los rasgos que en alguna ocasión han rechazado la hipótesis nula para el conjunto femenino.

En el caso del conjunto de datos femenino, el número de veces que se rechaza la hipótesis nula como máximo es tres. Este hecho ocurre tan solo con los rasgos 52 y 56. El rasgo 52 describe el tiempo de recuperación en amplitud, mientras que el 
rasgo 56 es el tiempo relativo de detención del flujo glotal. Sin embargo, el número de veces que se repite en dos ocasiones aumenta hasta alcanzar once veces. Los quince rasgos restantes tan solo han rechazado la hipótesis nula en una ocasión para $\alpha=0,05$. Sin embargo, cuando el nivel de relevancia es de $\alpha=0,1$ el número de rasgos aumenta considerablemente y el número máximo de veces que la hipótesis nula se rechaza es de cinco, para el rasgo 50, el cual representa el tiempo de apertura relativo. Siguen los rasgos 57 y 58, los cuales representan el tiempo relativo de inicio del flujo glotal y el tiempo relativo de cierre. Se observa también otro grupo de diez rasgos que rechazan la hipótesis en tres ocasiones. Por otro lado, otros ocho rasgos rechazaron la $H_{0}$ en dos ocasiones, muchos de ellos son de tipo cepstral y otros son biomécanicos. Finalmente, se tiene un grupo de 27 rasgos que rechazaron la hipótesis nula tan solo en una ocasión.

Análogamente a la prueba de $K S$, se quiere visualizar la aportación individual en relación al rechazo de la hipótesis nula para ambos niveles de relevancia por parte de los dos conjuntos de datos, masculino y femenino, respectivamente. Estos datos quedan reflejados en las Figuras 5.25 para el conjunto masculino y 5.26 para el femenino.

Null Hypothesis Rejected by Males (Mann-Whitney)

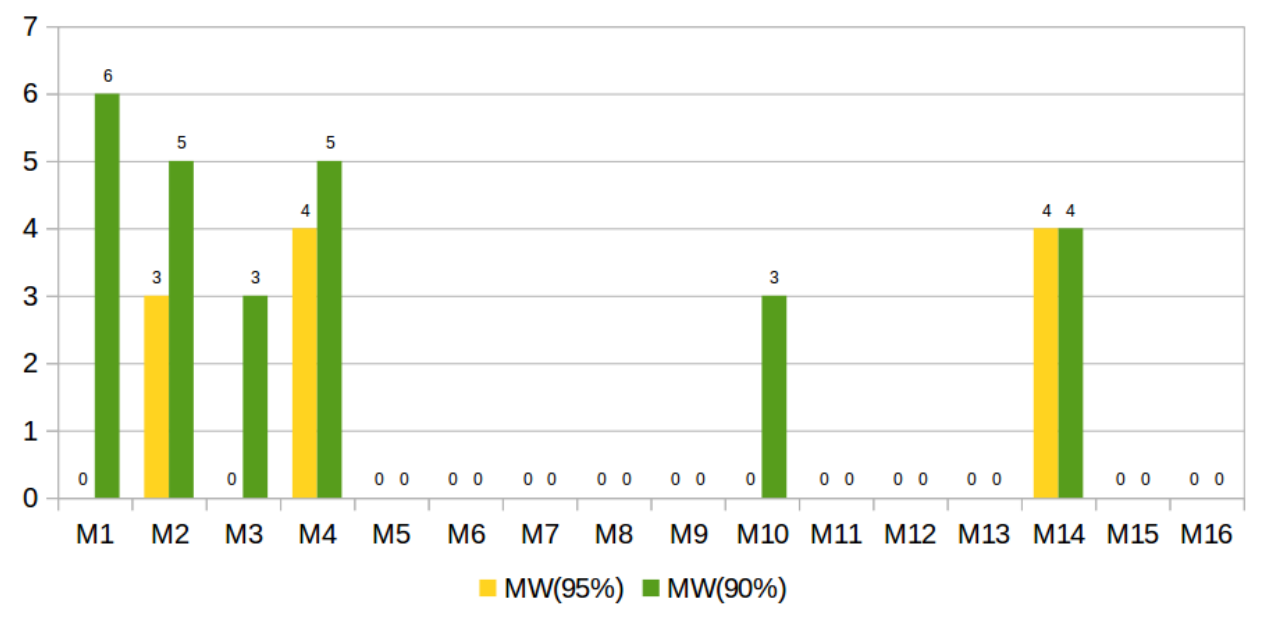

Figura 5.25: Resumen del número de veces en que es rechazada la hipótesis nula por individuo para el conjunto de datos masculino según la prueba $M W(5 \%)$ y $M W(10 \%)$.

Analizando la Figura 5.25 se puede observar que el número de veces que la hipótesis nula es rechazada aquí en comparación con la prueba de Kolmogorov-Smirnov es mucho menor. Hay que tener en cuenta que esta prueba no paramétrica compara si dos distribuciones poseen la misma mediana, para ello define una serie de rangos o intervalos y a partir de ahí devuelve el resultado de la hipótesis nula.

Cuando $\alpha=0,05$, tan solo tres individuos rechazan en alguno de sus rasgos la hipótesis nula, o dicho de otra forma, alguno de sus rasgos presentan diferencias significativas en sus medianas para las distribuciones neutras frente a las distribuciones 
de estrés. El individuo, M14, presenta cuatro rasgos que rechazan la hipótesis nula con ambos niveles de relevancia, por consiguiente los cuatro rasgos que la rechazan lo hacen para p-values bastante pequeños. Si observamos la evolución cuando aumentamos el nivel de relevancia encontramos que los individuos M1, M3 y M10, pasan de cero rechazos para $\alpha=0,05$ a un número no superior a seis. Por otro lado, los casos $M 2$ y $M 4$ rechazan la hipótesis nula en alguno de sus rasgos cuando $\alpha=0,1$. Finalmente, los casos M5, M6, M7, M8, M9, M11, M12, M13, M15 y M16 no generaron ningún rechazo de hipótesis con ambos valores de $\alpha$.

Por otro lado, si se visualiza con detenimiento la Figura 5.26, correspondiente al conjunto femenino, se puede observar que el número de veces que se rechaza la hipótesis nula es muy superior en cualquiera de los dos niveles de relevancia, si es comparada con el conjunto de datos masculino, por supuesto. El número de individuos que en algún momento rechazan la hipótesis nula con un nivel de relevancia estricto es de siete, (F3, F4, F9, F12, F13, F15 y F18), mientras que si el nivel de relevancia es más laxo, este número aumenta a nueve, donde se incluyen $F 8$ y $F 11$. Aun así, de las dieciocho mujeres incluidas en el conjunto de datos femenino, tan solo el $50 \%$ de ellas presenta algún tipo de diferencia en sus medianas cuando se comparan ambas distribuciones según los consabidos supuestos (neutro vs estrés), lo cual indica un índice bajo de casos en que no se rechazó $H_{0},(F 1, F 2, F 5, F 6, F 7$, F10, F14, F16 y F17).

Null Hyphotesis Rejected by Females (Mann-Whitney)

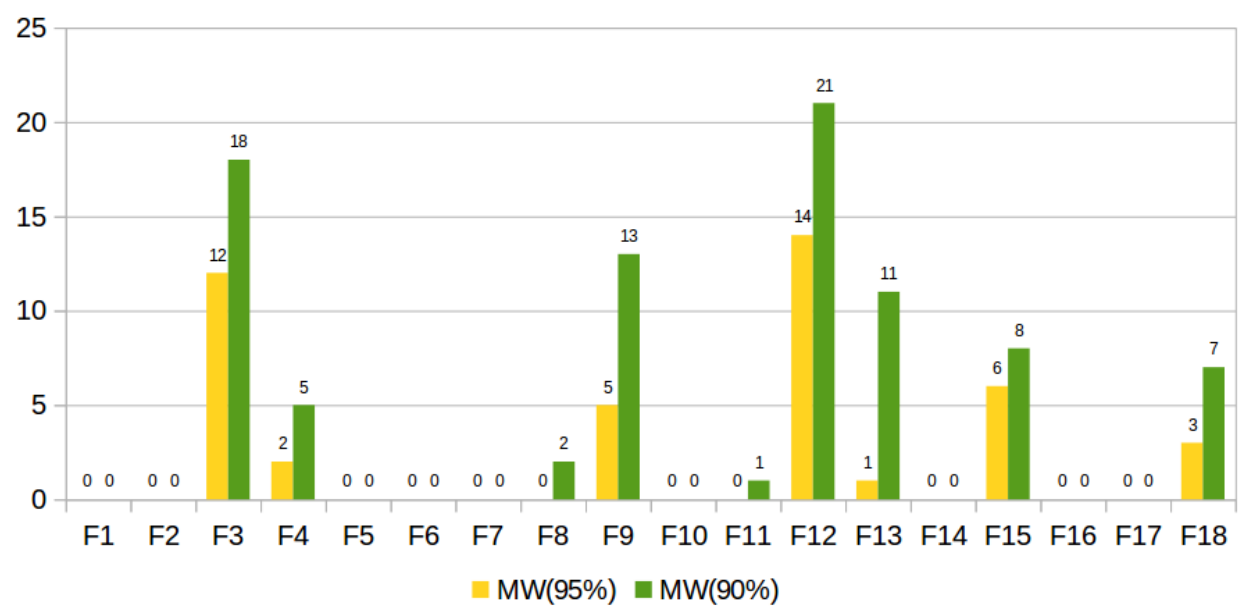

Figura 5.26: Resumen del número de veces en que es rechazada la hipótesis nula por individuo para el conjunto de datos femenino según la prueba $M W(5 \%)$ y $M W(10 \%)$.

Para concluir esta sección, los dos planteamientos presentados con pruebas $K S$ y $M W$, seleccionan rasgos análogos cuando se compara el conjunto de datos como un "ente" único o por separado, lo cual quiere decir que los rasgos que emergen del primer estudio se pueden considerar especialmente relevantes, puesto que se repiten de manera constante cuando los individuos son comparados entre ellos mismos. Además, el segundo enfoque muestra una posible aplicación como pre-procesado pa- 
ra la validación de datos presentada en la Sección 5.3, ya que el cálculo de la tasa de verosimilitud logarítmica se basa en el cálculo de un individuo respecto del resto de la población. Por consiguiente, si lo que se busca es un conjunto de datos con distribuciones diferenciadas en ambos supuestos, estas pruebas no paramétricas pueden ser aplicables y de gran utilidad.

Antes de finalizar esta sección, cabe comentar que tanto para el conjunto femenino como para el conjunto masculino, todos los casos que tan solo tenían una muestra en alguno de sus supuestos estados, no generaron resultado alguno. Por consiguiente, se puede concluir que estas pruebas requieren más de una muestra para ambos supuestos estados de cara a establecer diferencias significativas entre ellos, en cualquier otro caso no se podrá discernir entre ambos. En las Figuras 5.27 y 5.28 se presenta el resumen de ambas pruebas separadas por género. 


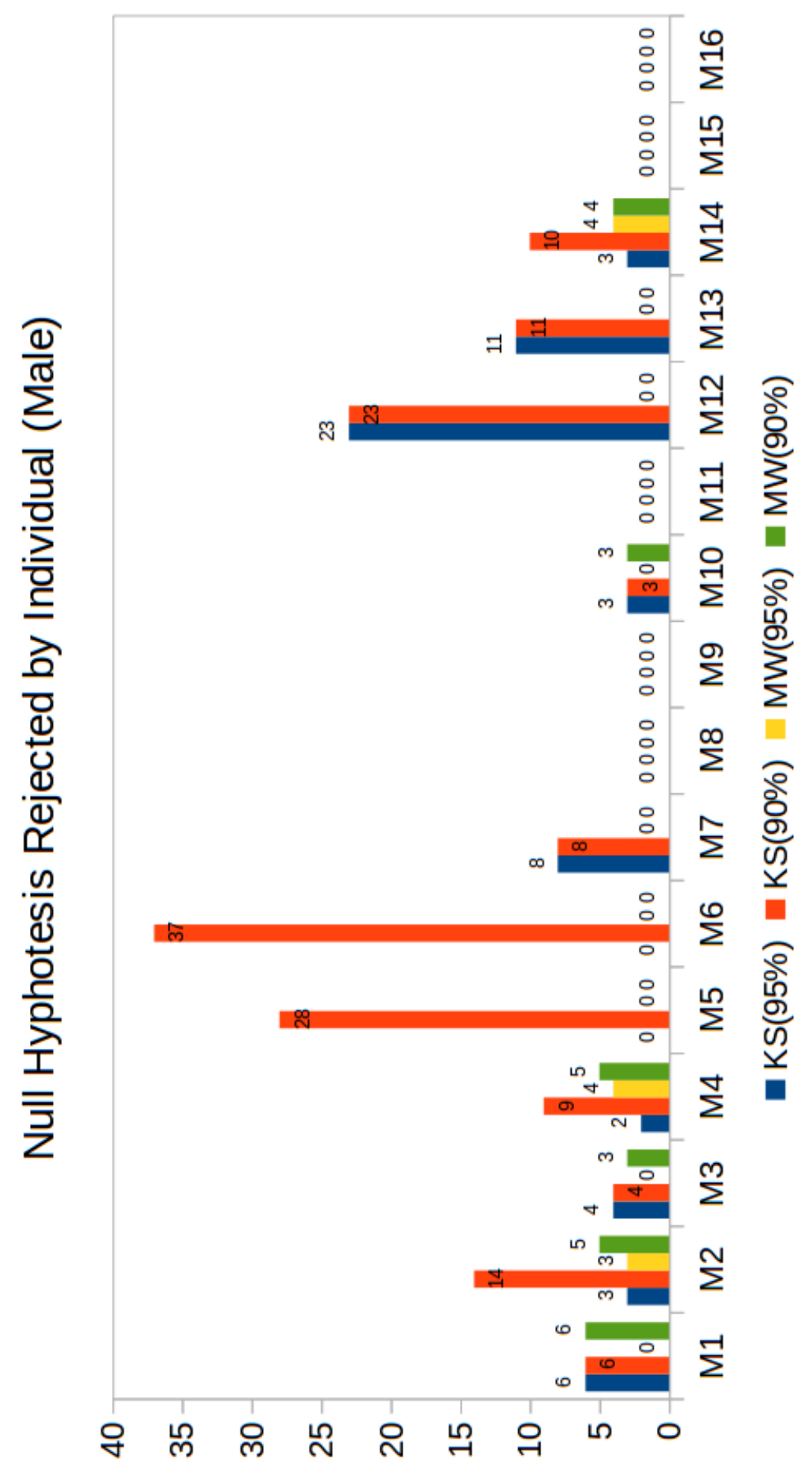

Figura 5.27: Resumen del número de veces en que es rechazada la hipótesis nula por individuo para el conjunto de datos masculino según las pruebas $K S(5 \%)$, $K S(10 \%), M W(5 \%)$ y $M W(10 \%)$. 


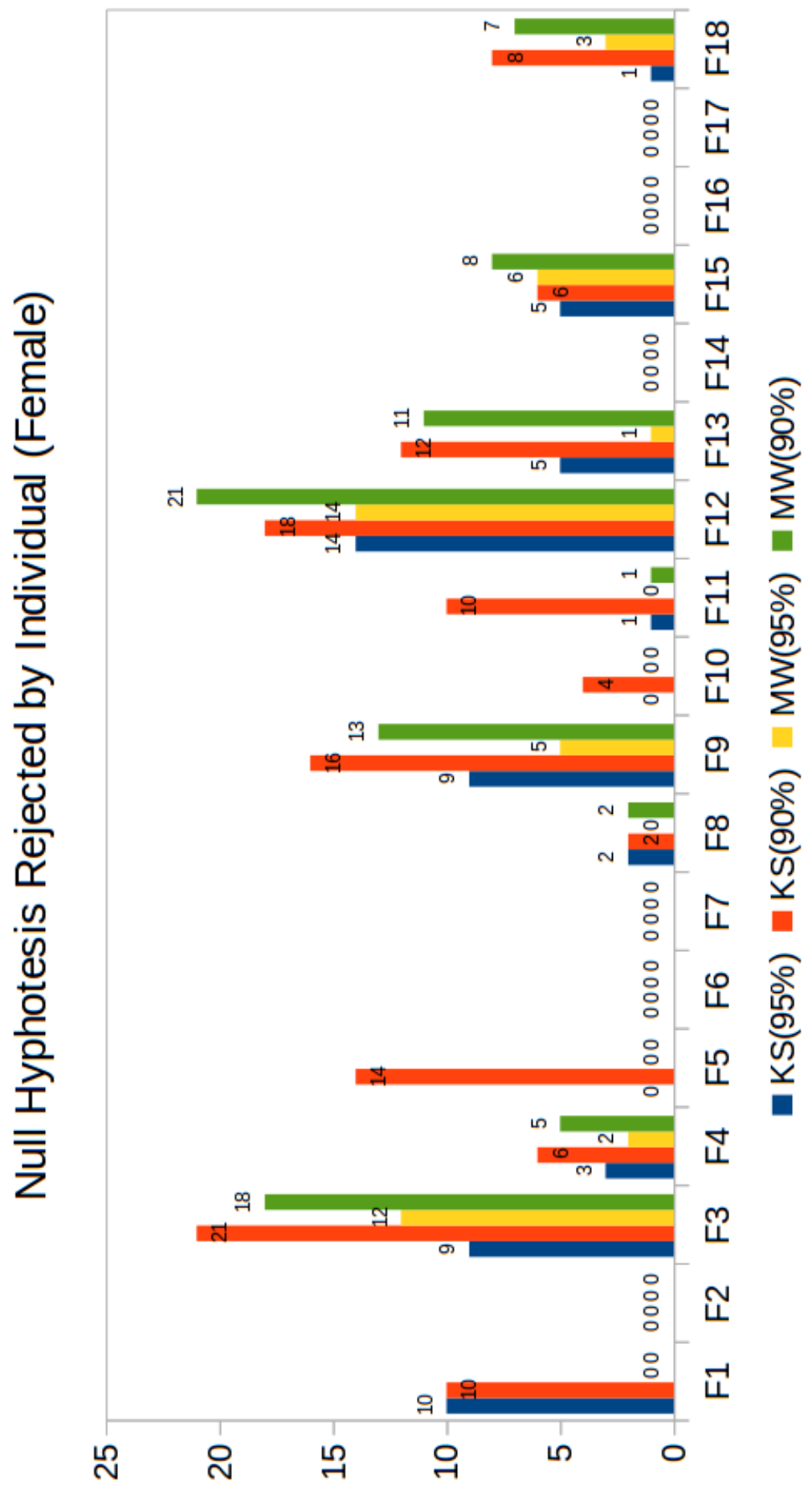

Figura 5.28: Resumen del número de veces en que es rechazada la hipótesis nula por individuo para el conjunto de datos femenino según las pruebas $K S(5 \%), K S(10 \%)$, $M W(5 \%)$ y $M W(10 \%)$ 



\section{Capítulo 6}

\section{CONCLUSIONES}

"No hay nada más repartido de modo equitativo en el mundo que la razón: todo el mundo está convencido de tener suficiente." René Descartes (1596-1650); filósofo y científico francés.

El presente estudio pretende ser una contribución sobre la selección de rasgos característicos para la detección del estrés en la voz, para lo cual se ha centrado en cuatro temas principales, datos, descriptores/rasgos, clasificación y comportamiento. Los resultados de dicho estudio han permitido extraer un conjunto de conclusiones que serán comentadas en el presente capítulo.

Una de las primeras y principales conclusiones a las que se ha llegado en el desarrollo de este trabajo es que la adquisición de datos emocionales espontáneos es una tarea ardua. Fue necesario generar nuestro propio corpus debido a la falta de estandarización en la obtención de datos emocionales y la inexistencia de normas que garantizasen la reproducibilidad.

Desde el punto de vista de los rasgos se concluye que los considerados clásicamente (jitter, shimmer, HNR, etc.) aparecen marginalmente en lo que a detección emocional se refiere, pero no son relevantes o definitorios. Sin embargo, los biomecánicos han mostrado ser buenos descriptores para la caracterización del estrés en voz. A título ilustrativo, en las Figuras 6.1 y 6.2 se presentan los parámetros más relevantes separados por género, según los resultados generados a lo largo de este trabajo.

Como se puede ver en la Figura 6.1 existe un claro "vencedor" respecto del resto de los 72 rasgos. Este rasgo es el número 68, la frecuencia del temblor neurológico, el cual apareció seleccionado en todas y cada una de las diferentes pruebas utilizadas para determinar la relevancia en la detección de estrés en el conjunto masculino. A continuación, aparecen nueves rasgos que resultaron relevantes en cuatro de los casos de estudio llevados a cabo. Estos son el 22, 23, 28, 29, 33, 58, 60, 64 y 66. Los cuatro últimos rasgos son biomecánicos y tres de ellos están íntimamente relaciones con el temblor, al igual que el 68. 


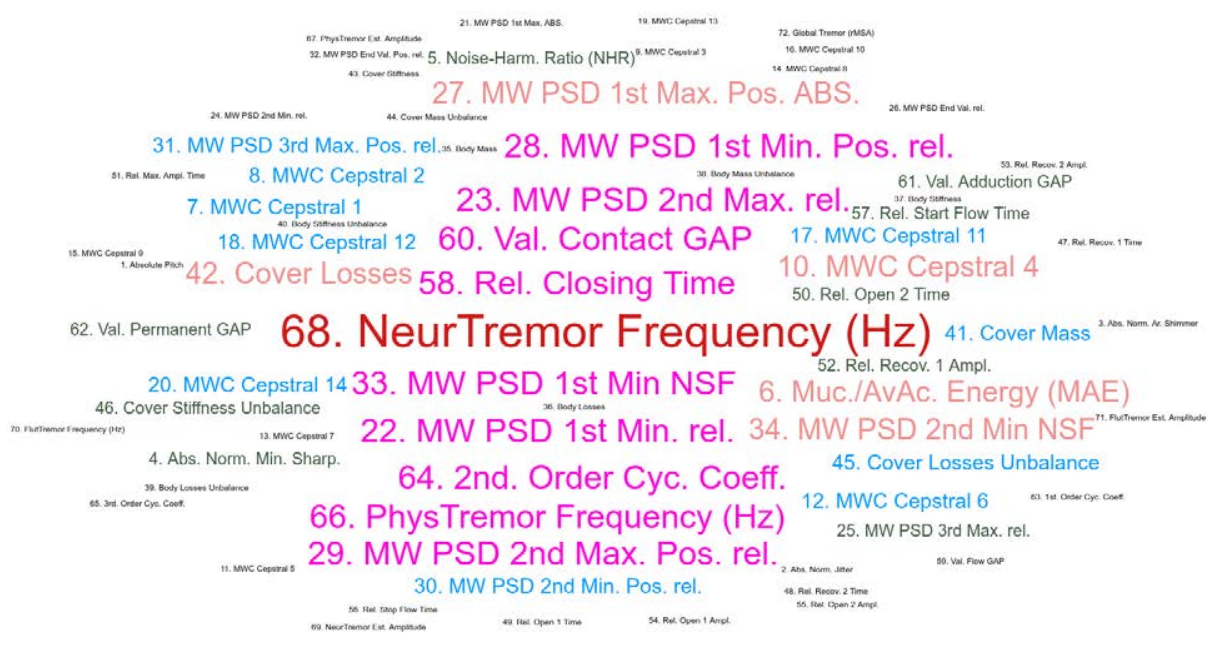

Figura 6.1: Rasgos más relevantes respecto al conjunto masculino. El grado de relevancia viene dado por su posición central y por el tamaño del rotulado.

Análogamente, en la Figura 6.2 se puede observar el conjunto de rasgos tipados por relevancia para el conjunto femenino. A diferencia del conjunto masculino, se puede observar que no existe un único rasgo especialmente relevante como ocurrió en el caso de los hombres. En este caso han surgido dos rasgos que han resaltado respecto de los 72 posibles, los cuales fueron el 5 y el 66, este último nuevamente ligado con el temblor. Además, existen cinco rasgos que quedaron bien posicionados en cuatro ocasiones. Estos son el 9, 14, 27, 32 y 68. Como se puede observar, si que se observan ciertas similitudes entre los rasgos relativos a ambos conjuntos, de hecho los rasgos, 66 y 68, han quedado clasificados entre los más relevantes en ambos conjuntos.

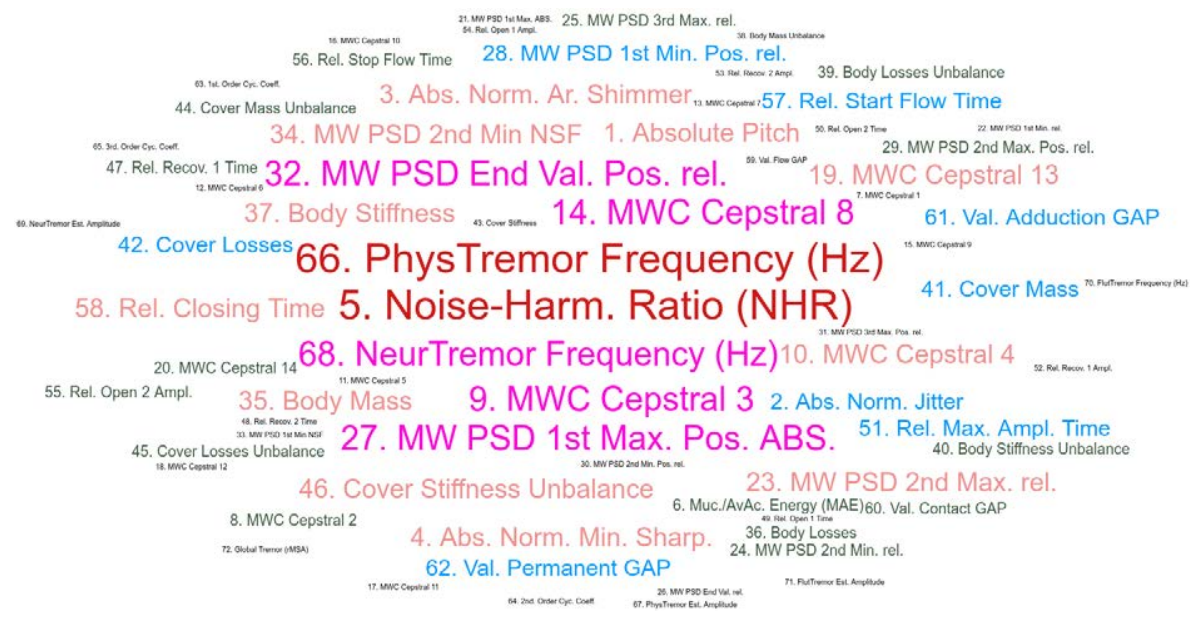

Figura 6.2: Rasgos más relevantes respecto al conjunto femenino. El grado de relevancia viene dado por su posición central y por el tamaño del rotulado.

Como se ha podido observar en las anteriores figuras la caracterización del estrés es totalmente dependiente del género, es decir, es necesario llevar a cabo dicha caracterización por separado para obtener respuestas fiables y robustas. En el 
Apéndice $\mathrm{C}$ se presenta la relación de los 72 rasgos y la presencia de los mismos en los diferentes casos de estudio y en la Figura C.1 se representa el número de veces que cada rasgo ha sido seleccionado como relevante para el conjunto de todos los casos de estudio y para ambos géneros.

Se han utilizado cinco técnicas diferentes para la clasificación del estrés a través de la voz mediante el algoritmo de clasificación SVM. Tres de ellas eran técnicas aisladas, Rank Features, Correlación de Pearson e ICA y las otras dos compuestas o híbridas, tales como, (Rank Features y PCA) y (Rank Features y PLS).

Si hablamos de técnicas aisladas, Rank Features, ofrece valores bastante competitivos para el conjunto femenino $(86,67 \%)$, sin embargo para el masculino sus resultados son peores en media $(75 \%)$. Por otro lado, ICA no llega al $75 \%$ de tasa de precisión, sin embargo sus resultados parecen ser más estables en el conjunto masculino. El uso de técnicas de reducción de dimensionalidad, como PCA o PLS se ha mostrado altamente conveniente, ya que permiten mejorar notablemente las tasas de clasificación. Por ejemplo, la combinación Entropía/Cuadrático con PCA, dio como resultado una tasa de clasificación del $90 \%$ para el conjunto femenino. Por otro lado, la combinación ROC/Polinomial con PLS dio una tasa de clasificación del $80 \%$ para el conjunto masculino. Finalmente, se puede concluir que el sistema híbrido $\mathrm{RF} / \mathrm{PCA}$ es el más eficaz en cuanto a tasa de clasificación en el conjunto femenino, mientras que el sistema compuesto RF/PLS lo es en el conjunto masculino. Sin embargo, el uso de estas combinaciones compuestas ralentiza el proceso de ejecución y por consiguiente supone un inconveniente si se pretende aplicarlos en entornos de tiempo real. Además, las tasas de clasificación que se obtienen con las técnicas híbridas en comparación con las técnicas aisladas, tan solo suponen una mejora del 3,33\% para el conjunto femenino y un 5\% para el masculino. Por otro lado, la técnica de correlación de Pearson requirió tiempos de ejecución bastante más reducidos y tal vez debería recibir más atención en futuros trabajos.

Cabe asimismo comentar que la técnica utilizada para el entrenamiento, leaveone-out, es la correcta dado el número de elementos, pero no obstante, no permite un sistema de entrenamiento altamente eficiente para la tarea encomendada, puesto que siempre se clasifica a través de una única muestra. En nuestra opinión esta metodología es poco eficiente a la hora de extraer conclusiones definitivas de cara a diseñar un modelo completo para la detección del estrés de forma automática.

Para concluir esta sección, cabe comentar que el problema fundamental que plantea el análisis de estos resultados presentados es que no son contrastables con ningún otro estudio, puesto que los rasgos que aquí se utilizan para clasificar las muestras no han sido utilizados en ningún otro caso para caracterizar estrés o emociones. Además, no hemos sido capaces de encontrar resultados independientes del género para el caso de la detección del estrés en la literatura.

Hay que tener en cuenta que la metodología utilizada, "exige" al individuo llevar a cabo una acción realmente incomoda, pero sobre todo políticamente incorrecta y 
por ello algunas de las conclusiones preliminares a partir de los resultados obtenidos apuntan a que a veces la persona oculta deliberadamente o inopinadamente lo que piensa, lo cual no significa necesariamente que mienta, tan solo que no parece expresar su verdadera opinión, sino lo que socialmente ha sido consensuado como "correcto". El motivo a nuestro entender es lógico, la persona quiere preservar su integridad frente terceros y no quiere desvelar opiniones políticas, sociales, u otras que puedan ser juzgadas como "inadecuadas" o "antisociales". Pero sin duda, emitir una respuesta al cuestionario elaborado no es una tarea fácil, porque todas ellas eran controvertidas y con un gran trasfondo social. Para concluir, la gente no quiere ser juzgada, quiere vivir en un cierto anonimato en lo que en algunas cuestiones de su vida se refiere. Por consiguiente, algunas de las respuestas producidas bajo el supuesto de estado de estrés o de incongruencia, por sus marcas biométricas apuntaban a que podrían estar en clara contracción con el supuesto, esto es, manifestando congruencia en vez de incongruencia.

Además, los resultados revelan que las mujeres cuando defienden una idea contradictoria con su punto de vista sincero parecen relajar la tensión de los pliegues vocales, en contra de la tendencia masculina, que es la opuesta. Hay que decir que este hecho es muy relevante. Se concluyó que tal vez estos resultados son debidos al importante dimorfismo entre las laringes adultas de hombres y mujeres, es decir, la rigidez mucho más alta correspondiente a las cuerdas vocales femeninas que tendería hacia el descenso, mientras que en la voz masculina, menos tensa biomecánicamente, se respondería con un aumento de la tensión. Parece ser que la voz femenina manifiesta la situación de incongruencia o estrés mediante una reducción del tono, en alrededor de una quinta tonal. El estrés en voces femeninas se percibe en la mayoría de los casos con un descenso de casi cinco semitonos (prácticamente de una media de 220 Hercios a alrededor de 180 Hercios) asociado a un incremento del temblor espontáneo en la banda de 5-8 Hercios. Por lo que respecta a los hombres, el estrés tiende a manifestarse con una elevación en el tono también alrededor de una quinta, y la aparición de temblor en la banda de 5-8 Hercios es aún más elevada que en el caso femenino.

Finalmente, se puede concluir que los hombres y las mujeres manifiestan comportamientos opuestos cuando tienen que enfrentarse a situaciones de estrés. Se puede considerar que este tipo de comportamiento obedece claramente al dimorfismo sexual humano, y debería merecer una consideración más intensa en futuros trabajos. 


\section{Capítulo 7}

\section{APORTACIONES}

En este capítulo se menciona las aportaciones más destacadas que se han logrado a lo largo de este trabajo.

- Propuesta de una plataforma cooperativa para la evocación de emociones, captura online de la voz y validación subjetiva de emociones.

- Propuesta de una metodología para evocar estrés y análisis de la coherencia en las respuestas dadas mediante la voz.

- Identificación de un conjunto de parámetros biométricos para caracterizar el estrés en la voz.

A continuación se presentan las publicaciones derivadas de algunas de las contribuciones que se han realizado.

1. P. Gómez-Vilda, M. L. de Ipiña, V. Rodellar-Biarge, D. Palacios-Alonso and M. Ecay-Torres, Articulation characterization in AD speech production. En Congress on Converging Clinical and Engineering Research on Neurorehabilitation. Springer, 2016, pp. 861-866.

2. P. Gómez-Vilda, P. Lirio, D. Palacios-Alonso, V. Rodellar-Biarge, and N. Polo. Monitoring Parkinson's Disease Rehabilitation from Phonation Biomechanics. En Converging Clinical and Engineering Research on Neurorehabilitation II, Springer International Publishing, 2016, pp. 93-97.

3. P. Gómez-Vilda, D. Palacios-Alonso, V. Rodellar-Biarge, A. Álvarez-Marquina, V. Nieto-Lluis, R. Martínez-Olalla. Parkinson's Disease Monitoring by Biomechanical Instability of Phonation. Neurocomputing, 2016.

4. P. Gómez-Vilda, V. Rodellar-Biarge, D. Palacios-Alonso, V. Nieto-Lluis, R. Martínez-Olalla, A. Álvarez-Marquina, J. Lasso-Vázquez, B. Scola-Yurrita and D. Poletti-Serafini, Pattern Matching of Voice Quality Features from VocalFold Paralysis Patients Treated with Stem-Cell Grafting. En International Conference on Pattern Recognition Systems (ICPRS-16), IET, 2016, pp. 1-6. Otorgado el premio al mejor artículo de la conferencia. 
5. V. Rodellar-Biarge, D. Palacios-Alonso, V. Nieto-Lluis and P. Gómez-Vilda, Analysis of emotional stress in voice for deception detection. En 4th International Work Conference on Bioinspired Intelligence (IWOBI), 2015, pp. 127-132.

6. D. Palacios-Alonso, V. Rodellar-Biarge, V. Nieto-Lluis and P. Gómez-Vilda, Spontaneous emotional speech recordings through a cooperative online video game. En Congreso de la Sociedad Española para las Ciencias del Videojuego, 2015, pp. 122-131.

7. V. Rodellar-Biarge, D. Palacios-Alonso, V. Nieto-Lluis and P. Gómez-Vilda, Towards the search of detection in speech-relevant features for stress. Expert Systems, vol. 32, 2015, pp. 710-718.

8. V. Rodellar, D. Palacios, P. Gómez and E. Bartolomé, A methodology for monitoring emotional stress in phonation. En 5th IEEE Conference on Cognitive Infocommunications (CogInfoCom), 2014, pp. 231-236.

9. V. Rodellar-Biarge, D. Palacios-Alonso, V. Nieto-Lluis and P. Gómez-Vilda, Speech parameter selection for emotional stress characterization in women. En International Work Conference on Bio-Inspired Intelligence (IWOBI), 2014, pp. 21-24.

10. V. Rodellar-Biarge, D. Palacios-Alonso, E. Bartolomé, P. Gómez-Vilda, Emotional Stress Detection in Contradictory versus Self-consistent Speech by Means of Voice Biometrical Signature. En Natural and Artificial Models in Computation and Biology: 5th International Work-Conference on the Interplay Between Natural and Artificial Computation (IWINAC), Springer, vol. 2, 2013, pp. $74-82$.

11. D. Palacios-Alonso, V. Rodellar-Biarge, Detección de emociones expresadas con la voz mediante caracterización biométrica. En Conferencia de la Asociación Española para la Inteligencia Artificial, 2013. Otorgado el primer premio del Doctoral Consortium.

12. V. Rodellar, D. Palacios-Alonso, E. Bartolomé and P. Gómez-Vilda, Vocal fold stiffness estimates for emotion description in speech. En Biosignals, 2013, pp. 112-119. 


\section{Capítulo 8}

\section{LÍNEAS FUTURAS}

"Sin utopia, ninguna actividad verdaderamente fecunda es posible."
Mijail Saltikov-Chedrin (1826-1889); escritor ruso.

El campo de la detección del estrés y de las emociones a través de la voz es un área de investigación todavía por desarrollar en muchos aspectos. A partir de esta contribución se abren múltiples líneas de investigación, las cuales se detallarán de forma sucinta seguidamente.

1. Aumentar el tamaño del conjunto de datos. Como ya se ha mencionado en repetidas ocasiones, la obtención de muestras espontáneas es una tarea bastante compleja. Sin embargo es fundamental generar un corpus más grande para darle mayor peso estadístico a los resultados aquí alcanzados.

2. Nueva metodología de evocación de estrés. La técnica de captación de estrés utilizada en este trabajo, adolece fundamentalmente de la imposibilidad de repetir el caso de estudio más de una vez. Si el usuario ha realizado bien o no la prueba, no importa, puesto que una vez descubierto el procedimiento de la misma, la espontaneidad se desvanece. Dicho esto, una de las líneas de investigación fundamentales que se considera prioritaria es el diseño de nuevas técnicas, metodologías o procedimientos de evocación de estrés a través de la voz. Básicamente, lo que se busca elaborar es una técnica que sea reproducible tantas veces como el usuario esté dispuesto a colaborar. Por ejemplo, se había planteado en la posibilidad de captar emociones a través de videojuegos. Hoy en día, los juegos en línea y cooperativos son los más demandados del mercado. Además, gracias a la conexión por Internet los sujetos participantes no tendrían que encontrarse en el mismo lugar físico, tan solo necesitarían un videojuego, unos cascos con micrófono y una plataforma de captación de voz en tiempo real.

3. Estudios longitudinales. A partir de la anterior idea, surge la necesidad de monitorizar el estrés en un mismo individuo a lo largo de un periodo de tiempo. Esta técnica se realiza en estudios de índole clínica, como por ejemplo los chequeos trimestrales de los enfermos de enfermedades neurodegenerativas. Estos reconocimientos periódicos ofrecen información muy rica cuanto al 
aspecto evolutivo en respuesta a determinados factores endógenos y exógenos, los cuales se pueden utilizar para optimizar los algoritmos diseñados para clasificar el estrés.

4. Profundización en el estudio de la relación entre el temblor neurodegenerativo y el estrés. A la vista de la semejanza en el comportamiento observado entre el estrés en la voz y el deterioro neurológico en cuanto a manifestación del temblor, se quiere ahondar más en esta línea de investigación e intentar generar un indicador de pre-diagnosis de enfermedades neurodegenerativas, es decir, utilizar el temblor y otras características para detectar el comienzo o la afección de este tipo de enfermedades neurológicas. De hecho, algunas de las manifestaciones de la alteración de la voz por estrés responden a patrones muy similares a los que se observan en pacientes de Parkinson, aunque en este segundo caso las manifestaciones son persistentes, mientras que en el primero son de tipo transitorio. Actualmente, el grupo de investigación se encuentra en contacto con diferentes instituciones clínicas y se han obtenido algunos resultados prometedores en base a esta idea.

5. Crear una red de colaboración internacional. Dada la plataforma web implementada, uno de los principales hitos que se pretende alcanzar en el futuro es la creación de una red de colaboración internacional para el estudio del estrés y emociones en español. Con esta iniciativa, además de aumentar el número de muestras del conjunto de datos, obtendríamos muestras con diversidad de acentos y regiones, lo cual enriquecería el valor del conjunto de datos. De esta forma, podríamos generar una base de datos amplia, de referencia y abierta a la comunidad científica, si bien cabe tener en cuenta en este caso el factor cultural en un vasto sentido geográfico.

6. Generación de un estándar. A partir del anterior punto, es vital lograr un estándar en el campo de la detección de estrés y emociones a través de la voz. Este punto ha sido tratado a lo largo de este trabajo y es uno de los puntos débiles de este campo de estudio. Cada grupo de investigación ha desarrollado casos únicos y no reproducibles por el resto de la comunidad científica, por lo tanto un gran avance sería poder trabajar todos con un corpus genérico y bien definido.

7. Evaluador de estrés en tiempo real. Finalmente, otra línea de investigación que se quiere abordar es la creación de una aplicación para la detección de estrés en tiempo real. Haciendo uso de las nuevas tecnologías, smartphones o tabletas, se quiere diseñar e implementar una aplicación multiplataforma que sea capaz de evaluar en tiempo real las muestras de voz captadas y ofrecer un resultado casi inmediato. 


\section{Bibliografía}

[1] Airas, M., Y Alku, P. Emotions in vowel segments of continuous speech: analysis of the glottal flow using the normalised amplitude quotient. Phonetica 63, 1 (2006), pp. 26-46. (Ver en la página 106).

[2] Altun, H., y Polat, G. Boosting selection of speech related features to improve performance of multi-class svms in emotion detection. Expert Systems with Applications 36, 4 (2009), pp. 8197-8203. (Ver en la página 55).

[3] Álvarez, I., Górriz, J. M., Ramírez, J., Salas-Gonzalez, D., López, M., Puntonet, C. G., Y Segovia, F. Independent component analysis of SPECT images to assist the Alzheimer's disease diagnosis. In The Sixth International Symposium on Neural Networks (2009), Springer, pp. 411-419. (Ver en la página 95).

[4] Amir, N., Kerret, O., Y Karlinski, D. Classifying emotions in speech: a comparison of methods. In INTERSPEECH (2001), pp. 127-130. (Ver en la página 55).

[5] Arciuli, J., Mallard, D., Y Villar, G. "um, i can tell you're lying": Linguistic markers of deception versus truth-telling in speech. Applied Psycholinguistics 31, 3 (2010), pp. 397-411. (Ver en la página 30).

[6] Arciuli, J., Villar, G., Y Mallard, D. Lies, lies and more lies. In Proceedings of the 31st Annual Conference of the Cognitive Science Society (CogSci) (2009), pp. 2329-2334. (Ver en las páginas 30 and 108).

[7] Aristóteles. Retórica. Gredos, Madrid, 1990. (Ver en la página 2).

[8] Arnold, M. B. Emotion and personality. Columbia University Press, 1960. (Ver en la página 2).

[9] Atal, B., Y Rabiner, L. A pattern recognition approach to voiced-unvoicedsilence classification with applications to speech recognition. IEEE Transactions on Acoustics, Speech, and Signal Processing 24, 3 (1976), pp. 201-212. (Ver en la página 60).

[10] Ayadi, M. E., Kamel, M. S., y Karray, F. Survey on speech emotion recognition: Features, classification schemes, and databases. Pattern Recognition 44, 3 (2011), pp. 572-587. (Ver en las páginas 20, 21, 54, and 86). 
[11] Ayadi, M. M. E., Kamel, M. S., y Karray, F. Speech emotion recognition using gaussian mixture vector autoregressive models. In International Conference on Acoustics, Speech and Signal Processing-ICASSP (2007), vol. 4, IEEE, pp. 957-960. (Ver en la página 55).

[12] Bachu, R., Kopparthi, S., Adapa, B., y Barkana, B. Separation of voiced and unvoiced using zero crossing rate and energy of the speech signal. In Conference Proceedings of American Society for Engineering Education (ASEE) (2008), pp. 1-7. (Ver en la página 60).

[13] Banse, R., y Scherer, K. R. Acoustic profiles in vocal emotion expression. Journal of personality and social psychology 70, 3 (1996), pp. 614-636. (Ver en la página 60).

[14] Bartolomé, E. Contribución al estudio de las alteraciones de la fonación en habla contradictoria frente a espontánea. Tesis de Máster, Universidad Internacional Menéndez Pelayo. (2012). (Ver en la página 115).

[15] Benesty, J. Handbook of speech processing. Springer Science \& Business Media, 2008. (Ver en la página 54).

[16] Berlanga, V., Y Rubio, M. Clasificación de pruebas no paramétricas. cómo aplicarlas en SPSS. REIRE, Revista d'Innovació i Recerca en Educació 5 (2012), pp. 101-113. (Ver en la página 90).

[17] Berry, D. A. Mechanisms of modal and nonmodal phonation. Journal of Phonetics 29, 4 (2001), pp. 431-450. (Ver en la página 75).

[18] Bhutekar, S. D., y Chandak, M. B. Designing and recording emotional speech databases. Proceedings on National Conference Innovative Paradigms in Engineering and Technology ncipet, 14 (2012), pp. 4-10. (Ver en la página 22).

[19] BiometroPhon. http://www.glottex.com/, 15 de Noviembre de 2016. (Ver en la página 56).

[20] Bishop, C. M. Neural networks for pattern recognition. Oxford university press, 1995. (Ver en la página 87).

[21] Bishop, C. M. Pattern recognition and machine learning. Springer, 2006. (Ver en las páginas 93 and 132).

[22] Boslaugh, S. Statistics in a nutshell. O'Reilly Media, Inc., 2012. (Ver en las páginas 88, 89, and 132).

[23] Burges, C. J. A tutorial on support vector machines for pattern recognition. Data mining and knowledge discovery 2, 2 (1998), pp. 121-167. (Ver en la página 98). 
[24] Burkhardt, F., Paeschke, A., Rolfes, M., Sendlmeier, W. F., Y WeIss, B. A database of german emotional speech. In Interspeech (2005), vol. 5, pp. 1517-1520. (Ver en las páginas 23 and 37).

[25] Cai, L., Jiang, C., Wang, Z., Zhao, L., y Zou, C. A method combining the global and time series structure features for emotion recognition in speech. In Proceedings of the International Conference on Neural Networks and Signal Processing (2003), vol. 2, IEEE, pp. 904-907. (Ver en las páginas 55 and 60).

[26] Casado, C., y Colomo, R. Un breve recorrido por la concepción de las emociones en la filosofía occidental. A parte rei. Revista Filosofía 47 (2006), pp. 1-10. (Ver en la página 2).

[27] Catford, J. C. Mountain of tongues: the languages of the caucasus. Annual Review of Anthropology 6, 1 (1977), pp. 283-314. (Ver en las páginas XVII and 14).

[28] Cervera-Paz, F., Vega-Vázquez, F., y Urrutia, R. G.-T. Estructura histológica de la cuerda vocal, vol. 1. Garsi, 1996. (Ver en la página 12).

[29] Chavhan, Y., Dhore, M., y Yesaware, P. Speech emotion recognition using support vector machine. International Journal of Computer Applications 1, 20 (2010), pp. 6-9. (Ver en la página 53).

[30] Childers, D. G., Y Wu, K. Gender recognition from speech. part II: Fine analysis. The Journal of the Acoustical Society of America 90, 4 (1991), pp. 1841-1856. (Ver en la página 56).

[31] Chóliz, M. La expresión de las emociones en la obra de Darwin. Línea. Valencia (1995). (Ver en la página 3).

[32] Chrousos, G. P. Stress and disorders of the stress system. Nature Reviews Endocrinology 5, 7 (2009), pp. 374-381. (Ver en la página 8).

[33] Cohen, M. X., y Frank, M. J. Neurocomputational models of basal ganglia function in learning, memory and choice. Behavioural brain research 199, 1 (2009), pp. 141-156. (Ver en la página 79).

[34] Colombi, J. M., Ruck, D. W., Anderson, T. R., Rogers, S. K., Y OXLEY, M. Cohort selection and word grammar effects for speaker recognition. In IEEE International Conference on Acoustics, Speech, and Signal Processing (1996), vol. 1, pp. 85-88. (Ver en la página 60).

[35] Columbus, C. El hombre bicentenario - imdb webpage, 1999. URL:http: //www. imdb.com/title/tt0182789/ [accedida: 2015-08-16]. (Ver en la página 7$)$.

[36] DaRwin, C. El origen de las especies por la selección natural. Ediciones Ibéricas y LCL, 1963. (Ver en la página 3). 
[37] DaRwin, C. La expresión de las emociones en los animales y en el hombre. Alianza editorial, 1998. (Ver en la página 3).

[38] Dellaert, F., Polzin, T., Y Waibel, A. Recognizing emotion in speech. In IEEE Fourth International Conference on Spoken Language (1996), vol. 3, pp. 1970-1973. (Ver en las páginas 55 and 60).

[39] Deller, J. R., Proakis, J. G., y Hansen, J. H. Discrete time processing of speech signals. Prentice Hall PTR, 1993. (Ver en las páginas 54, 78, 79, and 81).

[40] Demenko, G., Y Jastrzebska, M. Analysis of voice stress in call centers conversations. In 6th International Conference of Speech Prosody (2012). (Ver en la página 119).

[41] DePaulo, B. M., Lindsay, J. J., Malone, B. E., Muhlenbruck, L., Charlton, K., y Cooper, H. Cues to deception. Psychological bulletin 129, 1 (2003), pp. 74-118. (Ver en la página 119).

[42] Descartes, R. Las pasiones del alma, vol. 290. Edaf, 2005. (Ver en la página 2).

[43] Devillers, L., Vaudable, C., y Chastagnol, C. Real-life emotionrelated states detection in call centers: a cross-corpora study. In Interspeech (2010), vol. 10, pp. 2350-2353. (Ver en la página 24).

[44] Duda, R. O., Hart, P. E., y Stork, D. G. Pattern classification. John Wiley \& Sons, 2012. (Ver en la página 87).

[45] Durbin, J. The fitting of time-series models. Revue de l'Institut International de Statistique (1960), pp. 233-244. (Ver en la página 79).

[46] Ekman, P. Handbook of cognition and emotion. ch. Basic Emotions. Wiley Online Library, (1999), pp. 45-60. (Ver en la página 5).

[47] Ekman, P., y Friesen, W. V. Constants across cultures in the face and emotion. Journal of personality and social psychology 17, 2 (1971), pp. 124129. (Ver en las páginas XVII and 6).

[48] Engberg, I. S., y Hansen, A. V. Documentation of the Danish emotional speech database DES. Internal AAU report, Center for Person Kommunikation, Denmark (1996). (Ver en la página 23).

[49] Fant, G. Acoustic Theory of Speech Production: With Calculations Based on X-Ray Studies of Russian Articulations. Walter de Gruyter, 1970. (Ver en la página 73$)$.

[50] Fant, G. The voice source in connected speech. Speech Communication 22, 2-3 (1997), pp. 125-139. (Ver en las páginas 62 and 67). 
[51] Fay, M. P., y Proschan, M. A. Wilcoxon-mann-whitney or t-test? on assumptions for hypothesis tests and multiple interpretations of decision rules. Statistics surveys 4 (2010), pp. 1-39. (Ver en la página 92).

[52] Fernández, R., Y PicARd, R. Recognizing affect from speech prosody using hierarchical graphical models. Speech Communication 53, 9 (2011), pp. 1088-1103. (Ver en la página 54).

[53] Fernández, R., y Picard, R. W. Modeling drivers' speech under stress. Speech Communication 40, 1 (2003), pp. 145-159. (Ver en las páginas 25, 30, and 54).

[54] Fernández, T. Prólogo a la edición en castellano de La expresión de las emociones en los animales y en el hombre. Madrid: Alianza, 1984. (Ver en la página 3).

[55] Fernández, J. G. Los sonidos del lenguaje. Síntesis, 1988. (Ver en las páginas 55 and 56 ).

[56] Finnegan, E. M., Luschei, E. S., Barkmeier, J. M., Y Hoffman, H. T. Synchrony of laryngeal muscle activity in persons with vocal tremor. Archives of Otolaryngology-Head \& Neck Surgery 129, 3 (2003), pp. 313-318. (Ver en la página 78).

[57] Flanagan, J. L. Speech analysis synthesis and perception, vol. 3. Springer Science \& Business Media, 2013. (Ver en la página 61).

[58] Frank, M. G., Y Ekman, P. Appearing truthful generalizes across different deception situations. Journal of personality and social psychology 86, 3 (2004), pp. 486-495. (Ver en la página 113).

[59] Giannakopoulos, X., Karhunen, J., y Oja, E. An experimental comparison of neural algorithms for independent component analysis and blind separation. International journal of neural systems 9, 2 (1999), pp. 99-114. (Ver en la página 96).

[60] Gibbons, J. D., y Chakraborti, S. Nonparametric statistical inference. Springer, 2011. (Ver en la página 158).

[61] GiLl, B. Panel discussion: What is the voice source? In International Voice Symposium. Steinhardt School. New York (2014). (Ver en la página 62).

[62] Gómez, P., Martínez, R., Díaz, F., Lázaro, C., Álvarez, A., RodeLLAR, V., Y NiETO, V. Voice pathology detection by vocal cord biomechanical parameter estimation. In International Conference on Nonlinear Analyses and Algorithms for Speech Processing (2005), Springer, pp. 242-256. (Ver en la página 77$)$.

[63] Gómez-Vilda, P., Fernández-Baillo, R., Rodellar-Biarge, V., Lluis, V. N., álvarez Marquina, A., Mazaira-Fernández, L. M., 
Martínez-Olalla, R., y Godino-Llorente, J. I. Glottal source biometrical signature for voice pathology detection. Speech Communication 51, 9 (2009), pp. 759-781. (Ver en las páginas 74 and 128).

[64] Gómez-Vilda, P., Y Nieto-Lluis, V. Informe Técnico para documentar la funcionalidad de la aplicación informática BioMetßPhon. Grupo de informática aplicada al procesado de señal e imagen (GIAPSI). Documento Interno., 2015. (Ver en la página 62).

[65] Gómez-Vilda, P., Nieto-Lluis, V., Rodellar-Biarge, V., Álvarez Marquina, A., Mazaira-Fernández, L. M., Martínez-Olalla, R., Muñoz-Mulas, C., Fernández-Fernández, M., y Ramírez-Calvo, C. Estimating tremor in vocal fold biomechanics for neurological disease characterization. In 18th IEEE International Conference on Digital Signal Processing (2013), pp. 1-6. (Ver en las páginas 82, 115, and 117).

[66] González, I. V. Videolaringoestroboscopia: una técnica para visualizar las cuerdas vocales. Estudios de fonética experimental 17 (2008), pp. 418-432. (Ver en la página 11).

[67] Grichkovtsova, I., Morel, M., y Lacheret, A. The role of voice quality and prosodic contour in affective speech perception. Speech Communication 54, 3 (2012), pp. 414-429. (Ver en la página 53).

[68] HANSEN, J. SUSAS-speech under simulated and actual stress, robust speech processing lab (1977). (Ver en la página 24).

[69] Hansen, J. H., Bou-Ghazale, S. E., Sarikaya, R., y Pellom, B. Getting started with SUSAS: A speech under simulated and actual stress database. In Eurospeech (1997), vol. 97, pp. 1743-1746. (Ver en la página 24).

[70] Hansen, J. H., Kim, W., Rahurkar, M., Ruzanski, E., y Meyerhoff, J. Robust emotional stressed speech detection using weighted frequency subbands. EURASIP Journal on Advances in Signal Processing (2011), pp. 1-10. (Ver en las páginas 30 and 86).

[71] HAO KAO, Y., Y SHAN LEE, L. Feature analysis for emotion recognition from mandarin speech considering the special characteristics of chinese language. In InterSpeech (2006), pp. 1814-1817. (Ver en las páginas 55 and 87).

[72] Haq, S., Jackson, P. J., Y Edge, J. Audio-visual feature selection and reduction for emotion classification. In Proc. Int. Conf. on Auditory-Visual Speech Processing (AVSP'08), Tangalooma, Australia (2008), pp. 185-190. (Ver en la página 55).

[73] Hasrul, M. N., Hariharan, M., y YaAcob, S. Human affective (emotion) behaviour analysis using speech signals: A review. In International Conference on Biomedical Engineering (2012), pp. 217-222. (Ver en las páginas XXI, 22, 54,55 , and 87). 
[74] Hastie, T. J., Tibshirani, R. J., Y Friedman, J. H. The elements of statistical learning: data mining, inference, and prediction. Springer, 2011. (Ver en las páginas 100 and 132).

[75] Hernández, J., Morris, R. R., y Picard, R. W. Call center stress recognition with person-specific models. In International Conference on Affective Computing and Intelligent Interaction (2011), Springer, pp. 125-134. (Ver en la página 120).

[76] Hirano, M. Clinical examination of voice. Disorders of human communication. Springer London, Limited, 1981. (Ver en la página 12).

[77] Hoelper, C., Frankort, A., Erdmann, C., y Vary, P. A novel voiced/unvoiced/silence classification scheme for offline speech coding. In 11th European IEEE Signal Processing Conference (2002), pp. 1-4. (Ver en la página 60).

[78] Hollander, M., Wolfe, D. A., y Chicken, E. Nonparametric statistical methods. John Wiley \& Sons, 2013. (Ver en la página 158).

[79] Hotelling, H. Analysis of a complex of statistical variables into principal components. Journal of educational psychology 24, 6 (1933), pp. 417-441. (Ver en la página 93).

[80] Hyvärinen, A. Fast and robust fixed-point algorithms for independent component analysis. IEEE Transactions on Neural Networks 10, 3 (1999), pp. 626-634. (Ver en las páginas 96 and 145).

[81] Hyvärinen, A., Karhunen, J., y OJA, E. Independent component analysis, vol. 46. John Wiley \& Sons, 2004. (Ver en la página 95).

[82] Hyvärinen, A. Survey on independent component analysis. Neural Computing Surveys 2 (1999), pp. 94-128. (Ver en la página 95).

[83] Hyvärinen, A., Y OJA, E. A fast fixed-point algorithm for independent component analysis. Neural computation 9, 7 (1997), pp. 1483-1492. (Ver en las páginas 96 and 145).

[84] HyväRinen, A., Y OJA, E. Independent component analysis: algorithms and applications. Neural Networks 13, 4 (2000), pp. 411-430. (Ver en la página 95).

[85] Illán, I. Análisis en componentes de imágenes funcionales para la ayuda al diagnóstico de la enfermedad de Alzheimer. Tesis doctoral. Universidad de Granada. (2009). (Ver en la página 95).

[86] Illán, I., Górriz, J., Ramírez, J., Salas-Gonzalez, D., López, M., Segovia, F., Chaves, R., Gómez-Rio, M., Puntonet, C. G., Y AlzHeimer's Disease Neuroimaging Initiative. $18 \mathrm{f}$-fdg pet imaging analysis for computer aided Alzheimer's diagnosis. Information Sciences 181, 4 (2011), pp. 903-916. (Ver en la página 95). 
[87] IzARD, C. E. The psychology of emotions. Springer Science \& Business Media, 1991. (Ver en la página 3).

[88] Jolliffe, I. Principal component analysis. John Wiley \& Sons, 2002. (Ver en la página 132).

[89] Jonze, S. Her - official webpage, 2013. URL: http://www .herthemovie.com/ [accedida: 2015-05-04]. (Ver en la página 7).

[90] Kane, J., Y Gobl, C. Evaluation of Automatic Glottal Source Analysis, vol. 7911. Advances in Nonlinear Speech Processing. Springer, 2013, pp. 1-8. (Ver en la página 54).

[91] Kent, R. D., Y Read, C. The Acoustic Analysis of Speech. Singular/Thomson Learning, 2002. (Ver en la página 56).

[92] Koolagudi, S. G., Y RaO, K. S. Emotion recognition from speech: a review. International Journal of Speech Technology 15, 2 (2012), pp. 99-117. (Ver en la página 54).

[93] Kunn, H. W. Nonlinear programming: a historical view. In Traces and Emergence of Nonlinear Programming. Springer, 2014, pp. 393-414. (Ver en la página 99$)$.

[94] Kullback, S., Y Leibler, R. A. On information and sufficiency. The annals of mathematical statistics 22, 1 (1951), pp. 79-86. (Ver en la página 92).

[95] Kwon, O.-W., Chan, K., HaO, J., Y Lee, T.-W. Emotion recognition by speech signals. 8th European Conference on Speech Communication and Technology (INTERSPEECH), pp. 125-128. (Ver en las páginas 55 and 87).

[96] LECH, M., Y HE, L. Stress and emotion recognition using acoustic speech analysis. Mental Health Informatics. Springer, 2014, pp. 163-184. (Ver en la página 53).

[97] Lee, C. M., Y Narayanan, S. Emotion recognition using a data-driven fuzzy inference system. In INTERSPEECH (2003), pp. 157-160. (Ver en las páginas 55 and 60$)$.

[98] Lefter, I., Rothkrantz, L. J., Leeuwen, D. A. V., Y Wiggers, P. Automatic stress detection in emergency (telephone) calls. International Journal of Intelligent Defence Support Systems 4, 2 (2011), pp. 148-168. (Ver en la página 119).

[99] Lewis, M., Haviland-Jones, J. M., Y Barrett, L. F. Handbook of emotions. Guilford Press, 2010. (Ver en la página 106).

[100] Lippold, O. Physiological microtremor. Scientific American 3, 224 (1971), pp. 65-73. (Ver en la página 120). 
[101] Llamazares, M. V. Apuntes sobre acústica y fonética. Departamento de Filología Hispánica de la Universidad de León, 2016. (Ver en la página 56).

[102] Llisteri, J. Las características acústicas de los sonidos del habla. Departamento de Filología Española de la Universidad Autónoma de Barcelona, 2016. (Ver en la página 56).

[103] Lombard, E. Le signe de l'elevation de la voix. Ann.Maladies Oreille, Larynx, Nez, Pharynx 37, 25 (1911), pp. 101-119. (Ver en la página 25).

[104] López, M., Ramírez, J., Górriz, J., Álvarez, I., Salas-Gonzalez, D., Segovia, F., y Chaves, R. SVM-based CAD system for early detection of the Alzheimer's disease using kernel PCA and LDA. Neuroscience letters 464 , 3 (2009), pp. 233-238. (Ver en las páginas 95 and 132).

[105] López, M., Ramírez, J., Górriz, J., Salas-Gonzalez, D., Álvarez, I., Segovia, F., Y Puntonet, C. Automatic tool for Alzheimer's disease diagnosis using PCA and Bayesian classification rules. Electronics Letters 45 , 8 (2009), pp. 389-391. (Ver en la página 95).

[106] Lu, H., Frauendorfer, D., Rabbi, M., Mast, M. S., Chittaranjan, G. T., Campbell, A. T., Gatica-Perez, D., y Choudhury, T. Stresssense: Detecting stress in unconstrained acoustic environments using smartphones. In Proceedings of the 2012 ACM Conference on Ubiquitous Computing (2012), pp. 351-360. (Ver en las páginas 30 and 86).

[107] Ludlow, C. L. Central nervous system control of voice and swallowing. Journal of clinical neurophysiology : official publication of the American Electroencephalographic Society 32, 4 (2015), pp. 294-303. (Ver en la página 79).

[108] Luengo, I., Navas, E., Hernáez, I., y SÁnchez, J. Automatic emotion recognition using prosodic parameters. In 9th European Conference on Speech Communication and Technology (Interspeech) (2005), pp. 493-496. (Ver en las páginas 55, 59, and 87).

[109] Luschei, E. S., Ramig, L. O., Baker, K. L., Y Smith, M. E. Discharge characteristics of laryngeal single motor units during phonation in young and older adults and in persons with Parkinson disease. Journal of neurophysiology 81, 5 (1999), pp. 2131-2139. (Ver en la página 73).

[110] López, J. M., Cearreta, I., Garay, N., de Ipiña, K. L., y BerisTAIN, A. Creación de una base de datos emocional bilingüe y multimodal. In Proceedings of the 7th Spanish Human Computer Interaction Conference, Interaccion (2006), vol. 6, pp. 55-66. (Ver en la página 23).

[111] Makhoul, J. Linear prediction: A tutorial review. Proceedings of the IEEE 63, 4 (1975), pp. 561-580. (Ver en la página 61).

[112] Mann, H. B., Y Whitney, D. R. On a test of whether one of two random variables is stochastically larger than the other. The annals of mathematical statistics (1947), pp. 50-60. (Ver en la página 91). 
[113] Markaki, M., y Stylianou, Y. Voice pathology detection and discrimination based on modulation spectral features. IEEE Transactions on Audio, Speech, and Language Processing 19, 7 (2011), pp. 1938-1948. (Ver en la página 80).

[114] Martino, F. D., Gentile, F., Esposito, F., Balsi, M., Salle, F. D., Goebel, R., Y Formisano, E. Classification of fMRI independent components using IC-fingerprints and support vector machine classifiers. NeuroImage 34, 1 (2007), pp. 177-194. (Ver en la página 95).

[115] Massey JR, F. J. The Kolmogorov-Smirnov test for goodness of fit. Journal of the American statistical Association 46, 253 (1951), pp. 68-78. (Ver en la página 150).

[116] Mbitiru, N., Tay, P., Zhang, J. Z., y Adams, R. D. Analysis of stress in speech using empirical mode decomposition. In International Conference of IAJC-IJME (2008), Citeseer, pp. 140-146. (Ver en la página 120).

[117] Merkx, P., Truong, K. P., y Neerincx, M. A. Inducing and measuring emotion through a multiplayer first-person shooter computer game. In Proceedings of the Computer Games Workshop (2007), pp. 06-07. (Ver en la página 37).

[118] Mermelstein, P. Automatic segmentation of speech into syllabic units. The Journal of the Acoustical Society of America 58, 4 (1975), pp. 880-883. (Ver en la página 60).

[119] Mertens, C., Grenez, F., Viallet, F., Ghio, A., Skodda, S., Y Schoentgen, J. Vocal tremor analysis via AM-FM decomposition of empirical modes of the glottal cycle length time series. In 16th Annual Conference of the International Speech Communication Association (Interspeech 2015) (2015). (Ver en la página 80).

[120] Mertens, C., Schoentgen, J., Grenez, F., y Skodda, S. Acoustical analysis of vocal tremor in Parkinson speakers. MAVEBA13 (2013), pp. 19-22. (Ver en la página 80).

[121] Meyer, G. J., Finn, S. E., Eyde, L. D., Kay, G. G., Moreland, K. L., Dies, R. R., Eisman, E. J., Kubiszyn, T. W., y Reed, G. M. Psychological testing and psychological assessment: A review of evidence and issues. American psychologist 56, 2 (2001), pp. 128-165. (Ver en la página 127).

[122] Miller, L. H. Table of percentage points of Kolmogorov statistics. Journal of the American Statistical Association 51, 273 (1956), pp. 111-121. (Ver en la página 150).

[123] Minifie, F., Hixon, T., Williams, F., y Broad, D. Normal aspects of speech, hearing, and language. Prentice-Hall, 1973. (Ver en las páginas XVII and 14). 
[124] Mittal, V. K., Y Yegnanarayana, B. Effect of glottal dynamics in the production of shouted speech. The Journal of the Acoustical Society of America 133, 5 (2013), pp. 3050-3061. (Ver en la página 54).

[125] Moore, E., Clements, M. A., Peifer, J. W., Y Weisser, L. Critical analysis of the impact of glottal features in the classification of clinical depression in speech. IEEE Transactions on Biomedical Engineering 55, 1 (2008), pp. 96-107. (Ver en las páginas 31, 54, and 106).

[126] Moreno-Palomares., M. T. Diseño de una estructura hardware reusable para front-end y extracción paramétrica en un sistema de reconocimiento de voz. Proyecto fin de carrera. Universidad Politécnica de Madrid, 2005. (Ver en la página 59).

[127] Moro-Velázquez, L., Gómez-García, J. A., Godino-Llorente, J. I., Y ANDRADE-MIRANDA, G. Modulation spectra morphological parameters: a new method to assess voice pathologies according to the grbas scale. BioMed research international 2015 (2015). (Ver en la página 80).

[128] Mulas, C. M. Speech signals feature extraction model for a speaker's gender and age identification system. Tesis Doctoral. Universidad Politécnica de Madrid (2014). (Ver en la página 22).

[129] Nadal, R., y Armario, A. Mecanismos de susceptibilidad al estrés. Hipertensión y riesgo vascular 27, 3 (2010), pp. 117-124. (Ver en las páginas 8 and 9).

[130] NARAyAnan, S. The role of cortico-basal-thalamic loops in cognition: a computational model and preliminary results. Neurocomputing 52 (2003), pp. 605-614. (Ver en la página 79).

[131] Neiberg, D., Elenius, K., y Laskowski, K. Emotion recognition in spontaneous speech using GMMs. In Interspeech (2006), pp. 809-812. (Ver en la página 55).

[132] Nicholson, J., Takahashi, K., y Nakatsu, R. Emotion recognition in speech using neural networks. In 6th International Conference on Neural Information Processing (ICONIP) (1999), vol. 2, pp. 495-501. (Ver en la página 87).

[133] Origlia, A., Cutugno, F., y Galatà, V. Continuous emotion recognition with phonetic syllables. Speech Communication 57 (2014), pp. 155-169. (Ver en la página 54).

[134] Ortony, A., y Turner, T. J. What's basic about basic emotions? Psychological review 97, 3 (1990), pp. 315-331. (Ver en la página 7).

[135] O'shaughnessy, D. Speech communication: human and machine. Universities Press, 1987. (Ver en la página 59). 
[136] PaO, T.-L., Chen, Y.-T., Yeh, J.-H., Y Chang, Y.-H. Emotion recognition and evaluation of mandarin speech using weighted D-KNN classification. In 17th Conference on Computational Linguistics and Speech Processing (ROCLING) (2005), pp. 1695-1709. (Ver en la página 55).

[137] Pavlov, I. P., y ANREP, G. V. Conditioned Reflexes. An Investigation of the Physiological Activity of the Cerebral Cortex... Translated and Edited by GV Anrep. London, 1927. (Ver en la página 17).

[138] Pearson, K. On lines and planes of closest fit to systems of points in space. The London, Edinburgh, and Dublin Philosophical Magazine and Journal of Science 2, 11 (1901), pp. 559-572. (Ver en la página 93).

[139] Perez, K. S., Ramig, L. O., Smith, M. E., y Dromey, C. The Parkinson larynx: tremor and videostroboscopic findings. Journal of Voice 10, 4 (1996), pp. 354-361. (Ver en la página 78).

[140] Petrushin, V. A. Emotion recognition in speech signal: experimental study, development, and application. Studies 3 (2000), pp. 493-496. (Ver en las páginas 55, 59, and 87).

[141] Picone, J. W. Signal modeling techniques in speech recognition. Proceedings of the IEEE 81, 9 (1993), pp. 1215-1247. (Ver en la página 59).

[142] Platón. Diálogos VI. Filebo, Timeo, Critias. Madrid, Gredos, 1992. (Ver en la página 2).

[143] Platt, J. C. 12 fast training of support vector machines using sequential minimal optimization. Journal of advances in kernel methods (1999), pp. 185208. (Ver en la página 132).

[144] Plutchik, R. A general psychoevolutionary theory of emotion. Theories of emotion 1, 4 (1980), pp. 3-31. (Ver en la página 4).

[145] Plutchik, R. The psychology and biology of emotion. HarperCollins College Publishers, 1994. (Ver en la página 4).

[146] Quilis, A. Principios de fonología y fonética españolas. Cuadernos de lengua española. Arco Libros, 1997. (Ver en las páginas 9 and 13).

[147] Rabiner, L., y JuAng, B. An introduction to hidden markov models. IEEE assp magazine 3, 1 (1986), pp. 4-16. (Ver en la página 86).

[148] Ramakrishnan, S. Recognition of emotion from speech: A review. Speech Enhancement, Modeling and recognition-algorithms and Applications (2012), pp. 121-138. (Ver en la página 21).

[149] Ramos, D., Gonzalez-Rodriguez, J., Domínguez, J. G., Y LucenaMolina, J. J. Addressing database mismatch in forensic speaker recognition with ahumada III: a public real-casework database in Spanish. Interspeech (2008), pp. 1493-1496. (Ver en la página 23). 
[150] Reynolds, D. An overview of automatic speaker recognition. In Proceedings of the International Conference on Acoustics, Speech and Signal Processing (ICASSP) (2002), pp. 4072-4075. (Ver en la página 86).

[151] Rodellar, V., Palacios, D., Gómez, P., y Bartolome, E. A methodology for monitoring emotional stress in phonation. In 5th IEEE Conference on Cognitive Infocommunications (CogInfoCom) (2014), pp. 231-236. (Ver en la página 75).

[152] Rodellar-Biarge, V. Métodos no invasivos para la medida de las características de transmisión del aparato auditivo. Tesis doctoral. Universidad Politécnica de Madrid, 1983. (Ver en la página 61).

[153] Rojas, A., Górriz, J., Ramírez, J., Illán, I., Martínez-Murcia, F. J., Ortiz, A., Río, M. G., y Moreno-Caballero, M. Application of empirical mode decomposition (EMD) on DaTSCAN SPECT images to explore Parkinson disease. Expert Systems with Applications 40, 7 (2013), pp. 2756-2766. (Ver en la página 80).

[154] Rong, J., Li, G., Y Chen, Y.-P. P. Acoustic feature selection for automatic emotion recognition from speech. Information processing and management 45 , 3 (2009), pp. 315-328. (Ver en la página 55).

[155] Rosipal, R., Y Krämer, N. Overview and recent advances in partial least squares. In Subspace, latent structure and feature selection. Springer, 2006, pp. 34-51. (Ver en la página 96).

[156] Rosipal, R., Trejo, L. J., y Matthews, B. Kernel PLS-SVC for linear and nonlinear classification. In $\operatorname{ICML}$ (2003), pp. 640-647. (Ver en la página 96).

[157] Ross, T. Fuzzy Logic with Engineering Applications. Wiley \& Sons, 2004. (Ver en la página 17).

[158] Rumsey, D. J. Statistics essentials for dummies. John Wiley \& Sons, 2010. (Ver en la página 88).

[159] Rumsey, D. J., Y Unger, D. U Can: Statistics For Dummies. John Wiley \& Sons, 2015. (Ver en la página 89).

[160] Scherer, K. R. Vocal communication of emotion: A review of research paradigms. Speech Communication 40, 1 (2003), pp. 227-256. (Ver en la página 55).

[161] Scherer, S., Hofmann, H., Lampmann, M., Pfeil, M., Rhinow, S., Schwenker, F., y PALM, G. Emotion recognition from speech: Stress experiment. In Language Resources and Evaluation Conference. (2008), pp. 13251330. (Ver en la página 30).

[162] SchreIER, J. Robot \& Frank - imdb webpage, 2012. URL:http://www . imdb.com/title/tt1990314/ [accedida: 2015-05-04]. (Ver en la página 7). 
[163] Schuller, B., Rigoll, G., y LANG, M. Hidden markov model-based speech emotion recognition. In International Conference on Acoustics, Speech, and Signal Processing (ICASSP) (2003), vol. 2, IEEE, pp. 1-4. (Ver en la página 55).

[164] Shami, M., Y Verhelst, W. An evaluation of the robustness of existing supervised machine learning approaches to the classification of emotions in speech. Speech Communication 49, 3 (2007), pp. 201-212. (Ver en las páginas 55 and 61$)$.

[165] Sidorova, J. Speech emotion recognition with TGI+.2 classifier. In Proceedings of the 12th Conference of the European Chapter of the Association for Computational Linguistics: Student Research Workshop (2009), pp. 54-60. (Ver en la página 55).

[166] Sigmund, M. Introducing the database ExamStress for speech under stress. In Proceedings of the 7th Nordic Signal Processing Symposium (NORSIG). (2006), pp. 290-293. (Ver en la página 25).

[167] Smekal, Z., Mekyska, J., Galaz, Z., Mzourek, Z., Rektorova, I., Y FAundeZ-Zanuy, M. Analysis of phonation in patients with Parkinson's disease using empirical mode decomposition. In International IEEE Symposium on Signals, Circuits and Systems (ISSCS) (2015), pp. 1-4. (Ver en la página 80).

[168] Smirnov, N. Table for estimating the goodness of fit of empirical distributions. The Annals of Mathematical Statistics 19, 2 (1948), pp. 279-281. (Ver en la página 91$)$.

[169] Smirnov, N. V. On the estimation of the discrepancy between empirical curves of distribution for two independent samples. Bull.Math.Univ.Moscou 2, 2 (1939), pp. 3-14. (Ver en la página 91).

[170] Spetsieris, P. G., Ma, Y., Dhawan, V., Y Eidelberg, D. Differential diagnosis of parkinsonian syndromes using pca-based functional imaging features. NeuroImage 45, 4 (2009), pp. 1241-1252. (Ver en la página 95).

[171] STEIDL, S. Automatic classification of emotion related user states in spontaneous children's speech. University of Erlangen-Nuremberg Erlangen, Germany, 2009. (Ver en la página 24).

[172] Story, B. H., Y Titze, I. R. Voice simulation with a bodycover model of the vocal folds. The Journal of the Acoustical Society of America 97, 2 (1995), pp. 1249-1260. (Ver en la página 75).

[173] Svec, J. G., Horáček, J., Šram, F., Y Veselý, J. Resonance properties of the vocal folds: in vivo laryngoscopic investigation of the externally excited laryngeal vibrations. The Journal of the Acoustical Society of America 108, 4 (2000), pp. 1397-1407. (Ver en la página 76). 
[174] Tardón, C. G. Videojuegos para la transformación social. Aportaciones conceptuales y metodológicas. Tesis Doctoral. Universidad de Deusto, 2014. (Ver en la página 17).

[175] Teager, H. Some observations on oral air flow during phonation. IEEE Transactions on Acoustics, Speech and Signal Processing 28, 5 (1980), pp. 599-601. (Ver en la página 54).

[176] Teager, H., Y TEAger, S. Evidence for nonlinear sound production mechanisms in the vocal tract. Speech production and speech modelling. Springer, 1990, pp. 241-261. (Ver en las páginas 54 and 59).

[177] Theis, F. J., Gruber, P., Keck, I. R., y Lang, E. W. Functional MRI analysis by a novel spatio-temporal ICA algorithm. In International Conference on Artificial Neural Networks (2005), Springer, pp. 677-682. (Ver en la página 95).

[178] Titze, I. Workshop on acoustic voice analysis: Summary statement. National Center for Voice and Speech (1995), pp. 26-30. (Ver en la página 76).

[179] Titze, I. R. Principles of voice production. Prentice Hall Englewood Cliffs, 1994. (Ver en la página 13).

[180] Titze, I. R., Y Martin, D. W. Principles of voice production. The Journal of the Acoustical Society of America 104, 3 (1998), pp. 1148. (Ver en la página 68).

[181] Tomkins, S. Affect Imagery Consciousness: Volume I: The Positive Affects. Springer Series. Springer Publishing Company, 1962. (Ver en la página 3).

[182] Tourville, J. A., Y Guenther, F. H. The diva model: A neural theory of speech acquisition and production. Language and cognitive processes 26, 7 (2011), pp. 952-981. (Ver en la página 79).

[183] Turk, M., y Pentland, A. Eigenfaces for recognition. Journal of cognitive neuroscience 3, 1 (1991), pp. 71-86. (Ver en la página 132).

[184] Vapnik, V. N., Y Vapnik, V. Statistical learning theory, vol. 1. John Wiley \& Sons, 1998. (Ver en la página 132).

[185] Vaudable, C., Rollet, N., y Devillers, L. Annotation of affective interaction in real-life dialogs collected in a call-center. The Workshop Programme (2010), pp. 47-52. (Ver en la página 24).

[186] Venables, W. N., y RiPley, B. D. Modern applied statistics with S-PLUS. Springer Science \& Business Media, 2013. (Ver en la página 100).

[187] Ververidis, D., Y Kotropoulos, C. A review of emotional speech databases. In Proc. Panhellenic Conference on Informatics (PCI) (2003), pp. 560574. (Ver en las páginas 20 and 21). 
[188] Ververidis, D., y Kotropoulos, C. Automatic speech classification to five emotional states based on gender information. In 12th European Conference of Signal Processing (2004), IEEE, pp. 341-344. (Ver en la página 54).

[189] Ververidis, D., Y Kotropoulos, C. Emotional speech recognition: Resources, features, and methods. Speech Communication 48, 9 (2006), pp. 11621181. (Ver en las páginas 55, 59, and 61).

[190] Ververidis, D., Y Kotropoulos, C. Fast sequential floating forward selection applied to emotional speech features estimated on DES and SUSAS data collections. In 14th European Signal Processing Conference (2006), IEEE, pp. 1-5. (Ver en las páginas 55 and 59).

[191] Ververidis, D., Kotsia, I., Kotropoulos, C., y Pitas, I. Multi-modal emotion-related data collection within a virtual earthquake emulator. In Workshop on Corpora for Research on Emotion and Affect. 6th Language Resources and Evaluation Conference. (2008), pp. 57-60. (Ver en la página 22).

[192] Villar, G., Arciuli, J., Y Mallard, D. Use of "um" in the deceptive speech of a convicted murderer. Applied Psycholinguistics 33, 1 (2012), pp. 83-95. (Ver en la página 30).

[193] Vlasenko, B., y Wendemuth, A. Tuning hidden Markov model for speech emotion recognition. Fortschritte der akustik 33, 1 (2007), pp. 317-320. (Ver en la página 55).

[194] Vlassis, N., Y LiKAs, A. A greedy EM algorithm for Gaussian mixture learning. Neural processing letters 15, 1 (2002), pp. 77-87. (Ver en la página 86).

[195] Vries, M. D., Schutte, H., Veldman, A., y Verkerke, G. Glottal flow through a two-mass model: comparison of navier-stokes solutions with simplified models. The Journal of the Acoustical Society of America 111, 4 (2002), pp. 1847-1853. (Ver en la página 73).

[196] Waaramaa, T., Laukkanen, A.-M., Airas, M., y Alku, P. Perception of emotional valences and activity levels from vowel segments of continuous speech. Journal of Voice 24, 1 (2010), pp. 30-38. (Ver en las páginas 53 and 54).

[197] Wang, J., Tsang, W. W., y Marsaglia, G. Evaluating Kolmogorov's distribution. Journal of Statistical Software 8, 18 (2003), pp. 1-4. (Ver en la página 150).

[198] WebB, A. R. Statistical pattern recognition. John Wiley \& Sons, 2003. (Ver en la página 98).

[199] Wilcoxon, F. Individual comparisons by ranking methods. Biometrics Bulletin 1, 6 (1945), pp. 80-83. (Ver en la página 91). 
[200] WolD, H. Quantitative sociology: international perspectives on mathematical and statistical model building, chapter path models with latent variables: the NiPALS Approach. Academic Press, 1975. (Ver en la página 97).

[201] Wold, H. Partial least squares. Encyclopedia of statistical sciences 6 (1985), pp. 581-591. (Ver en la página 96).

[202] Yacoub, S. M., Simske, S. J., Lin, X., Y Burns, J. Recognition of emotions in interactive voice response systems. In INTERSPEECH (2003), pp. 1-4. (Ver en la página 55).

[203] Yamada, T., Hashimoto, H., y Tosa, N. Pattern recognition of emotion with neural network. In 21st IEEE International Conference on Industrial Electronics, Control, and Instrumentation (1995), vol. 1, pp. 183-187. (Ver en la página 87).

[204] Yu, F., Chang, E., Xu, Y.-Q., Y Shum, H.-Y. Emotion detection from speech to enrich multimedia content. In Pacific-Rim Conference on Multimedia (2001), Springer, pp. 550-557. (Ver en la página 55).

[205] Zhou, G., Hansen, J. H., y Kaiser, J. F. Nonlinear feature based classification of speech under stress. IEEE Transactions on Speech and Audio Processing 9, 3 (2001), pp. 201-216. (Ver en las páginas 54 and 59).

[206] Zuo, X., Lin, L., Y Fung, P. A multilingual database of natural stress emotion. In Proceedings of the Eight International Conference on Language Resources and Evaluation (LREC) (2012), pp. 1174-1178. (Ver en la página 25). 



\section{Apéndice A}

\section{ÍNDICE DE SÍMBOLOS}

\begin{tabular}{|c|c|c|}
\hline Símbolo & Significado & Sección \\
\hline 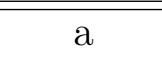 & "Neutro/Acuerdo (Agreement) & General al documento \\
\hline $\mathrm{a}$ & Coeficientes de mezclado & Sección 4.4.2 - ICA \\
\hline$a_{i}$ & Coeficientes del modelo & Sección 3.3.4.2 \\
\hline $\mathrm{A}$ & Hiperplano de separación & Sección 4.5.1 - SVM \\
\hline $\mathrm{b}$ & Intersección con el eje & Sección 4.2 - RL \\
\hline $\mathrm{b}$ & Umbral & Sección 4.5.1 - SVM \\
\hline$B W$ & $\begin{array}{l}\text { ancho de banda de la raíz } z_{i} \text { sobre el círculo } \\
\text { unitario }\end{array}$ & Sección 3.3.4.3 \\
\hline$c_{K m}$ & $\begin{array}{l}\text { Coeficientes de pivotamiento para cada ciclo } \\
\text { de fonación }\end{array}$ & Sección 3.3.4.2 \\
\hline $\mathrm{d}$ & Estrés/Desacuerdo (Disagreement) & General al documento \\
\hline $\mathrm{D}$ & Coeficiente de determinación & General al documento \\
\hline $\mathrm{e}$ & El número de Euler $(\approx 2,718)$ & Sección 4.5.2 - Log-LH \\
\hline $\mathrm{E}$ & Esperanza estadística & Sección 4.5.2 - Log-LH \\
\hline $\mathrm{f}$ & Mujer (Female) & General al documento \\
\hline$f_{b}$ & Fuerza del cuerpo de las cuerdas vocales & Sección 3.3.4.1 \\
\hline$f_{c}$ & Fuerza de la cubierta de las cuerdas vocales & Sección 3.3.4.1 \\
\hline$f_{f}$ & Banda de frecuencia del temblor oscilatorio & Sección 3.3.4.3 \\
\hline$f_{n}$ & Banda de frecuencia del temblor neurológico & Sección 3.3.4.3 \\
\hline$f_{p}$ & Banda de frecuencia del temblor fisiológico & Sección 3.3.4.3 \\
\hline$f_{0}$ & Frecuencia fundamental & General al documento \\
\hline $\mathrm{F}$ & Funciones de distribución & Sección 4.3.1 - KS \\
\hline $\mathrm{h}$ & Margen & Sección 4.5.1 - SVM \\
\hline$H_{0}$ & Hipótesis nula & General al documento \\
\hline$H(z)$ & Función de transferencia & Sección 3.3.4.3 \\
\hline $\mathrm{i}$ & Individuo (Individual) & General al documento \\
\hline $\mathrm{j}$ & Parámetro (Feature) & General al documento \\
\hline $\mathrm{J}$ & Conjunto de parámetros & General al documento \\
\hline $\mathrm{K}$ & Kernel & Sección 4.5.1 - SVM \\
\hline $\mathrm{K}$ & Subconjunto de parámetros & General al documento \\
\hline
\end{tabular}




\begin{tabular}{|c|c|c|}
\hline Símbolo & Significado & Sección \\
\hline$K_{b l}$ & $\begin{array}{l}\text { Elasticidad del cuerpo de la cuerda vocal iz- } \\
\text { quierda }\end{array}$ & Sección 3.3.4.1 \\
\hline$K_{b r}$ & $\begin{array}{l}\text { Elasticidad del cuerpo de la cuerda vocal de- } \\
\text { recha }\end{array}$ & Sección 3.3.4.1 \\
\hline$K_{c l}$ & $\begin{array}{l}\text { Elasticidad de la cubierta de la cuerda vocal } \\
\text { izquierda }\end{array}$ & Sección 3.3.4.1 \\
\hline$K_{c r}$ & $\begin{array}{l}\text { Elasticidad de la cubierta de la cuerda vocal } \\
\text { derecha }\end{array}$ & Sección 3.3.4.1 \\
\hline $\mathrm{m}$ & Hombre (Male) & General al documento \\
\hline $\mathrm{m}$ & Pendiente & Sección 4.2 - RL \\
\hline $\mathrm{m}$ & Ciclo de fonación & Sección 3.3.4.2 \\
\hline$M_{b l}$ & Masa del cuerpo de la cuerda vocal izquierda & Sección 3.3.4.1 \\
\hline$M_{b r}$ & Masa del cuerpo de la cuerda vocal derecha & Sección 3.3.4.1 \\
\hline$M_{c l}$ & $\begin{array}{l}\text { Masa de la cubierta de la cuerda vocal iz- } \\
\text { quierda }\end{array}$ & Sección 3.3.4.1 \\
\hline$M_{c r}$ & $\begin{array}{l}\text { Masa de la cubierta de la cuerda vocal dere- } \\
\text { cha }\end{array}$ & Sección 3.3.4.1 \\
\hline $\mathrm{n}$ & $\mathrm{N}^{\circ}$ de muestras o Cardinal & General al documento \\
\hline $\mathrm{p}$ & Probabilidad condicionada & Sección 4.5.2 - Log-LH \\
\hline $\mathrm{P}$ & Coeficiente de correlación de Pearson & General al documento \\
\hline$r_{i}$ & Módulo de la función de transferencia & Sección 3.3.4.3 \\
\hline $\mathrm{R}$ & Rango & Sección 4.3.2 - MWW \\
\hline $\mathrm{R}$ & Restricción & Sección 4.5.1 - SVM \\
\hline$R_{b l}$ & $\begin{array}{l}\text { Resistencia del cuerpo de la cuerda vocal iz- } \\
\text { quierda }\end{array}$ & Sección 3.3.4.1 \\
\hline$R_{b r}$ & $\begin{array}{l}\text { Resistencia del cuerpo de la cuerda vocal de- } \\
\text { recha }\end{array}$ & Sección 3.3.4.1 \\
\hline$R_{c l}$ & $\begin{array}{l}\text { Resistencia de la cubierta de la cuerda vocal } \\
\text { izquierda }\end{array}$ & Sección 3.3.4.1 \\
\hline$R_{c r}$ & $\begin{array}{l}\text { Resistencia de la cubierta de la cuerda vocal } \\
\text { derecha }\end{array}$ & Sección 3.3.4.1 \\
\hline $\mathrm{s}$ & Componentes independientes & Sección 4.4 .2 - ICA \\
\hline $\mathrm{s}$ & Vectores de soporte & Sección 4.5.1 - SVM \\
\hline $\mathrm{S}$ & Matriz de covarianza & Sección 4.4.1 - PCA \\
\hline$S_{a}$ & Onda acústica media & Sección 3.3.4.1 \\
\hline$S_{b}$ & $\begin{array}{l}\text { Retroalimentación hacia atrás del filtro de } \\
\text { celosía }\end{array}$ & Sección 3.3.4.3 \\
\hline$S_{f}$ & $\begin{array}{l}\text { Retroalimentación hacia delante del filtro de } \\
\text { celosía }\end{array}$ & Sección 3.3.4.3 \\
\hline$S_{g}$ & Fuente glotal & Sección 3.3.4.1 \\
\hline$S_{r}$ & Señal residual & Sección 3.3.4.1 \\
\hline$S_{r}(\omega)$ & Densidad de potencia espectral & Sección 3.3.4.1 \\
\hline $\mathrm{U}$ & Prueba de U-Mann-Whitney-Wilcoxon & Sección 4.3.2 - MWW \\
\hline $\mathrm{V}$ & Vector unitario & Sección 4.4.1 - PCA \\
\hline
\end{tabular}




\begin{tabular}{|c|c|c|}
\hline Símbolo & Significado & Sección \\
\hline$V_{b l}$ & $\begin{array}{l}\text { Velocidad del cuerpo de la cuerda vocal iz- } \\
\text { quierda }\end{array}$ & Sección 3.3.4.1 \\
\hline$V_{b r}$ & $\begin{array}{l}\text { Velocidad del cuerpo de la cuerda vocal de- } \\
\text { recha }\end{array}$ & Sección 3.3.4.1 \\
\hline$V_{c l}$ & $\begin{array}{l}\text { Velocidad de la cubierta de la cuerda vocal } \\
\text { izquierda }\end{array}$ & Sección 3.3.4.1 \\
\hline$V_{c r}$ & $\begin{array}{l}\text { Velocidad de la cubierta de la cuerda vocal } \\
\text { derecha }\end{array}$ & Sección 3.3.4.1 \\
\hline $\mathrm{W}$ & Individuo & General a documento \\
\hline $\mathrm{W}$ & $\begin{array}{l}\text { Vector de pesos para el conjunto de entrena- } \\
\text { miento }\end{array}$ & Sección 4.5.1 - SVM \\
\hline $\mathrm{W}$ & $\begin{array}{l}\text { Suma de rangos para la prueba de U-Mann- } \\
\text { Whitney-Wilcoxon }\end{array}$ & Sección 4.3.2 - MWW \\
\hline $\mathrm{W}$ & Matriz inversa de los coeficientes de mezcla & Sección 4.4.2 - ICA \\
\hline $\mathrm{x}$ & Vector fila & General al documento \\
\hline $\bar{x}$ & Media de la población muestral & General al documento \\
\hline $\bar{x}$ & Vector de observaciones & General al documento \\
\hline $\mathrm{X}$ & Conjunto de datos & General al documento \\
\hline $\mathrm{y}$ & Vector fila o Conjunto de etiquetas de clase & Sección 4.5.1 - SVM \\
\hline $\mathrm{Y}$ & Variable dependiente & Sección 4.2 - RL \\
\hline $\mathrm{Z}$ & Parámetro & General al documento \\
\hline $\mathrm{Z}$ & Prueba de Kolmogorov-Smirnov & Sección 4.3.1 - KS \\
\hline $\mathrm{Z}$ & Subconjunto de parámetros & General al documento \\
\hline$\alpha$ & Vector de pesos para el kernel de clasificación & Sección 4.5.1 - SVM \\
\hline$\beta$ & Conjunto de parámetros para un hiperplano & Sección 4.2 - RL \\
\hline$\beta$ & Factor de corrección & Sección 3.3.4.2 \\
\hline$\epsilon$ & Error & Sección 4.2 - RL \\
\hline$\eta_{T}$ & Tasa de amplitud cuadrada media & Sección 3.3.4.3 \\
\hline$\Gamma$ & Modelo Gaussiano & Sección 4.5.2 - Log-LH \\
\hline$\lambda$ & Multiplicadores de Lagrange y Autovalores & Sección 4.4.1 - PCA \\
\hline$\lambda$ & Multiplicadores de Lagrange & Sección 4.5.1 - SVM \\
\hline$\lambda$ & Ratio de log-verosimilitud & Sección 4.5.2 - Log-LH \\
\hline$\mu$ & Media de la población & General al documento \\
\hline$\mu$ & Estimación de la masa de las cuerdas vocales & Sección 3.3.4.1 \\
\hline$\Phi$ & Opeador para un filtro adaptativo & Sección 3.3.4.2 \\
\hline$\varphi$ & Fase de la función de transferencia & Sección 3.3.4.3 \\
\hline$\rho$ & Coeficiente de correlación de Pearson & Sección 4.2 - Pearson \\
\hline$\rho$ & Orden del polinomio & Sección 4.5.1 - SVM \\
\hline$\rho^{2}$ & Coeficiente de determinación & $\begin{array}{l}\text { Sección } 4.2 \text { - Coef. De- } \\
\text { terminación }\end{array}$ \\
\hline$\sigma$ & Desviación típica de la población muestral & General al documento \\
\hline$\sigma$ & Ancho del kernel & Sección 4.5.1 - SVM \\
\hline$\sigma$ & $\begin{array}{l}\text { Estimación de la viscosidad de las cuerdas } \\
\text { vocales }\end{array}$ & Sección 3.3.4.1 \\
\hline
\end{tabular}

Lista de símbolos utilizados (continua en la página siguiente). 


\begin{tabular}{cll}
\hline Símbolo & Significado & Sección \\
\hline \hline$\vartheta$ & Ponderación ratios de log-verosimilitud & Sección 4.5.2 - Log-LH \\
$\xi$ & Estimación de la elasticidad de las cuerdas & Sección 3.3.4.1 \\
& vocales & \\
$\xi_{f}$ & Banda de amplitud del temblor oscilatorio & Sección 3.3.4.3 \\
$\xi_{n}$ & Banda de amplitud del temblor neurológico & Sección 3.3.4.3 \\
$\xi_{p}$ & Banda de amplitud del temblor fisiológico & Sección 3.3.4.3 \\
$\zeta$ & Vectores de polos verdaderos & Sección 3.3.4.3 \\
$\hat{\zeta}$ & Vectores de polos estimados & Sección 3.3.4.3 \\
\hline
\end{tabular}




\section{Apéndice B}

\section{TABLAS ESTADÍSTICA NO PARÁMETRICA}

\section{B.1. Kolmogorov-Smirnov}

\section{B.1.1. Primera Parte: Todos vs Todos}

\begin{tabular}{lcc}
\hline Parámetros & p-value & Hipótesis \\
\hline \hline 1. Absolute Pitch & 0,412374928833881 & 0 \\
\hline 2. Abs. Norm. Jitter & 0,938877238077869 & 0 \\
\hline 3. Abs. Norm. Ar. Shimmer & 0,402604001476323 & 0 \\
\hline 4. Abs. Norm. Min. Sharp. & 0,117441680742451 & 0 \\
\hline 5. Noise-Harm. Ratio (NHR) & 0,422283336023689 & 0 \\
\hline 6. Muc./AvAc. Energy (MAE) & 0,822428792938056 & 0 \\
\hline 7. MWC Cepstral 1 & 0,237910628794856 & 0 \\
\hline 8. MWC Cepstral 2 & $\mathbf{0 , 0 3 1 6 6 8 2 3 4 2 2 1 0 5 8 9}$ & $\mathbf{1}$ \\
\hline 9. MWC Cepstral 3 & 0,156735807307038 & 0 \\
\hline 10. MWC Cepstral 4 & 0,96046307890198 & 0 \\
\hline 11. MWC Cepstral 5 & 0,991252068029399 & 0 \\
\hline 12. MWC Cepstral 6 & 0,212011557138468 & 0 \\
\hline 13. MWC Cepstral 7 & 0,992801699204236 & 0 \\
\hline 14. MWC Cepstral 8 & 0,495239580709885 & 0 \\
\hline 15. MWC Cepstral 9 & 0,812144283266003 & 0 \\
\hline 16. MWC Cepstral 10 & 0,517124027113789 & 0 \\
\hline 17. MWC Cepstral 11 & 0,896137228071188 & 0 \\
\hline 18. MWC Cepstral 12 & 0,596446455711638 & 0 \\
\hline 19. MWC Cepstral 13 & 0,92597804050079 & 0 \\
\hline 20. MWC Cepstral 14 & 0,0960443778923452 & 0 \\
\hline 21. MW PSD 1st Max. ABS. & 0,724222860503365 & 0 \\
\hline 22. MW PSD 1st Min. rel. & 0,312834062008354 & 0 \\
\hline 23. MW PSD 2nd Max. rel. & 0,619649710026648 & 0 \\
\hline 24. MW PSD 2nd Min. rel. & 0,562012336484759 & 0 \\
\hline 25. MW PSD 3rd Max. rel. & 0,84236702542511 & 0 \\
\hline
\end{tabular}




\begin{tabular}{|c|c|c|}
\hline Parámetros & p-value & Hipótesis \\
\hline 26. MW PSD End Val. rel. & 0,231223385499451 & 0 \\
\hline 27. MW PSD 1st Max. Pos. ABS. & 0,999999976363525 & 0 \\
\hline 28. MW PSD 1st Min. Pos. rel. & 0,999490570771002 & 0 \\
\hline 29. MW PSD 2nd Max. Pos. rel. & 0,911712649397529 & 0 \\
\hline 30. MW PSD 2nd Min. Pos. rel. & 0,0993664746664638 & 0 \\
\hline 31. MW PSD 3rd Max. Pos. rel. & 0,0752930263434128 & 0 \\
\hline 32. MW PSD End Val. Pos. rel. & 0,442502106660109 & 0 \\
\hline 33. MW PSD 1st Min NSF & 0,422283336023689 & 0 \\
\hline 34. MW PSD 2nd Min NSF & 0,712741985466282 & 0 \\
\hline 35. Body Mass & 0,689603356149956 & 0 \\
\hline 36. Body Losses & 0,608029222381434 & 0 \\
\hline 37. Body Stiffness & 0,596446455711638 & 0 \\
\hline 38. Body Mass Unbalance & 0,791017352904981 & 0 \\
\hline 39. Body Losses Unbalance & 0,791017352904981 & 0 \\
\hline 40. Body Stiffness Unbalance & 0,758151962391695 & 0 \\
\hline 41. Cover Mass & 0,171959146536808 & 0 \\
\hline 42. Cover Losses & 0,861369240500843 & 0 \\
\hline 43. Cover Stiffness & 0,473787997841239 & 0 \\
\hline 44. Cover Mass Unbalance & 0,473787997841239 & 0 \\
\hline 45. Cover Losses Unbalance & 0,96046307890198 & 0 \\
\hline 46. Cover Stiffness Unbalance & 0,432326674465182 & 0 \\
\hline 47. Rel. Recov. 1 Time & 0,746941564787771 & 0 \\
\hline 48. Rel. Recov. 2 Time & 0,911712649397529 & 0 \\
\hline 49. Rel. Open 1 Time & 0,746941564787771 & 0 \\
\hline 50. Rel. Open 2 Time & 0,0928154571675318 & 0 \\
\hline 51. Rel. Max. Ampl. Time & 0,832507852188589 & 0 \\
\hline 52. Rel. Recov. 1 Ampl. & 0,266106967288028 & 0 \\
\hline 53. Rel. Recov. 2 Ampl. & 0,392972825812169 & 0 \\
\hline 54. Rel. Open 1 Ampl. & 0,338215903757601 & 0 \\
\hline 55. Rel. Open 2 Ampl. & 0,422283336023689 & 0 \\
\hline 56. Rel. Stop Flow Time & 0,304672788100135 & 0 \\
\hline 57. Rel. Start Flow Time & 0,452806493873204 & 0 \\
\hline 58. Rel. Closing Time & 0,812144283266003 & 0 \\
\hline 59. Val. Flow GAP & 0,998243593242398 & 0 \\
\hline 60. Val. Contact GAP & 0,13813488527099 & 0 \\
\hline 61. Val. Adduction GAP & 0,724222860503365 & 0 \\
\hline 62. Val. Permanent GAP & 0,84236702542511 & 0 \\
\hline 63. 1st. Order Cyc. Coeff. & 0,550666075115322 & 0 \\
\hline 64. 2nd. Order Cyc. Coeff. & 0,608029222381435 & 0 \\
\hline 65. 3rd. Order Cyc. Coeff. & 0,473787997841238 & 0 \\
\hline 66. PhysTremor Frequency (Hz) & 0,0701129304685203 & 0 \\
\hline 67. PhysTremor Est. Amplitude & 0,832507852188589 & 0 \\
\hline 68. NeurTremor Frequency $(\mathrm{Hz})$ & 0,0137324510970147 & 1 \\
\hline 69. NeurTremor Est. Amplitude & 0,822428792938056 & 0 \\
\hline
\end{tabular}




\begin{tabular}{lcc}
\hline Parámetros & p-value & Hipótesis \\
\hline \hline 70. FlutTremor Frequency (Hz) & 0,689603356149956 & 0 \\
\hline 71. FlutTremor Est. Amplitude & 0,584910420193116 & 0 \\
\hline 72. Global Tremor (rMSA) & 0,701197856710763 & 0 \\
\hline Tabla B.1: Resultados para la prueba de contraste de \\
Kolmogorov-Smirnov el conjunto masculino cuando en- \\
frentamos todas las muestras neutras frente a las mues- \\
tras de estrés, teniendo en cuenta un $\alpha=0,05$.
\end{tabular}


APÉNDICE B. TABLAS ESTADÍSTICA NO PARÁMETRICA

\begin{tabular}{|c|c|c|}
\hline Parámetros & p-value & Hipótesis \\
\hline 1. Absolute Pitch & 0,412374928833881 & $\begin{array}{ll}0 \\
\end{array}$ \\
\hline 2. Abs. Norm. Jitter & 0,938877238077869 & 0 \\
\hline 3. Abs. Norm. Ar. Shimmer & 0,402604001476323 & 0 \\
\hline 4. Abs. Norm. Min. Sharp. & 0,117441680742451 & 0 \\
\hline 5. Noise-Harm. Ratio (NHR) & 0,422283336023689 & 0 \\
\hline 6. Muc./AvAc. Energy (MAE) & 0,822428792938056 & 0 \\
\hline 7. MWC Cepstral 1 & 0,237910628794856 & 0 \\
\hline 8. MWC Cepstral 2 & 0,0316682342210589 & 1 \\
\hline 9. MWC Cepstral 3 & 0,156735807307038 & 0 \\
\hline 10. MWC Cepstral 4 & 0,96046307890198 & 0 \\
\hline 11. MWC Cepstral 5 & 0,991252068029399 & 0 \\
\hline 12. MWC Cepstral 6 & 0,212011557138468 & 0 \\
\hline 13. MWC Cepstral 7 & 0,992801699204236 & 0 \\
\hline 14. MWC Cepstral 8 & 0,495239580709885 & 0 \\
\hline 15. MWC Cepstral 9 & 0,812144283266003 & 0 \\
\hline 16. MWC Cepstral 10 & 0,517124027113789 & 0 \\
\hline 17. MWC Cepstral 11 & 0,896137228071188 & 0 \\
\hline 18. MWC Cepstral 12 & 0,596446455711638 & 0 \\
\hline 19. MWC Cepstral 13 & 0,92597804050079 & 0 \\
\hline 20. MWC Cepstral 14 & 0,0960443778923452 & 1 \\
\hline 21. MW PSD 1st Max. ABS. & 0,724222860503365 & 0 \\
\hline 22. MW PSD 1st Min. rel. & 0,312834062008354 & 0 \\
\hline 23. MW PSD 2nd Max. rel. & 0,619649710026648 & 0 \\
\hline 24. MW PSD 2nd Min. rel. & 0,562012336484759 & 0 \\
\hline 25. MW PSD 3rd Max. rel. & 0,84236702542511 & 0 \\
\hline 26. MW PSD End Val. rel. & 0,231223385499451 & 0 \\
\hline 27. MW PSD 1st Max. Pos. ABS. & 0,999999976363525 & 0 \\
\hline 28. MW PSD 1st Min. Pos. rel. & 0,999490570771002 & 0 \\
\hline 29. MW PSD 2nd Max. Pos. rel. & 0,911712649397529 & 0 \\
\hline 30. MW PSD 2nd Min. Pos. rel. & 0,0993664746664638 & 1 \\
\hline 31. MW PSD 3rd Max. Pos. rel. & 0,0752930263434128 & 1 \\
\hline 32. MW PSD End Val. Pos. rel. & 0,442502106660109 & 0 \\
\hline 33. MW PSD 1st Min NSF & 0,422283336023689 & 0 \\
\hline 34. MW PSD 2nd Min NSF & 0,712741985466282 & 0 \\
\hline 35. Body Mass & 0,689603356149956 & 0 \\
\hline 36. Body Losses & 0,608029222381434 & 0 \\
\hline 37. Body Stiffness & 0,596446455711638 & 0 \\
\hline 38. Body Mass Unbalance & 0,791017352904981 & 0 \\
\hline 39. Body Losses Unbalance & 0,791017352904981 & 0 \\
\hline 40. Body Stiffness Unbalance & 0,758151962391695 & 0 \\
\hline 41. Cover Mass & 0,171959146536808 & 0 \\
\hline 42. Cover Losses & 0,861369240500843 & 0 \\
\hline 43. Cover Stiffness & 0,473787997841239 & 0 \\
\hline 44. Cover Mass Unbalance & 0,473787997841239 & 0 \\
\hline
\end{tabular}




\begin{tabular}{lcc}
\hline Parámetros & p-value & Hipótesis \\
\hline \hline 45. Cover Losses Unbalance & 0,96046307890198 & 0 \\
\hline 46. Cover Stiffness Unbalance & 0,432326674465182 & 0 \\
\hline 47. Rel. Recov. 1 Time & 0,746941564787771 & 0 \\
\hline 48. Rel. Recov. 2 Time & 0,911712649397529 & 0 \\
\hline 49. Rel. Open 1 Time & 0,746941564787771 & 0 \\
\hline 50. Rel. Open 2 Time & $\mathbf{0 , 0 9 2 8 1 5 4 5 7 1 6 7 5 3 1 8}$ & $\mathbf{1}$ \\
\hline 51. Rel. Max. Ampl. Time & 0,832507852188589 & 0 \\
\hline 52. Rel. Recov. 1 Ampl. & 0,266106967288028 & 0 \\
\hline 53. Rel. Recov. 2 Ampl. & 0,392972825812169 & 0 \\
\hline 54. Rel. Open 1 Ampl. & 0,338215903757601 & 0 \\
\hline 55. Rel. Open 2 Ampl. & 0,422283336023689 & 0 \\
\hline 56. Rel. Stop Flow Time & 0,304672788100135 & 0 \\
\hline 57. Rel. Start Flow Time & 0,452806493873204 & 0 \\
\hline 58. Rel. Closing Time & 0,812144283266003 & 0 \\
\hline 59. Val. Flow GAP & 0,998243593242398 & 0 \\
\hline 60. Val. Contact GAP & 0,13813488527099 & 0 \\
\hline 61. Val. Adduction GAP & 0,724222860503365 & 0 \\
\hline 62. Val. Permanent GAP & 0,84236702542511 & 0 \\
\hline 63. 1st. Order Cyc. Coeff. & 0,550666075115322 & 0 \\
\hline 64. 2nd. Order Cyc. Coeff. & 0,608029222381435 & 0 \\
\hline 65. 3rd. Order Cyc. Coeff. & 0,473787997841238 & 0 \\
\hline 66. PhysTremor Frequency (Hz) & $\mathbf{0 , 0 7 0 1 1 2 9 3 0 4 6 8 5 2 0 3}$ & $\mathbf{1}$ \\
\hline 67. PhysTremor Est. Amplitude & 0,832507852188589 & 0 \\
\hline 68. NeurTremor Frequency $\mathbf{( H z ) ~}$ & $\mathbf{0 , 0 1 3 7 3 2 4 5 1 0 9 7 0 1 4 7}$ & $\mathbf{1}$ \\
\hline 69. NeurTremor Est. Amplitude & 0,822428792938056 & 0 \\
\hline 70. FlutTremor Frequency (Hz) & 0,689603356149956 & 0 \\
\hline 71. FlutTremor Est. Amplitude & 0,584910420193116 & 0 \\
\hline 72. Global Tremor (rMSA) & 0,701197856710763 & 0 \\
\hline
\end{tabular}

Tabla B.2: Resultados para la prueba de contraste de Kolmogorov-Smirnov el conjunto masculino cuando enfrentamos todas las muestras neutras frente a las muestras de estrés, teniendo en cuenta un $\alpha=0,1$. 
APÉNDICE B. TABLAS ESTADÍSTICA NO PARÁMETRICA

\begin{tabular}{|c|c|c|}
\hline Parámetros & p-value & Hipótesis \\
\hline 1. Absolute Pitch & 0,0539481795926262 & 0 \\
\hline 2. Abs. Norm. Jitter & 0,0196851092149528 & 1 \\
\hline 3. Abs. Norm. Ar. Shimmer & 0,00493811840155943 & 1 \\
\hline 4. Abs. Norm. Min. Sharp. & 0,00624796179809596 & 1 \\
\hline 5. Noise-Harm. Ratio (NHR) & 0,0800078690070898 & 0 \\
\hline 6. Muc./AvAc. Energy (MAE) & 0,0624253886312889 & 0 \\
\hline 7. MWC Cepstral 1 & 0,485908854606239 & 0 \\
\hline 8. MWC Cepstral 2 & 0,471819629713465 & 0 \\
\hline 9. MWC Cepstral 3 & 0,919610804305143 & 0 \\
\hline 10. MWC Cepstral 4 & 0,059481038701854 & 0 \\
\hline 11. MWC Cepstral 5 & 0,291382281752326 & 0 \\
\hline 12. MWC Cepstral 6 & 0,318077231922812 & 0 \\
\hline 13. MWC Cepstral 7 & 0,212648852231496 & 0 \\
\hline 14. MWC Cepstral 8 & 0,0011099585609045 & 1 \\
\hline 15. MWC Cepstral 9 & 0,559053654139905 & 0 \\
\hline 16. MWC Cepstral 10 & 0,176362372000169 & 0 \\
\hline 17. MWC Cepstral 11 & 0,60075505261472 & 0 \\
\hline 18. MWC Cepstral 12 & 0,581704319346424 & 0 \\
\hline 19. MWC Cepstral 13 & 0,043096960989083 & 1 \\
\hline 20. MWC Cepstral 14 & 0,803830365473231 & 0 \\
\hline 21. MW PSD 1st Max. ABS. & 0,315334247216789 & 0 \\
\hline 22. MW PSD 1st Min. rel. & 0,930880332750571 & 0 \\
\hline 23. MW PSD 2nd Max. rel. & 0,742325585593484 & 0 \\
\hline 24. MW PSD 2nd Min. rel. & 0,734837621038022 & 0 \\
\hline 25. MW PSD 3rd Max. rel. & 0,457936953447239 & 0 \\
\hline 26. MW PSD End Val. rel. & 0,218867695360704 & 0 \\
\hline 27. MW PSD 1st Max. Pos. ABS. & 0,999883894770067 & 0 \\
\hline 28. MW PSD 1st Min. Pos. rel. & 0,600755052614721 & 0 \\
\hline 29. MW PSD 2nd Max. Pos. rel. & 0,424191929629234 & 0 \\
\hline 30. MW PSD 2nd Min. Pos. rel. & 0,820960946200963 & 0 \\
\hline 31. MW PSD 3rd Max. Pos. rel. & 0,847189792941265 & 0 \\
\hline 32. MW PSD End Val. Pos. rel. & 0,0971481278961254 & 0 \\
\hline 33. MW PSD 1st Min NSF & 0,979598904491228 & 0 \\
\hline 34. MW PSD 2nd Min NSF & 0,0763684978341432 & 0 \\
\hline 35. Body Mass & 0,0258843537861577 & 1 \\
\hline 36. Body Losses & 0,627615402658131 & 0 \\
\hline 37. Body Stiffness & 0,0539481795926262 & 0 \\
\hline 38. Body Mass Unbalance & 0,361174156901058 & 0 \\
\hline 39. Body Losses Unbalance & 0,178142292065862 & 0 \\
\hline 40. Body Stiffness Unbalance & 0,146661550809416 & 0 \\
\hline 41. Cover Mass & 0,00569000542539737 & 1 \\
\hline 42. Cover Losses & 0,0877268120212088 & 0 \\
\hline 43. Cover Stiffness & 0,764516285653019 & 0 \\
\hline 44. Cover Mass Unbalance & 0,60075505261472 & 0 \\
\hline
\end{tabular}




\begin{tabular}{lcc}
\hline Parámetros & p-value & Hipótesis \\
\hline \hline 45. Cover Losses Unbalance & 0,256739880972499 & 0 \\
\hline 46. Cover Stiffness Unbalance & 0,712156158277966 & 0 \\
\hline 47. Rel. Recov. 1 Time & 0,420896280953795 & 0 \\
\hline 48. Rel. Recov. 2 Time & 0,715956236154215 & 0 \\
\hline 49. Rel. Open 1 Time & 0,379426624753849 & 0 \\
\hline 50. Rel. Open 2 Time & 0,500194349425622 & 0 \\
\hline 51. Rel. Max. Ampl. Time & 0,507407183934155 & 0 \\
\hline 52. Rel. Recov. 1 Ampl. & 0,608410723969368 & 0 \\
\hline 53. Rel. Recov. 2 Ampl. & 0,696892275732788 & 0 \\
\hline 54. Rel. Open 1 Ampl. & 0,156079781551516 & 0 \\
\hline 55. Rel. Open 2 Ampl. & 0,0949846437216224 & 0 \\
\hline 56. Rel. Stop Flow Time & 0,635316195270283 & 0 \\
\hline 57. Rel. Start Flow Time & 0,0711727006533386 & 0 \\
\hline 58. Rel. Closing Time & 0,167672012924933 & 0 \\
\hline 59. Val. Flow GAP & 0,346403455045828 & 0 \\
\hline 60. Val. Contact GAP & 0,143625722505909 & 0 \\
\hline 61. Val. Adduction GAP & 0,654589899549656 & 0 \\
\hline 62. Val. Permanent GAP & 0,912407459819989 & 0 \\
\hline 63. 1st. Order Cyc. Coeff. & 0,992187550909688 & 0 \\
\hline 64. 2nd. Order Cyc. Coeff. & 0,343497711390892 & 0 \\
\hline 65. 3rd. Order Cyc. Coeff. & 0,21470661076936 & 0 \\
\hline 66. PhysTremor Frequency (Hz) & 0,218867695360704 & 0 \\
\hline 67. PhysTremor Est. Amplitude & 0,810744922354288 & 0 \\
\hline 68. NeurTremor Frequency (Hz) & 0,169382396005117 & 0 \\
\hline 69. NeurTremor Est. Amplitude & 0,912407459819989 & 0 \\
\hline 70. FlutTremor Frequency (Hz) & 0,38252404374975 & 0 \\
\hline 71. FlutTremor Est. Amplitude & 0,532993462741138 & 0 \\
\hline 72. Global Tremor (rMSA) & 0,734837621038023 & 0 \\
\hline
\end{tabular}

Tabla B.3: Resultados para la prueba de contraste de Kolmogorov-Smirnov el conjunto femenino cuando enfrentamos todas las muestras neutras frente a las muestras de estrés, teniendo en cuenta un $\alpha=0,05$. 
APÉNDICE B. TABLAS ESTADÍSTICA NO PARÁMETRICA

\begin{tabular}{|c|c|c|}
\hline Parámetros & $\mathrm{p}$-value & Hipótesis \\
\hline 1. Absolute Pitch & 0,0539481795926262 & 1 \\
\hline 2. Abs. Norm. Jitter & 0,0196851092149528 & 1 \\
\hline 3. Abs. Norm. Ar. Shimmer & 0,00493811840155943 & 1 \\
\hline 4. Abs. Norm. Min. Sharp. & 0,00624796179809596 & 1 \\
\hline 5. Noise-Harm. Ratio (NHR) & 0,0800078690070898 & 1 \\
\hline 6. Muc./AvAc. Energy (MAE) & 0,0624253886312889 & 1 \\
\hline 7. MWC Cepstral 1 & 0,485908854606239 & 0 \\
\hline 8. MWC Cepstral 2 & 0,471819629713465 & 0 \\
\hline 9. MWC Cepstral 3 & 0,919610804305143 & 0 \\
\hline 10. MWC Cepstral 4 & 0,059481038701854 & 1 \\
\hline 11. MWC Cepstral 5 & 0,291382281752326 & 0 \\
\hline 12. MWC Cepstral 6 & 0,318077231922812 & 0 \\
\hline 13. MWC Cepstral 7 & 0,212648852231496 & 0 \\
\hline 14. MWC Cepstral 8 & 0,0011099585609045 & 1 \\
\hline 15. MWC Cepstral 9 & 0,559053654139905 & 0 \\
\hline 16. MWC Cepstral 10 & 0,176362372000169 & 0 \\
\hline 17. MWC Cepstral 11 & 0,60075505261472 & 0 \\
\hline 18. MWC Cepstral 12 & 0,581704319346424 & 0 \\
\hline 19. MWC Cepstral 13 & 0,043096960989083 & $\overline{1}$ \\
\hline 20. MWC Cepstral 14 & 0,803830365473231 & 0 \\
\hline 21. MW PSD 1st Max. ABS. & 0,315334247216789 & 0 \\
\hline 22. MW PSD 1st Min. rel. & 0,930880332750571 & 0 \\
\hline 23. MW PSD 2nd Max. rel. & 0,742325585593484 & 0 \\
\hline 24. MW PSD 2nd Min. rel. & 0,734837621038022 & 0 \\
\hline 25. MW PSD 3rd Max. rel. & 0,457936953447239 & 0 \\
\hline 26. MW PSD End Val. rel. & 0,218867695360704 & 0 \\
\hline 27. MW PSD 1st Max. Pos. ABS. & 0,999883894770067 & 0 \\
\hline 28. MW PSD 1st Min. Pos. rel. & 0,600755052614721 & 0 \\
\hline 29. MW PSD 2nd Max. Pos. rel. & 0,424191929629234 & 0 \\
\hline 30. MW PSD 2nd Min. Pos. rel. & 0,820960946200963 & 0 \\
\hline 31. MW PSD 3rd Max. Pos. rel. & 0,847189792941265 & 0 \\
\hline 32. MW PSD End Val. Pos. rel. & 0,0971481278961254 & 1 \\
\hline 33. MW PSD 1st Min NSF & 0,979598904491228 & 0 \\
\hline 34. MW PSD 2nd Min NSF & 0,0763684978341432 & 1 \\
\hline 35. Body Mass & 0,0258843537861577 & 1 \\
\hline 36. Body Losses & 0,627615402658131 & 0 \\
\hline 37. Body Stiffness & 0,0539481795926262 & 1 \\
\hline 38. Body Mass Unbalance & 0,361174156901058 & 0 \\
\hline 39. Body Losses Unbalance & 0,178142292065862 & 0 \\
\hline 40. Body Stiffness Unbalance & 0,146661550809416 & 0 \\
\hline 41. Cover Mass & 0,00569000542539737 & 1 \\
\hline 42. Cover Losses & 0,0877268120212088 & 1 \\
\hline 43. Cover Stiffness & 0,764516285653019 & 0 \\
\hline 44. Cover Mass Unbalance & 0,60075505261472 & 0 \\
\hline
\end{tabular}




\begin{tabular}{lcc}
\hline Parámetros & p-value & Hipótesis \\
\hline \hline 45. Cover Losses Unbalance & 0,256739880972499 & 0 \\
\hline 46. Cover Stiffness Unbalance & 0,712156158277966 & 0 \\
\hline 47. Rel. Recov. 1 Time & 0,420896280953795 & 0 \\
\hline 48. Rel. Recov. 2 Time & 0,715956236154215 & 0 \\
\hline 49. Rel. Open 1 Time & 0,379426624753849 & 0 \\
\hline 50. Rel. Open 2 Time & 0,500194349425622 & 0 \\
\hline 51. Rel. Max. Ampl. Time & 0,507407183934155 & 0 \\
\hline 52. Rel. Recov. 1 Ampl. & 0,608410723969368 & 0 \\
\hline 53. Rel. Recov. 2 Ampl. & 0,696892275732788 & 0 \\
\hline 54. Rel. Open 1 Ampl. & 0,156079781551516 & 0 \\
\hline 55. Rel. Open 2 Ampl. & $\mathbf{0 , 0 9 4 9 8 4 6 4 3 7 2 1 6 2 2 4}$ & $\mathbf{1}$ \\
\hline 56. Rel. Stop Flow Time & 0,635316195270283 & 0 \\
\hline 57. Rel. Start Flow Time & $\mathbf{0 , 0 7 1 1 7 2 7 0 0 6 5 3 3 3 8 6}$ & $\mathbf{1}$ \\
\hline 58. Rel. Closing Time & 0,167672012924933 & 0 \\
\hline 59. Val. Flow GAP & 0,346403455045828 & 0 \\
\hline 60. Val. Contact GAP & 0,143625722505909 & 0 \\
\hline 61. Val. Adduction GAP & 0,654589899549656 & 0 \\
\hline 62. Val. Permanent GAP & 0,912407459819989 & 0 \\
\hline 63. 1st. Order Cyc. Coeff. & 0,992187550909688 & 0 \\
\hline 64. 2nd. Order Cyc. Coeff. & 0,343497711390892 & 0 \\
\hline 65. 3rd. Order Cyc. Coeff. & 0,21470661076936 & 0 \\
\hline 66. PhysTremor Frequency (Hz) & 0,218867695360704 & 0 \\
\hline 67. PhysTremor Est. Amplitude & 0,810744922354288 & 0 \\
\hline 68. NeurTremor Frequency (Hz) & 0,169382396005117 & 0 \\
\hline 69. NeurTremor Est. Amplitude & 0,912407459819989 & 0 \\
\hline 70. FlutTremor Frequency (Hz) & 0,38252404374975 & 0 \\
\hline 71. FlutTremor Est. Amplitude & 0,532993462741138 & 0 \\
\hline 72. Global Tremor (rMSA) & 0,734837621038023 & 0 \\
\hline
\end{tabular}

Tabla B.4: Resultados para la prueba de contraste de Kolmogorov-Smirnov para el conjunto femenino cuando enfrentamos todas las muestras neutras frente a las muestras de estrés, teniendo en cuenta un $\alpha=0,1$. 


\section{B.1.2. Segunda Parte: Pair-Wise}

\begin{tabular}{|c|c|}
\hline Parámetros & Veces seleccionado \\
\hline 23. MW PSD 2nd Max. rel. & 3 \\
\hline 25. MW PSD 3rd Max. rel. & 3 \\
\hline 30. MW PSD 2nd Min. Pos. rel. & 3 \\
\hline 7. MWC Cepstral 1 & 3 \\
\hline 31. MW PSD 3rd Max. Pos. rel. & 2 \\
\hline 34. MW PSD 2nd Min NSF & 2 \\
\hline 42. Cover Losses & 2 \\
\hline 44. Cover Mass Unbalance & 2 \\
\hline 50. Rel. Open 2 Time & 2 \\
\hline 55. Rel. Open 2 Ampl. & 2 \\
\hline 58. Rel. Closing Time & 2 \\
\hline 9. MWC Cepstral 3 & 2 \\
\hline 1. Absolute Pitch & 1 \\
\hline 10. MWC Cepstral 4 & 1 \\
\hline 11. MWC Cepstral 5 & 1 \\
\hline 13. MWC Cepstral 7 & 1 \\
\hline 15. MWC Cepstral 9 & 1 \\
\hline 18. MWC Cepstral 12 & 1 \\
\hline 19. MWC Cepstral 13 & 1 \\
\hline 20. MWC Cepstral 14 & 1 \\
\hline 22. MW PSD 1st Min. rel. & 1 \\
\hline 24. MW PSD 2nd Min. rel. & 1 \\
\hline 26. MW PSD End Val. rel. & 1 \\
\hline 28. MW PSD 1st Min. Pos. rel. & 1 \\
\hline 32. MW PSD End Val. Pos. rel. & 1 \\
\hline 33. MW PSD 1st Min NSF & 1 \\
\hline 35. Body Mass & 1 \\
\hline 37. Body Stiffness & 1 \\
\hline 4. Abs. Norm. Min. Sharp. & 1 \\
\hline 41. Cover Mass & 1 \\
\hline 45. Cover Losses Unbalance & 1 \\
\hline 46. Cover Stiffness Unbalance & 1 \\
\hline 47. Rel. Recov. 1 Time & 1 \\
\hline 48. Rel. Recov. 2 Time & 1 \\
\hline 51. Rel. Max. Ampl. Time & 1 \\
\hline 52. Rel. Recov. 1 Ampl. & 1 \\
\hline 54. Rel. Open 1 Ampl. & 1 \\
\hline 56. Rel. Stop Flow Time & 1 \\
\hline 57. Rel. Start Flow Time & 1 \\
\hline 59. Val. Flow GAP & 1 \\
\hline 6. Muc./AvAc. Energy (MAE) & 1 \\
\hline 61. Val. Adduction GAP & 1 \\
\hline
\end{tabular}




\begin{tabular}{lc}
\hline Parámetros & Veces seleccionado \\
\hline \hline 64. 2nd. Order Cyc. Coeff. & 1 \\
\hline 66. PhysTremor Frequency $(\mathrm{Hz})$ & 1 \\
\hline 68. NeurTremor Frequency $(\mathrm{Hz})$ & 1 \\
\hline 70. FlutTremor Frequency $(\mathrm{Hz})$ & 1 \\
\hline 71. FlutTremor Est. Amplitude & 1
\end{tabular}

Tabla B.5: Resultados para la prueba de contraste de Kolmogorov-Smirnov para el conjunto masculino cuando realizamos un estudio de tipo pair-wise, teniendo en cuenta un $\alpha=0,05$.

\begin{tabular}{ll}
\hline Parámetros & Veces seleccionado \\
\hline \hline 25. MW PSD 3rd Max. rel. & 5 \\
\hline 7. MWC Cepstral 1 & 5 \\
\hline 32. MW PSD End Val. Pos. rel. & 4 \\
\hline 42. Cover Losses & 4 \\
\hline 43. Cover Stiffness & 4 \\
\hline 45. Cover Losses Unbalance & 4 \\
\hline 47. Rel. Recov. 1 Time & 4 \\
\hline 55. Rel. Open 2 Ampl. & 4 \\
\hline 9. MWC Cepstral 3 & 4 \\
\hline 1. Absolute Pitch & 3 \\
\hline 12. MWC Cepstral 6 & 3 \\
\hline 15. MWC Cepstral 9 & 3 \\
\hline 18. MWC Cepstral 12 & 3 \\
\hline 20. MWC Cepstral 14 & 3 \\
\hline 23. MW PSD 2nd Max. rel. & 3 \\
\hline 30. MW PSD 2nd Min. Pos. rel. & 3 \\
\hline 33. MW PSD 1st Min NSF & 3 \\
\hline 35. Body Mass & 3 \\
\hline 37. Body Stiffness & 3 \\
\hline 44. Cover Mass Unbalance & 3 \\
\hline 50. Rel. Open 2 Time & 3 \\
\hline 54. Rel. Open 1 Ampl. & 3 \\
\hline 58. Rel. Closing Time & 3 \\
\hline 59. Val. Flow GAP & 3 \\
\hline 6. Muc./AvAc. Energy (MAE) & 3 \\
\hline 61. Val. Adduction GAP & 3 \\
\hline 66. PhysTremor Frequency (Hz) & 2 \\
\hline 68. NeurTremor Frequency (Hz) & 3 \\
\hline 72. Global Tremor (rMSA) & 3 \\
\hline 10. MWC Cepstral 4 & 3 \\
\hline 11. MWC Cepstral 5 & 3 \\
\hline 14. MWC Cepstral 8 & 3 \\
\hline
\end{tabular}




\begin{tabular}{lc}
\hline Parámetros & Veces seleccionado \\
\hline \hline 21. MW PSD 1st Max. ABS. & 2 \\
\hline 24. MW PSD 2nd Min. rel. & 2 \\
\hline 26. MW PSD End Val. rel. & 2 \\
\hline 31. MW PSD 3rd Max. Pos. rel. & 2 \\
\hline 34. MW PSD 2nd Min NSF & 2 \\
\hline 36. Body Losses & 2 \\
\hline 41. Cover Mass & 2 \\
\hline 48. Rel. Recov. 2 Time & 2 \\
\hline 49. Rel. Open 1 Time & 2 \\
\hline 56. Rel. Stop Flow Time & 2 \\
\hline 57. Rel. Start Flow Time & 2 \\
\hline 60. Val. Contact GAP & 2 \\
\hline 69. NeurTremor Est. Amplitude & 2 \\
\hline 70. FlutTremor Frequency (Hz) & 2 \\
\hline 71. FlutTremor Est. Amplitude & 2 \\
\hline 8. MWC Cepstral 2 & 2 \\
\hline 13. MWC Cepstral 7 & 1 \\
\hline 16. MWC Cepstral 10 & 1 \\
\hline 17. MWC Cepstral 11 & 1 \\
\hline 19. MWC Cepstral 13 & 1 \\
\hline 22. MW PSD 1st Min. rel. & 1 \\
\hline 28. MW PSD 1st Min. Pos. rel. & 1 \\
\hline 29. MW PSD 2nd Max. Pos. rel. & 1 \\
\hline 38. Body Mass Unbalance & 1 \\
\hline 4. Abs. Norm. Min. Sharp. & 1 \\
\hline 40. Body Stiffness Unbalance & 1 \\
\hline 46. Cover Stiffness Unbalance & 1 \\
\hline 5. Noise-Harm. Ratio (NHR) & 1 \\
\hline 51. Rel. Max. Ampl. Time & 1 \\
\hline 52. Rel. Recov. 1 Ampl. & 1 \\
\hline 63. 1st. Order Cyc. Coeff. & 1 \\
\hline 64. 2nd. Order Cyc. Coeff. & 1 \\
\hline 67. PhysTremor Est. Amplitude & 1 \\
\hline Ta. B.6. Restos para & \\
\hline
\end{tabular}

Tabla B.6: Resultados para la prueba de contraste de Kolmogorov-Smirnov para el conjunto masculino cuando realizamos un estudio de tipo pair-wise, teniendo en cuenta un $\alpha=0,1$.

\begin{tabular}{lc}
\hline Parámetros & Veces seleccionado \\
\hline \hline 50. Rel. Open 2 Time & 4 \\
\hline 52. Rel. Recov. 1 Ampl. & 4 \\
\hline 18. MWC Cepstral 12 & 3 \\
\hline 21. MW PSD 1st Max. ABS. & 3 \\
\hline
\end{tabular}




\begin{tabular}{|c|c|}
\hline Parámetros & Veces seleccionado \\
\hline 56. Rel. Stop Flow Time & "3 \\
\hline 58. Rel. Closing Time & 3 \\
\hline 8. MWC Cepstral 2 & 3 \\
\hline 1. Absolute Pitch & 2 \\
\hline 3. Abs. Norm. Ar. Shimmer & 2 \\
\hline 42. Cover Losses & 2 \\
\hline 49. Rel. Open 1 Time & 2 \\
\hline 54. Rel. Open 1 Ampl. & 2 \\
\hline 55. Rel. Open 2 Ampl. & 2 \\
\hline 6. Muc./AvAc. Energy (MAE) & 2 \\
\hline 64. 2nd. Order Cyc. Coeff. & 2 \\
\hline 10. MWC Cepstral 4 & 1 \\
\hline 17. MWC Cepstral 11 & 1 \\
\hline 20. MWC Cepstral 14 & 1 \\
\hline 24. MW PSD 2nd Min. rel. & 1 \\
\hline 30. MW PSD 2nd Min. Pos. rel. & 1 \\
\hline 32. MW PSD End Val. Pos. rel. & 1 \\
\hline 35. Body Mass & 1 \\
\hline 4. Abs. Norm. Min. Sharp. & 1 \\
\hline 41. Cover Mass & 1 \\
\hline 43. Cover Stiffness & 1 \\
\hline 44. Cover Mass Unbalance & 1 \\
\hline 45. Cover Losses Unbalance & 1 \\
\hline 47. Rel. Recov. 1 Time & 1 \\
\hline 48. Rel. Recov. 2 Time & 1 \\
\hline 53. Rel. Recov. 2 Ampl. & 1 \\
\hline 57. Rel. Start Flow Time & 1 \\
\hline 59. Val. Flow GAP & 1 \\
\hline 60. Val. Contact GAP & 1 \\
\hline 65. 3rd. Order Cyc. Coeff. & 1 \\
\hline 9. MWC Cepstral 3 & 1 \\
\hline
\end{tabular}

Tabla B.7: Resultados para la prueba de contraste de Kolmogorov-Smirnov para el conjunto femenino cuando realizamos un estudio de tipo pair-wise, teniendo en cuenta un $\alpha=0,05$.

\begin{tabular}{lc}
\hline Parámetros & Veces seleccionado \\
\hline \hline 21. MW PSD 1st Max. ABS. & 5 \\
\hline 56. Rel. Stop Flow Time & 5 \\
\hline 8. MWC Cepstral 2 & 5 \\
\hline 18. MWC Cepstral 12 & 4 \\
\hline 50. Rel. Open 2 Time & 4 \\
\hline 52. Rel. Recov. 1 Ampl. & 4 \\
\hline
\end{tabular}




\begin{tabular}{ll}
\hline Parámetros & Veces seleccionado \\
\hline \hline 6. Muc./AvAc. Energy (MAE) & 4 \\
\hline 1. Absolute Pitch & 3 \\
\hline 10. MWC Cepstral 4 & 3 \\
\hline 25. MW PSD 3rd Max. rel. & 3 \\
\hline 3. Abs. Norm. Ar. Shimmer & 3 \\
\hline 35. Body Mass & 3 \\
\hline 41. Cover Mass & 3 \\
\hline 42. Cover Losses & 3 \\
\hline 43. Cover Stiffness & 3 \\
\hline 53. Rel. Recov. 2 Ampl. & 3 \\
\hline 54. Rel. Open 1 Ampl. & 3 \\
\hline 55. Rel. Open 2 Ampl. & 3 \\
\hline 57. Rel. Start Flow Time & 3 \\
\hline 58. Rel. Closing Time & 3 \\
\hline 59. Val. Flow GAP & 3 \\
\hline 16. MWC Cepstral 10 & 2 \\
\hline 20. MWC Cepstral 14 & 2 \\
\hline 23. MW PSD 2nd Max. rel. & 2 \\
\hline 26. MW PSD End Val. rel. & 2 \\
\hline 29. MW PSD 2nd Max. Pos. rel. & 2 \\
\hline 30. MW PSD 2nd Min. Pos. rel. & 2 \\
\hline 31. MW PSD 3rd Max. Pos. rel. & 2 \\
\hline 32. MW PSD End Val. Pos. rel. & 2 \\
\hline 4. Abs. Norm. Min. Sharp. & 2 \\
\hline 47. Rel. Recov. 1 Time & 2 \\
\hline 49. Rel. Open 1 Time & 2 \\
\hline 5. Noise-Harm. Ratio (NHR) & 2 \\
\hline 64. 2nd. Order Cyc. Coeff. & 2 \\
\hline 65. 3rd. Order Cyc. Coeff. & 2 \\
\hline 9. MWC Cepstral 3 & 2 \\
\hline 13. MWC Cepstral 7 & 1 \\
\hline 14. MWC Cepstral 8 & 1 \\
\hline 17. MWC Cepstral 11 & 1 \\
\hline 19. MWC Cepstral 13 & 1 \\
\hline 24. MW PSD 2nd Min. rel. & 1 \\
\hline 28. MW PSD 1st Min. Pos. rel. & 1 \\
\hline 33. MW PSD 1st Min NSF & 1 \\
\hline 34. MW PSD 2nd Min NSF & 1 \\
\hline 36. Body Losses & 1 \\
\hline 37. Body Stiffness & 1 \\
\hline 38. Body Mass Unbalance & 1 \\
\hline 44. Cover Mass Unbalance & 1 \\
\hline 45. Cover Losses Unbalance & \\
\hline 46. Cover Stiffness Unbalance & \\
\hline
\end{tabular}




\begin{tabular}{ll}
\hline Parámetros & Veces seleccionado \\
\hline \hline 48. Rel. Recov. 2 Time & 1 \\
\hline 60. Val. Contact GAP & 1 \\
\hline 61. Val. Adduction GAP & 1 \\
\hline 62. Val. Permanent GAP & 1 \\
\hline 67. PhysTremor Est. Amplitude & 1 \\
\hline 68. NeurTremor Frequency (Hz) & 1 \\
\hline 69. NeurTremor Est. Amplitude & 1 \\
\hline 7. MWC Cepstral 1 & 1 \\
\hline 71. FlutTremor Est. Amplitude & 1 \\
\hline 72. Global Tremor (rMSA) & 1 \\
\hline
\end{tabular}

Tabla B.8: Resultados para la prueba de contraste de Kolmogorov-Smirnov para el conjunto femenino cuando realizamos un estudio de tipo pair-wise, teniendo en cuenta un $\alpha=0,1$.

\section{B.2. Mann-Whitney}

\section{B.2.1. Primera Parte: Todos vs Todos}

\begin{tabular}{lcc}
\hline Parámetros & p-value & Hipótesis \\
\hline \hline 1. Absolute Pitch & 0,529231540790179 & 0 \\
\hline 2. Abs. Norm. Jitter & 0,966132024643598 & 0 \\
\hline 3. Abs. Norm. Ar. Shimmer & 0,302719429015655 & 0 \\
\hline 4. Abs. Norm. Min. Sharp. & 0,114395987319956 & 0 \\
\hline 5. Noise-Harm. Ratio (NHR) & 0,306355505238217 & 0 \\
\hline 6. Muc./AvAc. Energy (MAE) & 0,972287086295792 & 0 \\
\hline 7. MWC Cepstral 1 & $\mathbf{0 , 0 4 1 1 5 7 6 4 0 7 2 0 4 7 6 8}$ & $\mathbf{1}$ \\
\hline 8. MWC Cepstral 2 & 0,0655895351362979 & 0 \\
\hline 9. MWC Cepstral 3 & 0,133216250331899 & 0 \\
\hline 10. MWC Cepstral 4 & 0,947680406316795 & 0 \\
\hline 11. MWC Cepstral 5 & 0,831873124080879 & 0 \\
\hline 12. MWC Cepstral 6 & 0,690940033183309 & 0 \\
\hline 13. MWC Cepstral 7 & 0,708092081806653 & 0 \\
\hline 14. MWC Cepstral 8 & 0,291984027075011 & 0 \\
\hline 15. MWC Cepstral 9 & 0,613095628976654 & 0 \\
\hline 16. MWC Cepstral 10 & 0,218196084972266 & 0 \\
\hline 17. MWC Cepstral 11 & 0,534297322568393 & 0 \\
\hline 18. MWC Cepstral 12 & 0,862101343571158 & 0 \\
\hline 19. MWC Cepstral 13 & 0,731192454793687 & 0 \\
\hline 20. MWC Cepstral 14 & 0,0580581596253512 & 0 \\
\hline 21. MW PSD 1st Max. ABS. & 0,67959219569158 & 0 \\
\hline 22. MW PSD 1st Min. rel. & 0,766298729900208 & 0 \\
\hline
\end{tabular}




\begin{tabular}{|c|c|c|}
\hline Parámetros & p-value & Hipótesis \\
\hline 23. MW PSD 2nd Max. rel. & 0,602297392921198 & 0 \\
\hline 24. MW PSD 2nd Min. rel. & 0,529231540790179 & 0 \\
\hline 25. MW PSD 3rd Max. rel. & 0,849983206928905 & 0 \\
\hline 26. MW PSD End Val. rel. & 0,317436724922285 & 0 \\
\hline 27. MW PSD 1st Max. Pos. ABS. & 0,375609235098942 & 0 \\
\hline 28. MW PSD 1st Min. Pos. rel. & 0,883185956468934 & 0 \\
\hline 29. MW PSD 2nd Max. Pos. rel. & 0,867978443722299 & 0 \\
\hline 30. MW PSD 2nd Min. Pos. rel. & 0,607628210354217 & 0 \\
\hline 31. MW PSD 3rd Max. Pos. rel. & 0,435477277913899 & 0 \\
\hline 32. MW PSD End Val. Pos. rel. & 0,654228977470796 & 0 \\
\hline 33. MW PSD 1st Min NSF & 0,389359590598309 & 0 \\
\hline 34. MW PSD 2nd Min NSF & 0,668316491897472 & 0 \\
\hline 35. Body Mass & 0,651543012173852 & 0 \\
\hline 36. Body Losses & 0,580962349764121 & 0 \\
\hline 37. Body Stiffness & 0,539387466537266 & 0 \\
\hline 38. Body Mass Unbalance & 0,447003925096871 & 0 \\
\hline 39. Body Losses Unbalance & 0,731192454793687 & 0 \\
\hline 40. Body Stiffness Unbalance & 1 & 0 \\
\hline 41. Cover Mass & 0,198659875398559 & 0 \\
\hline 42. Cover Losses & 0,959978980222664 & 0 \\
\hline 43. Cover Stiffness & 0,514182188093427 & 0 \\
\hline 44. Cover Mass Unbalance & 0,690940033183309 & 0 \\
\hline 45. Cover Losses Unbalance & 0,929256807413918 & 0 \\
\hline 46. Cover Stiffness Unbalance & 0,713843019060444 & 0 \\
\hline 47. Rel. Recov. 1 Time & 0,849983206928905 & 0 \\
\hline 48. Rel. Recov. 2 Time & 0,813851863468799 & 0 \\
\hline 49. Rel. Open 1 Time & 0,72539350538462 & 0 \\
\hline 50. Rel. Open 2 Time & 0,163481059919974 & 0 \\
\hline 51. Rel. Max. Ampl. Time & 0,929256807413918 & 0 \\
\hline 52. Rel. Recov. 1 Ampl. & 0,0560433356684652 & 0 \\
\hline 53. Rel. Recov. 2 Ampl. & 0,898639723285102 & 0 \\
\hline 54. Rel. Open 1 Ampl. & 0,284970922895256 & 0 \\
\hline 55. Rel. Open 2 Ampl. & 0,397921400406024 & 0 \\
\hline 56. Rel. Stop Flow Time & 0,133216250331899 & 0 \\
\hline 57. Rel. Start Flow Time & 0,70235774365599 & 0 \\
\hline 58. Rel. Closing Time & 0,843937216140532 & 0 \\
\hline 59. Val. Flow GAP & 0,868172790998624 & 0 \\
\hline 60. Val. Contact GAP & 0,139306402765028 & 0 \\
\hline 61. Val. Adduction GAP & 0,843937216140532 & 0 \\
\hline 62. Val. Permanent GAP & 0,313121710831744 & 0 \\
\hline 63. 1st. Order Cyc. Coeff. & 0,708092081806653 & 0 \\
\hline 64. 2nd. Order Cyc. Coeff. & 0,651543012173852 & 0 \\
\hline 65. 3rd. Order Cyc. Coeff. & 0,754539172846928 & 0 \\
\hline 66. PhysTremor Frequency (Hz) & 0,212478531023153 & 0 \\
\hline
\end{tabular}




\begin{tabular}{lcc}
\hline Parámetros & p-value & Hipótesis \\
\hline \hline 67. PhysTremor Est. Amplitude & 0,892532893152351 & 0 \\
\hline 68. NeurTremor Frequency (Hz) & 0,0601328128371789 & 0 \\
\hline 69. NeurTremor Est. Amplitude & 0,549640086665707 & 0 \\
\hline 70. FlutTremor Frequency (Hz) & 0,544501785046344 & 0 \\
\hline 71. FlutTremor Est. Amplitude & 0,575684378963674 & 0 \\
\hline 72. Global Tremor (rMSA) & 0,40659568941603 & 0 \\
\hline
\end{tabular}

Tabla B.9: Resultados para la prueba de contraste de Mann-Whitney para el conjunto masculino cuando enfrentamos todas las muestras neutras frente a las muestras de estrés, teniendo en cuenta un $\alpha=0,05$. 
APÉNDICE B. TABLAS ESTADÍSTICA NO PARÁMETRICA

\begin{tabular}{|c|c|c|}
\hline Parámetros & p-value & Hipótesis \\
\hline 1. Absolute Pitch & 0,529231540790179 & 0 \\
\hline 2. Abs. Norm. Jitter & 0,966132024643598 & 0 \\
\hline 3. Abs. Norm. Ar. Shimmer & 0,302719429015655 & 0 \\
\hline 4. Abs. Norm. Min. Sharp. & 0,114395987319956 & 0 \\
\hline 5. Noise-Harm. Ratio (NHR) & 0,306355505238217 & 0 \\
\hline 6. Muc./AvAc. Energy (MAE) & 0,972287086295792 & 0 \\
\hline 7. MWC Cepstral 1 & 0,0411576407204768 & 1 \\
\hline 8. MWC Cepstral 2 & 0,0655895351362979 & 1 \\
\hline 9. MWC Cepstral 3 & 0,133216250331899 & 0 \\
\hline 10. MWC Cepstral 4 & 0,947680406316795 & 0 \\
\hline 11. MWC Cepstral 5 & 0,831873124080879 & 0 \\
\hline 12. MWC Cepstral 6 & 0,690940033183309 & 0 \\
\hline 13. MWC Cepstral 7 & 0,708092081806653 & 0 \\
\hline 14. MWC Cepstral 8 & 0,291984027075011 & 0 \\
\hline 15. MWC Cepstral 9 & 0,613095628976654 & 0 \\
\hline 16. MWC Cepstral 10 & 0,218196084972266 & 0 \\
\hline 17. MWC Cepstral 11 & 0,534297322568393 & 0 \\
\hline 18. MWC Cepstral 12 & 0,862101343571158 & 0 \\
\hline 19. MWC Cepstral 13 & 0,731192454793687 & 0 \\
\hline 20. MWC Cepstral 14 & 0,0580581596253512 & 1 \\
\hline 21. MW PSD 1st Max. ABS. & 0,67959219569158 & 0 \\
\hline 22. MW PSD 1st Min. rel. & 0,766298729900208 & 0 \\
\hline 23. MW PSD 2nd Max. rel. & 0,602297392921198 & 0 \\
\hline 24. MW PSD 2nd Min. rel. & 0,529231540790179 & 0 \\
\hline 25. MW PSD 3rd Max. rel. & 0,849983206928905 & 0 \\
\hline 26. MW PSD End Val. rel. & 0,317436724922285 & 0 \\
\hline 27. MW PSD 1st Max. Pos. ABS. & 0,375609235098942 & 0 \\
\hline 28. MW PSD 1st Min. Pos. rel. & 0,883185956468934 & 0 \\
\hline 29. MW PSD 2nd Max. Pos. rel. & 0,867978443722299 & 0 \\
\hline 30. MW PSD 2nd Min. Pos. rel. & 0,607628210354217 & 0 \\
\hline 31. MW PSD 3rd Max. Pos. rel. & 0,435477277913899 & 0 \\
\hline 32. MW PSD End Val. Pos. rel. & 0,654228977470796 & 0 \\
\hline 33. MW PSD 1st Min NSF & 0,389359590598309 & 0 \\
\hline 34. MW PSD 2nd Min NSF & 0,668316491897472 & 0 \\
\hline 35. Body Mass & 0,651543012173852 & 0 \\
\hline 36. Body Losses & 0,580962349764121 & 0 \\
\hline 37. Body Stiffness & 0,539387466537266 & 0 \\
\hline 38. Body Mass Unbalance & 0,447003925096871 & 0 \\
\hline 39. Body Losses Unbalance & 0,731192454793687 & 0 \\
\hline 40. Body Stiffness Unbalance & 1 & 0 \\
\hline 41. Cover Mass & 0,198659875398559 & 0 \\
\hline 42. Cover Losses & 0,959978980222664 & 0 \\
\hline 43. Cover Stiffness & 0,514182188093427 & 0 \\
\hline 44. Cover Mass Unbalance & 0,690940033183309 & 0 \\
\hline
\end{tabular}




\begin{tabular}{lcc}
\hline Parámetros & p-value & Hipótesis \\
\hline \hline 45. Cover Losses Unbalance & 0,929256807413918 & 0 \\
\hline 46. Cover Stiffness Unbalance & 0,713843019060444 & 0 \\
\hline 47. Rel. Recov. 1 Time & 0,849983206928905 & 0 \\
\hline 48. Rel. Recov. 2 Time & 0,813851863468799 & 0 \\
\hline 49. Rel. Open 1 Time & 0,72539350538462 & 0 \\
\hline 50. Rel. Open 2 Time & 0,163481059919974 & 0 \\
\hline 51. Rel. Max. Ampl. Time & 0,929256807413918 & 0 \\
\hline 52. Rel. Recov. 1 Ampl. & $\mathbf{0 , 0 5 6 0 4 3 3 3 5 6 6 8 4 6 5 2}$ & $\mathbf{1}$ \\
\hline 53. Rel. Recov. 2 Ampl. & 0,898639723285102 & 0 \\
\hline 54. Rel. Open 1 Ampl. & 0,284970922895256 & 0 \\
\hline 55. Rel. Open 2 Ampl. & 0,397921400406024 & 0 \\
\hline 56. Rel. Stop Flow Time & 0,133216250331899 & 0 \\
\hline 57. Rel. Start Flow Time & 0,702357743365599 & 0 \\
\hline 58. Rel. Closing Time & 0,843937216140532 & 0 \\
\hline 59. Val. Flow GAP & 0,868172790998624 & 0 \\
\hline 60. Val. Contact GAP & 0,139306402765028 & 0 \\
\hline 61. Val. Adduction GAP & 0,843937216140532 & 0 \\
\hline 62. Val. Permanent GAP & 0,313121710831744 & 0 \\
\hline 63. 1st. Order Cyc. Coeff. & 0,708092081806653 & 0 \\
\hline 64. 2nd. Order Cyc. Coeff. & 0,651543012173852 & 0 \\
\hline 65. 3rd. Order Cyc. Coeff. & 0,754539172846928 & 0 \\
\hline 66. PhysTremor Frequency (Hz) & 0,212478531023153 & 0 \\
\hline 67. PhysTremor Est. Amplitude & 0,892532893152351 & 0 \\
\hline 68. NeurTremor Frequency (Hz) & $\mathbf{0 , 0 6 0 1 3 2 8 1 2 8 3 7 1 7 8 9}$ & $\mathbf{1}$ \\
\hline 69. NeurTremor Est. Amplitude & 0,549640086665707 & 0 \\
\hline 70. FlutTremor Frequency (Hz) & 0,544501785046344 & 0 \\
\hline 71. FlutTremor Est. Amplitude & 0,575684378963674 & 0 \\
\hline 72. Global Tremor (rMSA) & 0,40659568941603 & 0 \\
\hline
\end{tabular}

Tabla B.10: Resultados para la prueba de contraste de Mann-Whitney para el conjunto masculino cuando enfrentamos todas las muestras neutras frente a las muestras de estrés, teniendo en cuenta un $\alpha=0,1$. 
APÉNDICE B. TABLAS ESTADÍSTICA NO PARÁMETRICA

\begin{tabular}{|c|c|c|}
\hline Parámetros & p-value & Hipótesis \\
\hline 1. Absolute Pitch & 0,0414751664584483 & 1 \\
\hline 2. Abs. Norm. Jitter & 0,0218278281155521 & 1 \\
\hline 3. Abs. Norm. Ar. Shimmer & 0,00551080590712406 & 1 \\
\hline 4. Abs. Norm. Min. Sharp. & 0,0353498807563426 & 1 \\
\hline 5. Noise-Harm. Ratio (NHR) & 0,363631154416799 & 0 \\
\hline 6. Muc./AvAc. Energy (MAE) & 0,130978299303023 & 0 \\
\hline 7. MWC Cepstral 1 & 0,464768427463395 & 0 \\
\hline 8. MWC Cepstral 2 & 0,483829474426263 & 0 \\
\hline 9. MWC Cepstral 3 & 0,510716189846861 & 0 \\
\hline 10. MWC Cepstral 4 & 0,0264149687988023 & 1 \\
\hline 11. MWC Cepstral 5 & 0,257546470236404 & 0 \\
\hline 12. MWC Cepstral 6 & 0,341654395866748 & 0 \\
\hline 13. MWC Cepstral 7 & 0,181332757795798 & 0 \\
\hline 14. MWC Cepstral 8 & 0,000303078926785217 & 1 \\
\hline 15. MWC Cepstral 9 & 0,382254839819018 & 0 \\
\hline 16. MWC Cepstral 10 & 0,369775004419496 & 0 \\
\hline 17. MWC Cepstral 11 & 0,525704170709143 & 0 \\
\hline 18. MWC Cepstral 12 & 0,909396681591997 & 0 \\
\hline 19. MWC Cepstral 13 & 0,0414751664584483 & 1 \\
\hline 20. MWC Cepstral 14 & 0,609257474848393 & 0 \\
\hline 21. MW PSD 1st Max. ABS. & 0,875849126024508 & 0 \\
\hline 22. MW PSD 1st Min. rel. & 0,744448375455559 & 0 \\
\hline 23. MW PSD 2nd Max. rel. & 0,582518451663528 & 0 \\
\hline 24. MW PSD 2nd Min. rel. & 0,303924559561424 & 0 \\
\hline 25. MW PSD 3rd Max. rel. & 0,503306830739361 & 0 \\
\hline 26. MW PSD End Val. rel. & 0,298513434332115 & 0 \\
\hline 27. MW PSD 1st Max. Pos. ABS. & 0,463435576457055 & 0 \\
\hline 28. MW PSD 1st Min. Pos. rel. & 0,687714668794755 & 0 \\
\hline 29. MW PSD 2nd Max. Pos. rel. & 0,59821305646152 & 0 \\
\hline 30. MW PSD 2nd Min. Pos. rel. & 0,804992872547477 & 0 \\
\hline 31. MW PSD 3rd Max. Pos. rel. & 0,712571226813853 & 0 \\
\hline 32. MW PSD End Val. Pos. rel. & 0,0339706870986178 & 1 \\
\hline 33. MW PSD 1st Min NSF & 0,839506586849408 & 0 \\
\hline 34. MW PSD 2nd Min NSF & 0,0782383887532679 & 0 \\
\hline 35. Body Mass & 0,0422516516258305 & 1 \\
\hline 36. Body Losses & 0,54603224286245 & 0 \\
\hline 37. Body Stiffness & 0,0418618852348112 & 1 \\
\hline 38. Body Mass Unbalance & 0,335811403472966 & 0 \\
\hline 39. Body Losses Unbalance & 0,0559471655241233 & 0 \\
\hline 40. Body Stiffness Unbalance & 0,0762995020231031 & 0 \\
\hline 41. Cover Mass & 0,00466122435958119 & 1 \\
\hline 42. Cover Losses & 0,0756619821027901 & 0 \\
\hline 43. Cover Stiffness & 0,675544342532919 & 0 \\
\hline 44. Cover Mass Unbalance & 0,349545611720596 & 0 \\
\hline
\end{tabular}




\begin{tabular}{lcc}
\hline Parámetros & p-value & Hipótesis \\
\hline \hline 45. Cover Losses Unbalance & 0,262442656996078 & 0 \\
\hline 46. Cover Stiffness Unbalance & 0,280943316109232 & 0 \\
\hline 47. Rel. Recov. 1 Time & 0,888025687981126 & 0 \\
\hline 48. Rel. Recov. 2 Time & 0,815462030245881 & 0 \\
\hline 49. Rel. Open 1 Time & 0,165499195698877 & 0 \\
\hline 50. Rel. Open 2 Time & 0,491085204316819 & 0 \\
\hline 51. Rel. Max. Ampl. Time & 0,293167021875588 & 0 \\
\hline 52. Rel. Recov. 1 Ampl. & 0,564133307478615 & 0 \\
\hline 53. Rel. Recov. 2 Ampl. & 0,564133307478615 & 0 \\
\hline 54. Rel. Open 1 Ampl. & 0,186423931274259 & 0 \\
\hline 55. Rel. Open 2 Ampl. & 0,192935460504532 & 0 \\
\hline 56. Rel. Stop Flow Time & 0,500849721498735 & 0 \\
\hline 57. Rel. Start Flow Time & $\mathbf{0 , 0 1 7 3 9 6 5 3 4 0 6 2 4 2 1 5}$ & $\mathbf{1}$ \\
\hline 58. Rel. Closing Time & 0,0863986413231901 & 0 \\
\hline 59. Val. Flow GAP & 0,491106514305221 & 0 \\
\hline 60. Val. Contact GAP & 0,126129804177535 & 0 \\
\hline 61. Val. Adduction GAP & 0,316802427658338 & 0 \\
\hline 62. Val. Permanent GAP & 0,91803520315795 & 0 \\
\hline 63. 1st. Order Cyc. Coeff. & 0,964615418438804 & 0 \\
\hline 64. 2nd. Order Cyc. Coeff. & 0,309400447414773 & 0 \\
\hline 65. 3rd. Order Cyc. Coeff. & 0,446132547413492 & 0 \\
\hline 66. PhysTremor Frequency (Hz) & 0,082236470644145 & 0 \\
\hline 67. PhysTremor Est. Amplitude & 0,976918749507969 & 0 \\
\hline 68. NeurTremor Frequency (Hz) & 0,192935460504532 & 0 \\
\hline 69. NeurTremor Est. Amplitude & 0,735709042680487 & 0 \\
\hline 70. FlutTremor Frequency (Hz) & 0,498398984507876 & 0 \\
\hline 71. FlutTremor Est. Amplitude & 0,830471032277429 & 0 \\
\hline 72. Global Tremor (rMSA) & 0,8546123845577 & 0 \\
\hline
\end{tabular}

Tabla B.11: Resultados para la prueba de contraste de Mann-Whitney para el conjunto femenino cuando enfrentamos todas las muestras neutras frente a las muestras de estrés, teniendo en cuenta un $\alpha=0,05$. 
APÉNDICE B. TABLAS ESTADÍSTICA NO PARÁMETRICA

\begin{tabular}{|c|c|c|}
\hline Parámetros & $\mathrm{p}$-value & Hipótesis \\
\hline 1. Absolute Pitch & 0,0414751664584483 & 1 \\
\hline 2. Abs. Norm. Jitter & 0,0218278281155521 & 1 \\
\hline 3. Abs. Norm. Ar. Shimmer & 0,00551080590712406 & 1 \\
\hline 4. Abs. Norm. Min. Sharp. & 0,0353498807563426 & 1 \\
\hline 5. Noise-Harm. Ratio (NHR) & 0,363631154416799 & 0 \\
\hline 6. Muc./AvAc. Energy (MAE) & 0,130978299303023 & 0 \\
\hline 7. MWC Cepstral 1 & 0,464768427463395 & 0 \\
\hline 8. MWC Cepstral 2 & 0,483829474426263 & 0 \\
\hline 9. MWC Cepstral 3 & 0,510716189846861 & 0 \\
\hline 10. MWC Cepstral 4 & 0,0264149687988023 & 1 \\
\hline 11. MWC Cepstral 5 & 0,257546470236404 & 0 \\
\hline 12. MWC Cepstral 6 & 0,341654395866748 & 0 \\
\hline 13. MWC Cepstral 7 & 0,181332757795798 & 0 \\
\hline 14. MWC Cepstral 8 & 0,000303078926785217 & 1 \\
\hline 15. MWC Cepstral 9 & 0,382254839819018 & 0 \\
\hline 16. MWC Cepstral 10 & 0,369775004419496 & 0 \\
\hline 17. MWC Cepstral 11 & 0,525704170709143 & 0 \\
\hline 18. MWC Cepstral 12 & 0,909396681591997 & 0 \\
\hline 19. MWC Cepstral 13 & 0,0414751664584483 & $\mathbf{1}$ \\
\hline 20. MWC Cepstral 14 & 0,609257474848393 & 0 \\
\hline 21. MW PSD 1st Max. ABS. & 0,875849126024508 & 0 \\
\hline 22. MW PSD 1st Min. rel. & 0,744448375455559 & 0 \\
\hline 23. MW PSD 2nd Max. rel. & 0,582518451663528 & 0 \\
\hline 24. MW PSD 2nd Min. rel. & 0,303924559561424 & 0 \\
\hline 25. MW PSD 3rd Max. rel. & 0,503306830739361 & 0 \\
\hline 26. MW PSD End Val. rel. & 0,298513434332115 & 0 \\
\hline 27. MW PSD 1st Max. Pos. ABS. & 0,463435576457055 & 0 \\
\hline 28. MW PSD 1st Min. Pos. rel. & 0,687714668794755 & 0 \\
\hline 29. MW PSD 2nd Max. Pos. rel. & 0,59821305646152 & 0 \\
\hline 30. MW PSD 2nd Min. Pos. rel. & 0,804992872547477 & 0 \\
\hline 31. MW PSD 3rd Max. Pos. rel. & 0,712571226813853 & 0 \\
\hline 32. MW PSD End Val. Pos. rel. & 0,0339706870986178 & 1 \\
\hline 33. MW PSD 1st Min NSF & 0,839506586849408 & 0 \\
\hline 34. MW PSD 2nd Min NSF & 0,0782383887532679 & 1 \\
\hline 35. Body Mass & 0,0422516516258305 & 1 \\
\hline 36. Body Losses & 0,54603224286245 & 0 \\
\hline 37. Body Stiffness & 0,0418618852348112 & 1 \\
\hline 38. Body Mass Unbalance & 0,335811403472966 & 0 \\
\hline 39. Body Losses Unbalance & 0,0559471655241233 & 1 \\
\hline 40. Body Stiffness Unbalance & 0,0762995020231031 & 1 \\
\hline 41. Cover Mass & 0,00466122435958119 & 1 \\
\hline 42. Cover Losses & 0,0756619821027901 & 1 \\
\hline 43. Cover Stiffness & 0,675544342532919 & 0 \\
\hline 44. Cover Mass Unbalance & 0,349545611720596 & 0 \\
\hline
\end{tabular}




\begin{tabular}{lcc}
\hline Parámetros & p-value & Hipótesis \\
\hline \hline 45. Cover Losses Unbalance & 0,262442656996078 & 0 \\
\hline 46. Cover Stiffness Unbalance & 0,280943316109232 & 0 \\
\hline 47. Rel. Recov. 1 Time & 0,888025687981126 & 0 \\
\hline 48. Rel. Recov. 2 Time & 0,815462030245881 & 0 \\
\hline 49. Rel. Open 1 Time & 0,165499195698877 & 0 \\
\hline 50. Rel. Open 2 Time & 0,491085204316819 & 0 \\
\hline 51. Rel. Max. Ampl. Time & 0,293167021875588 & 0 \\
\hline 52. Rel. Recov. 1 Ampl. & 0,564133307478615 & 0 \\
\hline 53. Rel. Recov. 2 Ampl. & 0,564133307478615 & 0 \\
\hline 54. Rel. Open 1 Ampl. & 0,186423931274259 & 0 \\
\hline 55. Rel. Open 2 Ampl. & 0,192935460504532 & 0 \\
\hline 56. Rel. Stop Flow Time & 0,500849721498735 & 0 \\
\hline 57. Rel. Start Flow Time & $\mathbf{0 , 0 1 7 3 9 6 5 3 4 0 6 2 4 2 1 5}$ & $\mathbf{1}$ \\
\hline 58. Rel. Closing Time & $\mathbf{0 , 0 8 6 3 9 8 6 4 1 3 2 3 1 9 0 1}$ & $\mathbf{1}$ \\
\hline 59. Val. Flow GAP & 0,491106514305221 & 0 \\
\hline 60. Val. Contact GAP & 0,126129804177535 & 0 \\
\hline 61. Val. Adduction GAP & 0,316802427658338 & 0 \\
\hline 62. Val. Permanent GAP & 0,91803520315795 & 0 \\
\hline 63. 1st. Order Cyc. Coeff. & 0,964615418438804 & 0 \\
\hline 64. 2nd. Order Cyc. Coeff. & 0,309400447414773 & 0 \\
\hline 65. 3rd. Order Cyc. Coeff. & 0,446132547413492 & 0 \\
\hline 66. PhysTremor Frequency (Hz) & $\mathbf{0 , 0 8 2 2 3 6 4 7 0 6 4 4 1 4 5}$ & $\mathbf{1}$ \\
\hline 67. PhysTremor Est. Amplitude & 0,976918749507969 & 0 \\
\hline 68. NeurTremor Frequency (Hz) & 0,192935460504532 & 0 \\
\hline 69. NeurTremor Est. Amplitude & 0,735709042680487 & 0 \\
\hline 70. FlutTremor Frequency (Hz) & 0,498398984507876 & 0 \\
\hline 71. FlutTremor Est. Amplitude & 0,830471032277429 & 0 \\
\hline 72. Global Tremor (rMSA) & 0,8546123845577 & 0 \\
\hline
\end{tabular}

Tabla B.12: Resultados para la prueba de contraste de Mann-Whitney para el conjunto femenino cuando enfrentamos todas las muestras neutras frente a las muestras de estrés, teniendo en cuenta un $\alpha=0,1$. 


\section{B.2.2. Segunda Parte: Pair-Wise}

\begin{tabular}{ll}
\hline Parámetros & Veces seleccionado \\
\hline \hline 7. MWC Cepstral 1 & 2 \\
\hline 34. MW PSD 2nd Min NSF & 1 \\
\hline 41. Cover Mass & 1 \\
\hline 44. Cover Mass Unbalance & 1 \\
\hline 5. Noise-Harm. Ratio (NHR) & 1 \\
\hline 56. Rel. Stop Flow Time & 1 \\
\hline 59. Val. Flow GAP & 1 \\
\hline 61. Val. Adduction GAP & 1 \\
\hline 71. FlutTremor Est. Amplitude & 1 \\
\hline 9. MWC Cepstral 3 & 1
\end{tabular}

Tabla B.13: Resultados para la prueba de contraste de Mann-Whitney para el conjunto masculino cuando realizamos un estudio de tipo pair-wise, teniendo en cuenta un $\alpha=0,05$.

\begin{tabular}{ll}
\hline Parámetros & Veces seleccionado \\
\hline \hline 7. MWC Cepstral 1 & 3 \\
\hline 9. MWC Cepstral 3 & 2 \\
\hline 15. MWC Cepstral 9 & 1 \\
\hline 23. MW PSD 2nd Max. rel. & 1 \\
\hline 25. MW PSD 3rd Max. rel. & 1 \\
\hline 30. MW PSD 2nd Min. Pos. rel. & 1 \\
\hline 31. MW PSD 3rd Max. Pos. rel. & 1 \\
\hline 33. MW PSD 1st Min NSF & 1 \\
\hline 34. MW PSD 2nd Min NSF & 1 \\
\hline 41. Cover Mass & 1 \\
\hline 44. Cover Mass Unbalance & 1 \\
\hline 45. Cover Losses Unbalance & 1 \\
\hline 5. Noise-Harm. Ratio (NHR) & 1 \\
\hline 50. Rel. Open 2 Time & 1 \\
\hline 52. Rel. Recov. 1 Ampl. & 1 \\
\hline 56. Rel. Stop Flow Time & 1 \\
\hline 58. Rel. Closing Time & 1 \\
\hline 59. Val. Flow GAP & 1 \\
\hline 61. Val. Adduction GAP & 1 \\
\hline 64. 2nd. Order Cyc. Coeff. & 1 \\
\hline 68. NeurTremor Frequency (Hz) & 1 \\
\hline 69. NeurTremor Est. Amplitude & 1 \\
\hline 71. FlutTremor Est. Amplitude & 1 \\
\hline
\end{tabular}


Parámetros Veces seleccionado

Tabla B.14: Resultados para la prueba de contraste de

Mann-Whitney para el conjunto masculino cuando realizamos un estudio de tipo pair-wise, teniendo en cuenta un $\alpha=0,1$. 


\begin{tabular}{lc}
\hline Parámetros & Veces seleccionado \\
\hline \hline 52. Rel. Recov. 1 Ampl. & 3 \\
\hline 56. Rel. Stop Flow Time & 3 \\
\hline 1. Absolute Pitch & 2 \\
\hline 16. MWC Cepstral 10 & 2 \\
\hline 18. MWC Cepstral 12 & 2 \\
\hline 32. MW PSD End Val. Pos. rel. & 2 \\
\hline 42. Cover Losses & 2 \\
\hline 49. Rel. Open 1 Time & 2 \\
\hline 50. Rel. Open 2 Time & 2 \\
\hline 54. Rel. Open 1 Ampl. & 2 \\
\hline 55. Rel. Open 2 Ampl. & 2 \\
\hline 58. Rel. Closing Time & 2 \\
\hline 8. MWC Cepstral 2 & 2 \\
\hline 10. MWC Cepstral 4 & 1 \\
\hline 14. MWC Cepstral 8 & 1 \\
\hline 21. MW PSD 1st Max. ABS. & 1 \\
\hline 26. MW PSD End Val. rel. & 1 \\
\hline 35. Body Mass & 1 \\
\hline 4. Abs. Norm. Min. Sharp. & 1 \\
\hline 41. Cover Mass & 1 \\
\hline 43. Cover Stiffness & 1 \\
\hline 47. Rel. Recov. 1 Time & 1 \\
\hline 48. Rel. Recov. 2 Time & 1 \\
\hline 53. Rel. Recov. 2 Ampl. & 1 \\
\hline 57. Rel. Start Flow Time & 1 \\
\hline 59. Val. Flow GAP & 1 \\
\hline 6. Muc./AvAc. Energy (MAE) & 1 \\
\hline 61. Val. Adduction GAP & 1 \\
\hline Ta B.15: Rest & \\
\hline
\end{tabular}

Tabla B.15: Resultados para la prueba de contraste de Mann-Whitney para el conjunto femenino cuando realizamos un estudio de tipo pair-wise, teniendo en cuenta un $\alpha=0,05$. 


\begin{tabular}{|c|c|}
\hline Parámetros & Veces seleccionado \\
\hline 50. Rel. Open 2 Time & 5 \\
\hline 57. Rel. Start Flow Time & 4 \\
\hline 58. Rel. Closing Time & 4 \\
\hline 1. Absolute Pitch & 3 \\
\hline 16. MWC Cepstral 10 & 3 \\
\hline 21. MW PSD 1st Max. ABS. & 3 \\
\hline 32. MW PSD End Val. Pos. rel. & 3 \\
\hline 52. Rel. Recov. 1 Ampl. & 3 \\
\hline 53. Rel. Recov. 2 Ampl. & 3 \\
\hline 54. Rel. Open 1 Ampl. & 3 \\
\hline 56. Rel. Stop Flow Time & 3 \\
\hline 6. Muc./AvAc. Energy (MAE) & 3 \\
\hline 8. MWC Cepstral 2 & 3 \\
\hline 14. MWC Cepstral 8 & 2 \\
\hline 18. MWC Cepstral 12 & 2 \\
\hline 25. MW PSD 3rd Max. rel. & 2 \\
\hline 41. Cover Mass & 2 \\
\hline 42. Cover Losses & 2 \\
\hline 49. Rel. Open 1 Time & 2 \\
\hline 55. Rel. Open 2 Ampl. & 2 \\
\hline 59. Val. Flow GAP & 2 \\
\hline 10. MWC Cepstral 4 & 1 \\
\hline 13. MWC Cepstral 7 & 1 \\
\hline 17. MWC Cepstral 11 & 1 \\
\hline 19. MWC Cepstral 13 & 1 \\
\hline 20. MWC Cepstral 14 & 1 \\
\hline 22. MW PSD 1st Min. rel. & 1 \\
\hline 24. MW PSD 2nd Min. rel. & 1 \\
\hline 26. MW PSD End Val. rel. & 1 \\
\hline 3. Abs. Norm. Ar. Shimmer & 1 \\
\hline 30. MW PSD 2nd Min. Pos. rel. & 1 \\
\hline 31. MW PSD 3rd Max. Pos. rel. & 1 \\
\hline 33. MW PSD 1st Min NSF & 1 \\
\hline 34. MW PSD 2nd Min NSF & 1 \\
\hline 35. Body Mass & 1 \\
\hline 37. Body Stiffness & 1 \\
\hline 4. Abs. Norm. Min. Sharp. & 1 \\
\hline 43. Cover Stiffness & 1 \\
\hline 44. Cover Mass Unbalance & 1 \\
\hline 45. Cover Losses Unbalance & 1 \\
\hline 47. Rel. Recov. 1 Time & 1 \\
\hline 48. Rel. Recov. 2 Time & 1 \\
\hline 51. Rel. Max. Ampl. Time & 1 \\
\hline 61. Val. Adduction GAP & 1 \\
\hline
\end{tabular}




\begin{tabular}{lc}
\hline Parámetros & Veces seleccionado \\
\hline \hline 62. Val. Permanent GAP & 1 \\
\hline 64. 2nd. Order Cyc. Coeff. & 1 \\
\hline 7. MWC Cepstral 1 & 1 \\
\hline 9. MWC Cepstral 3 & 1 \\
\hline
\end{tabular}

Tabla B.16: Resultados para la prueba de contraste de Mann-Whitney para el conjunto femenino cuando realizamos un estudio de tipo pair-wise, teniendo en cuenta un $\alpha=0,1$. 


\section{Apéndice $\mathrm{C}$}

\section{TABLA DE RELACIÓN DE PARÁMETROS}

\begin{tabular}{|c|c|c|c|c|c|c|c|}
\hline PARAM. & RF1 & RF2 & RF3 & RF4 & KS & MW & $\mathrm{P}$ \\
\hline 1. Absolute Pitch & & & & & $\overline{\mathrm{X}}$ & $\mathrm{X}$ & $\overline{\mathrm{X}}$ \\
\hline 2. Abs. Norm. Jitter & & & & & $\mathrm{X}$ & $\mathrm{X}$ & \\
\hline 3. Abs. Norm. Ar. Shimmer & & & & $\mathrm{X}$ & $\mathrm{X}$ & $\mathrm{X}$ & \\
\hline 4. Abs. Norm. Min. Sharp. & & $\mathrm{X}$ & & & $\mathrm{X}$ & $\mathrm{X}$ & \\
\hline 5. Noise-Harm. Ratio (NHR) & $\mathrm{X}$ & $\mathrm{X}$ & $\mathrm{X}$ & $\mathrm{X}$ & $\mathrm{X}$ & & \\
\hline 6. Muc./AvAc. Energy (MAE) & & & & & $\mathrm{X}$ & & \\
\hline 7. MWC Cepstral 1 & & & & & & & \\
\hline 8. MWC Cepstral 2 & & & & & & & $\mathrm{X}$ \\
\hline 9. MWC Cepstral 3 & $\mathrm{X}$ & & $\mathrm{X}$ & $\mathrm{X}$ & & & $\mathrm{X}$ \\
\hline 10. MWC Cepstral 4 & & & & & $\mathrm{X}$ & $\mathrm{X}$ & $\mathrm{X}$ \\
\hline 11. MWC Cepstral 5 & & & & & & & \\
\hline 12. MWC Cepstral 6 & & & & & & & \\
\hline 13. MWC Cepstral 7 & & & & & & & \\
\hline 14. MWC Cepstral 8 & & & $\mathrm{X}$ & $\mathrm{X}$ & $\mathrm{X}$ & $\mathrm{X}$ & \\
\hline 15. MWC Cepstral 9 & & & & & & & \\
\hline 16. MWC Cepstral 10 & & & & & & & \\
\hline 17. MWC Cepstral 11 & & & & & & & \\
\hline 18. MWC Cepstral 12 & & & & & & & \\
\hline 19. MWC Cepstral 13 & & $\mathrm{X}$ & & & $\mathrm{X}$ & $\mathrm{X}$ & \\
\hline 20. MWC Cepstral 14 & & & & $\mathrm{X}$ & & & \\
\hline 21. MW PSD 1st Max. ABS. & & & & & & & \\
\hline 22. MW PSD 1st Min. rel. & & & & & & & \\
\hline 23. MW PSD 2nd Max. rel. & $\mathrm{X}$ & & $\mathrm{X}$ & $\mathrm{X}$ & & & \\
\hline 24. MW PSD 2nd Min. rel. & $\mathrm{X}$ & & & & & & \\
\hline 25. MW PSD 3rd Max. rel. & & $\bar{X}$ & $\mathrm{X}$ & & & & \\
\hline 26. MW PSD End Val. rel. & & & & & & & \\
\hline 27. MW PSD 1st Max. Pos. ABS. & $\mathrm{X}$ & $\bar{X}$ & $\mathrm{X}$ & $\bar{X}$ & & & \\
\hline 28. MW PSD 1st Min. Pos. rel. & & & $\mathrm{X}$ & $\mathrm{X}$ & & & \\
\hline
\end{tabular}

Sigue en la página siguiente 


\begin{tabular}{|c|c|c|c|c|c|c|c|}
\hline PARAM. & RF1 & RF2 & RF3 & $\mathrm{RF} 4$ & KS & MW & $\mathrm{P}$ \\
\hline 29. MW PSD 2nd Max. Pos. rel. & & & & $\overline{\mathrm{X}}$ & & & \\
\hline 30. MW PSD 2nd Min. Pos. rel. & & & & & & & \\
\hline 31. MW PSD 3rd Max. Pos. rel. & & & & & & & \\
\hline 32. MW PSD End Val. Pos. rel. & $\mathrm{X}$ & $\mathrm{X}$ & & & $\mathrm{X}$ & $\mathrm{X}$ & \\
\hline 33. MW PSD 1st Min NSF & & & & & & & \\
\hline 34. MW PSD 2nd Min NSF & & & & $\mathrm{X}$ & $\mathrm{X}$ & $\mathrm{X}$ & \\
\hline 35. Body Mass & & & & & $\mathrm{X}$ & $\mathrm{X}$ & $\mathrm{X}$ \\
\hline 36. Body Losses & & & & $\mathrm{X}$ & & & \\
\hline 37. Body Stiffness & & & & & $\mathrm{X}$ & $\mathrm{X}$ & $\mathrm{X}$ \\
\hline 38. Body Mass Unbalance & & & & & & & \\
\hline 39. Body Losses Unbalance & & & & & & $\mathrm{X}$ & \\
\hline 40. Body Stiffness Unbalance & & & & & & $\mathrm{X}$ & \\
\hline 41. Cover Mass & & & & & $\mathrm{X}$ & $\mathrm{X}$ & \\
\hline 42. Cover Losses & & & & & $\mathrm{X}$ & $\mathrm{X}$ & \\
\hline 43. Cover Stiffness & & & & & & & \\
\hline 44. Cover Mass Unbalance & & $\mathrm{X}$ & & & & & \\
\hline 45. Cover Losses Unbalance & & $\mathrm{X}$ & & & & & \\
\hline 46. Cover Stiffness Unbalance & & $\mathrm{X}$ & $\mathrm{X}$ & $\mathrm{X}$ & & & \\
\hline 47. Rel. Recov. 1 Time & & & & $\mathrm{X}$ & & & \\
\hline 48. Rel. Recov. 2 Time & & & & & & & \\
\hline 49. Rel. Open 1 Time & & & & & & & \\
\hline 50. Rel. Open 2 Time & & & & & & & \\
\hline 51. Rel. Max. Ampl. Time & & & $\mathrm{X}$ & $\mathrm{X}$ & & & \\
\hline 52. Rel. Recov. 1 Ampl. & & & & & & & \\
\hline 53. Rel. Recov. 2 Ampl. & & & & & & & \\
\hline 54. Rel. Open 1 Ampl. & & & & & & & \\
\hline 55. Rel. Open 2 Ampl. & & & & & $\mathrm{X}$ & & \\
\hline 56. Rel. Stop Flow Time & & & & $\mathrm{X}$ & & & \\
\hline 57. Rel. Start Flow Time & & & & & $\mathrm{X}$ & $\mathrm{X}$ & \\
\hline 58. Rel. Closing Time & $\mathrm{X}$ & & & $\mathrm{X}$ & & $\mathrm{X}$ & \\
\hline 59. Val. Flow GAP & & & & & & & \\
\hline 60. Val. Contact GAP & & $\mathrm{X}$ & & & & & \\
\hline 61. Val. Adduction GAP & $\mathrm{X}$ & $\mathrm{X}$ & & & & & \\
\hline 62. Val. Permanent GAP & $\mathrm{X}$ & $\mathrm{X}$ & & & & & \\
\hline 63. 1st. Order Cyc. Coeff. & & & & & & & \\
\hline 64. 2nd. Order Cyc. Coeff. & & & & & & & \\
\hline 65. 3rd. Order Cyc. Coeff. & & & & & & & \\
\hline 66. PhysTremor Frequency (Hz) & $\mathrm{X}$ & $\mathrm{X}$ & $\mathrm{X}$ & $\mathrm{X}$ & & $\mathrm{X}$ & \\
\hline 67. PhysTremor Est. Amplitude & & & & & & & \\
\hline 68. NeurTremor Frequency $(\mathrm{Hz})$ & $\mathrm{X}$ & $\mathrm{X}$ & $\mathrm{X}$ & $\mathrm{X}$ & & & \\
\hline 69. NeurTremor Est. Amplitude & & & & & & & \\
\hline 70. FlutTremor Frequency $(\mathrm{Hz})$ & & & & & & & \\
\hline 71. FlutTremor Est. Amplitude & & & & & & & \\
\hline
\end{tabular}

Sigue en la página siguiente 


\begin{tabular}{|l|c|c|c|c|c|c|c|}
\hline PARAM. & RF1 & RF2 & RF3 & RF4 & KS & MW & P \\
\hline \hline 72. Global Tremor (rMSA) & & & & & & & \\
\hline
\end{tabular}

Tabla C.1: Parámetros relevantes respecto de los casos de estudio llevados a cabo para el conjunto de datos femenino. $\mathrm{RF} 1=$ t-test, $\mathrm{RF} 2=$ entropía, $\mathrm{RF} 3=\mathrm{ROC}, \mathrm{RF} 4=$ Wilcoxon, KS = Kolmogorov-Smirnov, MW = U-MannWhitney y $\mathrm{P}=$ Pearson. 


\begin{tabular}{|l|c|c|c|c|c|c|}
\hline PARAM. & RF1 & RF2 & RF3 & RF4 & KS & MW \\
\hline \hline 1. Absolute Pitch & & & & & & \\
\hline 2. Abs. Norm. Jitter & & & & & & \\
\hline 3. Abs. Norm. Ar. Shimmer & & & & & & \\
\hline 4. Abs. Norm. Min. Sharp. & $\mathrm{X}$ & & & & & \\
\hline 5. Noise-Harm. Ratio (NHR) & & $\mathrm{X}$ & & & & \\
\hline 6. Muc./AvAc. Energy (MAE) & $\mathrm{X}$ & & $\mathrm{X}$ & $\mathrm{X}$ & & \\
\hline 7. MWC Cepstral 1 & & $\mathrm{X}$ & & & & $\mathrm{X}$ \\
\hline 8. MWC Cepstral 2 & & & & & $\mathrm{X}$ & $\mathrm{X}$ \\
\hline 9. MWC Cepstral 3 & & & & & & \\
\hline 10. MWC Cepstral 4 & $\mathrm{X}$ & & $\mathrm{X}$ & $\mathrm{X}$ & & \\
\hline 11. MWC Cepstral 5 & & & & & & \\
\hline 12. MWC Cepstral 6 & & & $\mathrm{X}$ & $\mathrm{X}$ & & \\
\hline 13. MWC Cepstral 7 & & & & & & \\
\hline 14. MWC Cepstral 8 & & & & & & \\
\hline 15. MWC Cepstral 9 & & & & & & \\
\hline 16. MWC Cepstral 10 & & & & & & \\
\hline 17. MWC Cepstral 11 & & & $\mathrm{X}$ & $\mathrm{X}$ & & \\
\hline 18. MWC Cepstral 12 & & & $\mathrm{X}$ & $\mathrm{X}$ & & \\
\hline 19. MWC Cepstral 13 & & & & & & \\
\hline 20. MWC Cepstral 14 & & & & & $\mathrm{X}$ & $\mathrm{X}$ \\
\hline 21. MW PSD 1st Max. ABS. & & & & & & \\
\hline 22. MW PSD 1st Min. rel. & $\mathrm{X}$ & $\mathrm{X}$ & $\mathrm{X}$ & $\mathrm{X}$ & & \\
\hline 23. MW PSD 2nd Max. rel. & $\mathrm{X}$ & $\mathrm{X}$ & $\mathrm{X}$ & $\mathrm{X}$ & & \\
\hline 24. MW PSD 2nd Min. rel. & & & & & & \\
\hline 25. MW PSD 3rd Max. rel. & & $\mathrm{X}$ & & & & \\
\hline 26. MW PSD End Val. rel. & & & & & & \\
\hline 27. MW PSD 1st Max. Pos. ABS. & $\mathrm{X}$ & $\mathrm{X}$ & $\mathrm{X}$ & & & \\
\hline 28. MW PSD 1st Min. Pos. rel. & $\mathrm{X}$ & $\mathrm{X}$ & $\mathrm{X}$ & $\mathrm{X}$ & & \\
\hline 29. MW PSD 2nd Max. Pos. rel. & $\mathrm{X}$ & $\mathrm{X}$ & $\mathrm{X}$ & $\mathrm{X}$ & & \\
\hline 30. MW PSD 2nd Min. Pos. rel. & & $\mathrm{X}$ & & & $\mathrm{X}$ & \\
\hline 31. MW PSD 3rd Max. Pos. rel. & & $\mathrm{X}$ & & & $\mathrm{X}$ & \\
\hline 32. MW PSD End Val. Pos. rel. & & & & & & \\
\hline 33. MW PSD 1st Min NSF & $\mathrm{X}$ & $\mathrm{X}$ & $\mathrm{X}$ & $\mathrm{X}$ & & \\
\hline 34. MW PSD 2nd Min NSF & $\mathrm{X}$ & & $\mathrm{X}$ & $\mathrm{X}$ & & \\
\hline 35. Body Mass & & & & & & \\
\hline 36. Body Losses & & & & & & \\
\hline 37. Body Stiffness & & & & & & \\
\hline 38. Body Mass Unbalance & & & & & & \\
\hline 39. Body Losses Unbalance & & & & & & \\
\hline 40. Body Stiffness Unbalance & & & & & & \\
\hline 41. Cover Mass & & $\mathrm{X}$ & $\mathrm{X}$ & & \\
\hline 42. Cover Losses & & & & & \\
\hline 43. Cover Stiffness & & & & \\
\hline
\end{tabular}

Sigue en la página siguiente 


\begin{tabular}{|c|c|c|c|c|c|c|}
\hline PARAM. & RF1 & RF2 & RF3 & RF4 & KS & MW \\
\hline 444. Cover Mass Unbalance & & & & & & \\
\hline 45. Cover Losses Unbalance & $\mathrm{X}$ & $\mathrm{X}$ & & & & \\
\hline 46. Cover Stiffness Unbalance & $\mathrm{X}$ & & & & & \\
\hline 47. Rel. Recov. 1 Time & & & & & & \\
\hline 48. Rel. Recov. 2 Time & & & & & & \\
\hline 49. Rel. Open 1 Time & & & & & & \\
\hline 50. Rel. Open 2 Time & & & & & $\mathrm{X}$ & \\
\hline 51. Rel. Max. Ampl. Time & & & & & & \\
\hline 52. Rel. Recov. 1 Ampl. & & & & & & $\mathrm{X}$ \\
\hline 53. Rel. Recov. 2 Ampl. & & & & & & \\
\hline 54. Rel. Open 1 Ampl. & & & & & & \\
\hline 55. Rel. Open 2 Ampl. & & & & & & \\
\hline 56. Rel. Stop Flow Time & & & & & & \\
\hline 57. Rel. Start Flow Time & $\mathrm{X}$ & & & & & \\
\hline 58. Rel. Closing Time & $\mathrm{X}$ & $\mathrm{X}$ & $\mathrm{X}$ & $\mathrm{X}$ & & \\
\hline 59. Val. Flow GAP & & & & & & \\
\hline 60. Val. Contact GAP & $\mathrm{X}$ & $\mathrm{X}$ & $\mathrm{X}$ & $\mathrm{X}$ & & \\
\hline 61. Val. Adduction GAP & & $\mathrm{X}$ & & & & \\
\hline 62. Val. Permanent GAP & & & $\mathrm{X}$ & & & \\
\hline 63. 1st. Order Cyc. Coeff. & & & & & & \\
\hline 64. 2nd. Order Cyc. Coeff. & $\mathrm{X}$ & $\mathrm{X}$ & $\mathrm{X}$ & $\mathrm{X}$ & & \\
\hline 65. 3rd. Order Cyc. Coeff. & & & & & & \\
\hline 66. PhysTremor Frequency $(\mathrm{Hz})$ & $\mathrm{X}$ & & $\mathrm{X}$ & $\mathrm{X}$ & $\mathrm{X}$ & \\
\hline 67. PhysTremor Est. Amplitude & & & & & & \\
\hline 68. NeurTremor Frequency $(\mathrm{Hz})$ & $\mathrm{X}$ & $\mathrm{X}$ & $\mathrm{X}$ & $\mathrm{X}$ & $\mathrm{X}$ & $\mathrm{X}$ \\
\hline 69. NeurTremor Est. Amplitude & & & & & & \\
\hline 70. FlutTremor Frequency $(\mathrm{Hz})$ & & & & & & \\
\hline 71. FlutTremor Est. Amplitude & & & & & & \\
\hline 72. Global Tremor (rMSA) & & & & & & \\
\hline
\end{tabular}

Tabla C.2: Parámetros relevantes respecto de los casos de estudio llevados a cabo para el conjunto de datos masculino. $\mathrm{RF} 1=$ t-test, $\mathrm{RF} 2=$ entropía, $\mathrm{RF} 3=\mathrm{ROC}, \mathrm{RF} 4=$ Wilcoxon, $\mathrm{KS}=$ Kolmogorov-Smirnov y MW = U-MannWhitney. 
72. Global Tremor (rMSA) 71. FlutTremor Est. Amplitude 70. FlutTremor Frequency $(\mathrm{Hz})$ 69. NeurTremor Est. Amplitude 68. NeurTremor Frequency $(\mathrm{Hz})$ 67. PhysTremor Est. Amplitude 66. PhysTremor Frequency $(\mathrm{Hz})$

65. 3rd. Order Cyc. Coeff.

64. 2nd. Order Cyc. Coeff.

63. 1st. Order Cyc. Coeff.

62. Val. Permanent GAP

61. Val. Adduction GAP 60. Val. Contact GAP 59. Val. Flow GAP 58. Rel Closing Time 57. Rel. Start Flow Time 56. Rel. Stop Flow Time

55. Rel. Open $2 \mathrm{Ampl}$.

54. Rel. Open $1 \mathrm{Ampl}$. 53. Rel. Recov. $2 \mathrm{Ampl}$ 52. Rel. Recov. 1 Ampl. 51. Rel. Max. Ampl. Time 50. Rel. Open 2 Time 49. Rel Open 1 Time 48. Rel. Recov. 2 Time 47. Rel. Recov. 1 Time 46. Cover Stiffness Unbalance 45. Cover Losses Unbalance 44. Cover Mass Unbalance 43. Cover Stiffness 42. Cover Losses 41. Cover Mass 40. Body Stiffness Unbalance 39. Body Losses Unbalance 38. Body Mass Unbalance 37. Body Stiffness 36. Body Losses 35. Body Mass 34. MW PSD 2nd Min NSF 33. MW PSD 1st Min NSF 32. MW PSD End Val. Pos. rel. 31. MW PSD 3rd Max, Pos, rel. 30. MW PSD 2nd Min. Pos. rel. 29. MW PSD 2nd Max. Pos. rel. 28. MW PSD 1st Min. Pos, rel. 27. MW PSD 1st Max Pos, ABS. 26. MW PSD End Val. rel. 25. MW PSD 3rd Max. rel 24. MW PSD 2nd Min. rel. 23. MW PSD 2nd Max. rel. 22. MW PSD 1st Min. rel. 21. MW PSD 1st Max. ABS. 20. MWC Cepstral 14 19. MWC Cepstral 13

18. MWC Cepstral 12

17. MWC Cepstral 11

16. MWC Cepstral 10

15. MWC Cepstral 9

14. MWC Cepstral 8

13. MWC Cepstral 7

12. MWC Cepstral 6

11. MWC Cepstral 5

10. MWC Cepstral 4

9. MWC Cepstral 3

8. MWC Cepstral 2

7. MWC Cepstral 1 6. Muc./AvAc. Energy (MAE) 5. Noise-Harm. Ratio (NHR)

4. Abs. Norm. Min. Sharp.

3. Abs. Norm. Ar. Shimmer 2. Abs. Norm. Jitte 1. Absolute Pitch

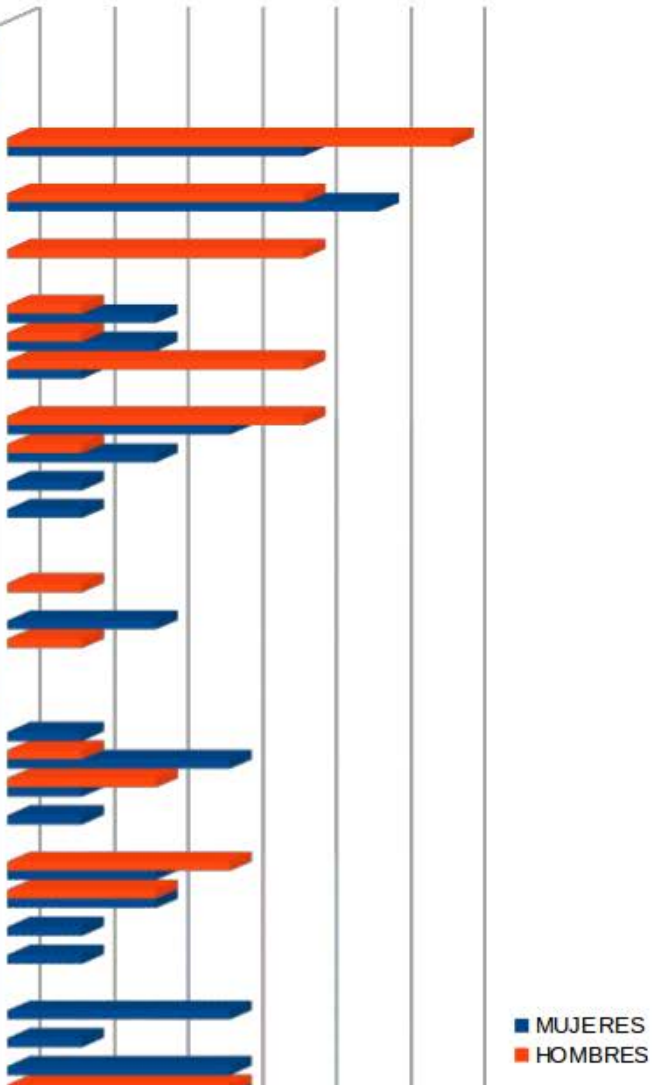

Figura C.1: Representación del número de veces que cada parámetro ha sido seleccionado como relevante para el conjunto de todos los casos de estudio y para ambos géneros. 


\section{Apéndice D}

\section{CONSENTIMIENTO INFORMADO PARA DONANTES DE SU VOZ}

El propósito de este documento de consentimiento es proporcionar a los participantes de esta donación una clara explicación de la naturaleza de la misma.

Las pruebas a realizar son:

- No invasivas, no molestas y no requieren preparación previa.

- Tienen una duración aproximadamente de 10-20 minutos.

- Consisten en un registro de voz (grabación) para un posterior análisis de la biomecánica de la fonación.

La participación en este estudio es estrictamente voluntaria. La información personal que se recoja será confidencial y no se usará para ningún otro propósito. Sus datos personales serán codificados usando un número de identificación y por lo tanto, serán anónimos.

Vd. puede hacer las preguntas que crea oportunas sobre el proceso de evaluación de la voz siempre que lo desee y en cualquier momento del estudio.

Vd. puede cancelar el proceso de grabación cuando lo desee sin necesidad de explicar las causas de la cancelación, en cuyo caso los datos incluidos y los registros de voz capturados hasta el momento serán automáticamente eliminados.

Respecto a la grabación:

La grabación es una donación de carácter voluntario y altruista sin contraprestación económica.

Los registros obtenidos de la voz del donante serán incorporados en formato wav a un fichero informático. 
Autorizo que mi voz donada sea utilizada en estudios de investigación relacionados con la biomecánica de la voz.

Gracias por su participación.

- He sido informado sobre los objetivos del estudio y acepto participar voluntariamente en el mismo. $\mathrm{Si}-\mathrm{No}$

- Entiendo que este estudio no implica ninguna clase de riesgo para mi persona. $\mathrm{Si}-\mathrm{No}$

- Me han comunicado y acepto que tendré que proporcionar algunos datos personales de carácter confidencial. Si - No

- He sido informado de que puedo hacer preguntas sobre este estudio en cualquier momento y que puedo retirarme del mismo cuando así lo decida. Si - No

\section{FIRMA DEL PARTICIPANTE}

- Nombre:

- Fecha:

- DNI: 